2. ECN Category

(mark one)

Suppl emental

Direct Revision

Change ECN

Temporary

standby

Supersedure

Cancel/Void
3. Originator's Name, Organization, MSIN, and Telephone No.

Kelly G. Carothers, Process

[x] Control, R2-11, 373-4556

6. Project Title/No./Work Order No.

Tank 241-C-106 Waste Retrieval

Sluicing System Process Control Plan

9. Document Numbers Changed by this ECN (includes sheet no. and rev.)

HNF-SD-WM-PCP-013, Rev. 0

4. USQ Required?
[X] Yes [] No Wf $^{2}$
TF-98- 0709
7. Bldg./Sys./Fac. No.
$241-\mathrm{C}-106$
10. Related ECN No(s).

$\mathrm{N} / \mathrm{A}$
5. Date

$07 / 20 / 98$

8. Approval Designator $S$

11. Related PO No. 12a. Modification Work

[] Yes (fill out Blk. 12b)

[X] No (NA Blks. 12b, $12 c, 12 \mathrm{~d})$ 12b. Work Package 1 12c. Modification Work Complete No.

N/A
N/A

Design Authority/Cog. Engineer Signature \& Date 12d, Restored to Original Condition (Temp. or Standby ECN only) $\mathrm{N} / \mathrm{A}$

13a. Description of Change

13b. Design Baseline Document?

Design Authority/Cog. Engineer signature \& Date

This ECN is being generated in order to incorporate comments from DOE-RL. include new technical information from the revised Project $W-320$ Thermal Analysis and updating tank compositions to be consistent with best-basis inventories.

14a. Justification (mark one)

Criteria Change $[X]$ Design Improvement [] Environmental

As-Found

[]

Facilitate const

[]

Const. Error/Omission

[]

Facility Deactivation Design Error/Omission

14b. Justification Details

Document is required to provide the basis for preparing procedures and operational plans in supporting sluicing of tank 241-C-106.

15. Distribution (include name, MSIN, and no. of copies)

See attached distribution. 


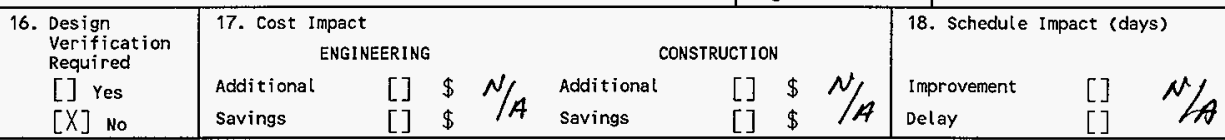

19. Change impact Review: Indicate the related documents (other than the engineering documents identified on side 1 ) that will be affected by the change described in Block 13 . Enter the affected document number in $B 10 c k 20$.

\section{SDD/DD}

Functional Design Criteria

Operating Specification

Criticality Specification

Conceptual Design Report

Equipment Spec.

Const. Spec.

Procurement Spec.

Vendor Information

OM Manual

FSAR/SAR

Safety Equipment List

Radiation Work Permit

Environmental Impact Statement

Environmental Report

Environmental Permit
[]
[]
[]
[]
[]
[]
[]
[]
[]
[]
[]
[]
[]
[]
[]
[]
[] Tank Calibration Manual

[]

[]

[]

[]

[]

[]

[]

Xegp

[] 2122198

[]

[]

[]

[]

[]

Health Physics Procedure

Spares Multiple Unit Listing

Test Procedures/Specification

Component Index

ASME Coded Item

Human Factor Consideration

Computer Software

Electric Circuit Schedule

ICRS Procedure

Process Control Manual/Plan

Process Flow Chart

Purchase Requisition

Tickler File

Fac. Proc. Samp. Schedule

Inspection Plan

Inventory Adjustment Request

[]

[]

[]

[]

[]

[]

[]

[]

[]

[]

[]

[]

[]

[]

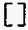

[]

20. Other Affected Documents: (NOTE: Documents listed below will not be revised by this ECN.) Signatures below indicate that the signing organization has been notified of other affected docunents listed below. Document Number/Revision Document Number/Revision Document Number Revision NHAe

Plant Operating PlocediceES agP $7 / 22 / 88$

21. Approvals

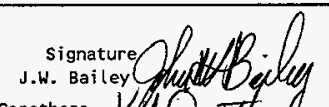

Design Authority J.W. Bailey

Cog. Eng. K.G. Carothers

Cog. Mgr. N.W. Kirch

$$
1
$$

nisionk

QA

Safety W.I. Dixon

Environ.

other J.W. Lentsch

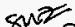<smiles>C#CCCCCCCCCCCCCCCCC</smiles>

D.G. Baide

for

G.N. Hanson

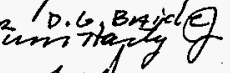

R.G. St ickney

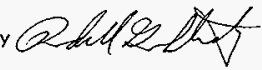

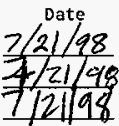

Design Agent

Signature

Date

QA

Safety

Design

Environ.

other

\section{DEPARTMENT OF ENERGY}

Signature or a Control Number that tracks the Approval Signature

ADDITIONAL 


\title{
Tank 241-C-106 Waste Retrieval Sluicing System Process Control Plan
}

\author{
K. G. Carothers \\ S. D. Estey \\ N. W. Kirch \\ L. A. Stauffer \\ J. W. Bailey \\ Lockheed Martin Hanford Corporation, Richland, WA 99352 \\ U.S. Department of Energy Contract DE-AC06-96RL13200
}

$\begin{array}{lll}\text { EDT/ECN: } & \text { EDT-610282 } & \text { UC: 2070 } \\ \text { Org Code: } & \text { 7A150 } & \text { Charge Code: D2M78 } \\ \text { B\&R Code: } & \text { EW } 3120074 & \text { Total Pages: } 203 \text { (JiCB ᄀ|25/98) }\end{array}$

Key Words: W-320, WRSS, Retrieva?, STuicing, Process, Control, Plan, Tank 241-C-106, Tank 241-AY-102, Mass Transfer, Temperature Limits, Flammable Gas

Abstract: Project $W-320$ has installed the Waste Retrieval Sluicing System at the 200 East Area on the Hanford Site to retrieve the sludge from single-she11 tank 241-C-106 and transfer it into double-shel1 tank 241-AY-102. Operation of the WRSS process will resolve the high-heat safety issue for tank 241-C-106 and demonstrate a technology for the retrieval of single-shell tank wastes. This process control plan coordinates the technical operating requirements (primarily mass transfer, temperature, and flammable gas) for the sluicing operation and provides overall technical guidance for the retrieval activity.

\footnotetext{
TRADEMARK DISCLAIMER. Reference herein to any specific commercial product, process, or service by trade name, trademark, manufacturer, or otherwise, does not necessarily constitute or imply its endorsement, recommendation, or favoring by the United States Government or any agency thereof or its contractors or subcontractors.

Printed in the United States of America. To obtain copies of this document, contact: Document control Services, P.O. Box 950, Mailstop H6-08, Richland WA 99352, Phone (509) 372-2420; Fax (509) 376-4989.
}
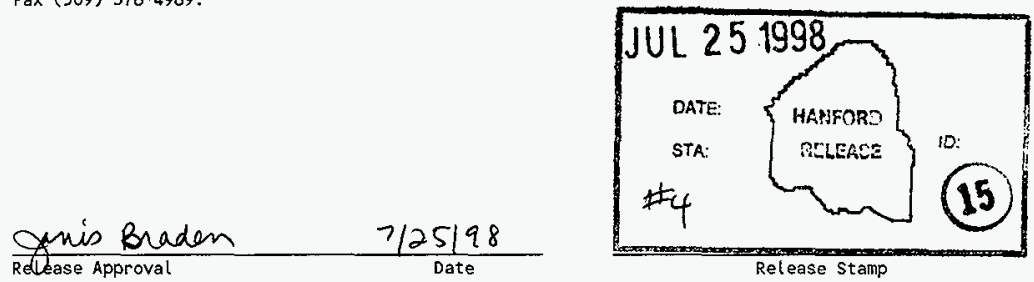

\section{Approved for Public Release}




\begin{tabular}{|c|c|c|c|}
\hline \multicolumn{2}{|r|}{ RECORD OF REVISION } & $\begin{array}{l}\text { (1) Document Number } \\
\text { HNF-SD-WM-PCP-013 }\end{array}$ & P-013 \\
\hline \multicolumn{4}{|c|}{$\begin{array}{l}\text { (2) ritle } \\
\text { Tank 241-C-106 Waste Retrieval Sluicing System Process Control Plan }\end{array}$} \\
\hline \multicolumn{4}{|c|}{ CHANGE CONTROL RECORD } \\
\hline \multirow{2}{*}{ (3) Revision } & \multirow{2}{*}{ (4) Description of Change - Replace, Add, and Delete Pages } & \multicolumn{2}{|c|}{ Authorized for Release } \\
\hline & & (5) Cog. Engr. & (6) Cog. Mgr. Date \\
\hline 0 & $\begin{array}{l}\text { (7) Initially released } 02 / 09 / 98 \text { by EDT- } \\
610282 \text {. }\end{array}$ & $\begin{array}{l}\text { K.G. } \\
\text { Carothers }\end{array}$ & N.W. Kirch \\
\hline & & & 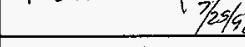 \\
\hline${ }^{1} \mathrm{Rg}$ & Incorporate per ECN-643804. & $\begin{array}{l}\text { K.G. } \\
\text { Carothers }\end{array}$ & $\begin{array}{l}\text { N.W. Kirch } \\
\text { purtent-10 }\end{array}$ \\
\hline & & & $7 / 25 / 58$ \\
\hline & & & \\
\hline & & & \\
\hline & & & \\
\hline & & & \\
\hline & & & \\
\hline & & & \\
\hline & & & \\
\hline & & & \\
\hline & & & \\
\hline & & & \\
\hline & & & \\
\hline 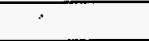 & & & \\
\hline & & & \\
\hline & & & \\
\hline & & & \\
\hline & & & \\
\hline & & & \\
\hline & & & \\
\hline & & & \\
\hline & & & \\
\hline & & & \\
\hline & & & \\
\hline & & & \\
\hline & & & \\
\hline & & & \\
\hline & & & \\
\hline & & & \\
\hline & & & \\
\hline & & & \\
\hline
\end{tabular}




\section{Tank 241-C-106 Waste Retrieval Sluicing System Process Control Plan}

K. G. Carothers

S. D. Estey

N. W. Kirch

L. A. Stauffer

Lockheed Martin Hanford Corp.

J. W. Bailey

Numatec Hanford Corporation

Date Published

July 1998

Prepared for the U.S. Department of Energy

Assistant Secretary for Environmental Management

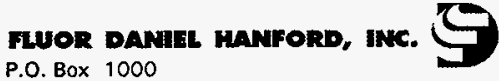

Richland, Washington 
HNF-SD-WM-PCP-013 REV. 1

CONTENTS

1.0 INTRODUCTION . . . . . . . . . . . . ........ . . . . 1 . .

2.0 PROCESS PERFORMANCE CRITERIA ................. . . 2-1

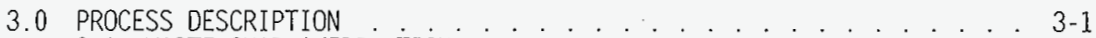

3.1 WASTE CHARACTERIZATION . . . . . . . . . 3-5

3.1.1 Tank 241-C-106 Waste Chemical and Physical Properties . 3-5

3.1.2 Tank 241-AY-102 Waste Chemical and Physical Properties. 3-9

3.2 SLUICING PREPARATIONS . . . . . . . . . . . . . .

3.2.1 Tank 241-C-106 Waste Subcooling . . 3-12

3.2.2 Waste Retrieval Sluicing System Baseline Measurements . 3-13

3.2.3 Waste Retrieval Sluicing System Supernatant Temperature Equalization . . 3-18

3.2.4 Tank 241-C-105 Supernatant Level Adjustment Transfer : 3-19

3.2.5 Tank 241-AY-102 Supernatant Leve1 Adjustment Transfer . 3-19

3.2.6 Tank 241-AY-102 Chemical Adjustment ... . . . . . 3-20

3.2.7 Tank 241-AY-102 Supernatant Sampling and Composition Baserine. . 3-20

3.2.8 Waste Retrieval Sluicing System Waste Compatibility . 3-21

3.2.9 Tank 241-AY-102 Supernatant Routing Contingency . . . 3-21

3.3 WASTE RETRIEVAL SLUICING SYSTEM OPERATION PLAN . . . . . . . $3-22$

3.4 PROCESS FLOWSHEET . . . . . . . . . . . . . . . . . . 3-27

3.4.1 Tank 241-C-106 Pre-siuicing Fiowsheet . . . . 3-27

3.4.2 Sluicing Operation Flowsheet . . . . . . . 3-27

3.4.3 Post Sluicing Monitoring Period Flowsheet . . . . . . . 3-38

3.5 EQUIPMENT DESCRIPTIONS . . . . . . . . . . . . . . . 3-38

3.5.1 Fluid Systems . . . . . . . . . . . . . $3-38$

3.5 .2 Ventilation Systems . . . . . . . 3-46

3.5.3 Instrument Descriptions . . . . . . . . . . 3-53

3.5.4 Waste Retrieval Sluicing System Control System . . . 3-67
Arrangement

3.5.5 Utility Systems . . . . . . . . . . . . . . . . . . .

4.0 PROCESS CONTROL

4.1 SLUICING PROCESS CONTROL

4.1.1 S7urry Concentration Contro7 . . . . . . . 4-5

4.1.2 Tank 241-C-106 Liquid Level Control . . . . . . .11

4.1.3 Sluice Nozzle Directional Control . . . . . . 4-13

4.1.4 Tank 241-C-106 Mass Transfer Control . . . . . . . . 4-15

4.1.5 Transfer Pipeline Flushing Control . . . . . . 4-20

4.2 TANK 241-AY-102 MASS TRANSFER VERIFICATION CONTROL . . . . . . 4-21

4.3 WASTE TEMPERATURE CONTROL . . . . . . . . . . . . . 4-25

4.3.1 Tank 241-C-106 Sludge Temperature Control . . . . . 4-26

4.3.2 Tank 241-AY-102 Waste Temperature Control . . . . . 4-34

4.4 FLAMMABLE GAS RETENTION CONTROL . . . . . . . . . $4-40$

4.4.1 Pre-Sluicing Flammable Gas Baseline . . . . . 4-41

4.4.2 Flammable Gas Controls During Sluicing Operations . . . 4-41

4.4.3 Flammable Gas Controls During Monitoring Periods . . . 4-42

4.4.4 Flammable Gas Controls After Completion of Tank

241-C-106 Retrieval ............ 4-46 


\section{CONTENTS (Continued)}

4.5 OTHER CONTROLS . . . . . . . . . . . . . . . . . . . . . .

4.5.1 Leak Detection. ........ . . . . . . . . . . . .

4.5.2 Tank 241-AY-102 Supernatant chemicai composition . 4-56

4.5.3 Criticality Safety. . . . . . . . . . . . . 4-56

4.5.4 Separable Organic . . . . . . . . . . . . . . . . . . .

4.6 PROCESS SAMPLING REQUIREMENTS AND SCHEDULE . . . . . . . . 4-58

5.0 RESPONSE TO OFF-NORMAL CONDITIONS .............. 5-1

5.1 PROCESS UPSETS . . . . . . . . . . . . . . . . . .

5.1.1 Loss of Tank $241-\hat{C}-106$ Sludge Subcooling Margin . . . 5-1

5.1.2 Tank 241-AY-102 Steady-State Temperature Predictions Above Limits . . . . . . . . . . . . . .

5.1.3 Tank 241-AY-102 Fiammabie Gas Retention Above Limits . 5-3

5.1.4 Transfer Pipeline Plugging . . . . . . . . . . . 5-4

5.1 .5 Aerosol Formation in Tank $241-\mathrm{C}-106.2 .5-5$

5.1.6 System Operating Temperature Limit Exceeded . . . . . . 5-6

5.2 FACILITY UPSETS . . . . . . . . . . . . . . . 5-7

5.2.1 Loss of $296-\mathrm{C}-006$ Ventilation System . . . . . . 5-7

5.2 .2 Loss of 241-AZ-702 Primary Ventilation System . . . . 5-7

5.2 .3 Loss of 296-A-16 Annulus Ventilation System . . . . . 5-8

5.2 .4 Loss of Electric Power . . . . . . 5-8

5.2 .5 Loss of Chilled Water Supply to HX-1361 Condenser . . . 5-9

5.2.6 Tank or Transfer Pipeline Waste Leak ...... 5-9

6.0 REFERENCES ................. . . . 6-1 APPENDIX

A INDEX OF TECHNICAL OPERATING REQUIREMENTS .......... . A-1 
HNF-SD-WM-PCP-013 REV. 1

\section{LIST OF FIGURES}

3-1 Retrieval Process Schematic. ................ 3-2

3-2 Tank 241-C-106 Cross Section View . . . . . . . . . . . 3-3

3-3 Tank 241-AY-102 Cross Section View . . . . . . . . . . 3-4

3-4 Tank 241-C-106 Heat Load Estimate. . . . . . . . . . . . . . 3-7

3-5 Pre-Sluicing Activities Time-Phased Logic . . . . . . . . . . . . . 3-15

3-6 Tank 241-C-106 Operational Plan . . . . . . . . . . . . . . 3-24

3-7 Waste Retrieval Sluicing System Process Flawsheet Tank 241-C-106 Ventilation System (296-P-16)............. 3-29

3-8 Process Flowsheet - Process Fluid Systems . . . . . . . . . . . 3-31

3-9 Waste Retrieval S7uicing System Process Flowsheet Tank 241-C-106 Ventilation System $(296-\mathrm{C}-006) . \ldots . . . . . .3-33$

3-10 Waste Retrieval Sluicing System Process Flowsheet Tank 241-AY-102 Primary Ventilation System and Annulus Supply System...... . 3-35

3-11 Waste Retrieval Sluicing System Fluid System Equipment Arrangement 3-40

3-12 Route for Transfer Pipelines . . . . . . . . . . . . . . . . . . 3-41

3-13 Tank 241-C-106 Submersible Slurry Pump/Winch . . . . . . . . 3-43

3-14 Tank 241-C-106 Sluicer Installation. . . . . . . . . . 3-45

3-15 Tank 241-C-106 Waste Retrieval Sluicing System Ventilation System

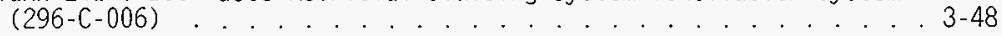

3-16 Tank 241-C-106 Existing Ventilation System (296-P-16) . . . . 3-49

3-17 Tank 241-AY-102 Primary Ventilation System (241-AZ-702) . . . . . 3-51

3-18 Tank 241-AY-102 Annulus Ventilation System (296-A-16) . . . . . 3-52

3-19 Slurry Pipeline Mag-Flow Meter and Closed Circuit Television System . . . . . . . . . . . . . . . . . . . .

3-20 ENRAF ${ }^{\mathrm{TM}} 854$ ATG Liquid Level Gauge . . . . . . . . . . . 3-56

3-21 Tank 241-AY-102 Axial Temperature Monitoring Cross Section .. . . 3-60

3-22 Tank 241-AY-102 Radial Temperature Monitoring Cross Section . . . . 3-61

3-23 Tank 241-C-106 Thermocouple Trees . . . . . . . . . . . 3-62 
HNF-SD-WM-PCP-013 REV. 1

\section{LIST OF FIGURES (Continued)}

3-24 Standard Hydrogen Monitoring System . . . . . . . . . . . . . 3-64

3-25 M0-211 Operator Control Station Layout . . . . . . . . . . . 3-68

3-26 M0-211 Control Station Layout . . . . . . . . . . . . 3-69

3-27 Sluicing Annunciator Pane . .. . . . . . . . . . . . 3-70

3-28 Waste Retrieval Sluicing System Sluicing Control Panel . . . . . 3-71

3-29 241-AY Tank Farm Sluicing Operator Control Station Layout . . . . . 3-74

3-30 241-AY Tank Farm Annunciator Panel . . . . . . . . . . . . 3-75

4-1 WRSS Process Control Logic Diagram ... . . . . . . . . . . 4-3

4-2 Tank 241-C-106 STurry Booster Pump (P-1362) Curve/System Curve . . 4-7

4-3 Slurry Booster Pump (P-1362) Curve/System Curve - Nomina 1 . . . . 4-8

4-4 Tank 241-C-106 Sluice Nozzle Directional Control. . . . . . . . . . 4-14

4-5 Slurry Solids Mass Fraction as Function of Slurry Density and Slurry Carrier Fluid Density for Solids Particulate Density of $2.61 \mathrm{~g} / \mathrm{mL}$. . . . . . . . . . . . . . . . . . . . . . . . .

4-6 Slurry Solids Mass Fraction as Function of Slurry Density and Slurry Solids Particulate Density for Carrier Fluid Density of $1.0 \mathrm{~g} / \mathrm{mL}$. . . . . . . . . . . . . . . . . . . . .

4-7 Saturation Pressure and Temperature . . . . . . . . . . . . . 4-27

4-8 Decision Map for Hydrogen Concentration Measurements . . . . . . . 4-47

4-9 Decision Map for Level Measurements . . . . . . . . . . . . . . . 4-48

4-10 Assumed Thermal Expansion Factor of the WRSS Liquid and Sludge . . 4-54

5-1 Estimated Sluicing Stream Temperatures for Varying STuicing Operating Durations . . . . . . . . . . . . . . . 5-6 
HNF-SD-WM-PCP-013 REV. 1

\section{LIST OF TABLES}

3-1 Predicted Current Inventory in Tank 241-C-106 . . . . . 3-5

3-2 Best-Basis Inventory Estimates for Nonradioactive Components in Tank 241-C-106 . . . . . . . . . . . . . .

3-3 Best-Basis Inventory Estimate for Radioactive Components in Tank 241-C-106 . . . . . . . 3-8

3-4 Best Estimate Parameters for 241-C-106 . . . . . . . . . 3-8

3-5 Inventory Estimates for Tank 241-AY-102 Supernatant . . . . . 3-9

3-6 Inventory Estimates for Tank 241-AY-102 Sludge . . . . . . . . 3-11

3-7 Inventory Estimate for Radioactive Components in Tank 241-AY-102 Sludge . . . . . . . . . . . . . . . . 3-11

3-8 Best Estimate Parameters for 241-AY-102 Waste . . . . . . . . 3-12

3-9 Tank 241-AY-102 Temperature Monitoring Locations . . . . . . . . 3-14

3-10 Presluicing Flammable Gas Baseline . . . . . . . . . . . . . 3-17

3-11 Process Evaluations Performed at WRSS Monitoring Periods . . . . . 3-28

4-1 Estimated Slurry Solids Loading for Slurry Pump System Flow Rates at 1,624 rpm Booster Pump Speed . . . . . . . . . . . . . . 4-9

4-2 Monitoring Frequency for Tank 241-AY-102 Mass Transfer Verification . . . . . . . . . . . . . . 4-23

4-3 Pressures and Waste Saturation Temperatures at Various Waste Depths in Tank 241-C-106 . . . . . . . . . . . . . . 4-27

4-4 Tank 241-C-106 Waste Temperature Limits During STuice Increments . 4-30

4-5 Saturation Temperature at Location of Maximum Waste Temperature . . 4-33

4-6 Applicable Tank 241-AY-102 Waste Thermocouples to Comply with $91{ }^{\circ} \mathrm{C}$ $\left(195^{\circ} \mathrm{F}\right)$ Limit During Sluice Batches . . . . . . . . . . . . . . . 4-36

4-7 Tank 241-AY-102 Waste Temperature Limits During Post-Sluicing Monitoring . . . . . . . . . . . . . . . . . . . 4-38

4-8 Monitoring Requirements During Sluicing Operations . . . . . . . 4-41

4-9 Monitoring Requirements During Monitoring Period . . . . . . . . 4-43

4-10 Decision Map . . . . . . . . . . . . . . . . . . . . . . 4-46 


$$
\text { HNF -SD-WM-PCP-013 REV. } 1
$$

\section{LIST OF TABLES (Continued)}

4-11 Monitoring Requirements After Completion of Retrieval . . . . . 4-49

4-12 WRSS Sampling Requirements. . . . . . . . . . . . . . 4-59

A1-1 Project $W-320$ Safety SSCs and TSRs and Defense-in Depth for Representative Accidents . . . . . . . . . . . A-3

A2-1 Operating Specification Document Controls for Tank 241-AY-102 . . A-14

A2-2 Operating Specification Document Controls for Tank 241-C-106 . . A-20

A4-1 Industrial Safety (Tank Farm HASP) Controls for Tank 241-C-106 . . A-25

A4-2 Industrial Safety (Tank Farm HASP) Controls for Tank 241-AY-102 . . A-27 
HNF-SD-WM-PCP-013 REV. 1

\section{LIST OF TERMS}

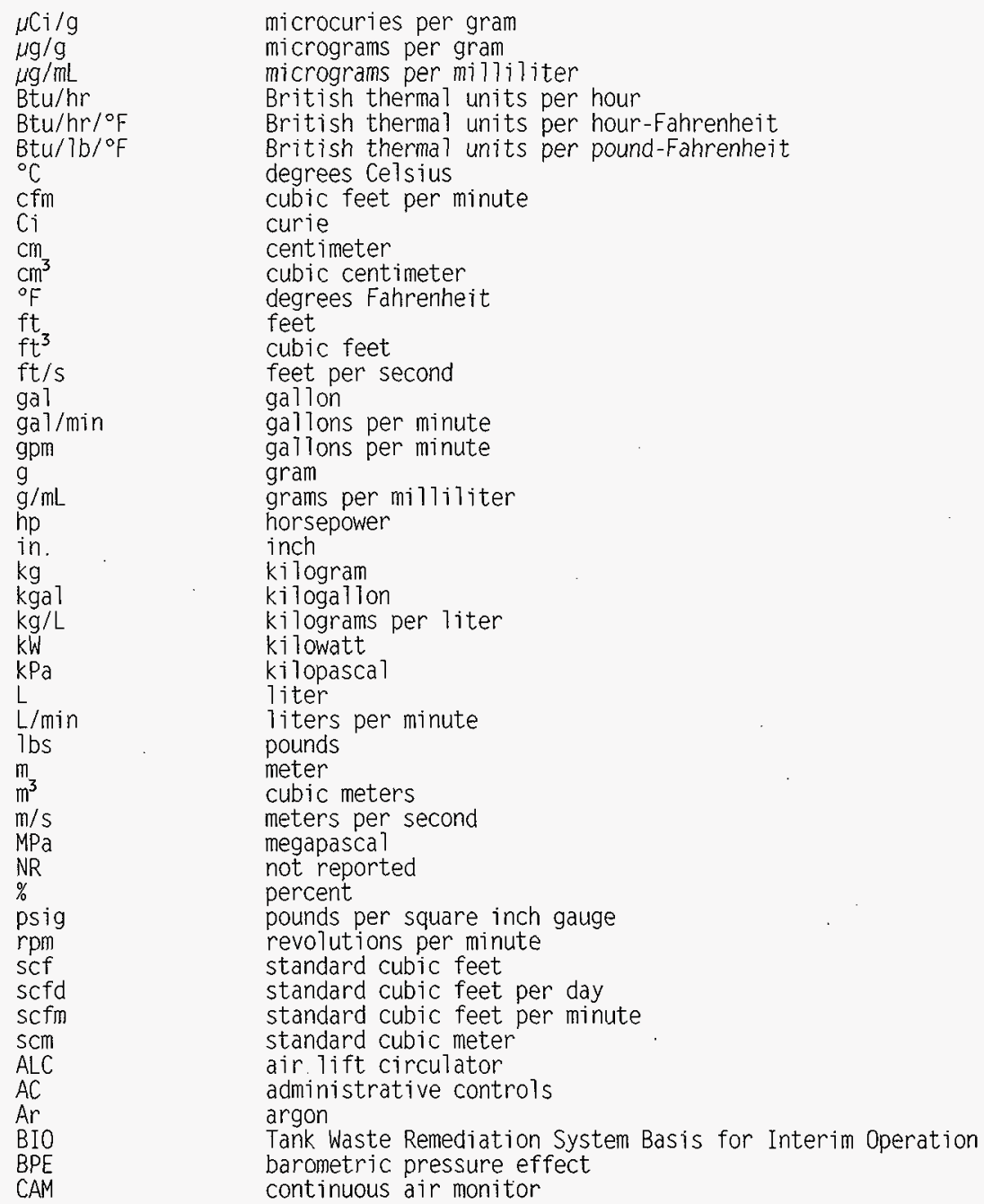


HNF-SD-WM-PCP-013 REV. 1

LIST OF TERMS (Continued)

$\begin{array}{ll}\text { CIU } & \text { Communication interface unit } \\ \text { DAS } & \text { data acquisition system } \\ \text { DOE-RL } & \text { U.S. Department of Energy, Richland Operations Office } \\ \text { ECOlogy } & \text { Washington State Department of Ecology } \\ \text { HEPA } & \text { high-efficiency particulate air ( filter) } \\ \text { LCO } & \text { Limiting Condition of Operation } \\ \text { LCS/LCO } & \text { Limited Control Setting/Limiting Condition of Operation } \\ \text { MIT } & \text { multifunctional instrument tree } \\ \text { PUREX } & \text { plutonium-uranium extraction (plant) } \\ \text { SHMS } & \text { standard hydrogen monitoring systems } \\ \text { TMACS } & \text { tank monitoring and control system } \\ \text { TRG } & \text { Tank 24l-C-106 Waste Retrieval Technical Review Group } \\ \text { TSR } & \text { TWRS technical safety requirement } \\ \text { TWRS } & \text { Tank Waste Remediation System } \\ \text { VFI } & \text { void fraction instrument } \\ \text { W.g. } & \text { water gauge } \\ \text { WRSS } & \text { Waste Retrieval Sluicing System }\end{array}$


HNF-SD-WM-PCP-013 REV. 1

\subsection{INTRODUCTION}

The Waste Retrieval Sluicing System (WRSS) was installed on single-shell tank 241-C-106 by Project $W-320$. The purpose of this system is to retrieve and transfer high-heat sludge from tank 241-C-106 to double-shel1 tank 241-AY-102, which is designed for high-heat waste storage. The transfer will eliminate the high-heat safety issue for tank 241-C-106 and demonstrate a technology for retrieval of single-shell tank waste.

Tank 241-C-106 is designated as a Watch-List tank because an uncontrolled high-temperature increase could result in a serious potential for the release of high-level waste if active cooling is not maintained in the tank. This designation was mandated by the National Defense Authorization Act of Fiscal Year 1991. Public Law 101-510. Section 3137. "Safety Measures for Waste Tanks at Hanford Nuclear Reservation" (the Wyden Amendment). The high-heat safety issue arises from the need to continue adding water (approximately 22,700 L $[6,000 \mathrm{gal}]$ per month) for cooling the stored sludge unti 1 about the year 2045. Tank 241-C-106 is well past its design life. Tanks of this type, built in the same time frame, currently have failure rate of approximately 50 percent. If a tank leak occurs, water additions cannot be stopped because sludge temperatures would exceed established limits and could cause structural damage to the tank concrete and a subsequent release of high-level waste to the environment. Continued water additions would further contaminate the environment.

Tank 241-C-106 has been selected to demonstrate the sluicing technique as a retrieval technology for single-she11 tank waste. The planned WRSS operations will complete the U.S. Department of Energy. Richland Operations Office (DOE-RL) commitments to the Hanford Federa 7 Facility Agreement and Consent Order (Ecology et al. 1996), or Tri-Party Agreement Mi lestone M-45-03A, "Initiate Sluicing Retrieval of 241-C-106," which states "initiate sluicing retrieval of tank 241-C-106 to resolve the high-heat issue and demonstrate waste retrieva1."

The purpose of the WRSS Process Control Plan is to coordinate the technical operating controls for the sluicing operation and to provide overall technical guidance for the retrieval activity. Also. Addendum 1 of the Tank Waste Remediation System Basis for Interim Operation (BI0) commits to a prescribed process control plan that implements processes and controls that are contained in the flammable gas, thermal, and chemistry topical reports (FDH 1998a). The BIO specifies that a number of processing parameters be included in the plan; sluicing pump performance information. control of the pumps, mass transfer limit, maximum sluicing duration, monitoring requirements, and monitoring durations. The process control plan includes a description of the sluicing process and operating sequence; safety, environmenta1, and process operating limits; and process control strategy. The scope of the process control plan covers pre-sluicing waste transfers, sluicing startup support and operations, activities through completion of the transfer of waste from tank 241-C-106 to tank 241-AY-102, and subsequent storage and monitoring of the wastes in both tanks. 
HNF-SD-WM-PCP-013 REV. 1

This page intentionally left blank. 
HNF-SO-WM-PCP-013 REV. 1

\subsection{PROCESS PERFORMANCE CRITERIA}

The primary objectives of the tank 241-C-106 Waste Retrieval Sluicing System (WRSS) operation are to eliminate the radiogenic high-heat safety issue and to demonstrate a technology for retrieval of single-shell tank wastes.

Therefore, the WRSS process will be considered successful when the following conditions are met.

- The amount of heat-generating waste transferred from single-she11 tank 241-C-106 to double-shell tank 241-AY-102 allows discontinuing water additions to tank $241-\mathrm{C}-106$. Removing the first $0.61 \mathrm{~m}(2 \mathrm{ft})$ of sludge is projected to reduce the heat load in tank 241-C-106 enough to maintain waste temperatures within allowable limits without the continued addition of water (Ogden et al. 1998).

- The maximum feasible waste recovery from tank 241-C-106 has been achieved or, if sluicing operations are stopped for an extended period, an adequate volume of sludge has been removed from the tank to allow it to be stabilized (i.e., less than $18,900 \mathrm{~L}[5,000$ gal] supernatant and less than $189,000 \mathrm{~L}$ [50,000 gal] interstitial liquid). The goal is to remove enough tank $241-C-106$ waste to lower the heat load of the remaining sludge to less than $7.6 \mathrm{~kW}$ $(26,000 \mathrm{Btu} / \mathrm{hr})$. A thermal analysis has estimated the minimum amount of sludge needing to be removed is $1.6 \mathrm{~m}(5.2 \mathrm{ft}$ ) (Ogden et a1. 1998). Maximum waste recovery is considered equivalent to the Project W-320 Justification of Mission Need criterion of retrieving 95 percent of the sludge (Lyt7e 1993)

- No safety concerns exist with respect to the thermal behavior in tanks 241-C-106 and 241-AY-102; and no unsafe increase in flammable gas generation, retention, and release in tank 241-AY-102 occurs as a result of the sludge transfer.

Material balance procedures will provide an initial estimate of the high-heat solids transferred from tank 241-C-106 to tank 241-AY-102 during the course of the WRSS operation. However, because of uncertainties in the distribution of radionuclides in the waste, determining the end point for the sluicing operation wi 11 depend on the performance of a thermal analysis to verify the amount of heat generating material remaining in tank 241-C-106. The in-tank temperature trends of the remaining waste and the cooling performance of the ventilation system will be monitored and the data will be used to develop an estimate of the heat load in the tank. 
HNF-SD-WM-PCP-013 REV. 1

This page intentionally left blank. 
HNF-SD-WM-PCP-013 REV. 1

\subsection{PROCESS DESCRIPTION}

The Waste Retrieval Sluicing System (WRSS) uses a modified past practice sluicing process to suspend the solids in single-shell tank 24l-C-106 for subsequent transfer to double-shel1 tank 241-AY-102. Supernatant from tank 241-AY-102 is used as the sluicing fluid during the retrieval. Figure 3-1 shows a schematic of the sluicing process.

The major equipment items making up the WRSS include the following: two nearly identical pump systems (one for delivery of the sluice stream to tank 241-C-106 and a second for delivery of the slurry to tank 241-AY-102): a sluicer system; a slurry distributor; and interfarm piping to complete a dedicated, closed-loop sluicing system. The major process monitoring and control instrumentation includes the following: two identical flowmeters, one installed on the slurry pipeline and the other on the sluice pipeline: a coriolis mass flowmeter installed on the slurry pipeline; ENRAF ${ }^{1}$ liquid level gauges and densitometer, thermocouples, hydrogen monitoring systems, and in-tank imaging systems. Figures $3-2$ and 3-3 show cross section views of tank 241-C-106 and tank 241-AY-102 with the major tank process components. other major equipment items are the tank $241-\mathrm{C}-106$ ventilation system and the tank 241-AY-102 primary tank and annulus ventilation systems.

In the WRSS process, supernatant near the top of tank 241-AY-102 is withdrawn with a sluice pump and transported to tank 241-C-106 to form a fluid stream at the sluicer nozzle capable of loosening and suspending the solids particles at the surface of the settled sludge. As a result of the sluicing action. a slurry is formed and migrates to the suction of the slurry pump. A tandem slurry pumping system withdraws the slurry from the tank and pumps it through the transfer pipeline as a turbulent stream keeping the solids in suspension. When the slurry reaches tank 24l-AY-102, it is discharged through the submerged slurry distributor into the supernatant layer where solids particles begin to settle under the force of gravity. Clarified supernatant near the top of tank 241-AY-102 continues to be pumped to the sluice nozzle to sustain the process. The duration of the sluicing operation is constrained by the rate of sludge removal from tank $241-C-106$ and the amount of sludge build-up in tank 241-AY-102.

This section describes the following: waste characteristics for sluice and receiver tanks (241-C-106 and 241-AY-102. respectively), pre-sluicing preparations, process flowsheets, retrieval activity including the time-phased logic for the retrieval process, and major equipment and instrumentation. This section also provides a description of sluicing system functions. including preparations for system startup. normal sluicing operations. measurement, and shutdown activities.

'ENRAF is a trademark of the ENRAF Corporation, Houston, Texas. 


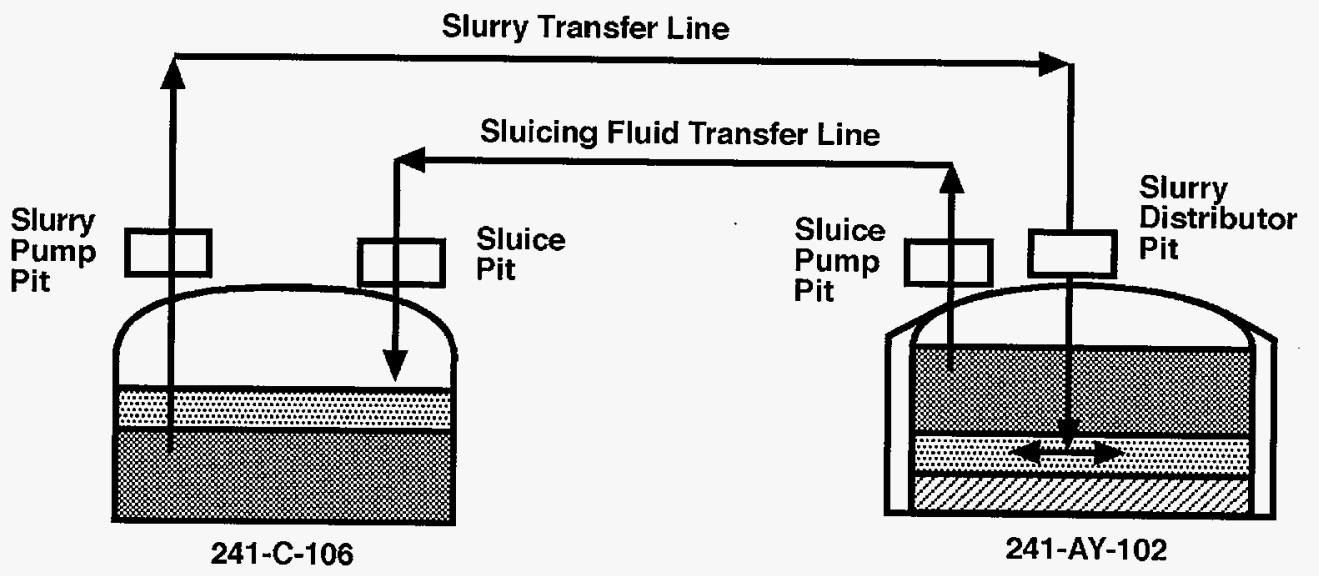

HG97110098.9 
HNF-SD-WM-PCP-013 REV. 1

Figure 3-2. Tank 241-C-106 Cross Section View.

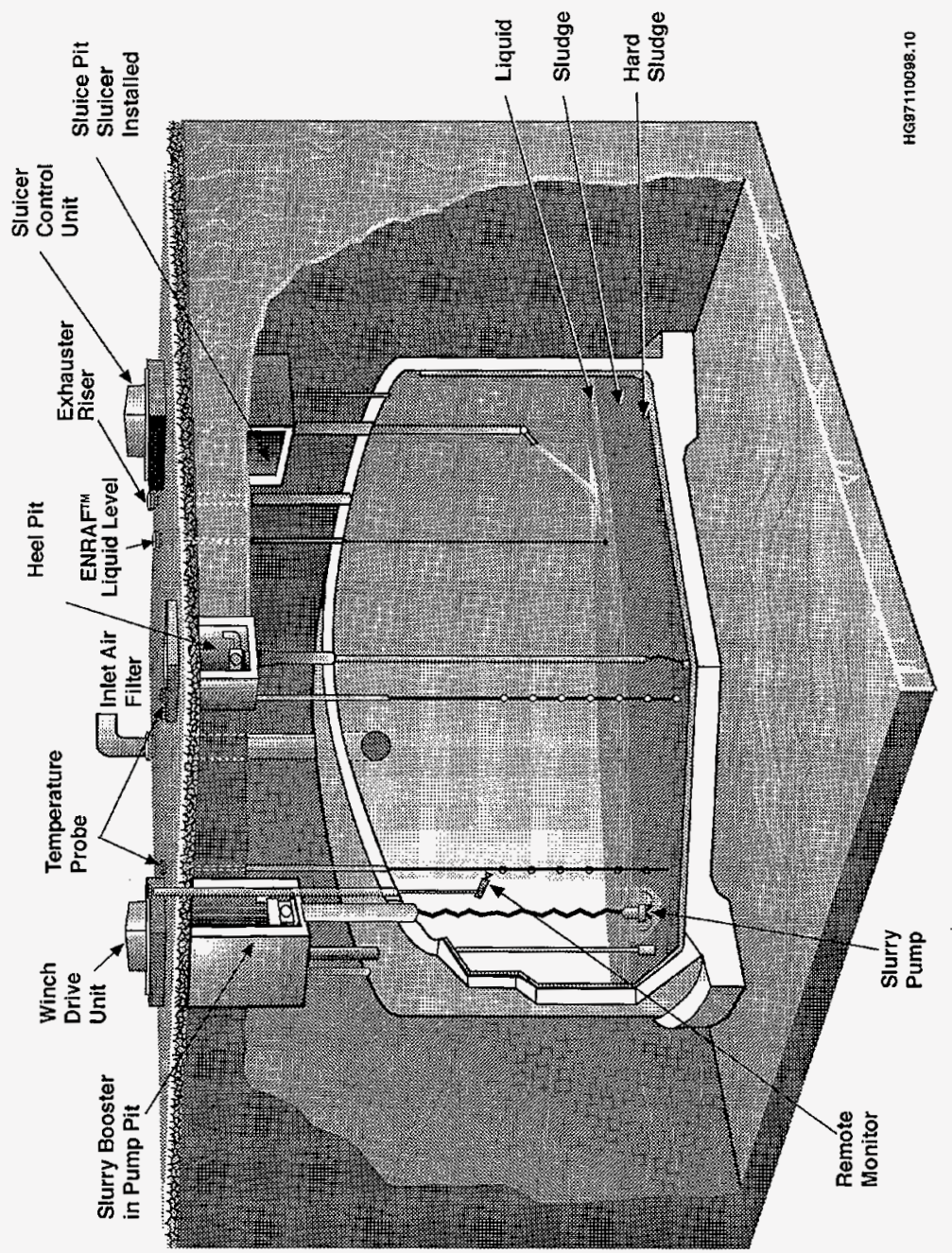


HNF-SD-WM-PCP-013 REV. 1

Figure 3-3. Tank 24l-AY-102 Cross Section View.

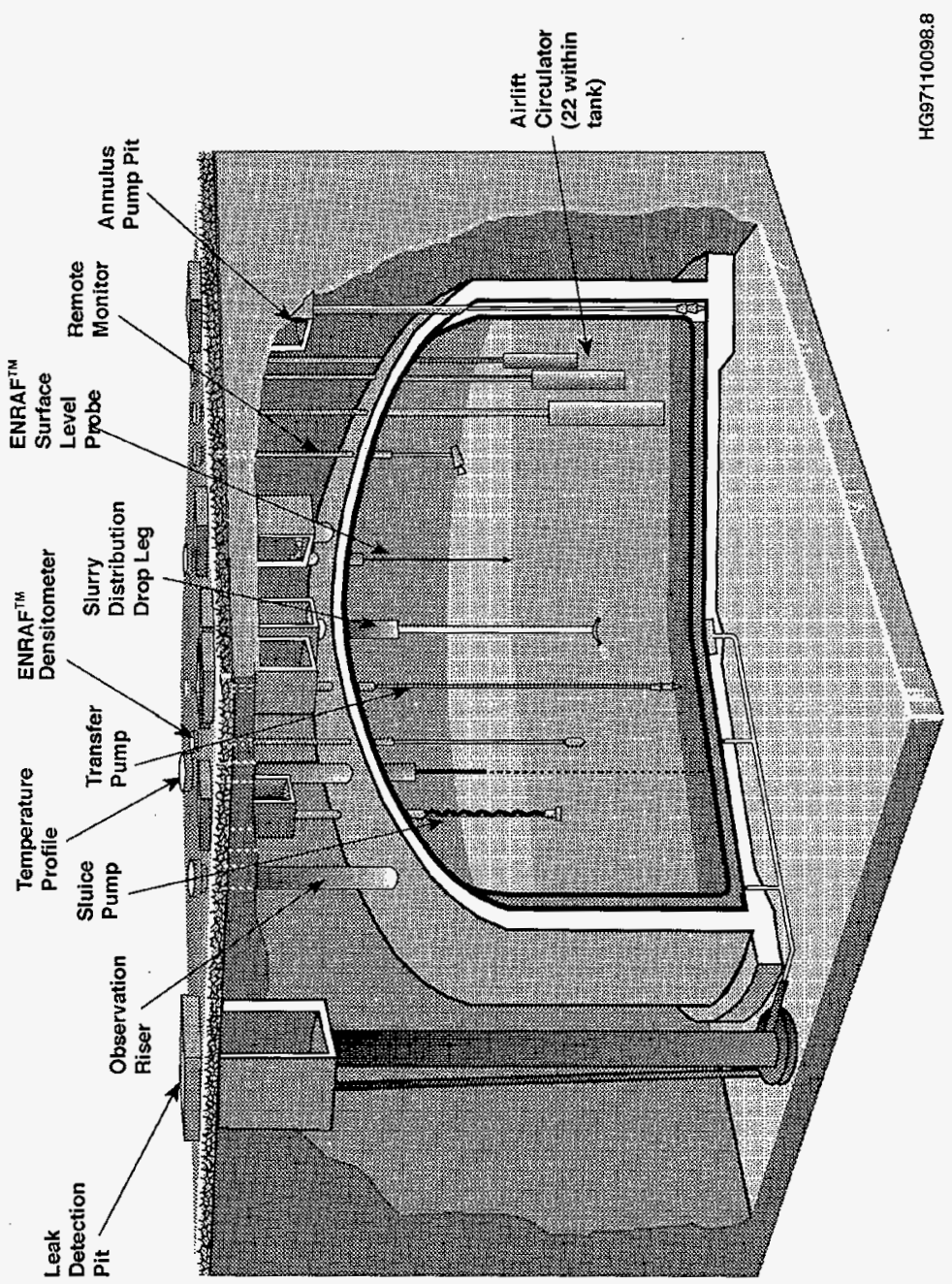




\subsection{WASTE CHARACTERIZATION}

This section summarizes the key waste characterization information required for process control of the tank 241-C-106 WRSS. The information is taken from previous reviews of the waste data, which are documented in Lambert (1997) and Reynolds (1997) for tank 241-C-106 and by Shelton (1997) for tank 241-AY-102. Also. best estimates of parameters important to the thermal hydraulic modeling are documented in Ogden et al. (1998).

\subsubsection{Tank 241-C-106 Waste Chemical and Physical Properties}

Tank 241-C-106 contains $746,000 \mathrm{~L}$ (197 kgal) of sludge, which is predicted to contain layers from four waste sources, and a supernatant liquid that is periodically replenished for cooling purposes. Table 3-1 shows the estimated volume of these layers based on the Hanford defined waste model. These layers are presented in ascending order from the tank bottom.

Table 3-1. Predicted Current Inventory in Tank 241-C-106. ${ }^{1}$

\begin{tabular}{|c|c|c|c|}
\hline Waste Type & Maste Vor wine & Siligge (I) & $\begin{array}{l}\text { Perreent or } \\
\text { Sturge layer. }\end{array}$ \\
\hline Uranium Recovery & $56.7(15)$ & $0-33(0-13)$ & 7.6 \\
\hline CWP1 & $128.7(34)$ & $33-63.5(13-25)$ & 17.3 \\
\hline$\overline{A R}$ & $242.2(64)$ & $63.5-124(25-49)$ & 32.4 \\
\hline$\overline{B L}$ & $75.7(20)$ & $124-142(49-56)$ & 10.3 \\
\hline Unk (BL) & $121.1(32)$ & $142-171(56-67.5)$ & 16.2 \\
\hline Unk (AR) & $121.1(32)$ & $171-201(67.5-79)$ & 16.2 \\
\hline Supernatant & variable & & \\
\hline
\end{tabular}

Notes:

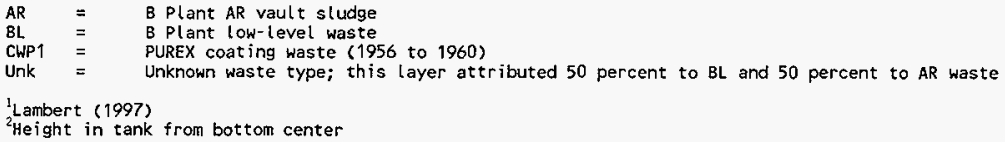

A comparison of waste sample information and Hanford defined waste information was performed to establish a best-basis inventory for tank 241-C-106 (Lambert 1997). Tables 3-2 and 3-3 list the major chemical elements and radionuclides. Bulk concentration is calculated from the total inventory value divided by the total estimated mass of wet sludge (1, 160,000 kg [2,550,000 1bs]). The expected compounds are taken from the results of a thermodynamic equilibrium model in Reynolds (1997). The model estimates that greater than 90 percent (by mass) of the solids will consist of five compounds: $\mathrm{NaAlSiO}_{4}$. $\mathrm{Fe}(\mathrm{OH})_{3}$. $\mathrm{NaHCO}_{3}, \mathrm{Na}_{2} \mathrm{C}_{2} \mathrm{O}_{4}$, and $\mathrm{Al}(\mathrm{OH})_{3}$. 
Table 3-2 total inventory values include constituents of both the solids fraction and the soluble salts fraction of the sludge. Water, which makes up approximately 47.2 wt\% of the sludge (Schreiber et al. 1996), is not accounted for in the Table 3-2 values. This water and the soluble salts make up the sludge interstitial liquid. Considering that the water content of the interstitial liquid is 78.6 wt\% (Reynolds 1997), the sludge solids and interstitial liquid fractions are estimated at $463,000 \mathrm{~kg}$ and $697,000 \mathrm{~kg}$. respectively.

Table 3-2. Best-Basis Inventory Estimates for Nonradioactive Components in Tank 241-C-106.

\begin{tabular}{|c|c|c|c|}
\hline (1) aralyte & 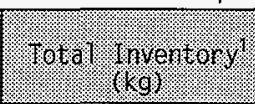 & 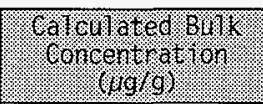 & Experted Compontro? \\
\hline $\mathrm{AT}$ & 36,000 & 31,000 & $\mathrm{NaAlSiO}_{4}, \mathrm{Al}(\mathrm{OH})_{3}$ \\
\hline $\mathrm{Ca}$ & 2,020 & 1,700 & $\mathrm{CaCO}_{3}$ \\
\hline TIC as $\mathrm{CO}_{3}$ & 147,500 & 127,000 & $\mathrm{NaHCO}_{3}$ \\
\hline $\mathrm{Fe}$ & 46,800 & 40,400 & $\mathrm{Fe}(\mathrm{OH})_{3}$ \\
\hline$M n$ & 1.610 & 1.400 & $\mathrm{MnCO}_{3}$ \\
\hline $\mathrm{Na}$ & 145,000 & 125,000 & several \\
\hline $\mathrm{NO}_{2}$ & 21,700 & 18,700 & $\mathrm{NaNO}_{2}$ \\
\hline $\mathrm{NO}_{3}$ & 1.920 & 1.700 & $\mathrm{NaNO}_{3}$ \\
\hline OH Total & 92,400 & 79.700 & several \\
\hline $\mathrm{Pb}$ & 1,740 & 1,500 & $\mathrm{~Pb}(\mathrm{OH})_{2}$ \\
\hline $\mathrm{P}$ aS $\mathrm{PO}_{4}$ & 14.400 & 12.400 & \\
\hline Si & 18.400 & 15,900 & $\mathrm{NaAlSiO}_{4}$ \\
\hline $\mathrm{S}$ as $\mathrm{SO}_{4}$ & 6,080 & 5.200 & \\
\hline TOC & 15,200 & 13,100 & $\mathrm{Na}_{2} \mathrm{C}_{2} \mathrm{O}_{4}$ \\
\hline U Total & 1,400 & 1,200 & \\
\hline
\end{tabular}

\footnotetext{
Notes: 'Lambert (1997)

${ }^{2}$ Reynolds (1997)
}

The tank 241-C-106 waste heat load determined from the Table 3-3 best-basis inventory is approximately 102,000 Btu/hr decayed to August 1998, which corresponds to the earliest possible startup of the WRSS. Considerable uncertainty exists in heat load estimates based on waste sampling results. Figure 3-4 i7lustrates the trend in heat load since 1990 based on tank temperature and psychrometric measurements which appears consistent with the best basis. However, a best estimate heat load for tank 241-C-106 waste of $118,000 \mathrm{Btu} / \mathrm{hr}$ as of August 1998 has been determined from thermal modeling (Ogden et al. 1998). 


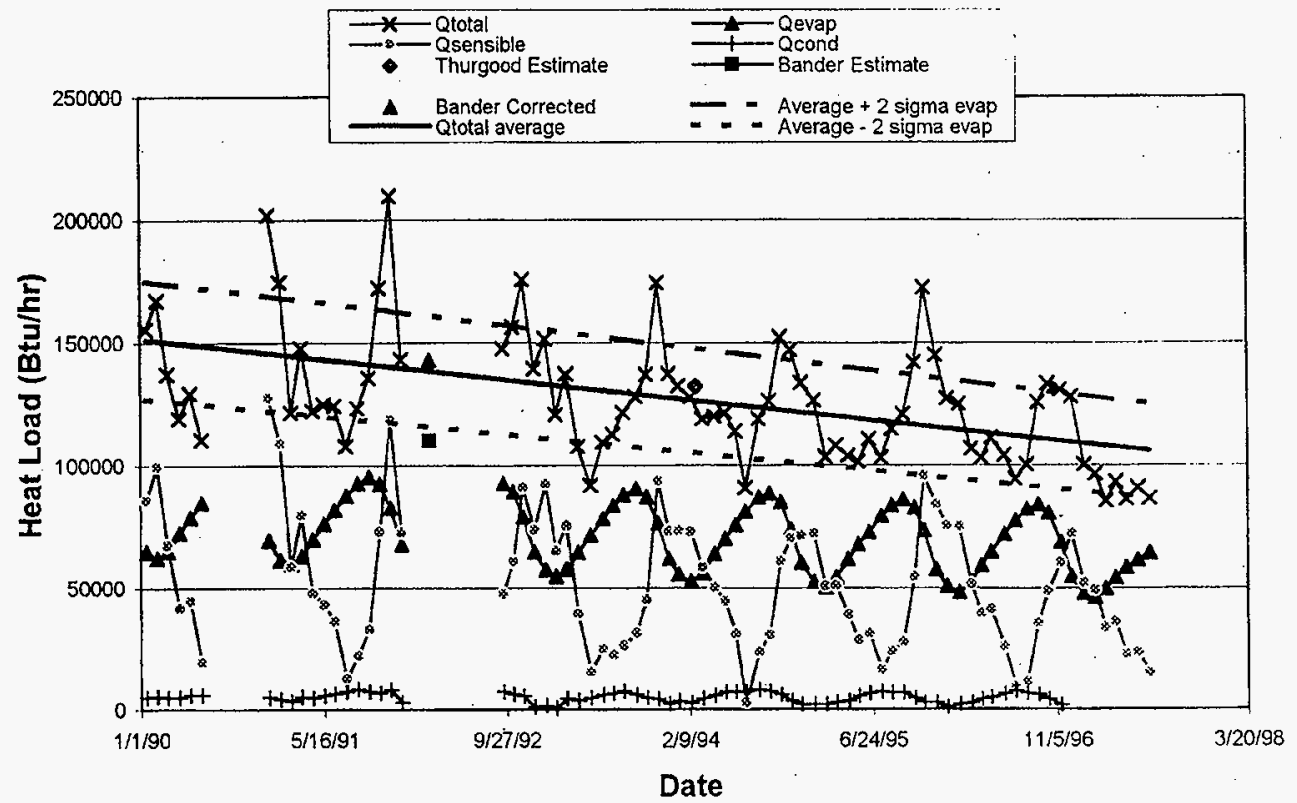


HNF-SD-WM-PCP-013 REV. 1

Table 3-3. Best-Basis Inventory Estimate for Radioactive Components in Tank 241-C-106. (Decayed to January 1, 1994)

\begin{tabular}{|c|c|c|c|}
\hline 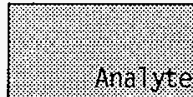 & 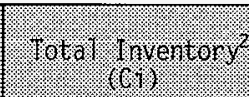 & 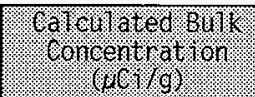 & 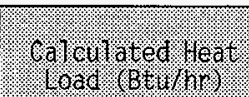 \\
\hline${ }^{90} \mathrm{Sr}$ & $4,770,000$ & 4.100 & 109.000 \\
\hline${ }^{137} \mathrm{Cs}$ & 267,000 & 230 & 4,300 \\
\hline${ }^{154} \mathrm{Eu}$ & 2.300 & 2.0 & \\
\hline $239 / 240 \mathrm{Pu}$ & 2,860 & 2.5 & \\
\hline${ }^{241} \mathrm{Am}$ & 1,120 & 1.0 & \\
\hline${ }^{243} \mathrm{Cm}$ & 16.2 & 0.01 & \\
\hline
\end{tabular}

Note:

${ }^{1}$ Activities decayed to January 1,1994 , is a best-basis inventory convention.

${ }^{2}$ Lambert (1997)

For the purposes of thermal hydraulic modeling, a series of best estimate physical properties were determined (see Table 3-4).

Table 3-4. Best Estimate Parameters for 241-C-106. (2 sheets)

\begin{tabular}{|l|l|}
\hline \multicolumn{1}{|c|}{ Phystear Paraneter } \\
\hline Fluffing factor & 1.4 (Range 1.0 to 1.8) \\
\hline Liquid thermal conductivity & $0.35 \mathrm{Btu} / \mathrm{hr} / \mathrm{ft} /{ }^{\circ} \mathrm{F}$ \\
\hline Particle thermal conductivity & $5.0 \mathrm{Btu} / \mathrm{hr} / \mathrm{ft} /{ }^{\circ} \mathrm{F}$ \\
\hline Liquid heat capacity & $0.8 \mathrm{Btu} / 1 \mathrm{~b} /{ }^{\circ} \mathrm{F}$ \\
\hline Particle heat capacity & $0.2 \mathrm{Btu} / 1 \mathrm{~b} /{ }^{\circ} \mathrm{F}$ \\
\hline Total heat load & $123,000 \mathrm{Btu} / \mathrm{hr}$ (January 1997) \\
\hline Heat load distribution & \\
0 & $0.6 \mathrm{~m}(0$ to $2 \mathrm{ft})$ \\
0.6 to $1.8 \mathrm{~m}(2$ to $6 \mathrm{ft})$ & $17,670 \mathrm{Btu} / \mathrm{hr}$ \\
\hline
\end{tabular}


Table 3-4. Best Estimate Parameters for 241-C-106. (2 sheets)

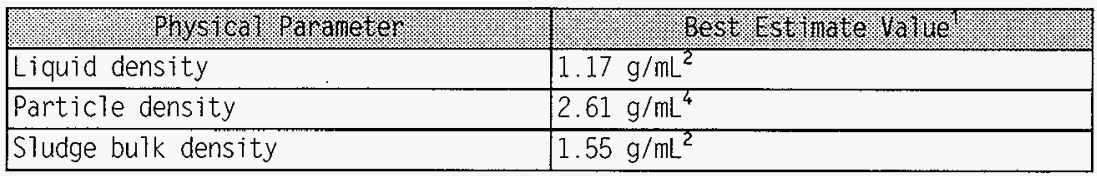

Notes:

${ }^{\mathrm{l}}$ Ogden et al. (1998)

${ }^{2}$ Lambert (1997)

${ }^{3}$ Distance from sludge surface

${ }^{4} T$ The density of the solid particles within tank $241-\mathrm{c}-106$ sludge reflects the compounds in the sludge. The densities of major compounds range from $2.2 \mathrm{~g} / \mathrm{mL}$ for sodium bicarbonate and $2.4 \mathrm{~g} / \mathrm{mL}$ for aluminum hydroxide to over $4 \mathrm{~g} / \mathrm{mL}$ for iron hydroxides. The particle density is based on the densities of the major compounds and the weight fraction of solid particles in the sludge. The assumed value for particle density in Table 3-4 will be used for initial retrieval calculations and will be adjusted, as necessary, as retrieval proceeds.

\subsubsection{Tank 241-AY-102 Waste Chemical and Physical Properties}

Table 3-5 1ists the inventory for tank 241-AY-102 supernatant from the best basis (Shelton 1997) except as noted. Tank 241-AY-102 currently contains $83,300 \mathrm{~L}(22 \mathrm{kgal})$ of solids which are predicted to be mostly $\mathrm{B}$ Plant low-level waste and some PUREX low-level waste. There is a large volume of di 1ute (98.5 weight percent water) supernatant ( $3 \mathrm{million} \mathrm{L} \mathrm{[801} \mathrm{kgal]} \mathrm{as} \mathrm{of}$ August 31, 1997) which will be used for the sluicing fluid. Some of this supernatant liquid will be removed before initial sluicing operations. resulting in a different liquid volume at that time.

Table 3-5. Inventory Estimates for Tank 241-AY-102 Supernatant. ${ }^{1}$ ( 2 sheets)

\begin{tabular}{|c|c|c|}
\hline : : Analve & $\begin{array}{l}\text { Touat Supernatint } \\
\text { Invertory (fige? }\end{array}$ & 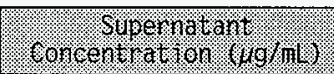 \\
\hline A1 & 33.3 & 10.9 \\
\hline $\mathrm{Ca}$ & NR & NR \\
\hline$\overline{C 1}$ & 322 & 105 \\
\hline TIC as $\mathrm{CO}_{3}$ & 9,740 & 3.180 \\
\hline $\mathrm{Fe}$ & $<3.58$ & $<1.2$ \\
\hline $\mathrm{Mn}$ & NR & NR \\
\hline $\mathrm{Na}$ & $73,500^{2}$ & 24,240 \\
\hline $\mathrm{NO}_{2}$ & 2,402 & 784 \\
\hline $\mathrm{NO}_{3}$ & 1.270 & 415 \\
\hline $\mathrm{OH}$ & $30.250^{2}$ & $9.980^{2}$ \\
\hline
\end{tabular}


Table 3-5. Inventory Estimates for Tank 241-AY-102 Supernatant. ${ }^{1}$ (2 sheets)

\begin{tabular}{|c|c|c|}
\hline 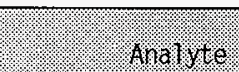 & 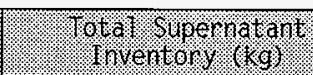 & 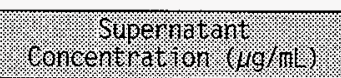 \\
\hline $\mathrm{Pb}$ & NR & NR \\
\hline $\mathrm{P}$ as $\mathrm{PO}_{4}$ & 1,720 & 560 \\
\hline Si & 36.6 & 11.6 \\
\hline $\mathrm{S}$ as $\mathrm{SO}_{4}$ & 797 & 260 \\
\hline TOC & 1,950 & 613 \\
\hline U Total & 53.3 & 17.4 \\
\hline
\end{tabular}

Notes:

$N R=$ not reported

'Shel ton (1997)

${ }^{2}$ The tank 241-AY-102 supernatant chemical composition from Shelton (1997) is referenced to September 30, 1996. On October 2, 1996, 60,200 L $(15,897 \mathrm{gal})$ of $\mathrm{NaOH}$ solution was added to the tank. Another $82,000 \mathrm{~L}(21,650 \mathrm{gal})$ of $\mathrm{NaOH}$ solution was added to the tank on June 30, 1998, and the tank supernatant was sampled on July 7, 1995. The results indicated the OH concentration was 0.58 molar. This value was used for the $O H$ concentration in this table. The Na concentration was adjusted based on the total mass of $\mathrm{Na}$ added since the best basis.

Tables 3-6 and 3-7 list the estimated sludge chemical and radionuclide inventory for tank 241-AY-102. The sludge inventory is taken from the best basis (Shelton 1997). which uses a sludge volume of $114.000 \mathrm{~L}$ (30 kgal). except as noted. A solids analysis on a grab sample taken in December 1994 jdentified an average ${ }^{90} \mathrm{Sr}$ concentration of $15,500 \mu \mathrm{Ci} / \mathrm{g}$ (Herting $1996 \mathrm{~b}$ ). This value better represents the sludge than the current best-basis concentration because the calculated heat load is more inline with non-sample based heat load estimates. The Table 3-7 sample-based heat load for the tank when decayed to August 1998 decreases to approximately 51,000 Btu/hr.

Ogden et a1. (1998) evaluated the tank 241-AY-102 heat load using three independent methods: tank level and ventilation flow data, sample data, and thermal modeling utilizing tank level and temperature data. A heat load estimate of $45.000 \mathrm{Btu} / \mathrm{hr}$ (as of 1995) determined from the thermal modeling was selected as the best-estimate heat load because it is based on measurements of tank level and dome temperature, which are very reliable and insensitive to properties of the waste. Any sample-based heat load will have a high uncertainty because of the shaliow layer of solids $(<12 \mathrm{in}$.) and the difficulty experienced in sampling and analyzing the sludge and measuring the sludge Tevel. Consequently, the project thermal analysis uses the bestestimate heat load of $45,000 \mathrm{Btu} / \mathrm{hr}$ (Ogden et a7. 1998). When decayed to August 1998, the best-estimate heat load is $41,200 \mathrm{Btu} / \mathrm{hr}$. 
Table 3-6. Inventory Estimates for Tank 241-AY-102 Sludge. ${ }^{1}$

\begin{tabular}{|c|c|c|}
\hline 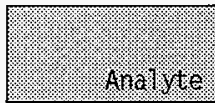 & 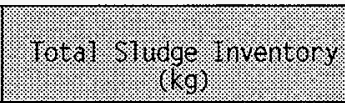 & 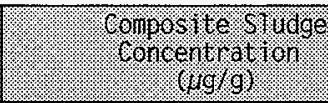 \\
\hline Al & 6.010 & 37.800 \\
\hline $\mathrm{Ca}$ & 2.230 & 14.000 \\
\hline C] & 1,320 & 8,330 \\
\hline $\mathrm{TIC}$ as $\mathrm{CO}_{3}$ & NR & NR \\
\hline $\mathrm{Fe}$ & 13,300 & 83,800 \\
\hline $\mathrm{Mn}$ & 1.400 & 8,790 \\
\hline $\mathrm{Na}$ & 6.580 & 41,400 \\
\hline $\mathrm{NO}_{2}$ & 468 & 2,940 \\
\hline $\mathrm{NO}_{3}$ & 110 & 694 \\
\hline OH Total & NR & NR \\
\hline $\mathrm{Pb}$ & NR & NR \\
\hline $\mathrm{P}$ as $\mathrm{PO}_{4}$ & 9,030 & 56.800 \\
\hline $\mathrm{Si}$ & 1,920 & 12,100 \\
\hline $\mathrm{S}$ as $\mathrm{SO}_{4}$ & 120 & 754 \\
\hline TOC & 7.290 & 45,800 \\
\hline U Total & 2,350 & 14,800 \\
\hline
\end{tabular}

Note:

'Shel ton (1997)

Table 3-7. Inventory Estimate for Radioactive Components in Tank 241-AY-102 STudge. (Decayed to January 1, 1994) ${ }^{1}$

\begin{tabular}{|c|c|c|c|}
\hline inglye & $\begin{array}{l}\text { Toral shigee } \\
\text { Invergort? }\end{array}$ & 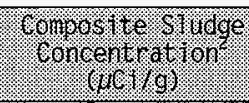 & 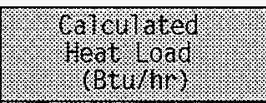 \\
\hline${ }^{90} \mathrm{Sr}$ & $2,470,000$ & $15,500^{3}$ & 56,600 \\
\hline${ }^{137} \mathrm{Cs}$ & 36.900 & 232 & 590 \\
\hline${ }^{154} \mathrm{Eu}$ & 5,140 & 32 & 160 \\
\hline $239 / 240 \mathrm{Pu}$ & 574 & 3.61 & \\
\hline${ }^{243 / 244} \mathrm{Cm}$ & 81 & 0.51 & \\
\hline
\end{tabular}

Notes: 'Activities decayed to January 1, 1994, is a best-basis inventory convention.

${ }^{2}$ Shel ton (1997)

${ }^{3}$ Herting $1996 b$ 
For the purposes of thermal hydraulic modeling, a series of best estimate physical properties were determined (see Table 3-8).

Table 3-8. Best Estimate Parameters for 241-AY-102 Waste.

\begin{tabular}{|c|c|}
\hline 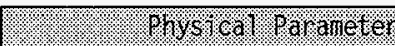 & 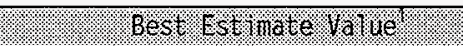 \\
\hline Sludge thermal conductivity & $0.35 \mathrm{Btu} / \mathrm{hr} / \mathrm{ft} /{ }^{\circ} \mathrm{F}$ \\
\hline Sludge heat capacity & $0.8 \mathrm{Btu} / 7 \mathrm{~b} /{ }^{\circ} \mathrm{F}$ \\
\hline Sludge heat load & $41,200 \mathrm{Btu} / \mathrm{hr}$ (August 1998) \\
\hline 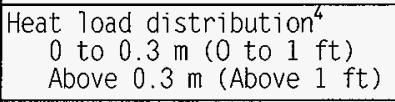 & $\begin{array}{l}41,200 \mathrm{Btu} / \mathrm{hr} \\
\text { homogenized tank } 241-\mathrm{C}-106 \text { sludge }\end{array}$ \\
\hline STudge density & $1.40 \mathrm{~g} / \mathrm{mL}^{3}$ \\
\hline Supernatant density & $0.99 \mathrm{~g} / \mathrm{mL}^{3}$ \\
\hline
\end{tabular}

Notes:

${ }^{1}$ Ogden et al. (1998)

${ }^{2}$ Shel ton (1997)

${ }^{3}$ Distance from tank bottom

\subsection{SLUICING PREPARATIONS}

A number of operations and activities must be completed to prepare tanks 241-C-106 and 241-AY-102 for sluicing and acquire information needed for process control. The sequence and timing of these pre-sluicing events are important for initiating the WRSS process. Figure 3-5 illustrates the time-phased order for conducting these operations. The specific requirements for each operation are discussed below.

\subsubsection{Tank 241-C-106 Waste Subcooling}

The sludge in tank $241-\mathrm{C}-106$ is to be cooled before sluicing startup to prevent a potential steam release event during early stages of sludge retrieval operations. The saturation temperature (i.e., boiling point) of the waste near the tank bottom is estimated at $113^{\circ} \mathrm{C}\left(235^{\circ} \mathrm{F}\right)$. Before starting sluicing operations, waste temperatures measured by thermocouple trees 8 and 14 must be reduced and maintained below the Limiting Control Setting 3.3.1 of $\leq 96{ }^{\circ} \mathrm{C}\left(205^{\circ} \mathrm{F}\right)$ (FDH 1998b) (see Appendix A-1). The more restrictive limit of Administrative Control (AC) 5.26 requires cooling the tank 24l-C-106 sludge to its wintertime temperature (FOH 1998b). Wintertime temperatures are achieved when the waste is cooled until the temperature of thermocouple 1 on the riser 8 thermocouple tree reaches $64{ }^{\circ} \mathrm{C}$ ( $148{ }^{\circ} \mathrm{F}$ ) (Bander et al. 1996). 
HNF-SD-WM-PCP-013 REV. I

Sludge cooling is accomplished by operating the tank 241-C-106 exhauster (296-P-16) to draw air through the inlet filter system. The WRSS chiller skid supplies a chilled propylene glycol/water solution to the intake air cooling coil (CC-1361) to cool the air stream to approximately $4{ }^{\circ} \mathrm{C}\left(40^{\circ} \mathrm{F}\right)$.

The waste subcooling operation will need to begin approximately 91 days before the scheduled date for sluicing startup. The minimum operating time is based on thermal analyses for tank 241-C-106 sluicing using a heat load determined from 1994 process data and decayed to January 1997 (Sathyanarayana 1997a and 1997b). In the analyses, the sludge cooling operation is assumed to extend for 83 days after the sludge reaches average summertime conditions.

Alternately, thermal analysis may be performed to demonstrate subcooling throughout the sludge if cooling was interrupted for an extended period before starting sluicing. As seen in Figure 3-5, the startup condition of tank 241-C - 106 needs to be established before beginning supernatant temperature equalization operations.

\subsubsection{Waste Retrieval Sluicing System Baseline Measurements}

Before starting the waste disturbing operations of the WRSS process, a minimum set of data are required to establish a baseline for process control purposes. The parameters that require baseline measurements include waste temperatures, liquid levels, and flammable gas generation and composition.

3.2.2.1 Temperature/Thermal Data Baseline. The temperatures in tanks 241-C-106 and 241-AY-102 are to be monitored for a period of not less than 30 days before the start of sluicing operations. To achieve this thermal baseline before waste disturbing operations begin. Figure 3-5 shows the latest time for initiating measurements is 38 days before the scheduled start of sluicing. Tank 241-C-106 temperature measurements wi 11 be obtained from thermocouple trees 8 and 14. Table 3-9 lists the thermocouples to be monitored on tank 241-AY-102.

The tank 241-C-106 and Table 3-9 thermocouple measurements, which make up the pre-sluicing thermal baseline. are compared to the project thermal analyses to ensure that the temperatures of the tanks are consistent with the predicted temperatures. Because the actual performance of both the 296-P-16 exhauster with inlet air cooling and the tank 241-AY-102 ventilation systems will be determined during the pre-sluicing operations. the project thermal models.will also be benchmarked as part of this baselining activity. This benchmarking involves performing a heat balance on each tank based on the waste heat load and heat removal mechanisms (i.e., the cooling supplied by the tank ventilation). Consequent7y, steady-state conditions are not required for the baseline/benchmark activities because these conditions are the output of the activity. 
Table 3-9. Tank 241-AY-102 Temperature Monitoring Locations. (2 sheets)

\begin{tabular}{|c|c|c|}
\hline (1) Instruinent & S: Inocation & Thernocouple Nunber. \\
\hline $\begin{array}{l}\text { Mult ifunctional Instrument } \\
\text { Tree (MIT) }\end{array}$ & Riser $5 \mathrm{~A}$ & TE-06230 through TE-06251 \\
\hline \multicolumn{3}{|l|}{ Sludge Thermowel1s } \\
\hline & Riser $16 \mathrm{C}$ & TE-102-73 \\
\hline & Riser 16A & TE-102-74 \\
\hline \multirow{5}{*}{$\begin{array}{l}\text { Air Lift Circulator } \\
\text { (ALC) Thermowells }\end{array}$} & ALC 6 & TE-102-42 \\
\hline & ALC 8 & $T E-102-44$ \\
\hline & ALC 16 & TE-102-50 \\
\hline & $\overline{A L C} 21$ & TE-102-55 \\
\hline & ALC 11 & TE-102-59 \\
\hline \multirow[t]{12}{*}{ Profile Temperature Trees $^{3}$} & \multirow[t]{3}{*}{ Riser 13B } & TE-102-60 \\
\hline & & TE-102-61 \\
\hline & & TE-102-62 \\
\hline & \multirow[t]{3}{*}{ Riser $13 \mathrm{C}$} & $T E-102-63$ \\
\hline & & TE-102-64 \\
\hline & & TE-102-65 \\
\hline & \multirow[t]{3}{*}{ Riser 13D } & TE-102-66 \\
\hline & & TE-102-67 \\
\hline & & TE-102-68 \\
\hline & \multirow[t]{3}{*}{ Riser $13 \mathrm{~A}$} & TE-102-69 \\
\hline & & TE-102-70 \\
\hline & & TE-102-71 \\
\hline \multirow[t]{2}{*}{$\begin{array}{l}\text { Tank Structure } \\
\text { Thermocouples }\end{array}$} & Insulating concrete & $\begin{array}{l}\text { TE-102-1 through TE-102-7, } \\
\text { TE-102-10 through TE-102-17. } \\
\text { TE-102-20 through TE-102-25 }\end{array}$ \\
\hline & Tank knuckle & TE-102-26 and TE-102-27 \\
\hline
\end{tabular}

Notes:

${ }^{1}$ sludge thermocouples are positioned $10 \mathrm{~cm}(4 \mathrm{in.})$ above the tank bottom.

'All air lift circulator thermocouples are installed in Riser 3 . They extend to within $7.6 \mathrm{~cm}$ (3 in.) of the tank bottom.

${ }^{3}$ Profile thermocouples are $($ isted in descending order at $760 \mathrm{~cm}(300 \mathrm{in.}), 400 \mathrm{~cm}(158 \mathrm{in}$.), and $7.10 \mathrm{~cm}$ ( $4 \mathrm{in.})$ elevations above the tank bottom. 
Figure 3-5. Pre-S7uicing Activities Time-Phased Logic.

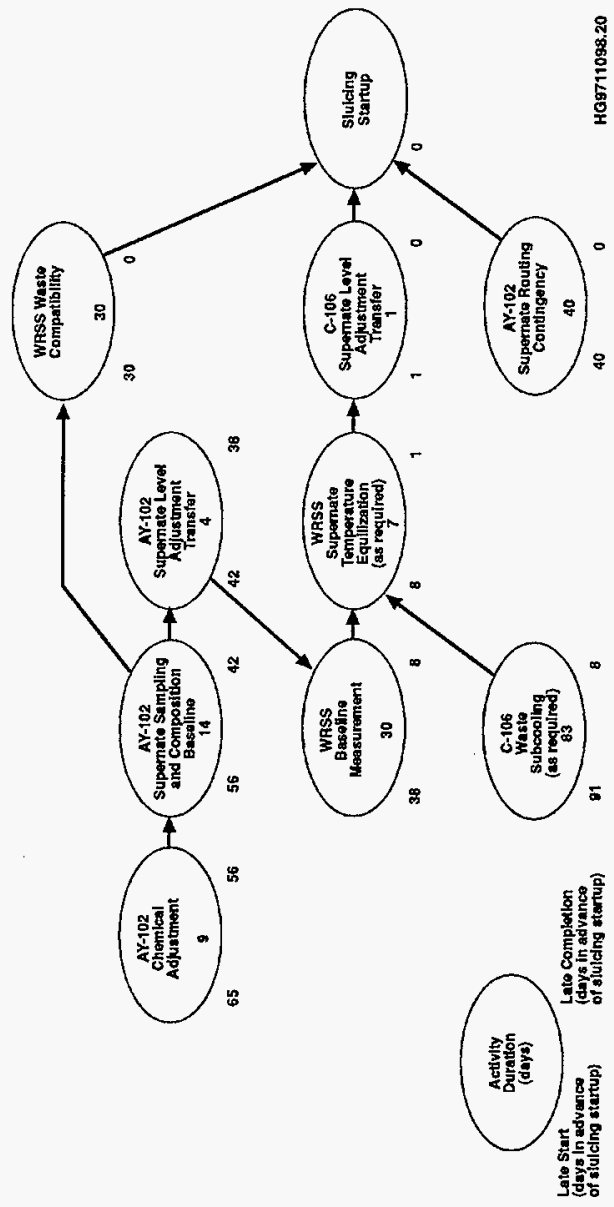


HNF-SD-WM-PCP-013 REV. 1

The tank 241-AY-102 supernatant transfers and chemical adjustment operations that occur before beginning the baseline measurements have little bearing on the baselining activity. The supernatant is very dilute and contributes little to the heat load of the tank. Though the heat of solution from the chemical adjustment step wi 11 tend to warm the waste. no measurable temperature increase is expected because of the large heat sink of the supernatant and the small volume of the chemical addition. The effect from the operating changes to the annulus ventilation system will far outweigh any influence that the supernatant transfers and chemical adjustment will have on the baseline temperature measurements.

3.2.2.2 Waste Retrieval STuicing System Flammable Gas Generation and Composition Baseline. The control of flammable gas releases during sluicing operations and of gas retention in tank 241-AY-102 (once tank 241-C-106 retrieval begins) are a major focus of the WRSS process. Gas release rates are determined directly by monitoring the hydrogen concentration in the headspaces of both tanks using installed standard hydrogen monitoring systems (SHMS) and by measuring the ventilation rates. Retained gas estimates are determined by several methods, all of which have significant uncertainties. As specified in the Tank Waste Remediation System Basis for Interim Operation (FDH 1998a), a presluicing flammable gas baseline will be established for both tanks 241-C-106 and 241-AY-102. This baseline wil1 be established using a minimum four-week monitoring period to comply with the FOH (1998a) safety analysis requirements. Table 3-10 1 ists the parameters to be established during the baseline period.

The current ventilation flow rate through tank $241-\mathrm{C}-106$ is relatively high $(2,700 \mathrm{cfm})$. This rate precludes an accurate estimate of gas composition from headspace grab samples. However, when ventilation flowis reduced with the new system to be used in the WRSS process, the gas compositions will be measured more accurately. During June 1997, the gas composition and generation rate was measured when the tank $241-\mathrm{C}-106$ ventilation system was shutdown for 48 hours.

Like the thermal baseline, the latest time for initiating flammable gas baseline measurements is 38 days before the scheduled start of sluicing (see Figure 3-5). This start time is consistent with the WRSS authorization basis requirements (FDH 1998a). However, starting the flammable gas baseline measurements earlier than the late start date may be justifiable to meet the technical requirements for the baseline.

The baseline retained gas inventory in tank 241-C-106 has been estimated using the barometric pressure effect (BPE) model (Stewart et al. 1998) Obtaining the baseline using the barometric pressure evaluation method described in Stewart et a1. (1997) required measurements to be taken during the winter months when barometric pressure variations were the greatest. Five significant barometric pressure swings that occurred between October 1997 and March 1998 provided the data for the estimate. A best-estimate retained gas inventory of $24 \mathrm{scm}$ ( $840 \mathrm{scf}$ ) was obtained from the average leve1/pressure correlation slopes for the five pressure swings. A conservative estimate of $50 \mathrm{scm}(1.770 \mathrm{scf})$ representing the $99 \%$ confidence level was determined from the five waste level changes and barometric conditions. These values of retained gas are well below the expected maximum value of 2,400 scf from 
Table 3-10. Stewart et a7. (1998) concluded that "the strategy for controlling flammable gas accumulation and release ... is conservative."

The retained gas volume in tank 241-AY-102 is far below the detection limit of the barometric pressure response method. The gas volume baseline will therefore only confirm from other indirect data, such as waste level and MIT temperature profiles, that gas volume has not measurably increased.

Table 3-10. Presluicing Flammable Gas Baseline. (2 sheets)

\begin{tabular}{|c|c|c|c|}
\hline Corturol Parameter & W yerted? & Irstrument & Method vo beternine. \\
\hline $\begin{array}{l}\text { Flammable gas } \\
\text { release rate for } \\
\text { tank } 241-c-106\end{array}$ & $\begin{array}{l}6.5 \mathrm{scfd} \mathrm{H}_{2} \\
( \pm 0.2 \mathrm{scfd})\end{array}$ & $\begin{array}{l}\text { SHMS, vent flow } \\
\text { rate }\end{array}$ & $\begin{array}{l}\text { Mathematical } \\
\text { integration of hydrogen } \\
\text { concentration over time }\end{array}$ \\
\hline $\begin{array}{l}\text { Gas composition } \\
\text { for tank } 241-C-106\end{array}$ & \begin{tabular}{|lr}
$\mathrm{H}_{2}$ & $50 \%$ \\
$\mathrm{~N}_{2} \mathrm{O}$ & $15 \%$ \\
$\mathrm{~N}_{2}$ & $9 \%$ \\
$\mathrm{NH}_{3}$ & $3 \%$ \\
$\mathrm{CH}_{3}$ & $2 \%$ \\
$\mathrm{H}_{2} \mathrm{O}$ & $10 \%$ \\
\end{tabular} & $\begin{array}{l}\text { Grab samples from } \\
\text { SHMS cabinets }\end{array}$ & $\begin{array}{l}\text { Air is mathematically } \\
\text { subtracted using Ar as } \\
\text { tie element }\end{array}$ \\
\hline $\begin{array}{l}\text { Retained gas } \\
\text { inventory for } \\
\text { tank 241-C-106 }\end{array}$ & $\leq 2.400 \mathrm{ft}^{3}$ & $\begin{array}{l}\text { ENRAF }{ }^{T M} \text { surface } \\
\text { level, Hanford } \\
\text { weather station } \\
\text { data }\end{array}$ & $\begin{array}{l}\text { Correlation between } \\
\text { barometric pressure and } \\
\text { surface-level changes } \\
\text { used to calculate }\end{array}$ \\
\hline \begin{tabular}{|l} 
Flammable gas \\
release rate for \\
tank $241-$ AY-102 \\
\end{tabular} & $\begin{array}{l}14 \text { scfd } H_{2} \\
( \pm 6 \text { scfd })^{2}\end{array}$ & $\begin{array}{l}\text { SHMS, vent flow } \\
\text { rate }\end{array}$ & $\begin{array}{l}\text { Mathematical } \\
\text { integration of hydrogen } \\
\text { concentration over time }\end{array}$ \\
\hline $\begin{array}{l}\text { Gas composition } \\
\text { for } \\
\text { tank 241-AY-102 }\end{array}$ & $\begin{array}{lr}\mathrm{H}_{2} & 100 \% \\
\mathrm{~N}_{2} \mathrm{O} & 0 \% \\
\mathrm{~N}_{2} & 0 \% \\
\mathrm{NH}_{3} & 0 \% \\
\mathrm{CH}_{3} & 0 \% \\
\mathrm{H}_{2} \mathrm{O} & 0 \% \\
\end{array}$ & $\begin{array}{l}\text { Grab samples from } \\
\text { SHMS cabinets }\end{array}$ & $\begin{array}{l}\text { Air is mathematically } \\
\text { subtracted using } \mathrm{Ar} \text { as } \\
\text { tie element }\end{array}$ \\
\hline $\begin{array}{l}\text { Retained gas } \\
\text { inventory for } \\
\text { tank 241-AY-102 }\end{array}$ & $\leq 380 \mathrm{ft}^{3}$ & $\begin{array}{l}\text { ENRAF }{ }^{\mathrm{TM}} \text { surface } \\
\text { level, MIT } \\
\text { temperature } \\
\text { profile }\end{array}$ & $\begin{array}{l}\text { Confirm that no } \\
\text { significant increase in } \\
\text { retained gas volume has } \\
\text { occurred }\end{array}$ \\
\hline
\end{tabular}

Note:

'Pasamehmetoglu et al. (1997)

The baseline time period is during the tank 241-C-106 sludge subcooling operation. which requires use of the 296-P-16 exhauster. The subcooling operation wi 17. lower bottom waste temperatures in tank $241-\mathrm{C}-106$ by 2.2 to $3.3^{\circ} \mathrm{C}$ ( 4 to $5^{\circ} \mathrm{F}$ ) (Bander et al. 1996 and Sathyanarayana 1997a). The effect of this level of subcooling on gas generation and retention will be small when 
compared with the ventilation effects. Consequently. the high uncertainties anticipated in the flammable gas release rate and gas composition estimates for the tank will occur because of the large dilution factor caused by the high 296-P-16 exhaust flow rate. To he1p reduce the uncertainty in the flammable gas baseline, grab samples from the tank dome space will be taken using the SHMS. Duplicate grab samples will be taken once per week for a three-week period and two times per week during the fourth week of the baseline period. The grab samples will be analyzed for the constituents listed in Table 3-10 and argon (Ar) using high-resolution mass spectrometry.

Like the thermal baseline, performing the tank 241-AY-102 supernatant transfers and chemical adjustment before starting the flammable gas baseline will have little effect on the measured values. The supernatant generates low amounts of gas from radiolysis and other mechanisms because of its dilute nature. The volume of retained gas is small because of the thin layer of sludge $(20 \mathrm{~cm}[8 \mathrm{in.}])$ on the tank bottom (see Table 3-10).

Process Engineering will evaluate differences between the baseline measurements and the expected values for impacts on the flammable gas hazards safety analysis conclusions. The results of the evaluation and any recommendations for changes to the sluicing operation will be presented to the Tank 241-C-106 Waste Retrieval Technical Review Group (TRG) for review and concurrence.

\subsubsection{Waste Retrieval Sluicing System Supernatant Temperature Equalization}

Existing tank temperature operating specifications limit waste temperature transients to protect the structural integrity of tanks (LMHC 1997D and 1997C). For tank 241-AY-102, the limit for waste solution temperatures $\angle 52{ }^{\circ} \mathrm{C}$ $\left(125^{\circ} \mathrm{F}\right)$ is $<5.6^{\circ} \mathrm{C}\left(10^{\circ} \mathrm{F}\right)$ per hour. The tank $241-\mathrm{C}-106$ transient temperature Timit of $\leq 11{ }^{\circ} \mathrm{C}\left(20^{\circ} \mathrm{F}\right)$ per day is independent of waste temperature.

Because the WRSS process requires a large volume of supernatant in tank 241-AY-102, transfer of tank 241-C-106 waste at design flow rates cannot cause the receiver tank to exceed its transient temperature limit. If the initial temperature difference between the supernatant liquids exceeds $11^{\circ} \mathrm{C}$ $\left(20^{\circ} \mathrm{F}\right)$, a number of sma 17 liquid transfers from tank 241-AY-102 to tank 24i-C-106 and back to tank 241-AY-102 will be required to equalize the tank Tiquids temperatures.

The sluice pumping system (P-0621/P-0622) will be used to transfer tank 241-AY-102 supernatant to tank 241-C-106. When the supernatant is mixed, the slurry pump system (P-1361/P1362) wi1l transfer an equivalent amount of tank 241-C-106 supernatant back to tank 241-AY-102. During this operation. the sluicer is operated in semi-automatic mode to sweep the supernatant liquid surface to induce mixing. Also, the submersible slurry pump is positioned to minimize solids entrainment. The number and volume of transfer cycles to accomplish the equalization depends on the initial supernatant volume and initial temperature in tank 241-C-106 as we 11 as the supernatant temperature of tank 241-AY-102. Given below is an expression relating the pumping time to the process variabies to prevent exceeding the $11^{\circ} \mathrm{C}\left(20^{\circ} \mathrm{F}\right)$ per day limit: 
HNF-SD-WM-PCP-013 REV. 1

$$
\theta=\frac{-V_{\mathrm{sp}}}{Q} \ln \frac{1-\frac{T}{T_{\mathrm{A} Y}}}{1-\frac{T_{C}}{T_{A Y}}}
$$

where

$$
\begin{aligned}
& \theta=\text { pumping time (minutes) } \\
& V_{\text {sp }}=\text { volume of tank 241-C-106 supernatant } \\
& Q^{\mathrm{SP}}=\text { pumping rate }(\mathrm{gpm}) \\
& T_{A Y}=\text { Tank 241-AY-102 supernatant temperature } \\
& T_{C}^{A Y}=\text { Tank 241-C-106 initial supernatant temperature } \\
& T^{\mathrm{C}}=\text { Tank 241-C-106 supernatant temperature at time } \theta \text { (or } \mathrm{T}_{\mathrm{C}} \pm 11{ }^{\circ} \mathrm{C} \\
& {\left[20^{\circ} \mathrm{F}\right] \text { at the transient temperature limit: + if heating is }} \\
& \text { occurring and - if cooling) }
\end{aligned}
$$

As shown in Figure 3-5, the timing for starting the supernatant temperature equalization operation is at least eight days before the official start of the first sluice batch. This operation is to be scheduled as close as possible to starting sludge retrieval to avoid jeopardizing sludge subcooling and the baseline measurements, and to preclude the possibility of having to repeat the temperature equalization operation after an extended delay period.

\subsubsection{Tank 241-C-106 Supernatant Level Adjustment Transfer}

Just before sluicing begins, the supernatant level in tank 241-C-106 will be adjusted to $183 \mathrm{~cm}$ (72 in.) (FDH 1998a). At this starting level, sluicing is expected to be effective while sludge temperatures remain less than the local saturation temperature. This decant operation coincides with the final supernatant temperature equalization cycle.

\subsubsection{Tank 241-AY-102 Supernatant Level Adjustment Transfer}

Enough dilute noncomplexed supernatant in tank $241-A Y-102$ wi 11 be pumped to establish an initial liquid waste inventory of $1.67 \mathrm{million} \mathrm{L}(440,000 \mathrm{ga} 1)$. This represents a liquid depth of approximately $4.1 \mathrm{~m}(13.3 \mathrm{ft})$. This supernatant inventory equates to a waste level of $4.3 \mathrm{~m}$ (168 in.) after accounting for the $0.2 \mathrm{~m}$ ( $8 \mathrm{in}$.) of sludge currently in the tank. At this waste level, the initial conditions for flammable gas control are satisfied (Pasamehmetoglu et a1. 1997). Additionally, there will be enough space in tank 241-AY-102 to transfer a 11 the tank 241-C-106 sludge plus the anticipated liquid additions (e.g., transfer line flushes, ventilation equipment flushes, and maintenance related pit and riser washdowns) into the tank without exceeding the maximum liquid level limit of $9.2 \mathrm{~m}$ (364 in.).

The supernatant transfer will lower the waste surface level in tank 241-AY-102 to approximately $4.3 \mathrm{~m}$ (168 in.). This transfer will follow the chemical addition and mixing operation described in Section 3.2.6 and the supernatant 
sampling activity of Section 3.2.7. Only the hydroxide ion concentration determination is required before beginning the transfer. Tank 241-AW-102 is the planned receiver for this transfer (see procedure T0-230-022). To prepare for the transfer. a waste compatibility assessment will be completed and the transfer route established.

The transfer needs to be started a minimum of 42 days before sluicing startup to allow the baseline measurements to occur when minimum waste disturbances are projected (see Figure 3-5).

\subsubsection{Tank 241-AY-102 Chemical Adjustment}

Tank 241-AY-102 supernatant wi 17 be chemically adjusted by adding approximately $88,000 \mathrm{~L}(23,000 \mathrm{ga} 1)$ of 50 weight percent sodium hydroxide (caustic) to adjust the hydroxide concentration to 0.57 molar. Adjustments to the amount of caustic will be made if the volume of supernatant in the tank after the first pumping stage differs by more than $26.500 \mathrm{~L}(7,000 \mathrm{gal})$. The target hydroxide concentration is needed to maintain the mixture of tank 241-AY-102 and tank 241-C-106 wastes within double-shel1 tank corrosion control specifications throughout WRSS operations. At the completion of sluicing operations. the expected final hydroxide ion concentration of the liquid phase in tank $241-A Y-102$ is 0.1 molar. The caustic addition is to be accomplished by off-loading caustic solution from a tank truck through a transfer hose connected to riser 15-0 on the tank (see procedure T0-200-010). After the caustic is added, four of five $17-\mathrm{ft}$ air lift circulators will be activated and operated for a minimum of three days to ensure the concentrated caustic is uniformly mixed throughout the tank 241-AY-102 supernatant (see procedure T0-200-030). Figure 3-5 shows a late start date for beginning the caustic adjustment operation of 65 days before initiating sluicing operations.

\subsubsection{Tank 241-AY-102 Supernatant Sampling and Composition Baseline}

A supernatant sample of tank 241-AY-102 will be taken to establish a composition baseline for WRSS process control and to verify the end point of the chemical adjustment operation was achieved. Sufficient caustic needs to be added to the tank before the liquid level is lowered below the minimum level to operate the four operable $17-\mathrm{ft}$ air lift circulators. One purpose of the sample event is to determine whether the tank 241-AY-102 supernatant transfer can proceed. If the target hydroxide ion concentration is achieved. the sample will establish the basel ine chemical composition of the sluice material. The required analyses for the sample are specified in the sampling schedule (see Section 4.6). Baseline sampling of tank 241-AY-102 supernatant needs to start a minimum of 56 days before sluicing operations are scheduled to begin (see Figure $3-5$ ). 
HNF-SD-WM-PCP-013 REV. 1

\subsubsection{Waste Retrieval Sluicing System Waste Compatibility}

A Tank Waste Remediation System program exists for evaluating planned transfers of liquid wastes into and within the double-shell tank system. The requirements for such a liquid transfer are documented in Fowler (1995) and Mulkey (1997). The scope of the Data Quality Objectives for Tank Farms Waste Compatibility Program (Mulkey 1997) includes liquids (i.e., transfers with less than five percent solids by volume). Mulkey states, and the DOE-RL and the Washington State Department of Ecology (Ecology) have signed an agreement, that solids transfers will be evaluated on a case-by-case basis for determining compatibi]ity.

Waste compatibility evaluations, topical reports, and safety analyses have addressed the chemistry-associated issues and overall safety of transferring the tank 241-C-106 waste into tank 241-AY-102. As a result of waste characterization and compatibility testing of the tank wastes, Reynolds (1997) concluded that the retrieval "will pose no unacceptable risk to workers, public safety, or the environment." Retrieving the sludge from tank 241-C-106 is highly beneficial because the high-heat safety issue associated with the tank is resolved, and waste is removed from a single-shell tank nearing its design life and sent to a double-shell tank designed for high-heat waste storage. Similar conclusions were reached in an earlier compatibility assessment (Sederburg 1994). The study determined no chemical reactions from commingling the wastes would result in waste incompatibility. Other laboratory studies found substantial sludge dissolution when mixed with water and sodium hydroxide solutions (PNNL 1997). Fewer solids deposited in receiver tank 241-AY-102 are anticipated to lessen concerns for flammable gas retention and sludge thermal behavior.

The compatibility studies and safety evaluations results serve as the case-specific waste compatibility evaluations for compliance with the DOE-RL and Ecology agreement on compatibility of solids transfers. The authorization to operate the WRSS process is provided by Addendum 1 of FDH (1998a) and by completing readiness review requirements. Figure 3-5 shows waste compatibility will be verified before the start of sluicing. This verification will address any changes that may have occurred since completing the current waste compatibility evaluations. The verification will begin a minimum of 30 days before the start of sluicing.

\subsubsection{Tank 241-AY-102 Supernatant Routing Contingency}

The transfer line routing for tank 241-AY-102 supernatant must be operable within 10 days at any time during the WRSS operations. One contingency for mitigating flammable gas retention in tank 241-AY-102 settled solids, should it occur. is removal of the supernatant to reduce the chances of a gas release event occurring and/or minimizing the consequences of such an event. The P-0621/P-0622 sluice pump system is capable of pumping the supernatant down to approximately $3.2 \mathrm{~m}(10.5 \mathrm{ft})$. The decision to transfer supernatant and the volume to pump wi11 be based on recommendations of the TRG after evaluating a11 available information. 
HNF-SD-WM-PCP-013 REV. 1

The transfer routing includes the SN-100 and SL-200 lines between tanks 241-C-106 and 241-AY-102 and the SL-503 transfer 1ine in the 241-AY-02A pit. A jumper will be available for connecting the U1l nozzle (SL-100) to the U3 nozzle of the SL-503 transfer line. Tank 241-AP-106 is the selected receiver tank (see procedure T0-270-035). As a contingency, a waste compatibility assessment that assumes complete retrieval of tank 241-C-106 waste will be established for transferring the supernatant volume. If supernatant removal becomes necessary. the compatibility evaluation can be accepted if the waste composition of the receiver tank applies at the time, or the assessment can be updated quick $7 y$ to account for the differences.

\subsection{WASTE RETRIEVAL SLUICING SYSTEM OPERATION PLAN}

The retrieval of tank 241-C-106 sludge will be carried out in a series of small volume sluice batches followed by monitoring periods to ensure that control of thermal and flammable gas concerns is maintained. This approach has been selected to support the start of retrieval operations. The potential impacts of several waste characterization uncertainties will be addressed in paralle?.

The following definitions are used when describing planned sluicing operations:

- Batch. The sluicing batch is the smallest sluicing element. It is a single continuous or nearly continuous sluicing operation, the duration of which is controlled by the accumulated mass of transferred solids reaching the desired value or the maximum sluicing batch time limit being reached, whichever occurs first.

- Increment. The sluicing increment refers to a $124.900 \mathrm{~L}$ $(33,000$ ga 1$)$ volume of sludge. The volume in a sluicing increment

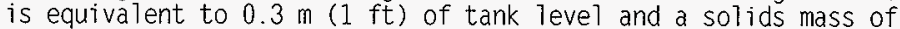
$77,300 \mathrm{~kg}$ (170,000 ibs). The increment size was selected based on estimates of the magnitude of "worst case" thermal conditions or flammable gas releases which could be accommodated in a single transfer. If the sluicing process can operate at optimum efficiency, only one sluicing batch is required to transfer one sluicing increment. Under less optimal conditions, two or more sluicing batches may be required to complete one sluicing increment.

- Campaign. The sluicing campaign refers to the combination of sluicing increments. The nominal volume of sludge transferred in a campaign is approximately $249,800 \mathrm{~L}(66.000 \mathrm{ga})$ ). Therefore, two sluicing increments represent a transferred sludge volume equivalent to a nominal sluicing campaign. Each campaign is equal in size. The third campaign is intended to remove all remaining sluicable sludge in tank 241-C-106, but the volume of this campaign is expected to be $<249,800 \mathrm{~L}(66,000 \mathrm{ga})$ ).

Figure 3-6 summarizes the planned batch processing approach. The number of sluicing batches and monitoring periods shown are based on best engineering judgments and Hanford Site past-practice sluicing experience. The actual 
number of sluicing batches needed to retrieve each increment and complete each campaign is unknown. The determining factor in campaign length is the ability of the sluicer to resuspend tank 241-C-106 sludge and flush the resulting slurry across the tank into the retrieval zone where the waste can be pumped out with the submersible slurry pump. Figure 3-6 reflects the maximum length of each sluicing batch operation and the expected duration of the monitoring periods. The basis for the durations are given in Section 4.0. The duration of monitoring periods is likely to vary because of uncertainties in both the waste behavior and the process parameters being monitored for process evaluations.

The campaign-increment-batch operating strategy is a conservative approach to achieving the WRSS process performance criteria. Key elements of this strategy are to ensure 1) heat is properly managed for tanks 241-C-106 and 241-AY-102 during sluicing operations, and 2) gas retention in tank 241-AY-102 waste does not exceed expectations as the depth of settled solids increases during the sludge retrieval. During the initial stages of retrieving sludge from tank 241-C-106, the hydraulic head (waste surface level) must be controlled to keep sludge temperatures lower than the local saturation temperature. thereby preventing a possible steam release event. Similarly, as the heat load and depth of settled sludge in tank 241-AY-102 increases during the retrieval, the mass of radiogenic high-heat solids transferred from tank 241-C-106 must be controlled to ensure the waste temperatures remain below the local saturation temperature. As the retrieval progresses, the increasing sludge height in tank 241-AY-102 wi11 also cause an increased potential for gas retention in the tank. Gas generation and gas retention must be monitored during and after the retrieval of tank 241-C-106 waste to allow timely corrective measures if a gas release event appears probable.

Conducting the retrieval process in batches assures that an excess amount of heat-generating material (i.e., greater than the $124.900 \mathrm{~L}$ [33.000 gal] increment volume) is not inadvertently transferred into tank 241-AY-102. As tank 241-C-106 sludge is pumped into tank 241-AY-102, the heat load and depth of settled solids in the tank increases. These changes result in increased temperatures in the solids layer. The magnitude of temperature increases will not become evident for months due to the large thermal time constant for tank 241-AY-102 (Ogden et a1. 1998)). Therefore, the transient temperature response to the waste additions coupled with a thermal model for the tank. must be used to predict the peak temperatures in the tank. Uncertainties in the heat transfer parameters (heat load, heat load distribution. and waste fluffing [ratio of the thickness of deposited sludge in tank 214-AY-102 to the original thickness of sludge retrieved from tank 241-C-106]). together with the large thermal time constant of tank 241-AY-102, dictate that transfers be made in sma11 batches to ensure that waste temperatures stay within limits. Consequently, the duration of each batch operation is limited by a solids mass transfer value or an allotted slurry pump system run time that is based on the uncertainty of online mass transfer measurements. A batch is terminated by whichever limit is reached first.

An increment size of $124.900 \mathrm{~L}$ (33.000 gal) achieves conservatism in the tank 241-AY-102 temperature process control. A WRSS thermal analysis predicts the initial retrieval of tank 241-C-106 sludge equivalent to twice a sluicing 


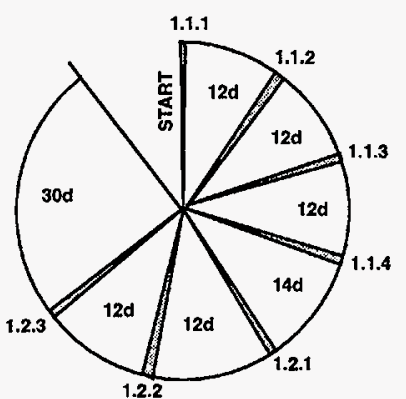

CAMPAIGN 1

Notation: X.Y.Z

$X$-campaign

$y$-Increment

z-batch

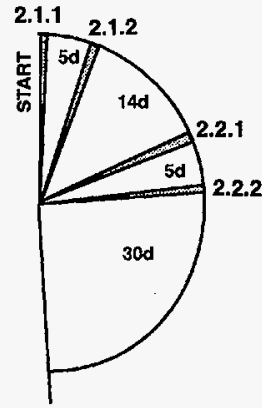

CAMPAIGN 2

Scale $;$ day $=3^{\circ}$

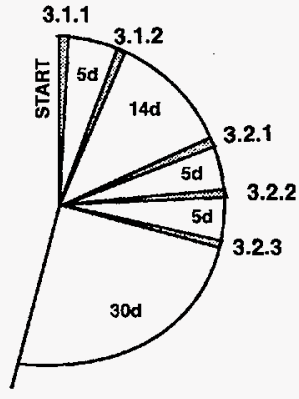

CAMPAIGN 3

HG9711008s.21a 
HNF-SD-WM-PCP-013 REV. 1

increment $[249,800 \mathrm{~L}(66,000$ ga 1$)]$, with a heat load and waste fluffing greater than expected. can be accommodated in tank 241-AY-102 without exceeding waste temperature limits. This can be accomplished even without enhanced annulus tank ventilation flow; no annulus blocking and low vacuum annulus operation (Ogden et a 1. 1998). The monitoring period following retrieval of a sluicing increment allows time for collecting tank thermal data and comparing the thermal responses of tanks 241-C-106 and 241-AY-102 to their expected behaviors. The batch approach implements the conservative process control strategy when multiple sluice batches are needed to retrieve a sluicing increment.

A sluicing campaign size of $249,800 \mathrm{~L}(66,000 \mathrm{gal})$, equivalent to $0.6 \mathrm{~m}$ (2 ft) of tank 241-C-106 sludge. corresponds to the amount of sludge needed to be initially retrieved from tank $241-\mathrm{C}-106$ to eliminate the need to add water to the tank to maintain temperature control (Ogden et al. 1998). Therefore, completion of the first campaign is expected to remove enough heat generating wastes to resolve the tank 241-C-106 high-heat safety issue. As noted, removing $0.6 \mathrm{~m}$ ( $2 \mathrm{ft}$ ) of waste to achieve this goal can be accomplished while maintaining tank 241-AY-102 within temperature limits, even assuming worst case waste thermal properties and minimum tank annulus ventilation to the bottom of the tank.

In addition to the limit imposed on the amount of material transferred, the first campaign also is characterized by the requirement to maintain a minimum hydraulic head on the tank 241-C-106 sludge. This requirement enables temperatures to remain below the local saturation temperature (boiling temperature). Subsequent campaigns wil1 retain the limit on material transferred but drop the requirement for minimum hydraulic head.

A monitoring period follows each batch, increment, and campaign. Long term monitoring begins after the completion of WRSS operations when all sluicable solids have been removed from tank 241-C-106. These monitoring periods are described in Section 4.0. During the operational phases of the WRSS process (i.e., sluicing batches and monitoring periods), a number of process variables are monitored on a continuous basis. These variables include the following:

- Tanks 241-C-106 and 241-AY-102 headspace gas concentration

- Tank 241-AY-102 waste level (ENRAF ${ }^{T M}$ liquid level gauge)

- Tank 241-AY-102 temperatures (profile thermocouple trees, sludge thermocouple probes, air lift circulators thermocouples. MIT thermocouples, and under-tank thermocouples)

- Tank 241-C-106 waste temperatures (thermocouple trees in risers R-8 and $\mathrm{R}-14$ )

- Tanks 241-C-106 and 241-AY-102 headspace pressures

- Tank 24I-C-106 ventilation exhaust flow rate, and condenser inlet pressure, pressure drop, and outlet temperature 
HNF-SD-WM-PCP-013 REV. 1

- Tank 241-C-106 chiller cooling solution flow rate, inlet and outlet temperatures

- Tank 241-AY-102 annulus ventilation flow rate and outlet temperatures

- Tank 241-AY-102 ventilation exhaust flow rate, outlet temperature, and relative humidity.

- Tank 241-AY-102 ventilation condenser cooling solution flow rate, inlet and outlet temperatures

In addition to the variables listed above, a number of additional process variables associated with the fluid handling equipment are monitored during the active sluicing operations. These variables include the following:

- Sluice pump system speed and flow rate

- Slurry pump system speed and flow rate

- Mass flowmeter slurry density, mass flow rate, and total solids mass transferred.

- Tank 241-AY-102 foaming (in-tank imaging system)

Other process variables are measured only during monitoring periods. They support the decision-making process on the amount of tank 241-C-106 sludge to be retrieved during the next sluice batch, if any, and on the best way to conduct the retrieval within the applicable technical constraints of the process. These variables include the following:

- Tank 241-AY-102 density profile (ENRAF ${ }^{\mathrm{TM}}$ densitometer) and solidliquid interface (ENRAFT ${ }^{M}$ densitometer and MIT validation probe)

- Tank 241-AY-102 supernatant and settled solids chemical and radionuclide composition, and physical properties obtained from grab samples

- Tank 241-AY-102 oil slick (in-tank imagining system)

- Tank 241-C-106 waste level (ENRAF ${ }^{T M}$ liquid level gauge).

During each monitoring period, specific process parameters are evaluated to determine the limitations placed on the next sluicing batch. The evaluations performed depend on whether the current sluicing batch completes an increment and/or a sluicing campaign. Table 3-11 lists the parameters that are evaluated and the monitoring period in which an evaluation is performed. Detailed descriptions of the evaluations are found in Section 4.0. 
HNF-SD-WM-PCP-013 REV. 1

Table 3-11. Process Evaluations Performed at WRSS Monitoring Periods.

\begin{tabular}{|c|c|c|c|c|}
\hline \multirow{2}{*}{ Process a prameter } & \multicolumn{4}{|c|}{ 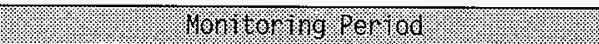 } \\
\hline & Bordor. & Ther enent & 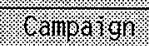 & leng. Yern: \\
\hline Mass $106-C$ solids transferred & $x$ & $x$ & $x$ & \\
\hline Heat load solids transferred & $\ddot{x}$ & $x$ & $x$ & \\
\hline Therma ] response $106-\mathrm{C}$ & & $1^{\text {st }} 20 \mathrm{nly}$ & $1^{\text {st }} 1$ Only & \\
\hline Thermal response 102-AY & & $x$ & $x$ & $\bar{x}$ \\
\hline Flammable gas released $106-C$ & & & $x$ & \\
\hline Flammable gas released $102-\mathrm{AY}$ & & & $x$ & $\bar{x}$ \\
\hline Flammable gas retention 102 -AY & & & $\bar{x}$ & $\bar{x}$ \\
\hline
\end{tabular}

\subsection{PROCESS FLOWSHEET}

Three operational phases characterize the WRSS process: 1) sluicing preparation, 2) startup and active sluicing concluding with the retrieval of all sluicable tank 241-C-106 solids, and 3) post-sluicing long-term monitoring. This section describes the process flowsheets for these phases, and Figures $3-7,3-8,3-9$, and $3-10$ diagram the process flow.

\subsubsection{Tank. 241-C-106 Pre-Sluicing Flowsheet}

The high cooling rate ventilation system operation for tank 241-C-106 uses the 296-P-16 exhauster, a high flow rate once-through system. In this mode, approximately $2,700 \mathrm{cfm}$ air enters the tank through the air inlet-cooling coil system and other pathways. A chiller system operates in combination with the cooling coil to supply a constant $4.4{ }^{\circ} \mathrm{C}\left(40{ }^{\circ} \mathrm{F}\right)$ inlet air flow at the air intake. The same volume is drawn out of the tank and passes through a de-entrainer, heater and high-efficiency particulate air (HEPA) filters. It is then exhausted through the 296-P-16 fan and the associated stack.

This high cooling/flow rate ventilation configuration will be used to provide tank 241-C-106 waste subcooling before the start of sluicing. Other than providing high flow rate ventilation to tank $241-C-106$ during large riser (12- and 36-in. diameter) opening maintenance activities, use of the 296-P-16 ventilation system after the initial waste subcooling operation has been completed is not anticipated during the WRSS process (see Figure 3-7).

\subsubsection{Sluicing Operation Flowsheet}

The sluicing operation process flowsheet covers the WRSS process from startup to shutdown. Active sluicing operations and monitoring periods make up this operational phase. The primary operating systems include the fluid handing systems and the tank ventilation systems for tanks 241-C-106 and 241-AY-102. In the monitoring periods that occur between sluice batches, the tank 
HNF-SD-WM-PCP-013 REV. 1

This page intentionally left blank. 
HNF-SD-WM-PCP-013 REV. 1

Figure 3-8. Process Flowsheet Process Fluid Systems.

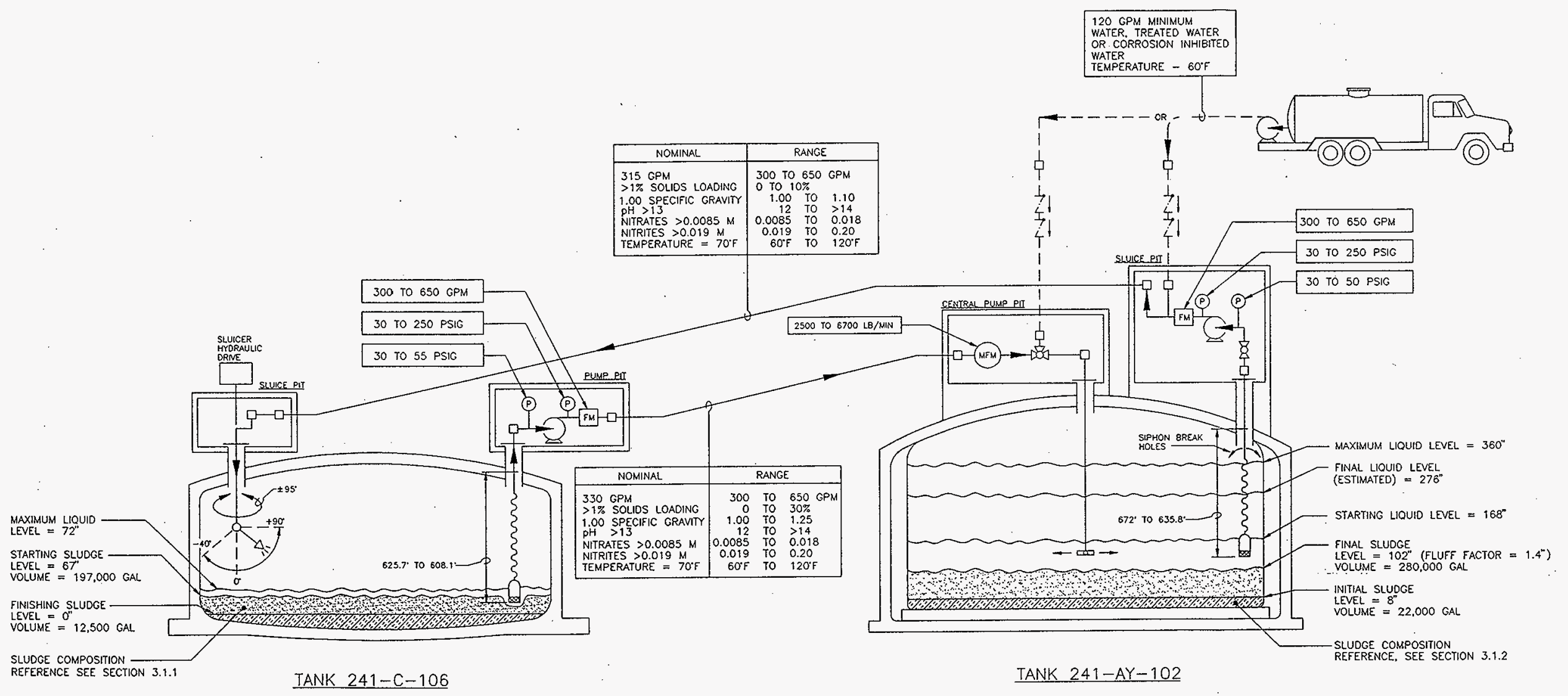


Figure 3-9. Waste Retrieval Sluicing System Process Flowsheet Tank 241-C-106

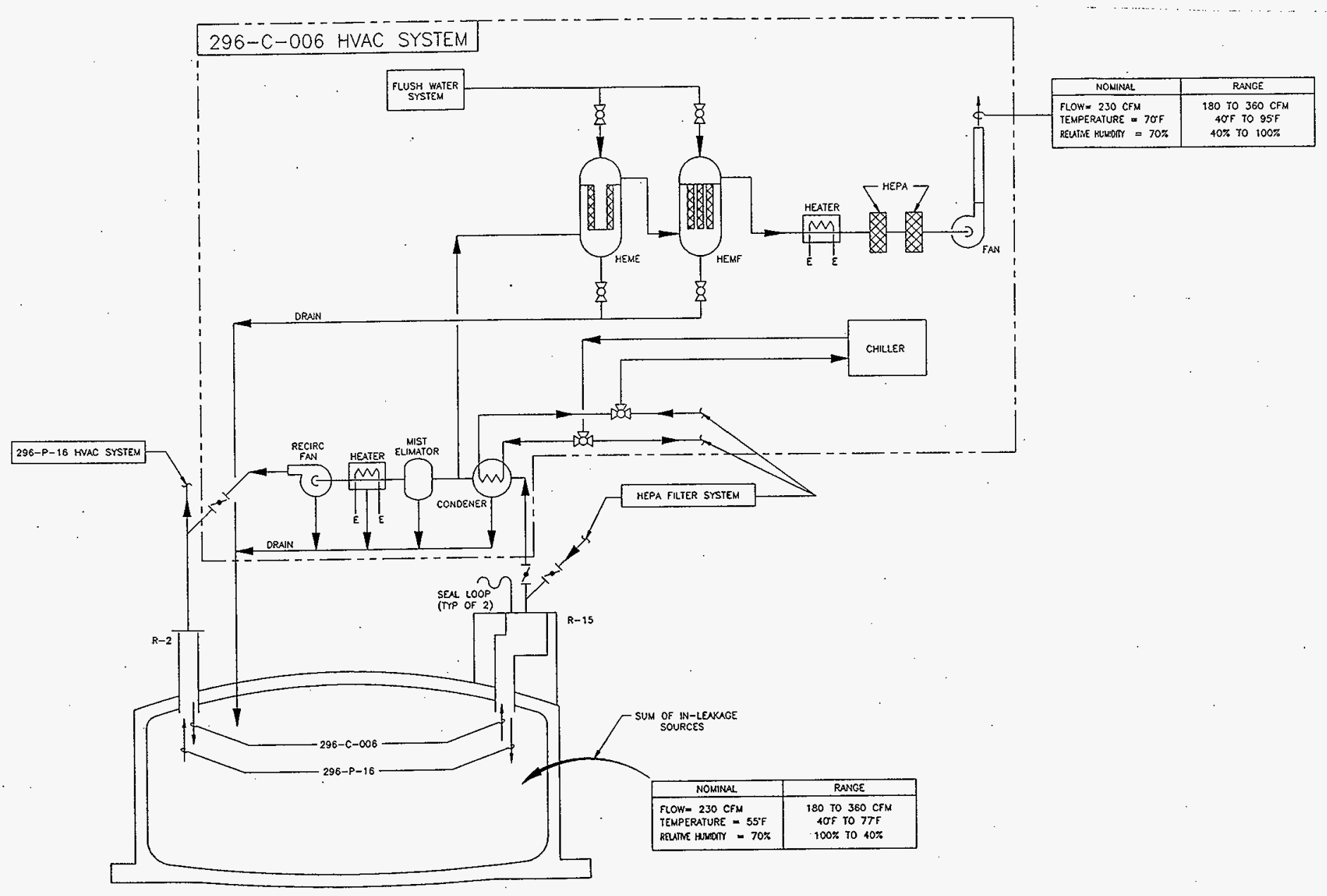

TANK $241-C-106$ 


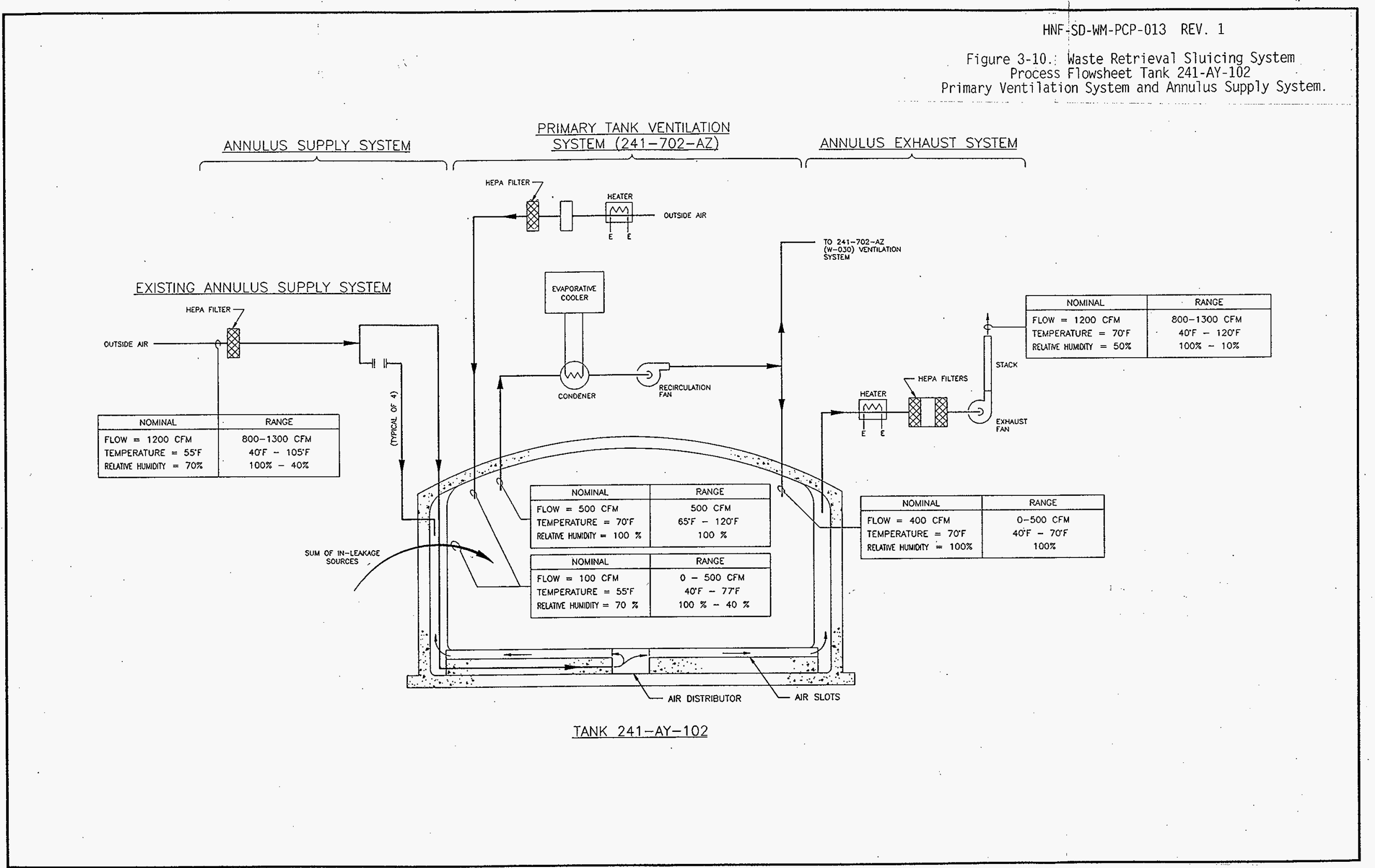


HNF-SD-WM-PCP-013 REV. 1

instrumentation and ventilation systems are all that remain operational. The fluid handling systems are shut down once the pre-determined amount of sludge has been transferred, or the maximum pump run time is reached.

3.4.2.1 Fluid Systems. The WRSS batch operations involve the concurrent transfer of tank 241-AY-102 supernatant to tank 241-C-106 and the transfer of the mobilized sludge slurry from tank 241-C-106 back to tank 241-AY-102. The slurried sludge transferred into tank $241-A \gamma-102$ settles out of the bulk supernatant and adds a layer of sludge to the tank bottom before the clarified supernatant is returned to mobilize more sludge (see Figure 3-8).

3.4.2.2 Tank Ventilation Systems. During the retrieval phase of the WRSS process, ventilation systems support the waste handling and storage in tanks 241-AY-102 and 241-C-106. These ventilation systems confine radionuclides and hazardous chemicals by maintaining a negative pressure in the tanks, cool the radiogenic heat-bearing waste stored in the tanks, flush the tanks of flammable gas. control humidity to enhance visibility using remote video camera systems, and decontaminate the ventilation stream before discharging it to the atmosphere (see Figures 3-9 and 3-10).

241-C-106 Ventilation Systems. The 296-C-006 ventilation system is used during the active sluicing phase of the WRSS process. In addition to the general ventilation functions listed above, the 296-C-006 system is ideally suited for sluicing operations because it incorporates the following:

- enhanced aerosols removal capabilities

- recirculation of dehumidified air to reduce the formation of fog and improve visibility for the remote viewing camera

- simplified filter media cleaning configuration to reduce operator radiation exposure.

During routine ventilation operation. approximately $230 \mathrm{cfm}$ air enters the tank through tank pits and from the cascade line from tank 241-C-105. The tank exhaust of approximate $1,220 \mathrm{cfm}$ passes through a chilled condenser before splitting into two separate streams. Approximately $230 \mathrm{cfm}$ of the $1.220 \mathrm{cfm}$ is drawn through the process building skid (241-C-91) and the associated exhaust skid (296-C-006) for discharge to the atmosphere. The remaining $990 \mathrm{cfm}$ is recirculated back to tank 241-C-106. The recirculation flow provides cooling and partial fog control, and the exhaust flow provides containment and flammable gas control in tank 241-C-106.

241-AY-102 ventilation systems. Two ventilation systems are connected to and support tank 241-AY-102 during sluicing operations. The new 241-AZ-702 system ventilates the primary tank and the 296-A-16 system ventilates the tank 241-AY-102 annulus.

The 241-AZ-702 ventilation system will normally operate in the recirculation mode. In this operating mode, approximately $100 \mathrm{cfm}$ enters the tank through the inlet air system and other pathways. A flow of approximately $500 \mathrm{cfm}$ exhausts from the tank and passes through an evaporative cooled condenser 
HNF-SD-WM-PCP-013 REV. 1

before being split into two separate streams. Approximately $100 \mathrm{cfm}$ of the $500 \mathrm{cfm}$ is exhausted through the 241-AZ-702 ventilation system cleanup train to the associated stack for discharge to the atmosphere. The remaining $400 \mathrm{cfm}$ is recirculated back to tank 241-AY-102 for waste cooling.

The annulus space in tank 241-AY-102 is ventilated by a dedicated, independent ventilation system. During WRSS operations, the annulus ventilation system will be operated in high vacuum mode with the annulus wall inlet blocked with blank flanges to achieve a flow of 800 to $1,300 \mathrm{cfm}$ to the annulus bottom cooling channels. This annulus ventilation requirement implements Limiting Condition of Operation (LCO) 3.3.3. "Tank 241-AY-102 Annulus Ventilation system."

\subsubsection{Post Sluicing Monitoring Period Flowsheet}

Following the retrieval of sluicable solids from tank 241-C-106, the 296-C-006 ventilation will continue to operate indefinitely to confine radionuclides and hazardous chemicals in the tank waste (see Figure 3-9). However, based on thermal considerations, active ventilation could be eliminated for long-term storage of the remaining tank heel depending on future programmatic needs. A thermal analysis of the tank that evaluated the effects of various levels of sludge removal predicts that the high heat safety issue wi 11 be resolved, and the need for active ventilation is eliminated after the second campaign is completed ( $i, e ., 1.2 \mathrm{~m} \mathrm{(} 4 \mathrm{ft}$ ) of sludge has been removed) (Sathyanarayana 1997a). Passive ventilation would be sufficient to cool the tank and maintain the waste within temperature limits. Whether passive ventilation would be sufficient to dissipate generated flammable gas would depend on the heel volume and chemical composition.

The ventilation configuration for tank $241-A Y-102$ is expected to be the same as that described in Section 3.4.2.2.

\subsection{EQUIPMENT DESCRIPTIONS}

This section describes major equipment items used by the WRSS process. The focus is on the equipment required to carry out the retrieval in a controlled manner. This equipment includes fluid systems, ventilation systems. instrument systems, control systems, and utilities. For additional equipment descriptions, refer to the approved authorization basis (FDH 1998a).

\subsubsection{Fluid Systems}

The equipment used to sluice the tank $241-C-106$ sludge, transport the slurry to the receiver tank, and distribute the solids uniformly over the sludge hee] in tank 241-AY-102 make up the WRSS fluid systems. The fluid handling equipment includes transfer pipelines, the slurry pump system. the sluice pump system, a sluicer in the source tank, and a slurry distributor in the receiving tank (see Figure 3-11). 
HNF-SD-WM-PCP-013 REV. 1

3.5.1.1 Transfer Pipelines. Two parallel waste transfer lines, approximately $520 \mathrm{~m}(1,700 \mathrm{ft})$ long. 7 ink tanks 241-C-106 and 241-AY-102. The 7ines concurrently transfer slurry to tank 241-AY-102 (through the SL100 slurry pipeline) and clarified supernatant to tank 241-C-106 (through the SN200 supernatant pipeline). The slurry line runs between pits 241-C-06A and 241-AY-02A. The sluice line runs between pits 241-AY-02E and 241-C-06C. Figure 3-12 shows the transfer line routing.

Process Piping. Pipe in pipe includes a $10 \mathrm{~cm}$ (4 in.). Schedule $40,304 \mathrm{~L}$ stainless steel, pipe code M9, primary pipeline encased in a $15 \mathrm{~cm}(6 \mathrm{in}$.), Schedule 40 , carbon steel, pipe code M26a, secondary pipeline. Low-end leak detection, high-end flushing capability, and cathodic protection are provided for both iines.

Reference Drawings/Specifications. Drawings $\mathrm{H}-2-818424, \mathrm{H}-2-818426$ sh $1-2$, $\mathrm{H}-2-818427$ sh 1-2, H-2-818482 sh 1-2, H-2-818432, H-2-181434, H-2-818532 sh $1-3, \mathrm{H}-2-818533, \mathrm{H}-2-818534, \mathrm{H}-2-818535, \mathrm{H}-2-818536$, and Construction Specification W-320-C1 (inter-farm), W-320-C7 (AY Farm), and W-320-C5 (C Farm).

Operational Limitations.

Flow Rate

$2,460 \mathrm{~L} / \mathrm{min}(650 \mathrm{gpm}), 5.0 \mathrm{~m} / \mathrm{s}(16.4 \mathrm{ft} / \mathrm{s})$ maximum (analyzed safety limit)

$1.300 \mathrm{~L} / \mathrm{min}(350 \mathrm{gpm}), 2.7 \mathrm{~m} / \mathrm{s}(8.8 \mathrm{ft} / \mathrm{s})$ nominal operating

$1,140 \mathrm{~L} / \mathrm{min}(300 \mathrm{gpm}), 2.3 \mathrm{~m} / \mathrm{s}(7.6 \mathrm{ft} / \mathrm{s})$ minimum (solids settling/line plugging)

Pressure $\quad-\quad 2.2 \mathrm{MPa}$ (320 psig) maximum

Temperature $\quad-\quad 82^{\circ} \mathrm{C}\left(180^{\circ} \mathrm{F}\right)$ structural maximum, $49^{\circ} \mathrm{C}\left(120^{\circ} \mathrm{F}\right)$ operational limit

Solids Loading - $\quad 30$ weight percent slurry line, 10 weight percent sluice line (The lower limit for the sluice line is required to minimize accident consequences of a tank 241-C-106 ventilation system failure - structural1y the sluice line is capable of 30 weight percent.)

3.5.1.2 Slurry Pump System. The slurry pump system is a tandem pump that includes an adjustable height, submersible slurry pump in the tank and a variable speed slurry booster pump in the pit above. The slurry pump system is located in the 241-C-06A pit in the 36 in. riser R-9.

Submersible and Booster Pumps. The submersible slurry pump is a centrifugal, direct drive, end suction, 40-hp immersible pump with a $0.6 \mathrm{~cm}(0.25 \mathrm{in}$.) mesh intake screen. It pumps waste from the tank to the 250 -hp. vertical direct drive, variable speed. centrifugal slurry booster pump that includes a nonreverse rotation brake to prevent damage to the gas seal. See drawing H-2-818508, sheet 1, for a diagram of the slurry booster pump. 
Figure 3-11. Waste Retrieval Sluicing System Fluid System Equipment Arrangement.

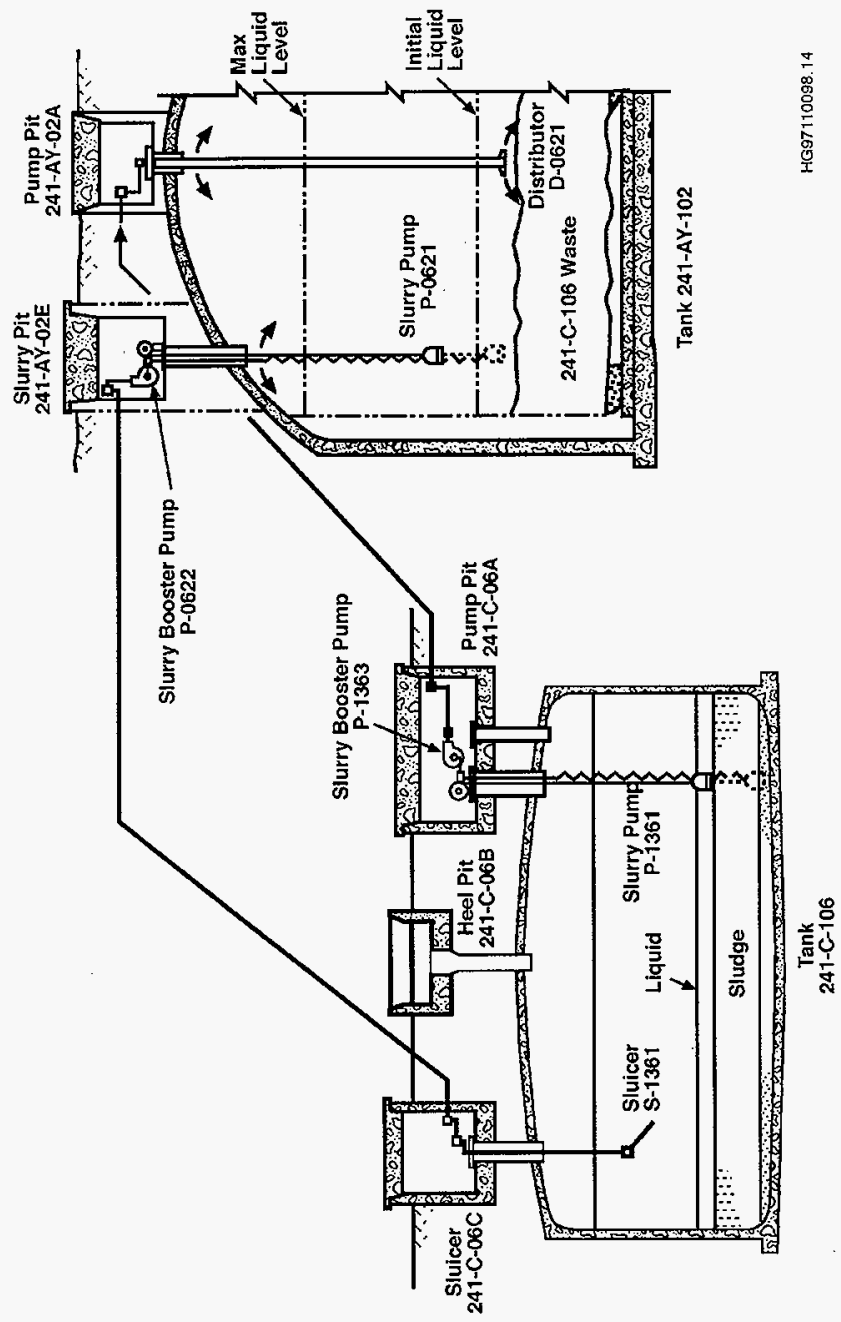


Figure 3-12. Route for Transfer Pipelines.

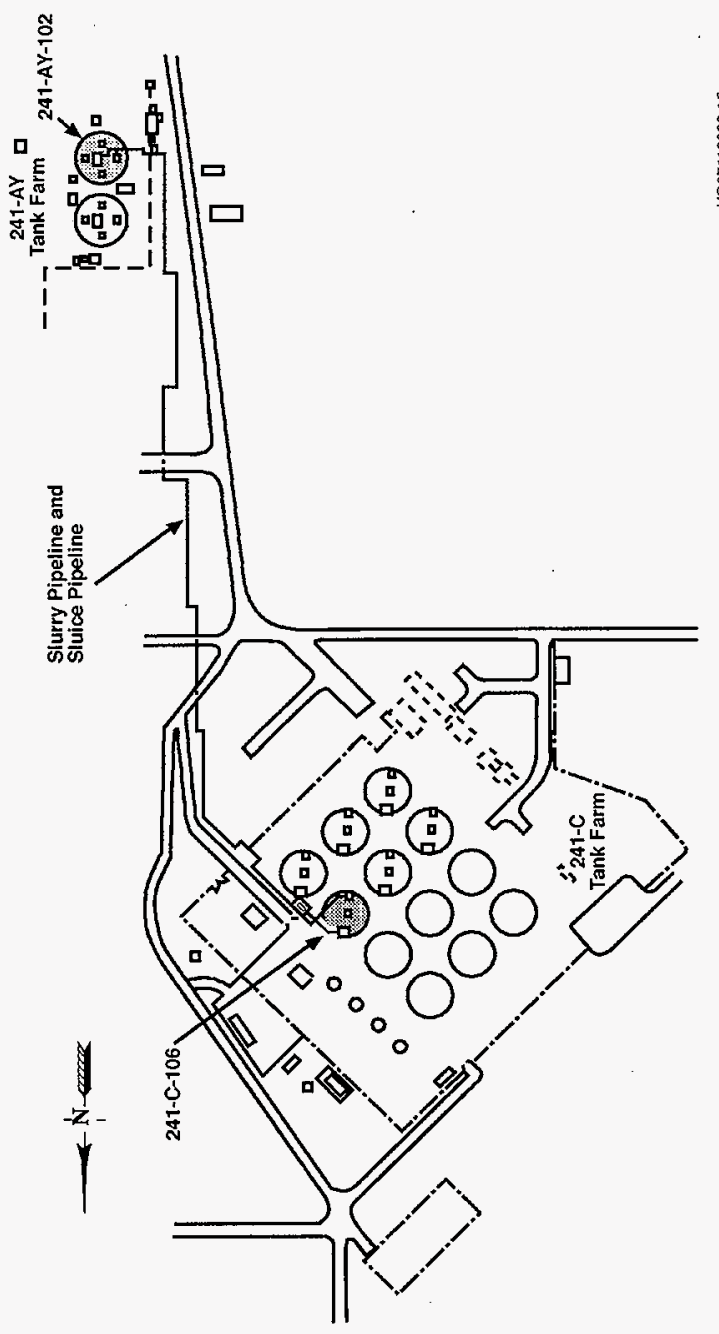


Pump Winch Assembly. The winch assembly supports the submersible slurry pump and enables the raising and lowering of this pump to the desired level. See drawing H-2-818494, sheet 1 , for a diagram of the winch and submersible slurry pump and Figure 3-13.

Reference Drawings/Specifications/Vendor Information. Drawings H-2-818494 sh 1-4, H-2-818495, H-2-818496 sh 1-6, H-2-818497 sh 1-2, H-2-818498 sh 1-2, $\mathrm{H}-2-818499$ sh $1-2, \mathrm{H}-2-818500, \mathrm{H}-2-818503$ sh $1-3, \mathrm{H}-2-818508$ sh $1-3$.

Procurement Specification W-320-P17, and Vendor Information File \# 22668 Supplements $50,51,52,61,62,147$, and 154 .

Operational Limitations.

Temperature
Discharge pressure
Flow rate/line velocity -
of combine submersible
and booster pumps

Minimum rotational speed -

Solids Loading $49^{\circ} \mathrm{C}\left(120^{\circ} \mathrm{F}\right)$ operational limit
$82^{\circ} \mathrm{C}\left(180^{\circ} \mathrm{F}\right)$ structural limit

$1.91 \mathrm{MPa}$ (277 psig) maximum

$2,460 \mathrm{~L} / \mathrm{min}$ (650 gpm), $5.0 \mathrm{~m} / \mathrm{s}(16.4$ $\mathrm{ft} / \mathrm{s})$ design maximum

$1,300 \mathrm{~L} / \mathrm{min}(350 \mathrm{gpm}), 2.7 \mathrm{~m} / \mathrm{s}(8.8 \mathrm{ft} / \mathrm{s})$ nominal operating

$1,140 \mathrm{~L} / \mathrm{min}(300 \mathrm{gpm}), 2.3 \mathrm{~m} / \mathrm{s}(7.6 \mathrm{ft} / \mathrm{s})$ safety minimum (Note: the $1.500 \mathrm{rpm}$ minimum pump speed may preclude operation at this low flow rate.)

1,500 rom (booster pump only to maintain upper bearing oiling)

0 to 50 weight percent design, 30 weight percent safety limit

The variable speed drive is a solid-state, high-performance unit that provides a continuous duty variable three-phase output at rated power. The variable speed drive varies the input frequency and voltage to the motor to obtain the desired pump speed. The variable-speed drive provides "soft start" capabilities and has been programmed to automatically ramp the pump speed to the minimum allowed $1.500 \mathrm{rpm}$. The base plate of the winch assemby is designed with a high capacity drain so the entire output of the pump system could be accommodated in case of a line break, thereby preventing the pit from flooding.

3.5.1.3 Sluice Pump System. The sluice pump system is identical to the slurry pump system except for minor differences in lengths and mounting flange details. The sluice pump system is located in the 241-AY-02E sluice pit in the 34 in. Riser 10C. Drawing H-2-818503, sheet 1 , is a detajled diagram of the sluice booster pump. Drawing H-2-818494, sheet 2, shows the winch assembly and submersible sluice pump. The winch assembly inside tank 241-AY-102 incorporates an engineered feature to prevent siphoning supernatant to tank 241-C-106 when the system is shut down. Two $0.6 \mathrm{~cm}(1 / 4 \mathrm{in}$.) holes on 
Figure 3-13. Tank 241-C-106 Submersible Slurry Pump/Winch.

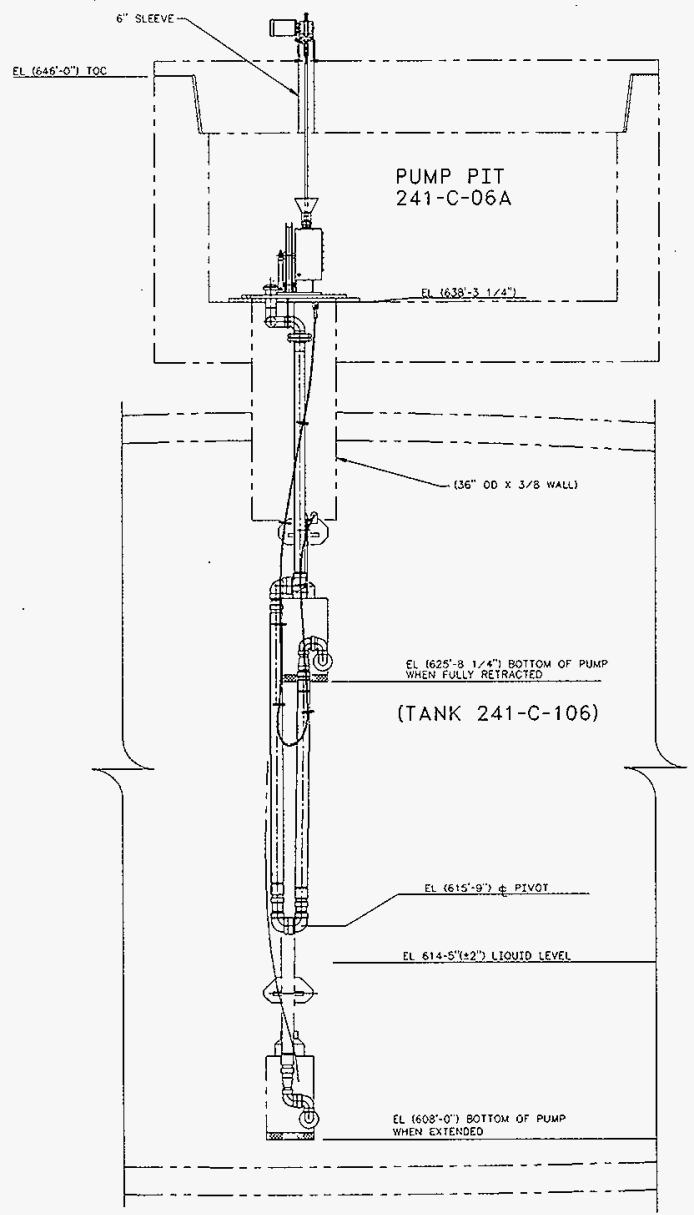

(1) INSTALLATION-C TANK 
the discharge line of the submersible sluice pump are located above the maximum allowed waste level in the tank. This feature is required because tank 241-C-106 is roughly $10.7 \mathrm{~m}$ (35 ft) lower in elevation than tank 241-AY-102.

3.5.1.4 Sluicer. A sluicer is installed in the 241-C-06C sluice pit riser R-3. It is used to mobilize sludge in tank 241-C-106 using clarified supernatant pumped from tank 241-AY-102 through the SN200 pipeline. The combined supernatant and sludge slurry formed by the sluice stream is then pumped to tank 241-AY-102 through the SL100 pipeline (see Figure 3-14).

The sluicer is constructed of 304L stainless steel and has a 2.5-cm (1-in.) diameter nozzle with two degrees of motion control (rotation 194 degrees and nozzle elevation 130 degrees). The nozzle pivots/rotates at a fixed elevation in the tank and can be aimed with a dedicated hydraulic system. The sluicer controls, located in the MO-211 control room, have two modes: manual and semi-automatic. The sluicer base plate also has a high-capacity drain.

Reference Drawings/Specifications/Vendor Information. Drawings H-2-818549. sheets 1-3, H-2-818550 sh 1-5, H-2-818551 sh 1-8, H-2-818553, H-2-818555, H-2-818556. H-2-818557; Procurement Specification W-320-P20; and Vendor Information File \# 22668 Supplement 153.

Operational Limitations.

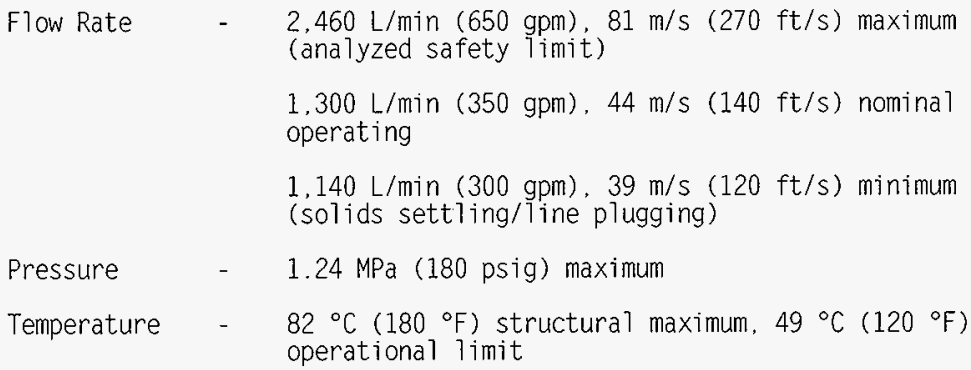

Solids Loading - 10 weight percent

3.5.1.5 Slurry Distributor. The tank 241-AY-102 slurry distributor, located in the 241-AY-02A pit. is a stainless steel, fixed-length drop leg with four opposed 2 in. nozzles that discharge below the liquid surface. The distributor is designed to provide equal distribution of slurry solids throughout the tank. Two $1.3 \mathrm{~cm}(1 / 2-i n$.) vacuum breaker holes are incorporated at the top end of the drop leg to eliminate any potential for siphoning back into tank 241-C-106. The distributer also has a high-capacity drain. 
HNF-SD-WM-PCP-013 REV. 1

Figure 3-14. Tank 241-C-106 Sluicer Installation.

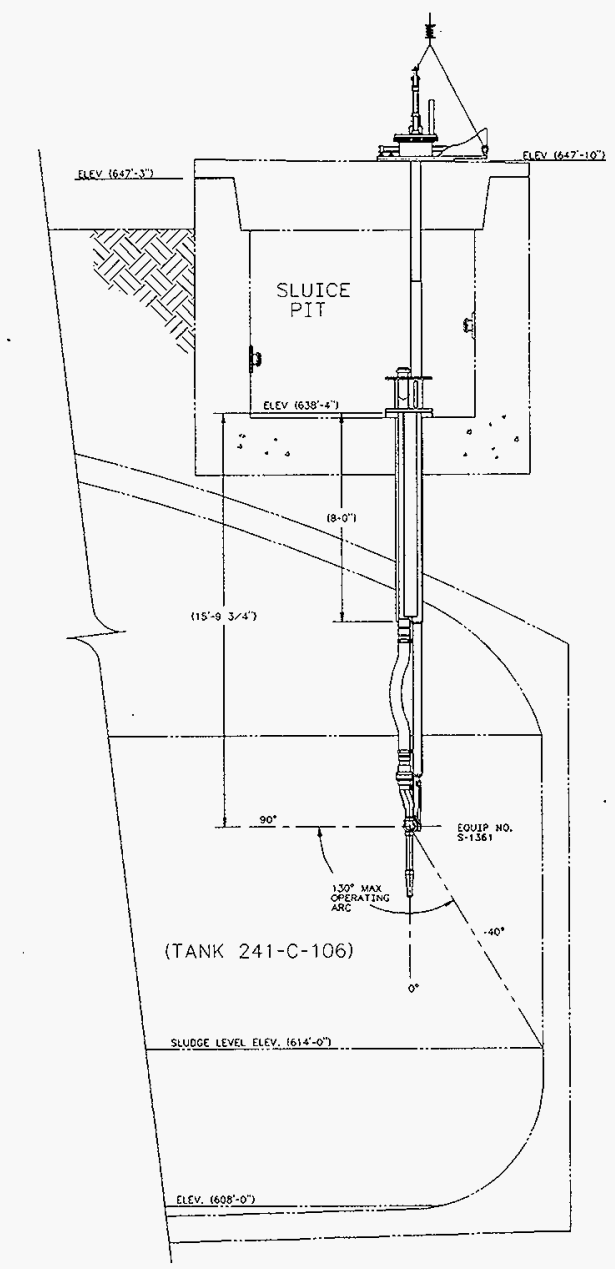


HNF-SD-WM-PCP-013 REV. 1

Reference Drawings/Specifications. Drawings H-2-818537 sheet 1-2. and Hanford Specification HS-BS-0084, Rev. B.

Operational Limitations.

Flow Rate - $\quad 2,460 \mathrm{~L} / \mathrm{min}(650 \mathrm{gpm}), 5.5 \mathrm{~m} / \mathrm{s}(18 \mathrm{ft} / \mathrm{s})$ maximum (analyzed safety limit)

$1,300 \mathrm{~L} / \mathrm{min}(350 \mathrm{gpm}), 3.0 \mathrm{~m} / \mathrm{s}(9.8 \mathrm{ft} / \mathrm{s})$ nominal operating

$1,140 \mathrm{~L} / \mathrm{min}(300 \mathrm{gpm}), 2.6 \mathrm{~m} / \mathrm{s}(8.4 \mathrm{ft} / \mathrm{s})$ minimum (solids settling/line plugging)

Temperature $-82^{\circ} \mathrm{C}\left(180^{\circ} \mathrm{F}\right)$ structural maximum, $49^{\circ} \mathrm{C}\left(120^{\circ} \mathrm{F}\right)$ operational limit

Pressure $\quad-\quad 1.91 \mathrm{MPa}$ (277 psig) maximum

Solids Loading - 30 weight percent

\subsubsection{Ventilation Systems}

The ventilation systems used to carry out the WRSS process provide multiple functions important to the handling and storage of waste. Tank 241-C-106 has two ventilation systems: one subcools the sludge before sluicing begins and the other is used during routine sluicing operations. Tank 241-AY-102 a lso has two ventilation systems: the 241-AZ-702 primary tank exhaust system and the 296-A-16 annulus ventilation system. A description of each ventilation system follows. In addition, contingency provisions have been made to provide a portable exhaust system to back up each of these ventilation functions. Section 3.5.2.3 describes the portable exhaust system.

3.5.2.1 Tank 241-C-106 Ventilation Systems. Tank 241-C-106 has two alternative ventilation systems: the 296-C-006 WRSS ventilation system provided by project $W-320$ and the existing 296-P-16 exhauster that ventilates tanks 241-C-105 and 241-C-106. Each is described below.

296-C-006 Ventilation System. The 296-C-006 ventilation system combines exhaust and recirculation functions and is designed to handle the high liquid and solids loading expected in the tank headspace during sluicing operations.

The system includes three skid assemblies: 1) the process building skid (241-C-91) includes the condenser, recirculation loop demister, heater and fan, and the high-efficiency mist eliminator and high-efficiency metal filter and their related controls; 2) the exhauster skid (296-C-006) includes the exhaust heater. HEPA filters, exhaust fan, stack, stack monitor and related instrumentation; and 3 ) the chiller skid that provides a chilled propylene glycol-water solution to the process building condenser or the inlet filter system cooling coil (see Figure 3-15). 
HNF -SD-WM-PCP-013 REV. 1

Reference Drawings/Specifications/Vendor Information. Drawings H-2-818494, Procurement Specification W-320-P1, and Vendor Information File \# 22668 Supplements.

\section{Operational Limitations.}

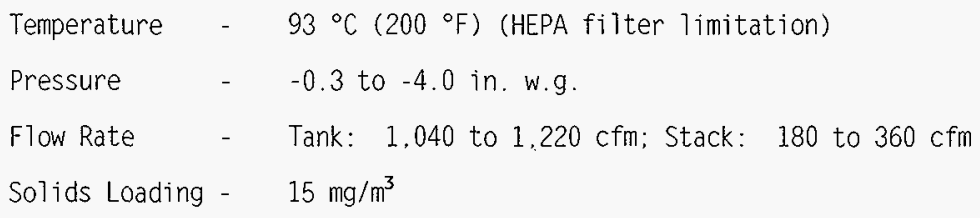

296-P-16 Ventilation System. The 296-P-16 ventilation system is a high capacity. once through exhaust system that was installed in the late 1960s to ventilate and cool tanks 241-C-105 and 241-C-106. For the retrieval process, this ventilation system serves only to pre-cool tank 241-C-106 waste in advance of starting sluicing operations. Figure $3-16$ is a flow diagram for this ventilation system.

Reference Drawings. Drawings H-2-35769, H-2-95267, H-2-72286, and H-2-95451.

Operationa l Limitations.

Temperature $\quad-\quad 93{ }^{\circ} \mathrm{C}\left(200^{\circ} \mathrm{F}\right)$ (HEPA filter limitation)
Pressure

The tank is protected from high negative or positive pressures by redundant seal loops installed by project $W-320$. If a ventilation outage occurs, passive breathing for tank 241-C-106 occurs through the 296-C-006 or 296-P-16 HEPA that is in service at the time of the outage, or through the air inlet filter that is part of the 296-P-16 system. This inlet filter is closed whenever the 296-C-006 ventilation system is operating since other flow pathways, including the tanks cascade line to tank $241-C-105$, provide the necessary air flow. A breather filter assembly installed on tank 241- $C-105$ provides passive ventilation whenever the 296-P-16 system is shut down.

3.5.2.2 Tank 241-AY-102 Ventilation Systems. During routine operations. tank 241-AY-102 is actively ventilated by two systems: the primary tank ventilation system and the annulus ventilation system. Primary ventilation is provided by the 241-AZ-702 system the annulus ventilation system is the 296-A-19. 
Figure 3-15. Tank 241-C-106 Waste Retrieval Sluicing System Ventilation System (296-C-006).

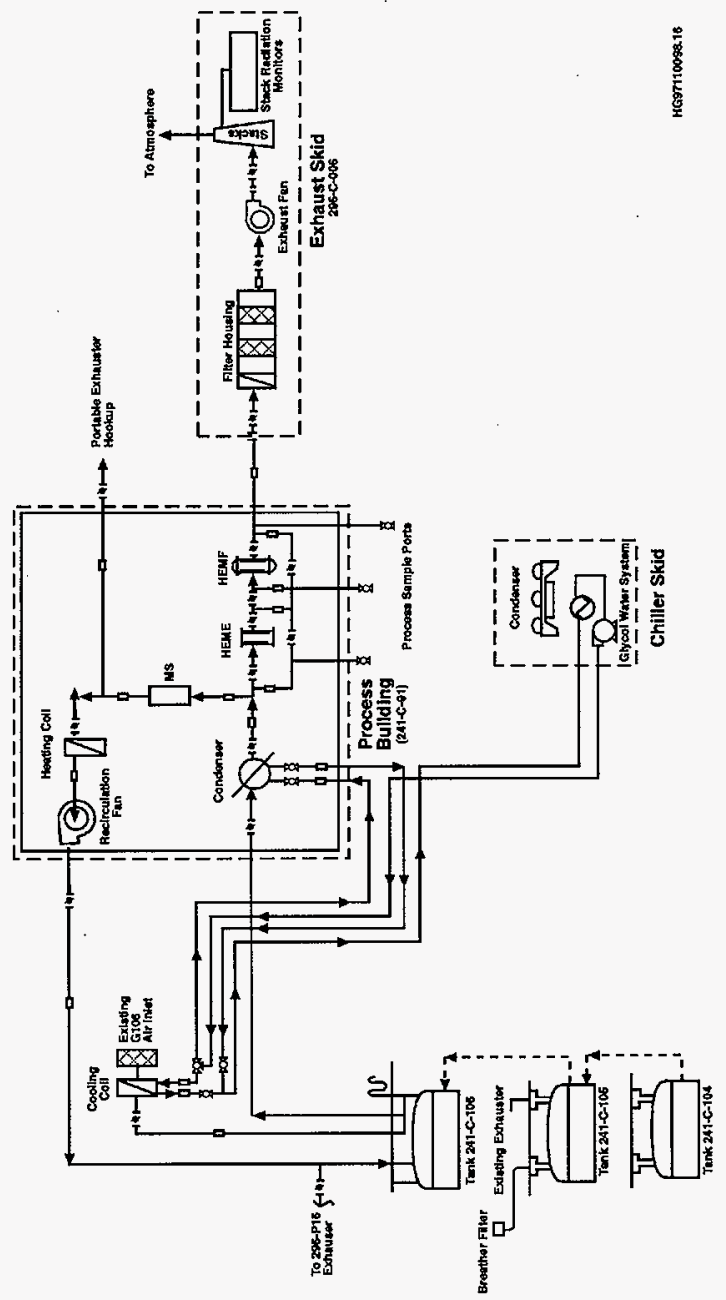


Figure 3-16. Tank 241-C-106 Existing Ventilation System (296-P-16).

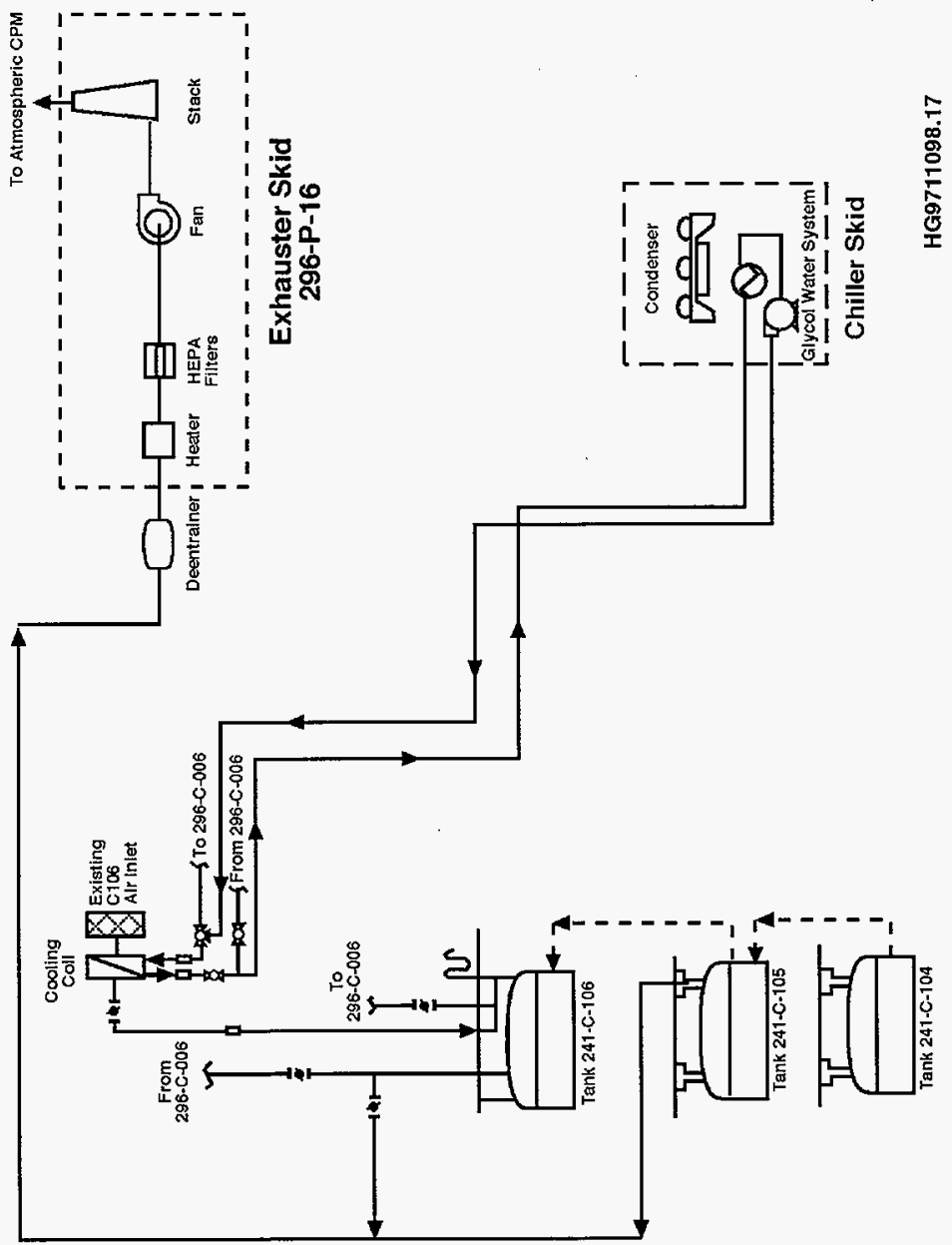


Primary Tank Ventilation (241-AZ-702). The basic design of the 241-AZ-702 ventilation system is similar to the ventilation system on tank 241-C-106 in that it features recirculation and exhaust features with the recirculation loop containing a condenser. The system consists of individual tank air iniet systems, individual tank recirculation equipment, and common tank exhaust equipment for the four 241-AY and 241-AZ Tank Farm waste tanks. The system is composed of five basic subsystems: 1) air inlet system, 2) tank exhaust recirculation system. 3) primary tank exhaust system. 4) 241-AZ-702 building ventilation system, and 5) monitoring and control system (see figure 3-17).

This primary ventilation system provides three modes of operation for tank 241-AY-102: recirculation mode, high-heat mode, and bypass mode.

1. Recirculation mode is considered the "normal" mode of treating tank exhaust. All exhaust from the tank is cooled by the tank exhaust recirculation equipment. Approximately 75 percent of the cooled exhaust is returned to the tank. and 25 percent is routed to the primary tank exhaust system where it is cooled again and filtered before being exhausted through the stack.

2. High-heat mode establishes a once-through cooling flow path that uses the individual tank recirculation condenser and the primary condenser to cool tank exhaust. No tank exhaust is recirculated to the tank.

3. Bypass mode establishes a flow path that bypasses the tank recirculation cooling equipment. Tank exhaust flows from the tank through a bypass valve to the primary tank exhaust system.

Reference Drawings/Specifications/Vendor Information. Drawings H-2-818494, $\mathrm{H}-2-131063, \mathrm{H}-2-131075$, sheets 1, $3 \mathrm{H}-2-131076$. Procurement Specification W-320-P1, and Vendor Information File \# 22668 Supplements.

Operational Limitations.

Temperature $\quad-\quad 91{ }^{\circ} \mathrm{C}\left(195^{\circ} \mathrm{F}\right)$ (HEPA filter limitation)
Pressure $\quad 0$ to $-4 \mathrm{in}$. W.g.

Flow rate - See HNF-SD-RE-TI-273 (depends on configuration)

Annulus Ventilation System (296-A-16). The tank 241-AY-102 annulus ventilation system (296-A-16) has been modified by project $W-320$ to provide enhanced tank bottom cooling and thermal performance monitoring instrumentation. The system consists of an annulus air inlet system. HEPA filtration, control valving, and air distribution piping: and an annulus exhaust system with a heater. HEPA filtration, exhaust fan, stack and associated instrumentation and controls (see Figure 3-18).

Reference Drawings/Specifications/Vendor Information. Drawings H-2-64462. Procurement Specification WHC-S-0418, WHC-S-0424, and Vendor Information File \# 17102. 17103, and 17105. 
Figure 3-17. Tank 241-AY-102 Primary Ventilation System (241-AZ-702).

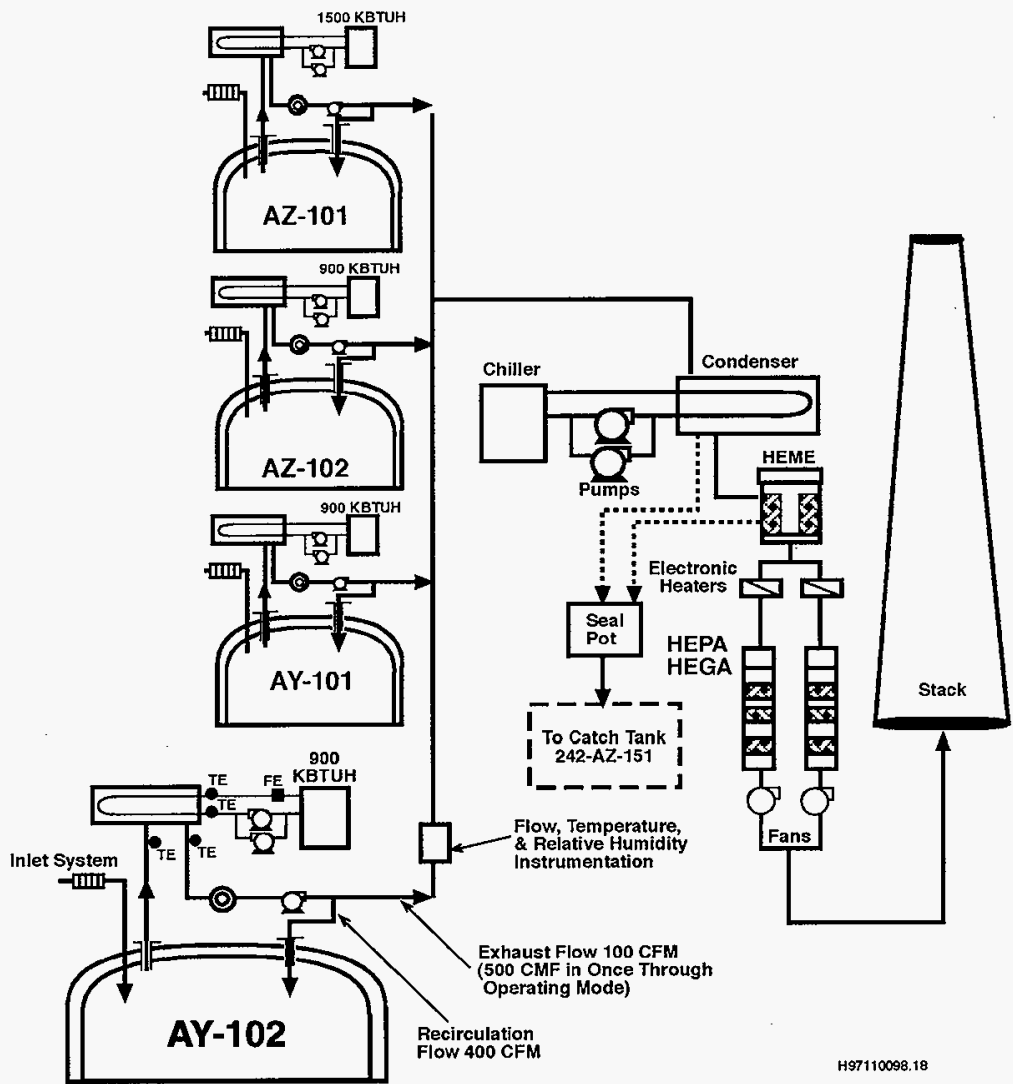


Figure 3-18. Tank 241-AY-102 Annulus Ventilation System (296-A-16).
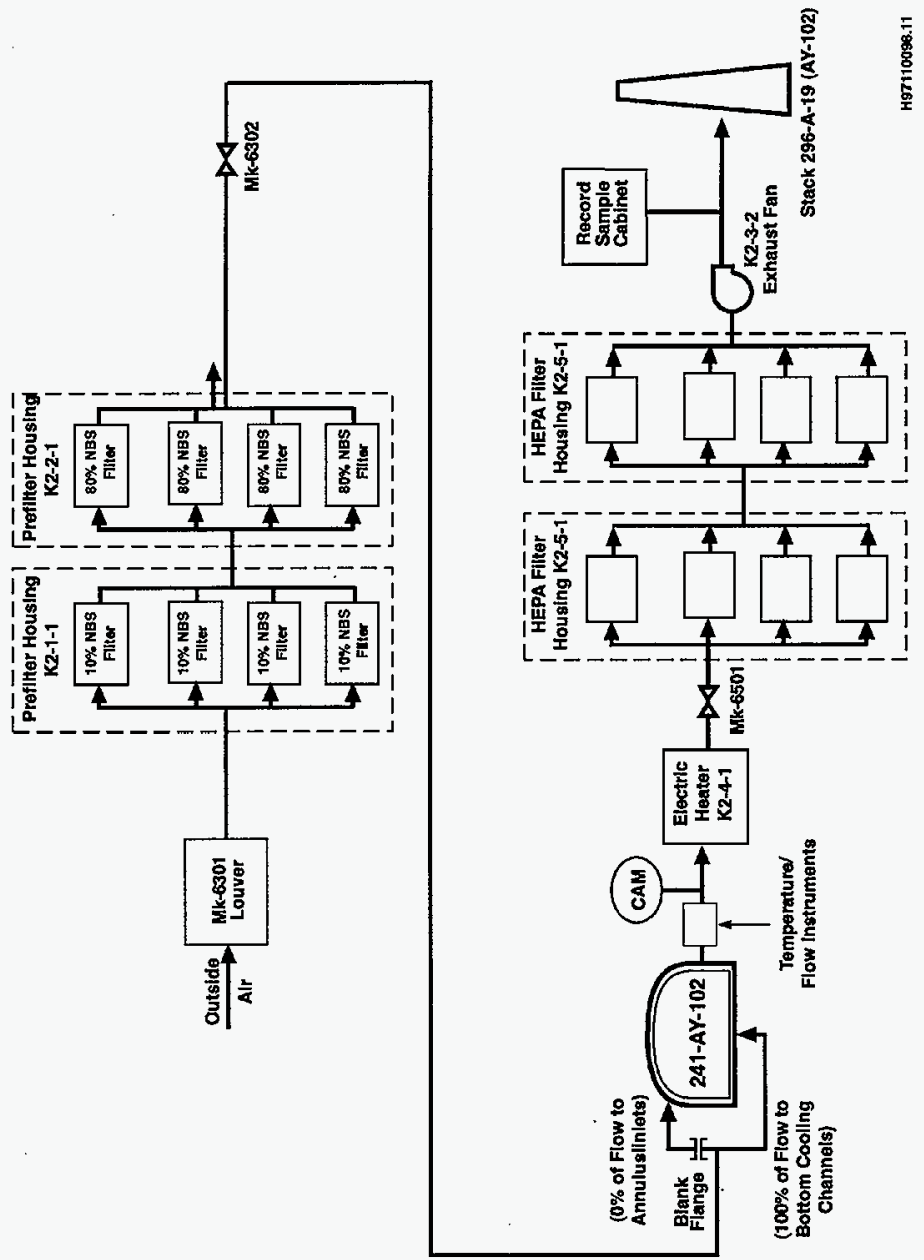
HNF-SD-WM-PCP-013 REV. 1

Operational Limitations.

\begin{tabular}{|c|c|}
\hline Temperature & $-\quad 93^{\circ} \mathrm{C}\left(200^{\circ} \mathrm{F}\right)$ maximum \\
\hline Pressure & -0.1 to -18.0 in. w.g. \\
\hline Flow rate & $\begin{array}{l}1,000 \text { to } 1,300 \mathrm{cfm} \text { to annulus bottom cooling channels } \\
\text { when annulus wall inlet blocked with blank flanges. }\end{array}$ \\
\hline
\end{tabular}

3.5.2.3 Portable Exhausters. If the tank 241-AY-102 or tank 241-C-106 ventilation systems become inoperable for any reason, portable exhausters will be available to restore ventilation to either the dome spaces (riser R-7 in tank 241-C-106 and riser 15K in tank 241-AY-102) or annulus (riser $19 \mathrm{~B}$ in tank 241-AY-102). Portable exhausters POR-007-VTP/SKID E or POR-008-VTP/SKID F could be used to ventilate either 241-C-106 or 241-AY-102 dome spaces at a flow rate of up to $500 \mathrm{cfm}$ or ventilate the 241-AY-102 annulus at a flow rate of $800 \mathrm{cfm}$ (Sathyanarayana et a1. 1998). The portable exhausters will be powered by either portable generators (H0-74-4761 and H0-74-4984) or available site power supply.

Reference Drawings/Specifications. Drawings H-14-102577, H-14-102610, and procurement specification HNF-S-0490. Rev. 1

\subsubsection{Instrument Descriptions}

There are three primary drivers for instrumentation: 1) flammable gas. 2) thermal control, and 3) leak detection. A secondary driver is personnel and equipment protection.

The need for instrumentation is driven by the sensitivity of the transfer system to solids in the WRSS. The basic process control requirements are to ensure that $124,900 \mathrm{~L}(33,000$ ga 7$)$ of sludge is removed from tank 241-C-106 in a carefully controlled manner and that the tank liquid level is held at or above a minimum level. Selected WRSS instruments are used to 1) ensure the total solids recovered and the rate of recovery meet process control requirements and, 2) provide sufficient recovery efficiency to complete the retrieval in a timely manner.

3.5.3.1 Process Control Instrumentation. During sluice batches. instruments will be used for a short time during active sluicing periods. The instrument outputs are available in a form and location where data can be collected, analyzed, and acted on quickly. The ease of information transfer is critical because a maximum of 12 hours will be allotted for any single sluicing period. During sluice batches, process control instruments provide information conveniently and collect enough process information to permit follow-on analysis. An example of this type of instrument is the mass flowmeter.

The mass flowmeter and pump performance parameters are two ways of acquiring "real-time" process information. The mass flowmeter measures online the mass and density of slurry being transferred, thereby enabling the control of the total amount of solids and slurry solids loading. The pump performance parameters indicate the solids content in the slurry. Process information 
during sluice batches allows the operator time to take corrective actions before exceeding process control parameters.

Slurry Line Coriolis Mass Flowmeter. A coriolis effect mass flowmeter (UE/UT-0621) measures online the mass and density of slurry transferred thereby enabling the control of the total amount of solids and slurry solids loading. The mass flowmeter measures slurry mass flow rate, density, and temperature. The device is configured to only measure mass flow rate and density. It is equipped with a "net flow" computer that converts instrument measurements into a total mass of solids transferred through the slurry line.

Online mass flow rate and density measurements are used to maintain the solids loading in the slurry line below the 30 weight percent safety limit. The measurements are necessary to ensure the slurry transfer pipeline flow is in the turbulent flow regime to prevent plugging. The mass flowmeter on the slurry transfer pipeline increases the operational efficiency of the sluicing process by allowing an increase in the permitted pump operating time during any single sluicing pump run. At high sluicing efficiencies (between 10 and 20 percent), the slurry line mass flowmeter is expected to indicate an actual rate of solids recovery.

Instrumenting the slurry line with a mass flowmeter permits sluicing periods about five times longer than would be allowed without an online mass flow measurement. With no online measurement, the allowable sluicing time would be limited by the time to reach the mass transfer limit, assuming slurry of maximum density was being transferred. The mass flowmeter is located in the 241-AY-02A pit of tank 241-AY-102. The accuracy of the flowmeter at the nominal process solids loading (10 to $20 \mathrm{wt} \%$ ) and volumetric flow rate ( 300 to $330 \mathrm{gal} / \mathrm{min})$ is estimated at \pm 0.11 percent.

Slurry Pipeline Maq-Flowmeter. The 241-C-06A pit jumper includes a magnetic flowmeter to determine the volumetric slurry flow rate to ensure that flow rates remain within the al lowed range 1,140 to $2,460 \mathrm{~L} / \mathrm{min}$ [300 to $650 \mathrm{gpm}$ ]) (see Figure 3-19). A combination of the pump speed setting and flow rate data will then be used to approximate the average solids loading of the slurry in the transfer line. This is used as a backup to the 241-AY-02A pit mass flowmeter data.

Tank 241-AY-102 ENRAF ${ }^{\text {TM }} 854$ ATG Liquid Level Gauqe. An ENRAF ${ }^{\text {TM }}$-Nonius Series 854 level gauge (WST-LIT-602A) is used to monitor the liquid level in tank 241-AY-102 (see Figure 3-20. Its level measuring principle is based on the detection of variations in the weight of a displacer suspended in the process fluid. The displacer is connected to a wire wound on a precision measuring drum. A level change causes a change in the weight of the displacer which will be detected by the force transducer. Electronics within the gauge cause a servomotor to adjust the position of the displacer drum. The gauge displays the level in decimal inches. An analog and digital output signal transmits the level data for remote data processing. The ENRAF ${ }^{T M}$ is located in riser 22A of tank 241-AY-102 and has an accuracy of \pm 0.01 inches. 
Figure 3-19. Slurry Pipeline Mag-Flow Meter and Closed Circuit Television System.

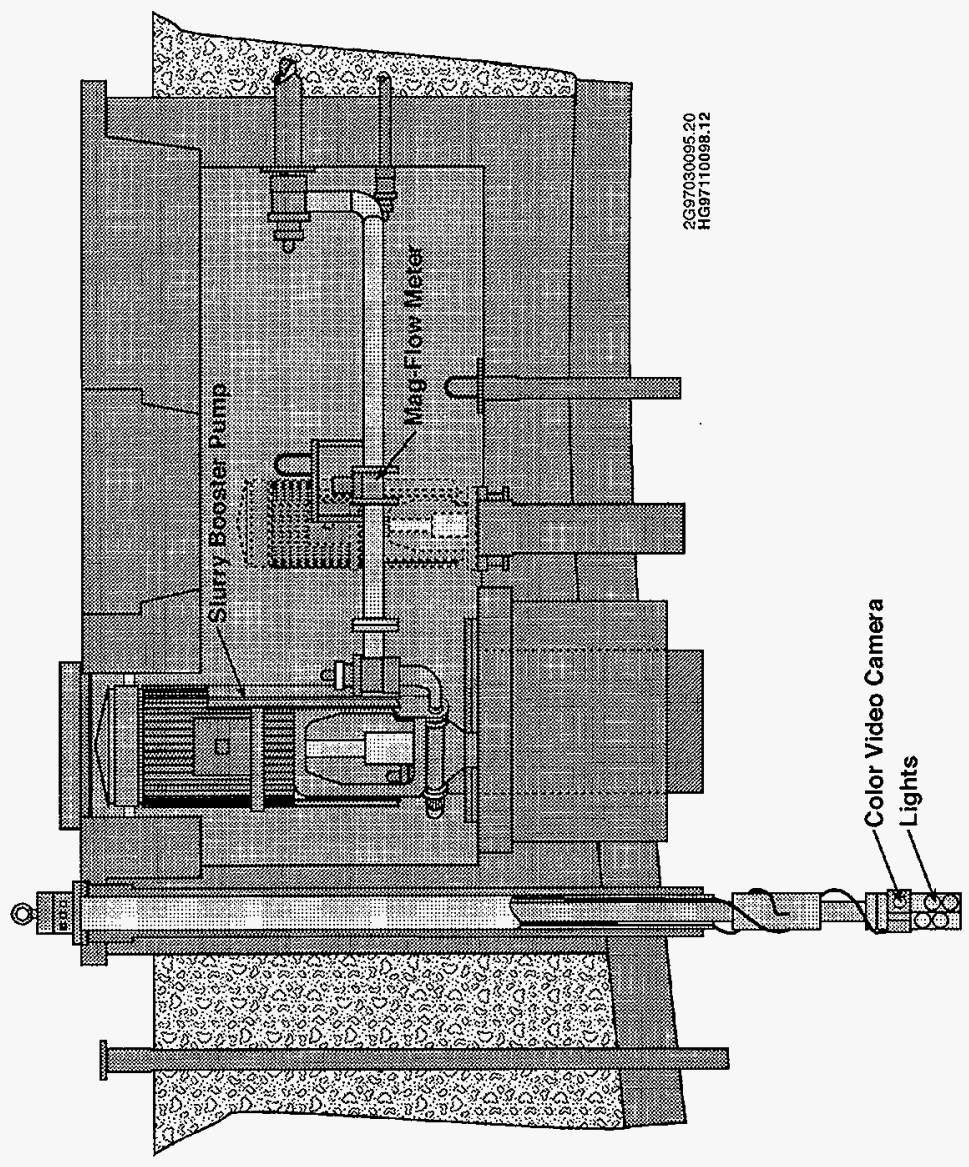


HNF-SD-WM-PCP-013 REV. 1

Figure 3-20. ENRAF ${ }^{T M} 854$ ATG Liquid Level Gauge.

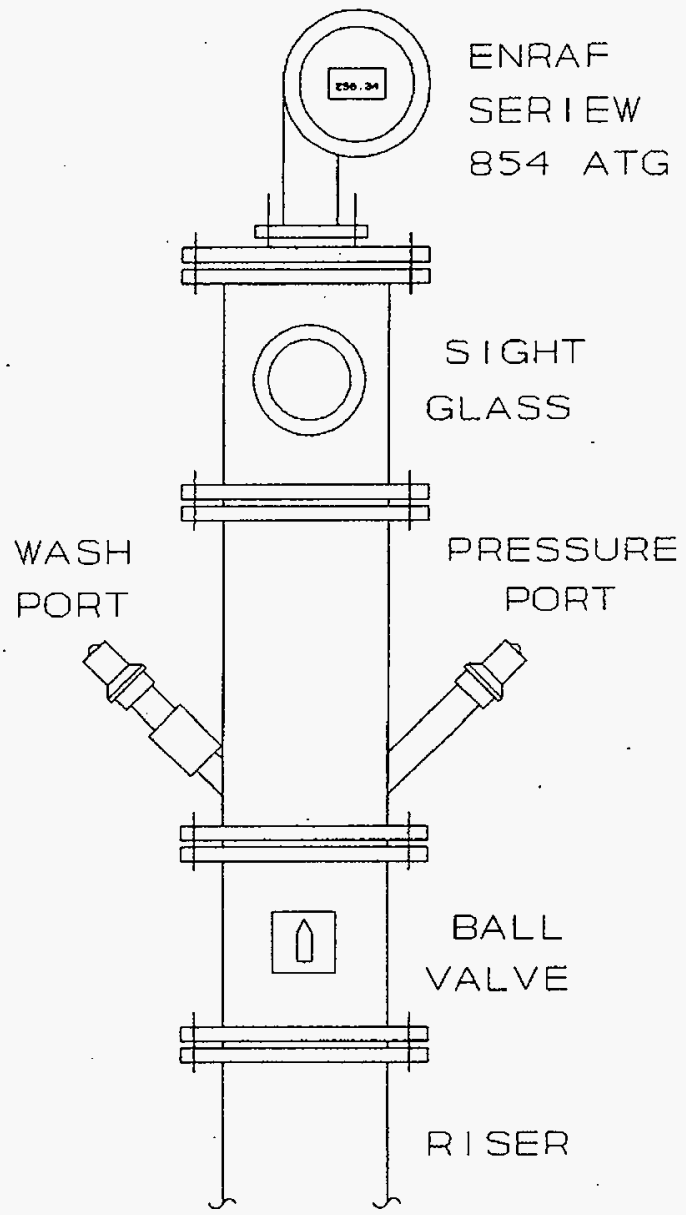


HNF-SD-WM-PCP-013 REV. 1

3.5.3.2 Process Monitoring Instrumentation. Instruments during monitoring periods are critical for analyzing process parameters such as determining slurry behavior (e.g. . solids settling) properties in the tanks, verifying new distribution of radioactive heat loads within the WRSS, verifying thermal properties of new waste distributions within the tanks, verifying thermal models developed for the WRSS, determining gas generation rates and retention. and analyzing for leaks within the system.

Because instrument indications during monitoring periods are not as critical as the mass flowmeter and pump parameters, a centralized instrument output and information interface is not required. However, the instrument outputs and information interface are still required for the process control. The instrument outputs are data-logged where applicable and available for analysis in a timely, systematic, and reliable fashion.

Tank 241-AY-102 measurements made during monitoring periods include the intank imaging system, ENRAF ${ }^{\mathrm{TM}}$ leve 7 , ENRAF ${ }^{\mathrm{TM}}$ densitometer, the MIT, in-tank thermocouples, dome pressure, SHMS, primary ventilation temperature, flow and humidity, chiller solution flows and temperatures, and annulus flow and exit temperature. Ventilation information, Tevel, SHMS, and temperature can be read at anytime through the data acquisition system (DAS).

The tank 241-C-106 measurements made during monitoring periods include a closed circuit television system, in-tank thermocouples, dome pressures, SHMS, ENRAF ${ }^{\mathrm{TM}}$ level, chiller solution flows and temperatures, and ventilation flows, temperatures, and pressures.

Tank 241-AY-102 ENRAF ${ }^{\text {TM }}$ Level Gauge. See the equipment description in Section 3.5.3.1. The ENRAF ${ }^{1 M}$ level gauge is being used for process monitoring as well as process control.

Tank 241-AY-102 ENRAF ${ }^{T M}$ Densitometer. The ENRAF ${ }^{T M}$ densitometer

(WST-DIT-602A/DI-602A) provides an accurate measurement of density versus depth in tank 241-AY-102 so the amount of solids transferred and the degree of settling can be evaluated. The ENRAF ${ }^{\mathrm{TM}}$ provides a density profile based on the measured buoyancy of a displacer with known volume and mass at varying depths in the liquid.

The ENRAF ${ }^{\text {TM }}$ densitometer is required for process control. This device provides information for making the decision on whether to continue. sluicing. During the monitoring period following each sluicing batch, the evaluation of the sluicing system performance requires measuring the mass and volume of sludge transferred to tank 241-AY-102. This information is obtained from a density profile of the slurry in the tank from which the volume and mass of resident solids can be determined. Although this device is not sensitive enough to discriminate solids concentrations during sluicing operations, it is very accurate at measuring density differences as solids settle during the monitoring periods. When the slurry/supernate interface develops in the tank. the densitometer is also able to detect it. However, the measurement frequency needs to balance the need for interface level information with the possibility of excavating a depression on the solids bed, which would compromise the measurement accuracy. Setting the ENRAF ${ }^{T^{M}}$ displacer wire 
HNF-SD-WM-PCP-013 REV. 1

tension to as high a level as possible will minimize the excavating effect of interface measurements.

The tank 241-AY-102 ENRAF ${ }^{T M}$ densitometer is an ENRAF' 854 ATG level gauge with densitometer software that enables the submerged buoyancy of the displacer to be converted to a density (see Figure 3-20). The instrument is located on riser $15-E$ and has an accuracy of $\pm 0.005 \mathrm{~kg} / \mathrm{L}$.

Tank 241-AY-102 Sludge Level Devices. Sludge level instruments are used to measure the depth of the sludge layer at the bottom of tank 241-AY-102. Each instrument has a 4-in. diameter steel "doughnut" suspended by calibrated tape from a reel. The reels are housed in plexiglass enclosures permanently mounted to the tank riser flange.

In operation, the disc is manually lowered until it comes to rest on the sludge. The tape measurement relative to a fixed mark on the plexiglass enclosure is noted. The difference between this reading and the reading obtained when the tank is empty represents the sludge depth. Tank 241-AY-102 has seven 6-in. risers to measure sludge levels. The sludge level devices are available as a backup to the primary method for determining solid-7iquid interface or radial distribution of sludge in the tank ( $i . e$. . ENRAF densitometer and MIT).

Tank 241-AY-102 Thermocouples. Thermocouples (TE-102-1 through 102-27. TE-102-29 through 102-74, and TE-102-82 through 102-105) in tank 241-AY-102 are located at numerous positions inside the tank for measuring waste and dome space temperatures and at locations in the insulating concrete and concrete structural shell (see Figures 3-21 and 3-22). The in-tank thermocouples are mounted on separate thermocouple trees, in thermocouple wells, and at the bottom of the air lift circulators. The in-tank thermocouples are type $J$, which are typically attributed an accuracy of around $\pm 1.1^{\circ} \mathrm{C}\left( \pm 2{ }^{\circ} \mathrm{F}\right)$ and a repeatability of $\pm 0.3^{\circ} \mathrm{C}\left( \pm 0.5^{\circ} \mathrm{F}\right)$ for standard limits of error grade.

Data are monitored in tank 241-AY-102 during the sluicing operation for process control and monitoring periods to update the technical information used to model the predicted thermal behavior of the tank. The radial temperature distribution is needed to evaluate the uniformity of the nonconvective waste layer and the impact of known blockages in the annulus ventilation system slot flow. Existing thermocouples are not adequate for accurately detecting the solid/liquid (convective/non-convective) interface level in the tank. Therefore, a multifunction instrument tree with provision for operating an internal validation probe has been added to the tank (see discussion below). However, the air lift circulator thermocouples and other existing thermocouples will provide adequate radial temperature data.

Tank 241-AY-102 Multifunction Instrument Tree. An upper temperature limit equivalent to $14^{\circ} \mathrm{C}\left(25^{\circ} \mathrm{F}\right)$ below local saturation temperature has been established for tank 241-AY-102 to eliminate the potential for a steam bump. This temperature limit may affect the amount of waste which can be transferred from tank 241-C-106. Data will be monitored in tank 241-AY-102 during sluicing and monitoring periods to update the technical information used to model the expected thermal behavior of the tank. Important information includes the nonconvective waste level and the tank heat load. 
HNF-SD-WM-PCP-013 REV. 1

The MIT thermocouples (TE/TT/TI-06230 through TE/TT/TI-06251) measure temperatures at 22 elevations (see drawings $\mathrm{H}-2-85122$ and $\mathrm{H}-2-828969$, and Figures 3-21 and 3-22). An integral validation probe that traverses the inside of a thermowell on the MIT is capable of measuring the temperature at any elevation in the tank. The MIT has been useful in locating solid-liquid interfaces by detecting the change in slope of the temperature profile in the solids and liquids. It provides a detailed vertical temperature profile through the waste and supernatant. The temperature data is used to determine the convective and nonconvective waste interface and to provide the transient thermal gradient in the nonconvective waste. The nonconvective waste level provides information about the waste fluffing factor. The transient waste temperature gradient is used to estimate the tank heat load.

The MIT is located in riser $5 \mathrm{~A}$ of tank 241-AY-102. It uses type $K$ thermocouples which typically have an accuracy of around $\pm 2.2^{\circ} \mathrm{C}\left(4{ }^{\circ} \mathrm{F}\right.$ ) and a repeatability of $\pm 0.3^{\circ} \mathrm{C}\left(0.5^{\circ} \mathrm{F}\right)$ for standard limits of error grade. The MIT thermocouples will be recorded to $\pm 0.06{ }^{\circ} \mathrm{C}\left(0.1^{\circ} \mathrm{F}\right)$.

Tank 241-C-106 Thermocouple Trees. Tank 241-C-106 has two thermocouple trees to monitor the waste temperature: one in riser $\mathrm{R}-8$ with six thermocouples, and one in riser R-14 with 12 thermocouples (see Figure 3-23: al1 thermocouples not shown).

The thermocouple tree in riser R-8, which is $10.4 \mathrm{~m}$ (34 ft) from the center of the tank, has four thermocouples in the waste (TE-C-106-1 through TE-C-106-4). The bottom thermocouple is $0.1 \mathrm{~m}(0.3 \mathrm{ft})$ from the local bottom of the tank with the other three thermocouples spaced $0.6 \mathrm{~m} \mathrm{(2} \mathrm{ft)} \mathrm{apart} \mathrm{vertically} \mathrm{up} \mathrm{the}$ tree. Riser R-8 also has two thermocouples in the dome air space (TE-C-106-5 and $T E-C-106-6)$. The thermocouples in riser $R-8$ are of type $E$, which have a standard accuracy of $\pm 1.7^{\circ} \mathrm{C}\left(3^{\circ} \mathrm{F}\right)$.

The thermocouple tree in riser R-14, which is $4.7 \mathrm{~m}$ (15.5 ft) from the center of the tank, has four thermocouples in the waste (TE-C-106-14-1 through TE-C-106-14-4). The bottom thermocouple is $0.34 \mathrm{~m}(1.1 \mathrm{ft})$ from the local bottom of the tank with the other three thermocouples spaced $0.6 \mathrm{~m}$ ( $2 \mathrm{ft}$ ) apart vertically up the tree. Riser.R-14 has eight thermocouples in the dome air space (TE-C-106-14-5 through TE-C-106-14-12). The thermocouples in riser $\mathrm{R}-14$ are of type $\mathrm{J}$, which have a typical accuracy of $\pm 1.1{ }^{\circ} \mathrm{C}$ (2 ${ }^{\circ} \mathrm{F}$ ) for standard limits of error grade.

Tank $241-C-106$ Submersible Slurry Pump Liquid-Level Detection. The submersible slurry pump liquid-level detection elements function to control the tank 241-C-106 liquid level as required by thermal hydraulic constraints. It consists of interlocks, switches, and displays for the slurry submersible pump and associated equipment. The submersible pump low-level indicator is equipped with an interlock that possesses a selectable 0 -15 minute duration time delay, automatic resetting, and keyed bypass switch for overriding the interlock. When selected, the interlock shuts down the slurry submersible pump when the low-liquid level sensor changes state. The low-liquid level interlock is activated when the sensor detects air. A keyed lockout switch deactivates the submersible pump winch when the pump low-level detector is providing a liquid level control function. 


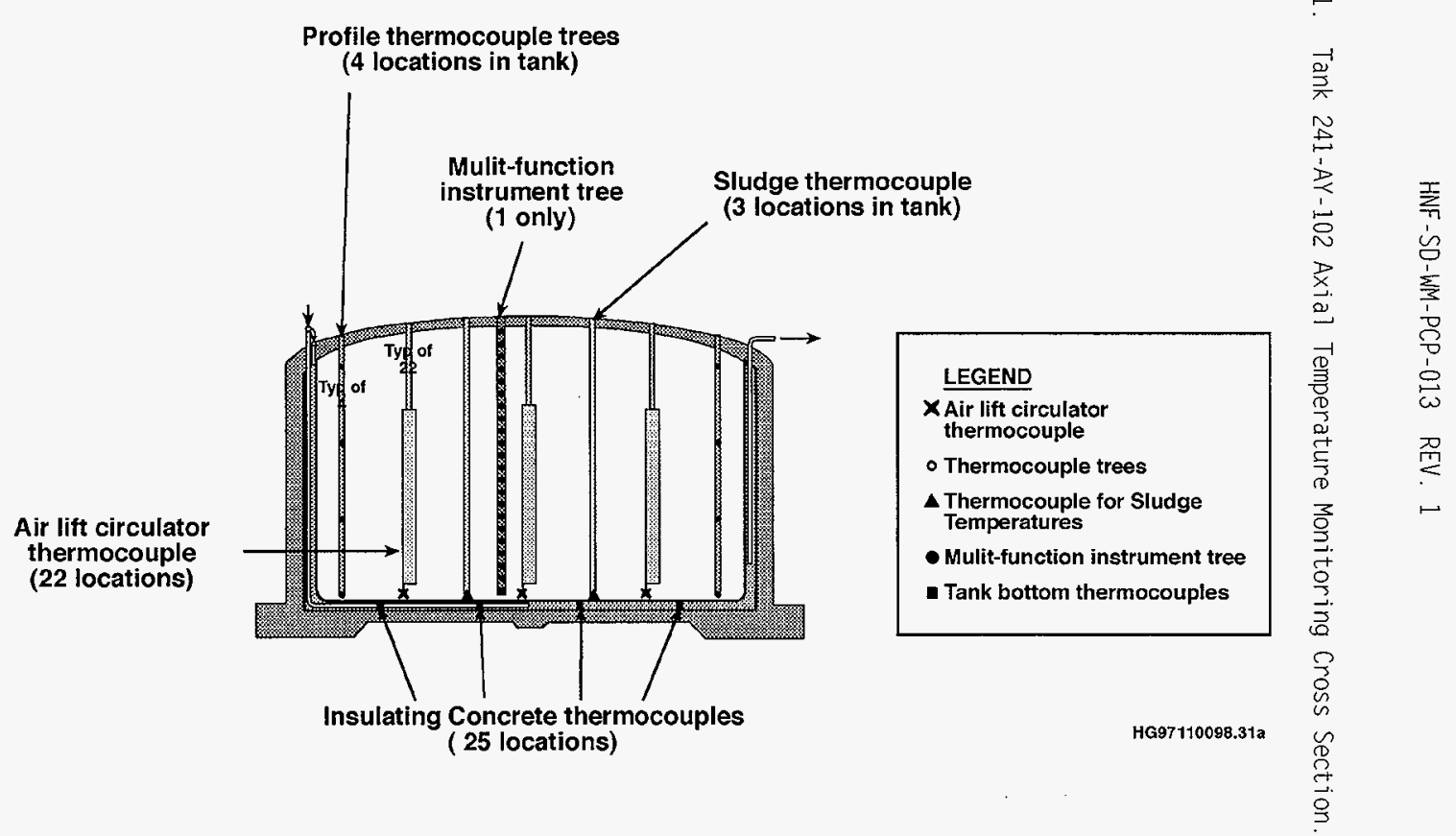



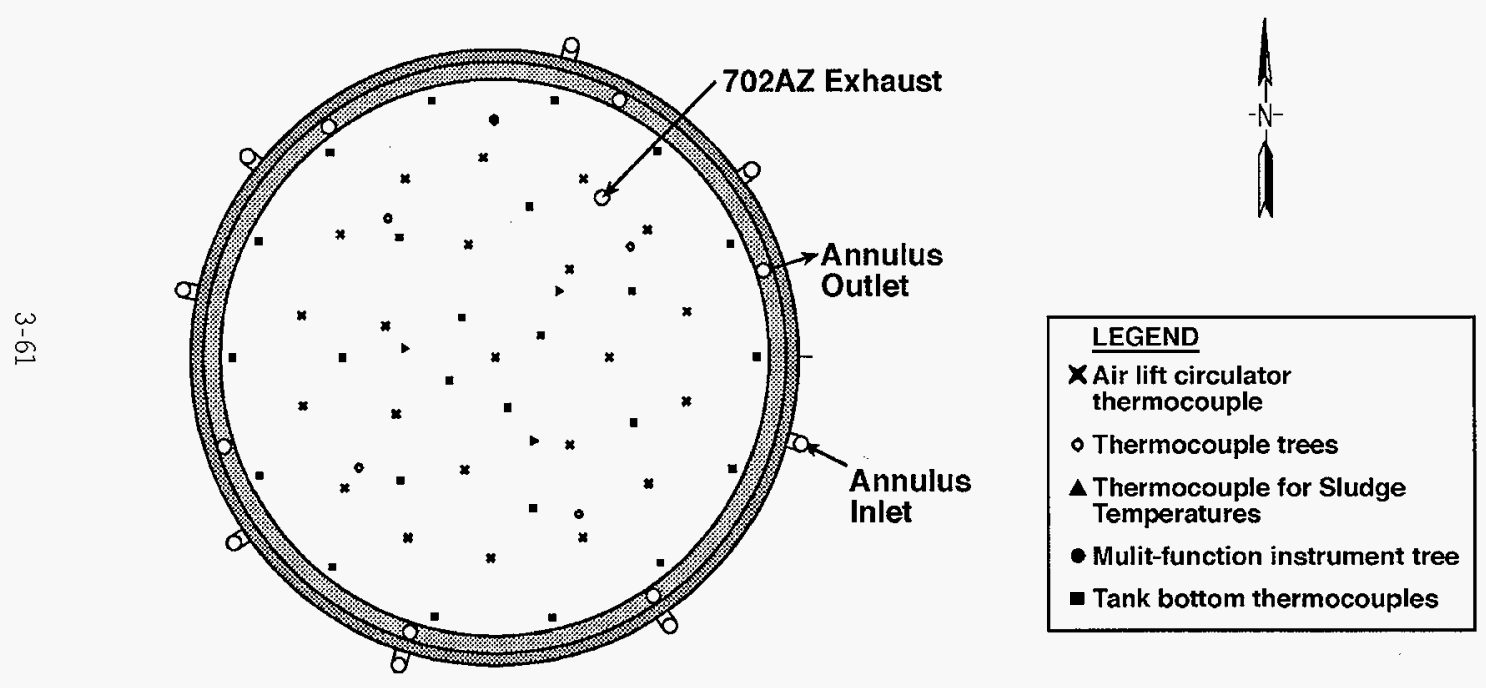

HG97110098.31 
Figure 3-23. Tank 241-C-106 Thermocouple Trees.

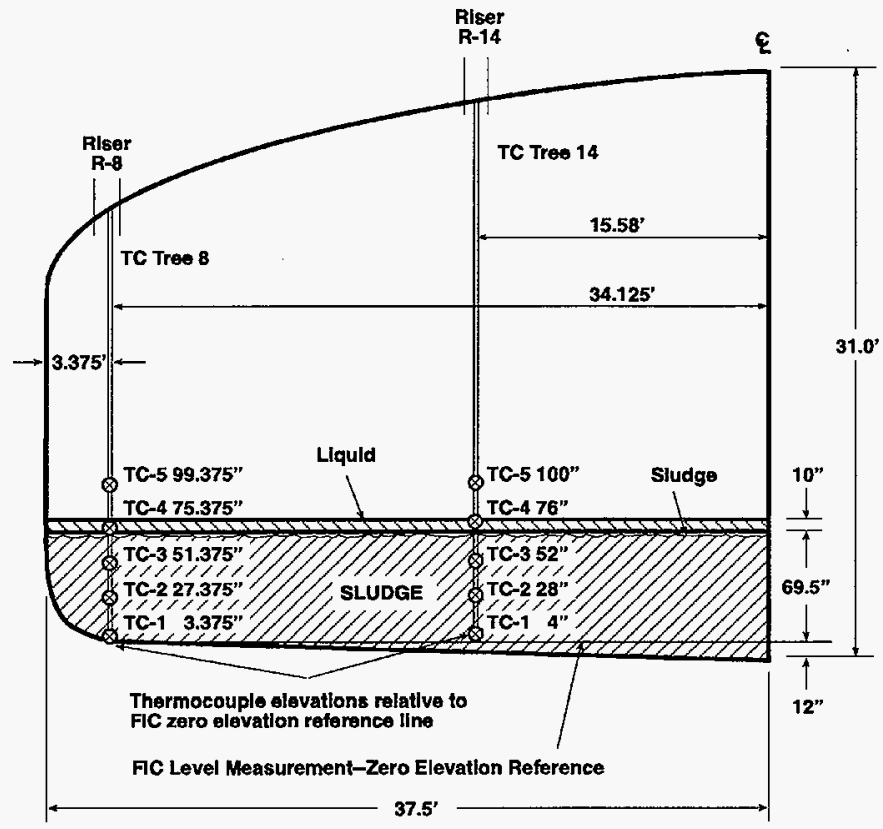

HG97110098.19 
HNF-SD-WM-PCP-013 REV. 1

Tank 241-C-106 ENRAF ${ }^{\text {TM }}$ Gauge. An ENRAF ${ }^{\text {TM }}$-Nonius Series 854 Tevel gauge (WST-LIT-1306) is located in riser R-1 of tank 241-C-106. See Section 3.5.3.1 for a similar description of the gauge for the tank 241-AY-102 ENRAFTM Standard Hydrogen Monitoring System. The SHMS system enables the continuous measurement of the hydrogen concentration in a tank's headspace. If concentrations of flammable gas greater than 25 percent of the lower flammability limit are detected, work or sluicing operations are suspended until the flammable gas is removed from the system. In addition, the SHMS is used as a process control instrument to track the release of hydrogen from tanks. From this data, a better understanding of the rate of gas retention can be developed which wi11, in turn. be compared to the anticipated tank behavior.

SHMS units are installed on tanks 241-C-106 and 241-AY-102 (see Figure 3-24). These systems will include gas chromatographs to allow the resolution of hydrogen release at the very low concentrations expected in these tanks. The data generated will be reviewed for unusual conditions before and during operation of the sluicing system.

The tank 241-C-106 SHMS is located in C-Farm; the sample tap is on riser R-2. The tank 241-AY-102 SHMS is located in AY Farm; the sample tap is on riser $15 \mathrm{C}$.

Tank Pressure Instrumentation. Existing tank 241-C-106 pressure instrumentation, located in riser R-15 (PIT-1361). measures the tank dome space pressure in inches of water. The instrument is located in tank $241-C-106$ Process Building Room 2. It has an accuracy of \pm 0.1 percent of the span (250 in. water) which is equal to 0.25 in. water.

A Fisher Porter Series 500 DP 4100 pressure indicator transmitter (PIT-AY102K1-1) in riser 58 is used to measure the pressure in tank 241-AY-102. It has a range from -6.0 to 4.0 in $\mathrm{w.g}$.

Tank 241-AY-102 Annulusventilation Instrumentation. Tank 241-AY-102 data will be monitored during sluicing and monitoring periods so technical information used to model the expected thermal behavior of the tank can be updated and the waste transferred from tank 241-C-106 can be maximized. The information provides important data about the energy balance for tank 241-AY-102 and is needed to estimate the tank heat load. The energy balance must also include an estimate of the energy removed by the tank annulus ventilation system. The energy balance calculation requires data for the air flow and temperature at the annulus exhaust. No humidity measurement is necessary since the annulus ventilation only removes sensible heat.

The tank 241-AY-102 annulus ventilation system exhaust flow rate and temperature monitors consist of an Air Monitor Corporation VOLU-probe/VS Model $C$ with Mass-tron signal conversion and a calculation module. This 
Figure 3-24. Standard Hydrogen Monitoring System.

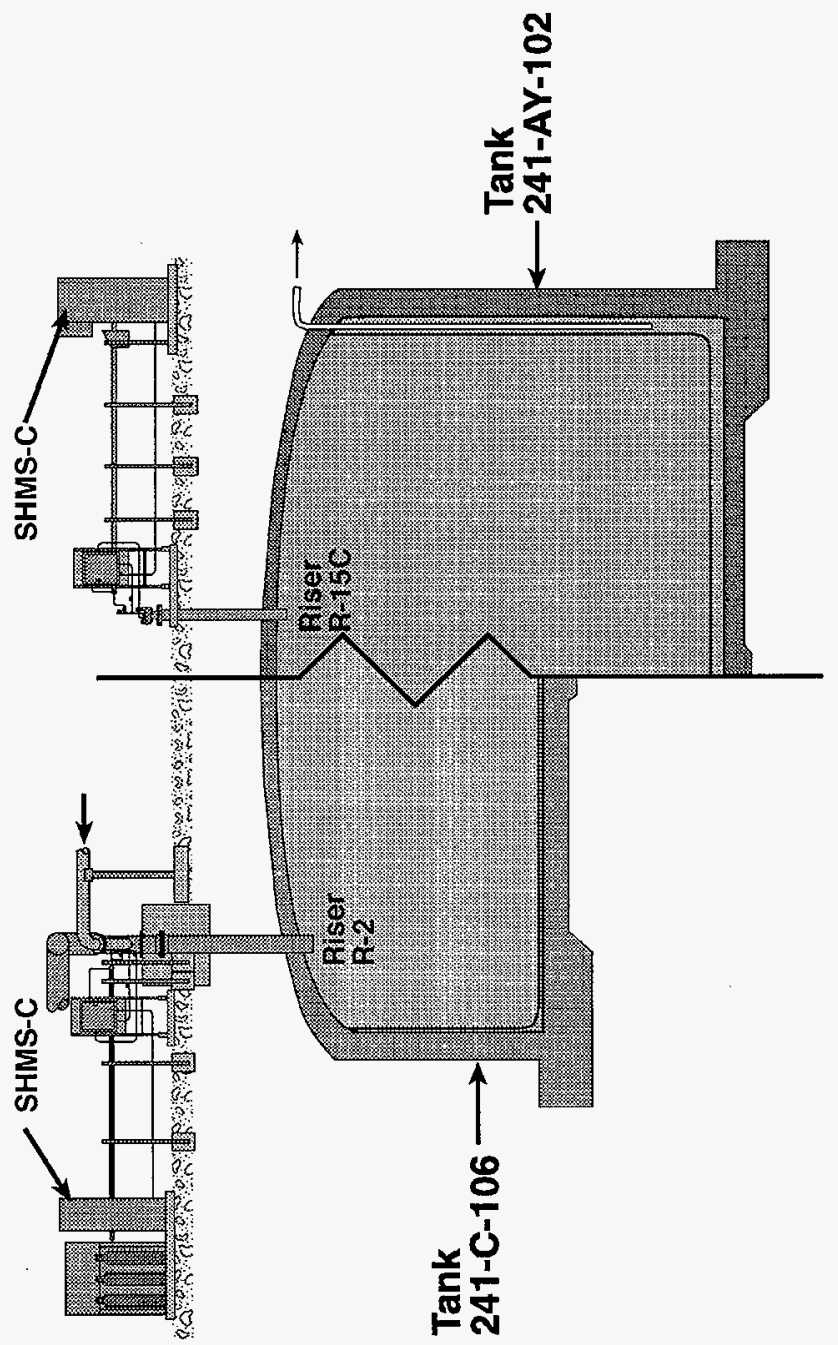


HNF-SD-WM-PCP-013 REV. 1

device is a pitot tube and associated temperature element that indicates flow rate corrected for temperature. The probe is installed in the ventilation duct ahead of the HEPA filters.

Tank 241-AY-102 Primary Ventilation Instrumentation. The energy balance must also include an estimate of the energy removed by the tank primary ventilation system. The primary system flow, temperature, relative humidity, and condenser heat removal data (i.e.. glycol temperature in and out and flow rate) are needed for this energy balance. In addition, the evaporation rate is an important input to the flammable gas evaluation.

A relative humidity meter (AE/AIT/AI-0623) is installed to provide psychrometric information on tank 241-AY-102 exhaust. The humidity monitor is installed at a point before the air stream from tank 241-AY-102 is mixed with the air streams from other tanks connected to the ventilation system. Tank 241-AY-102 headspace humidity is determined by a Hycal Engineering temperature-compensated humidity transmitter model $\mathrm{CT}-880-\mathrm{C}$. The device accuracy is stated as \pm 3.5 percent $\mathrm{RH}$ over the temperature range of $10^{\circ} \mathrm{C}$ to $90^{\circ} \mathrm{C}$ (50 ${ }^{\circ} \mathrm{F}$ to $194^{\circ} \mathrm{F}$ ) or \pm 2.5 percent $\mathrm{RH}$ over the temperature range of $15^{\circ} \mathrm{C}$ to $40^{\circ} \mathrm{C}\left(59^{\circ} \mathrm{F}\right.$ to $\left.104{ }^{\circ} \mathrm{F}\right)$, with a repeatability of \pm 0.5 percent $\mathrm{RH}$.

A MASS-tron Mass Flow transmitter ${ }^{1}$ is installed on the tank 241-AY-102 ventilation system exhaust duct to measure the exhaust gas flow rate. This flowmeter is a microprocessor-based differential pressure transmitter with optional temperature and/or static pressure density compensation. A direct temperature reading can be obtained from the MASS-tron MasS Flow transmitter. A second means of measuring the exhaust air temperature is by a resistance temperature detector (RID) (TI-AY2K48-1B) located between the ventilation cooling system condenser and moisture separator upstream of the flowmeter. This temperature will be recorded by the project data acquisition system.

In-Tank Imaging Systems. An in-tank imaging system is provided for tank 241-C-106 by project $W-320$. It provides real-time viewing of the tank's interior during sluicing operations and/or monitoring periods, whenever headspace visibility conditions permit. It will be used to help control and direct the sluicing operations. The imaging system consists of a remotely controlled television camera and an illumination source mounted in riser R-7. The system is intended to locate sludge accumulations and to enable optimal sluicer aiming while minimizing the volume of liquid in tank 241-C-106 (see Figure 3-19). The imaging system shares the riser assignment with the portable exhauster. which is a backup for ventilating the tank in the event the main ventilation system fails. Removal of the imaging system would be required to activate the portable exhauster.

A temporary mobile color camera system will be installed for surveillance in tank 241-AY-102 during transfers from tank 241-C-106. It will be installed in riser $15 \mathrm{~A}$ and used during active sluicing operations to monitor foaming inside the tank.

'Air Monitor Corporation 
HNF-SD-WM-PCP-013 REV. 1

If no foaming is observed during the first campaign, video monitoring may be discontinued. The high liquid level sensor on the immersible sluice pump could be used to detect foam buildup if the temporary camera system is removed.

Reference Drawings/Specifications/Vendor Information. Drawings H-2-818690, Procurement Specification WHC-S-0439, and Vendor Information Fi Te \# 22668. supplement 105 .

Operational Limitations.

Temperature - $-10^{\circ} \mathrm{C}$ to $80^{\circ} \mathrm{C}\left(14^{\circ} \mathrm{F}\right.$ to $\left.176^{\circ} \mathrm{F}\right)$

Waste Retrieval Sluicing System Leak Detection Equipment. Existing leak detection systems and newly installed leak detection instrumentation will provide monitoring and early warning capability needed to respond to a potential system failure during sluicing operations. The tanks, transfer pipelines, and process pits are all equipped with leak detection systems.

The primary means for detecting a leak from tank 241-C-106 during sluicing operations is liquid level monitoring using the ENRAF ${ }^{\text {TM }}$ level gauge. The tank liquid level can be monitored continuously except for the short duration sluicing periods (i.e., $\leq 12$ hours). Also, seven existing dry wells can be monitored to survey for Teaks from tank 241-C-106. The we17s are open-bottom. mi ld steel casings 15 or $20 \mathrm{~cm}$ ( 6 or 8 in.) in diameter with depths ranging from 25 to $33 \mathrm{~m}$ ( 75 to $100 \mathrm{ft}$ ). Radiation probes are used on a monthly schedule to determine the radiation profile in the we11. A change in the baseline profile would signify a potential tank leak. Sluicing operations would be shut down in a controlled manner for evidence of a tank leak.

A leak from the primary tank 241-AY-102 vessel will be contained in the annulus between the primary and secondary tanks. The annulus is designed to collect and transmit released waste to a common point within the annulus for detection and transfer. Conductivity probes installed in the annulus and a continuous air monitor on the annulus ventilation exhaust train provide the leak detection capability for the tank.

Leakage from the primary transfer piping (inner pipe) are detected and contained by the secondary confinement system (outer pipe). The secondary confinement system is designed to drain fluid released from the primary piping to a common point for collection, detection, and removal. The alarms for the sluice pipeline leak detector (LDE-1364) at sluice pit 241-C-06C and the slurry pipeline leak detector (LDE-1363) at pump pit 241-C-06A are located in the Mo-211 operator station.

Each process pit has a leak detector with an alarm function in addition to the high-capacity pit drains. If these leak detectors alarm, the sluicing operation wi 11 enter a controlled shutdown. The alarms for the tank 241-C-106 sluice pit 241-C-06C leak detector (LDE-1368) and the pump pit 241-C-06A leak detector (LDE-1366) are located in the MO-211 operator station. The alarms for the tank 241-AY-102 sluice pit 241-AY-02E leak detector (LDE-102-32) and the pump pit 241-AY-02A leak detector (LDE-102-22A) are located in the Electrical Equipment Skid. 241-AY-51. 
Other Specific Waste Retrieval Sluicing System Instrumentation. The WRSS incorporates accelerometers (seismic switches) that wi 71 stop running transfer pumps if a significant seismic event is detected. This will minimize the volume of process wastes that could be released inadvertently to the environment if there is a breach in containment integrity.

3.5.3.3 Instrument List. The instrumentation discussed in Section 3.5.3 comprises some of the equipment needed for process control of the sluicing operations. For a complete list of WRSS instrumentation including calibration requirements see the $W-320$ instrument list in HNF-2520 (King 1998). The minimum instrumentation required to support sluicing operations are those classified as safety class and safety significant (Bevins 1998).

Instrumentation required by operating procedures wi 11 be evaluated on a caseby-case basis if it becomes inoperable to determine its effect on sluicing efficiency and determine the need for repair or replacement.

\subsubsection{Waste Retrieval Sluicing System Control System Arrangement}

The WRSS is controlled from two main locations: the M0-211 control room trailer at C Farm and the 241-AY-51 electrical equipment skid at AY Farm. In addition. there are several auxiliary control locations at the two farms where electrical and other subsystem detailed control capabilities are provided.

The MO-211 control room has a main C Farm systems instrumentation control console, an annunciator panel, and a data acquisition system. The C Farm sluicing control console includes the sluicer and slurry pump/winch system controls, an annunciator panel, and an in-tank imaging system monitor and controls (see Figures $3-25$ and 3-26). The in-tank imaging panel contains controls for positioning and illuminating the field-of-view and a television monitor displaying the view in the tank.

Figure 3-27 provides a detailed look at the sluicing annunciator pane?. This panel shows process and tank conditions that require operator actions.

Figure 3-28 provides a detailed look at the sluicer and slurry pump system control panel. The control panel contains the sluicer aiming controls that direct the sluice fluid stream spray within tank 241-C-106. The sluicer control has two operating modes as follows:
Semi-automatic Mode -
Elevation and sweep range pre-set
(routine sluicing)
Manual Mode - Joystick controls sluicer aiming. Used with
in-tank imaging system.

The pump controls include submersible pump elevation (winch) control, booster pump speed control, and monitoring of the pump flow rate. This panei also displays selected tank farm instrumentation readouts of temperatures and levels. 
HNF-SD-WM-PCP-013 REV. 1

Figure 3-25. M0-211 Operator Control Station Layout.

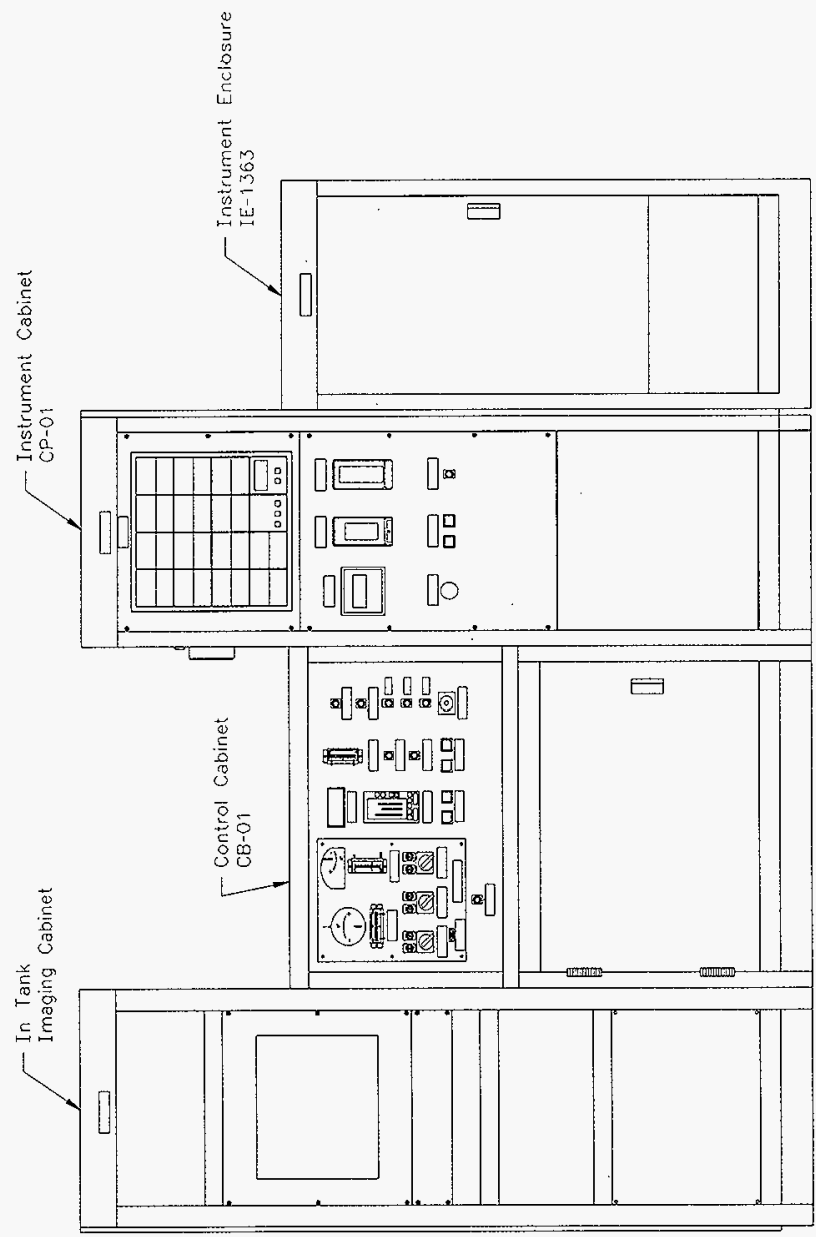

6
0
0
0
0
5
0
\pm
5
0
1
0
0
0
0
0 
HNF-SD-WM-PCP-013 REV. 1

Figure 3-26. M0-211 Control Station Layout.

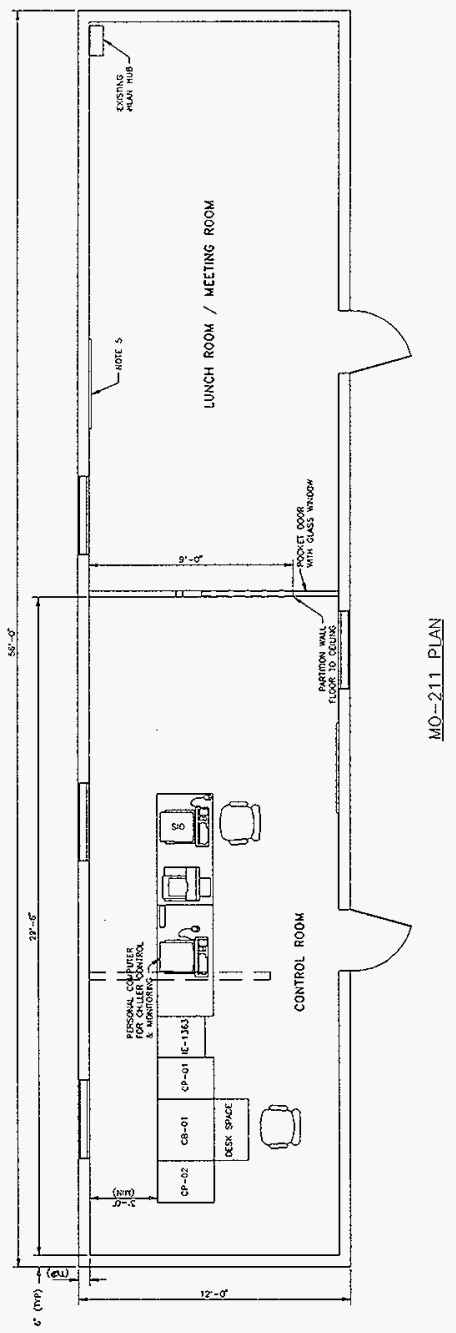


Figure 3-27. Sluicing Annunciator Panel.

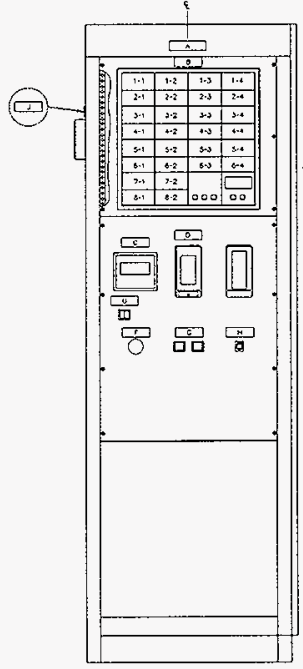

(1) INSTRUMENT CABINET CP-01 ASSEMELYY

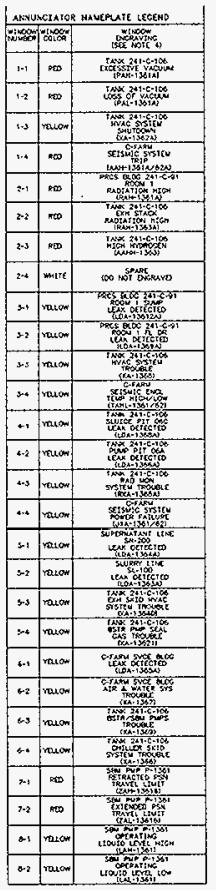


HNF-SD-WM-PCP-013 REV. 1

Figure 3-28. Waste Retrieval Sluicing System Sluicing Control Panel.

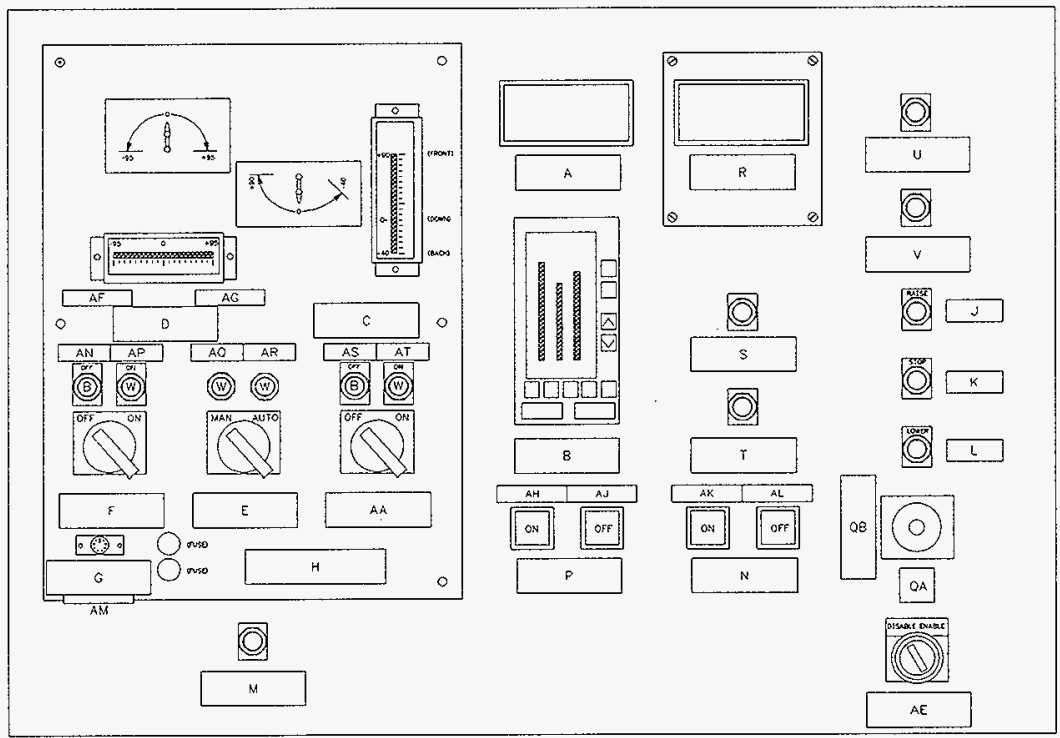

(2) SLUICING CABINET C8-O1 
HNF-SD-WM-PCP-013 REV. 1

The M0-211 control room operator will have remote control over the following equipment:

- aiming of the sluicer in pit 241-C-06C

- submersible slurry pump and its height adjusting winch in pit $241-C-06 A$

- in-tank imaging system at tank 241-C-106

- tank 241-C-106 296-C-006 ventilation system operation

- booster pump speed control and on/off.

The operator(s) will also receive indications for the following parameters:

- slurry booster pump on/off indication, and speed

- slurry pump winch position

- slurry header volumetric flow. density, mass flow

- supernatant header volumetric flow (available only to 24l-AY Tank Farm operators and not in M0-211)

- graphical display of the operating sluicer position

- in-tank imaging system display from tank 241-C-106

- ventilation system instrumentation and exhaust monitoring system

- selected thermocouple readings from tank 241-AY-102

- tank level instrumentation

- WRSS transfer line leak detection instrumentation.

The C Farm inputs to the tank monitoring and control system (Tank Monitoring and Control System [TMACS]) include the following waste tank thermocouples:

- thermocouple tree in riser 8: TC-1, 2, 3, 4, 5

- thermocouple tree in riser 14: TC-1, 2, 3, 4, 5, 6, 7, 8, 9 .

The tank 241-AY-51 electrical equipment skid houses the 241-AY Tank Farm sluicing control room. Figure 3-29 shows the arrangement of the sluicing operator station which includes the sluice pump system controls and annunciator panel. Figure 3-30 shows the annunciator panel in 241-AY-51.

The 241-AY-Tank Farm inputs to the DAS/TMACS include the following:

- sludge temperature: TC-73, -74

- air lift circulators (ALC) temperature: TC-42, $-44,-50,55,-59$

- profile temperature: TC-60,-61,-62, -63, -64, -65, -66, -67, -68 , $-69,-70,-71$

- tank side wa11 temperature: TC-26, 27

- tank bottom insulating concrete temperature: TC-1 through -7. -10 through $-17,-20$ through -25

\subsubsection{Utility Systems}

Electrical Power. The majority of the electrical power for WRSS operations is provided by two new electrical distribution systems installed at 241-AY Tank Farm and 241-C Tank Farm. These electrical systems include transformers. motor control centers, and wiring to the power equipment. 
Reference Drawings/Specifications/Vendor Information. Electrical One Line Drawings $\mathrm{H}-2-820748$ sheets $1-3$, other project electrical drawings are identified on the project drawing 1ists H-2-818423. (Refer to the project master equipment list for specification and vendor information references.)

Raw Water. To meet equipment flushing and process water needs at $C$ Farm, a raw water 7 ine was installed to the air and water service building, 241-C-73 from the $30.5 \mathrm{~cm}$ (12 in.) fire water line northwest of 241-C Tank Farm. Water requirements at tank AY-102 are to be met using a tank truck or over-ground hoses from existing raw water sources.

Water Pipeline. $5 \mathrm{~cm}$ (2 in.), carbon steel, pipe code M5.

Reference Drawings / Specifications / Vendor Information. Drawings

$\mathrm{H}-2-818430, \mathrm{H}-2-818435, \mathrm{H}-2-818481$ sh $1-6, \mathrm{H}-2-818482$ sh 1 \& $3, \mathrm{H}-2-818519$ sh 1-2. $\mathrm{H}-2-818521 . \mathrm{H}-2-818531$ sh $1-2$, and Construction Specification W-320-C1 (to 241-C-73), and $W-320-C 5$ (in C Farm). 
Figure 3-29. 241-AY Tank Farm Sluicing Operator Control Station Layout.

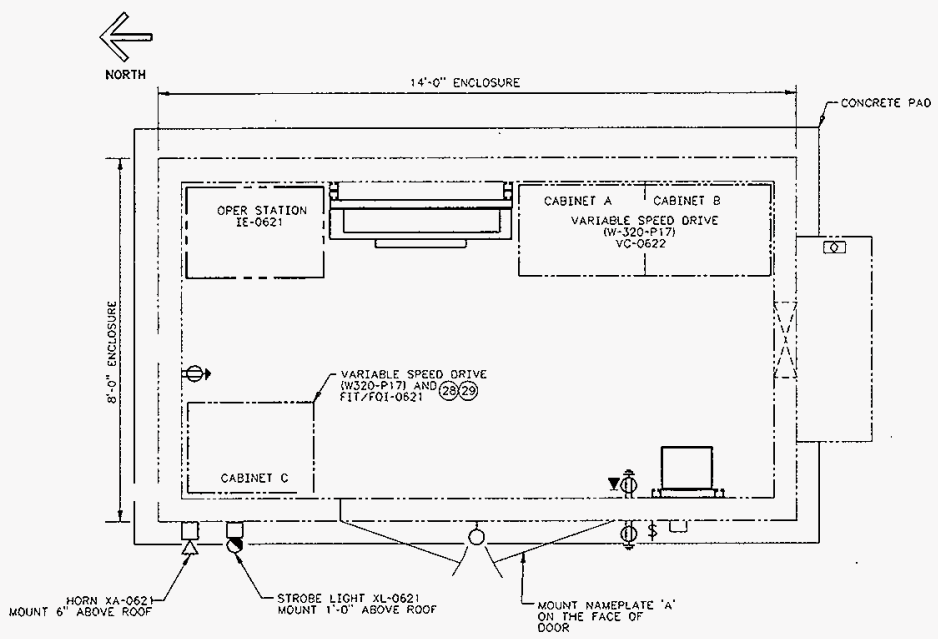

PLAN - ELECTRICAL EQUIPMENT SKID and CONCRETE PAD

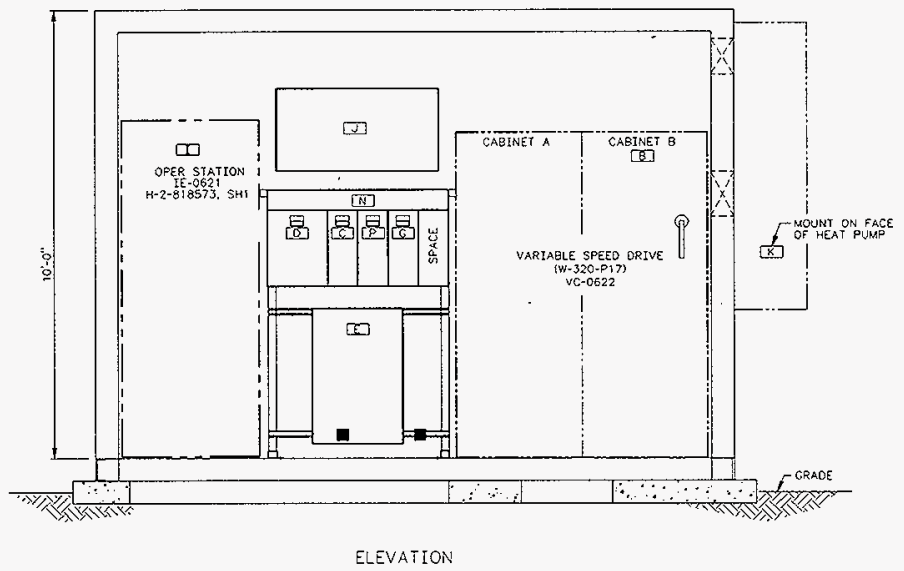


Figure 3-30. 241-AY Tank Farm Annunciator Panel.

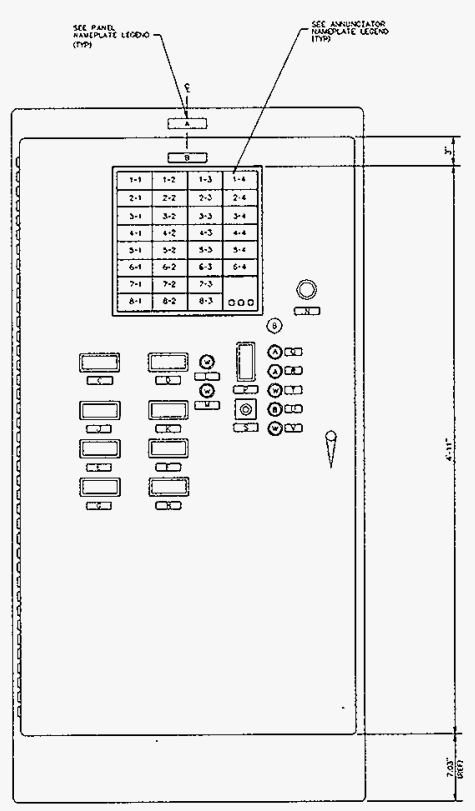

(1) INSTRUMENT ENCLOSURE IE-0621 ASSEMRLY
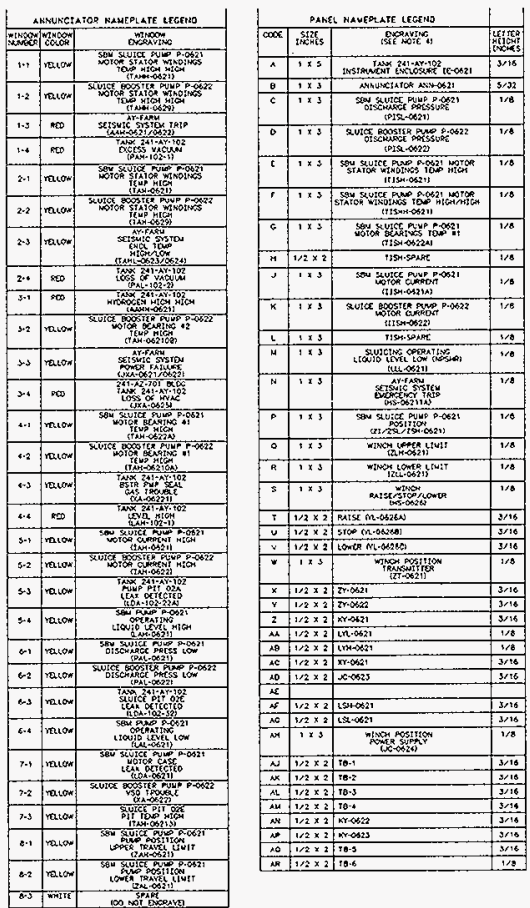
HNF-SO-WM-PCP-013 REV. 1

This page intentionally left blank. 
HNF-SD-WM-PCP-013 REV. 1

\subsection{PROCESS CONTROL}

The WRSS process control establishes how tank 241-C-106 retrieval wi 11 be performed to accomplish the processing goals (see Section 2.0) and to comply with technical operating requirements such as the basis for interim operation (FDH 1998a), technical safety requirements (FDH 1998b), and the Operating Specification Document (LMHC 1996: LMHC 1997a, 1997b. and 1997C).

More specifically, the primary drivers for the design of the process control strategy relate to thermal considerations in tanks 241-C-106 and 241-AY-102 and to flammable gas behavior in tank 241-AY-102. The sluice batch-increment-campaign approach implements this strategy. Incremental sluicing with mass control followed by variable-length monitoring periods will provide the necessary temperature and flammable gas control for the retrieval process.

Figure 4-1 shows the process contral logic for the WRSS process. During active sluicing, operators will have direct control over the following process variables: the liquid level in tank 241-AY-102, sluice booster pump and slurry booster pump speeds. solids loading of the slurry being transferred in the slurry pipeline (sluice nozzle and submersible slurry pump positioning). and the mass of tank 241-C-106 waste transferred to tank 241-AY-102 (slurry pump system run time and mass flowmeter totalizer). The direct control of the tank 241-AY-102 liquid level provides an indirect means for controlling the liquid level of tank 241-C-106, which in turn controls the waste temperatures in tank 241-C-106 below local saturation temperatures.

Tank 241-AY-102 waste temperatures and flammable gas parameters cannot be directly controlled by operators during sluicing operations. These parameters are controlled indirectly by limiting the mass of tank $241-\mathrm{C}-106$ solids that can be transferred into tank 241-AY-102. Changes to the tank 241-AY-102 thermal and flammable gas baselines occur during specified monitoring periods and have a bearing on how subsequent retrieval actions will be performed.

Section 4.1 describes the process control for active sluicing operations and focuses on parameters directly controlled by operators. Sections $4.2,4.3$, and 4.4 describe the process controls for tank 241-AY-102 mass transfer verification, waste temperature, and flammable gas retention; issues that require evaluation during the specific monitoring periods. Section 4.5 addresses other parameters that are important to the process but for which operators have little direct or indirect control. Finally. Section 4.6 gives the process sampling requirements and schedule needed to ensure that the retrieval process is proceeding as expected. 
HNF-SD-WM-PCP-013 REV. 1

This page intentionally left blank. 


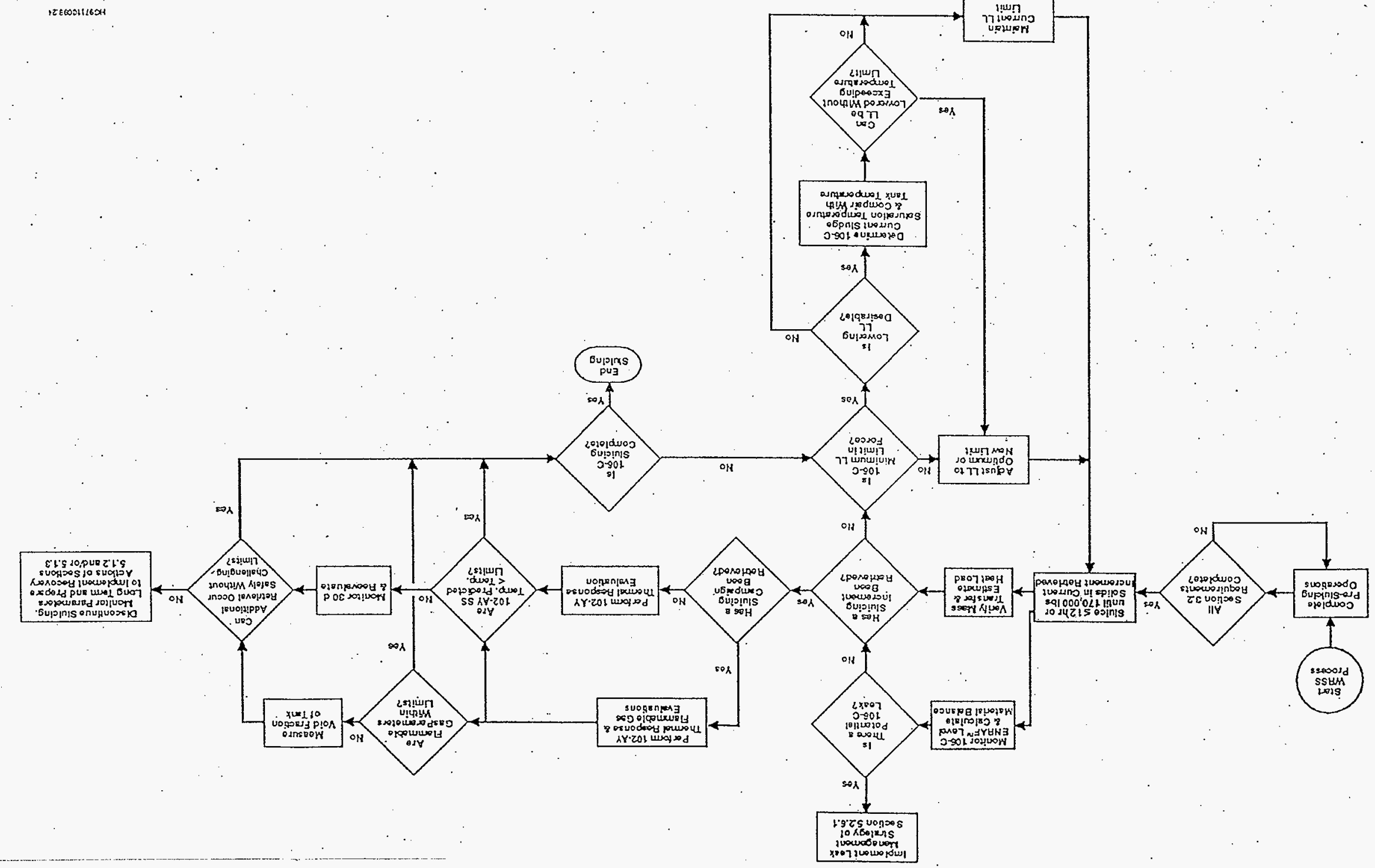




\subsection{SLUICING PROCESS CONTROL}

Waste retrieval from tank 241-C-106 and waste transfer to tank 241-AY-102 are conducted in sluice batches. For each sluice batch, the operator has direct control over process variables at startup, during routine sluicing, and at shutdown. These variables include tank liquid levels, sluice and slurry booster pump speeds, sluice nozzle position, submersible slurry pump elevation, and slurry pump system run time. By controlling these variables, the sluicing operation can proceed and specific parameters can be maintained within established safety and operating limits. The parameters of particular interest include slurry concentration, tank 241-C-106 waste temperatures. solids mass transfer into tank 241-AY-102, sluice nozzle movement, leak prevention/minimization, and transfer system flushing. The process control for each of these parameters is presented in the subsections below.

Other process variables (i.e., primary tank pressures, tank 241-AY-102 waste temperature, headspace hydrogen concentration. transfer system leak detectors, and ventilation system flows) which could affect the duration of a sluicing batch are continuously monitored. However, the operator has very little control over these variables except to terminate the batch. If any variable exceeds limits, the event is considered off normal.

\subsubsection{STurry Concentration Control}

This section describes the method incorporated into the WRSS control process to prevent the slurry concentration from exceeding the design limit of 30 weight percent solids in the slurry transfer pipeline. Solids concentration control in the sluice stream is not required because a rapid buildup of high solids loading cannot occur in the large volume of tank 241-AY-102 supernatant. As sluicing operations proceed, most of the solids transferred into the tank are expected to settle out, adding to the solids heel. Therefore, no instrumentation has been installed on the sluice transfer pipeline to monitor and control solids loading to the 10 weight percent design Timit.

The operator will control the solids content in the slurry transfer pipeline by directing the sluicer nozzle, adjusting the level of the submersible slurry pump suction (when permitted by thermal-hydraulic constraints), and setting transfer system flows with variable speed pumps based on measured slurry properties. The slurry properties are measured directly by the slurry pipeline mass flowmeter and inferred from the slurry pipeline flowmeter.

The 241-AY-02A pit mass flowmeter has been installed as the principal solids loading process control instrument. This instrument indicates the slurry mass flow rate and average slurry density at the receiver tank end of the transfer line. Knowledge of the carrier solution density (i.e., tank 241-AY-102 supernate density), the solids particulate density (see Table 3-4 or based on grab samples laboratory measurements), and the measured slurry density are required to determine slurry solids loading. The relationship between the mass fraction of solids in the slurry and the system densities is given below. 
HNF-SD-WM-PCP-013 REV. 1

$$
C_{m}=100 \frac{\rho_{p}\left(\rho_{m}-\rho_{f}\right)}{\rho_{m}\left(\rho_{p}-\rho_{f}\right)}
$$

where

$\mathrm{C}_{\mathrm{m}}=$ mass fraction of solids in slurry (expressed as a percent)

$\rho_{\mathrm{p}}=2.61 \mathrm{~g} / \mathrm{mL}$, solids particulate density (see Table 3-4)

$\rho_{\mathrm{f}}=0.99 \mathrm{~g} / \mathrm{mL}$, Carrier solution density (see Table 3-8)

$\rho_{\mathrm{m}}=$ slurry density measured by mass flowmeter

The slurry solids mass loading can be determined from the output of the mass flowmeter. This parameter is displayed in the M0-211 control room and can be monitored to control solids loading during a sluicing batch.

The uncertainty in the solids volume fraction in the slurry as measured by the mass $f 1$ owmeter was determined to be \pm 3 vol\% based on the derivation for the standard deviation and applicable parameter values. ${ }^{1}$ This volume fraction uncertainty translates into a mass fraction uncertainty of approximately $\pm 7 \mathrm{wt} \%$. Consequently, the uncertainty in the mass flowmeter is acceptable for the flowmeter to be useful in controlling the slurry solids loading to the 30 wt\% limit. At the nominal $10-20$ wt\% operating range, the solids loading will remain below the safety limit.

A second indication of slurry solids loading is provided by the slurry flow rate measured by the mag-flow meter installed in the 241-C-06A pit. This flow rate measurement basically reflects the average value for the entire slurry pipeline. The solids loading is indirectly determined with knowledge of the slurry flow rate and the slurry booster pump speed setting together with the combined pump curve and system curve. The pump curve correlates the pump speed, discharge pressure, and flow rate. The pump speed and flow rate parameters are displayed in the MO-211 control room. The pump system discharge pressure is insensitive to changes in flow rate over the nominal operating range and does not need to be monitored by the operator for control purposes.

Figure 4-2 shows the slurry pump system pump curve and overlaid systems curve for the transfer route. By setting the speed of the slurry booster pump and monitoring the slurry pipeline flow rate with the mag-flow meter, the solids loading of the slurry can be estimated. Figure $4-3$ focuses on the expected operating range for the pumping system. The minimum pump speed of $1.500 \mathrm{rpm}$ is required to maintain the level of lubrication specified by the pump manufacturer.

Sluicing Startup. Before the start of sluicing operations, the operations described in Section 3.2 are completed including decanting tank 241-C-106

\footnotetext{
'See Pacific Northwest National Laboratory memorandum, C. W. Stewart to J. W. 8ailey, "Transmittal of Letter Report, Uncertainty in Solids Mass Iransferred from C-106 to AY-102," (PNNLW320:060898) dated June 1998.
} 
HNF-SD-WM-PCP-013 REV. 1

Figure 4-2. Tank 241-C-106 Slurry Booster Pump (P-1362) Curve/System Curve.

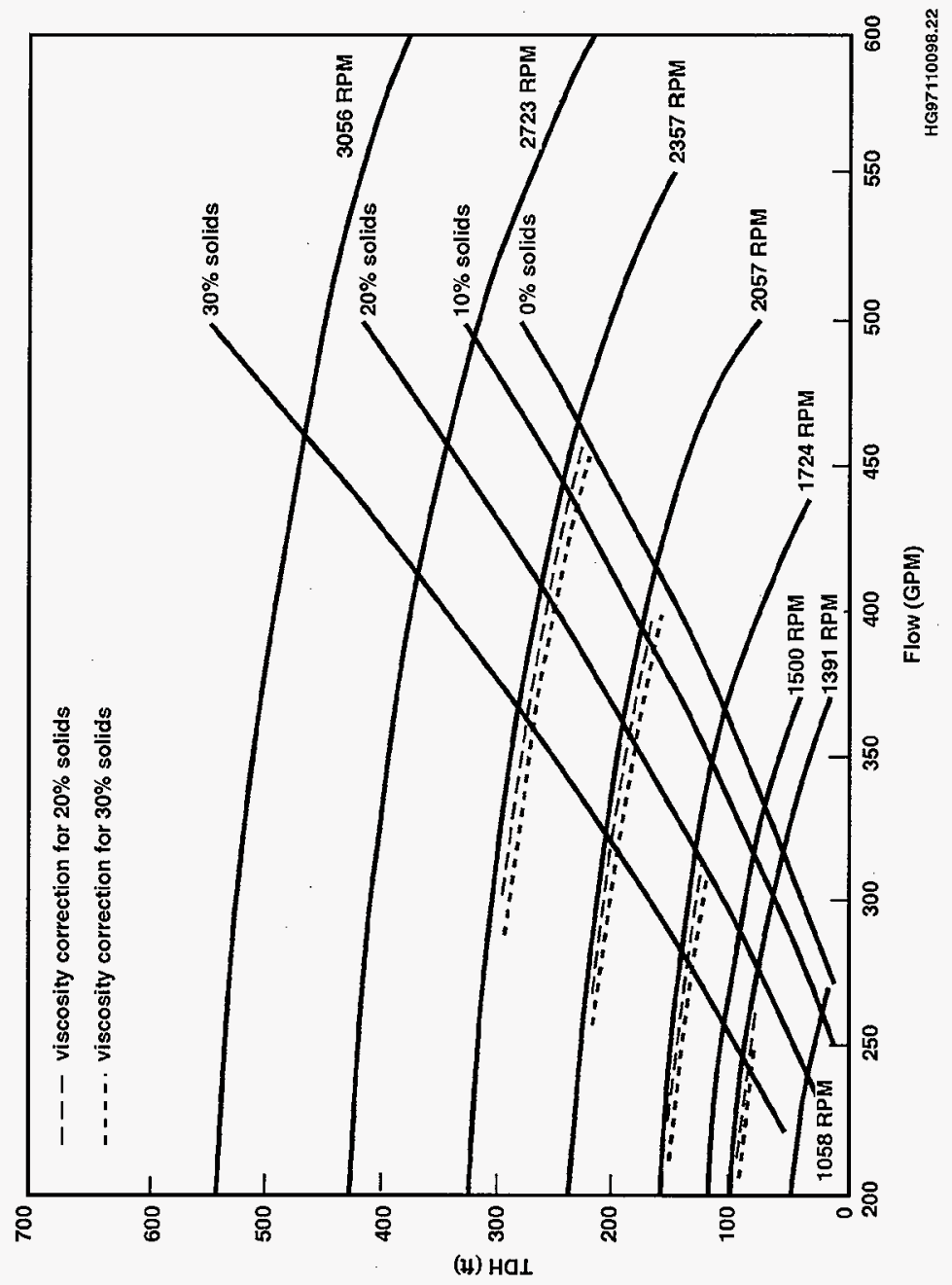


Figure 4-3. Slurry Booster Pump (P-1362) Curve/System Curve - Nominat.

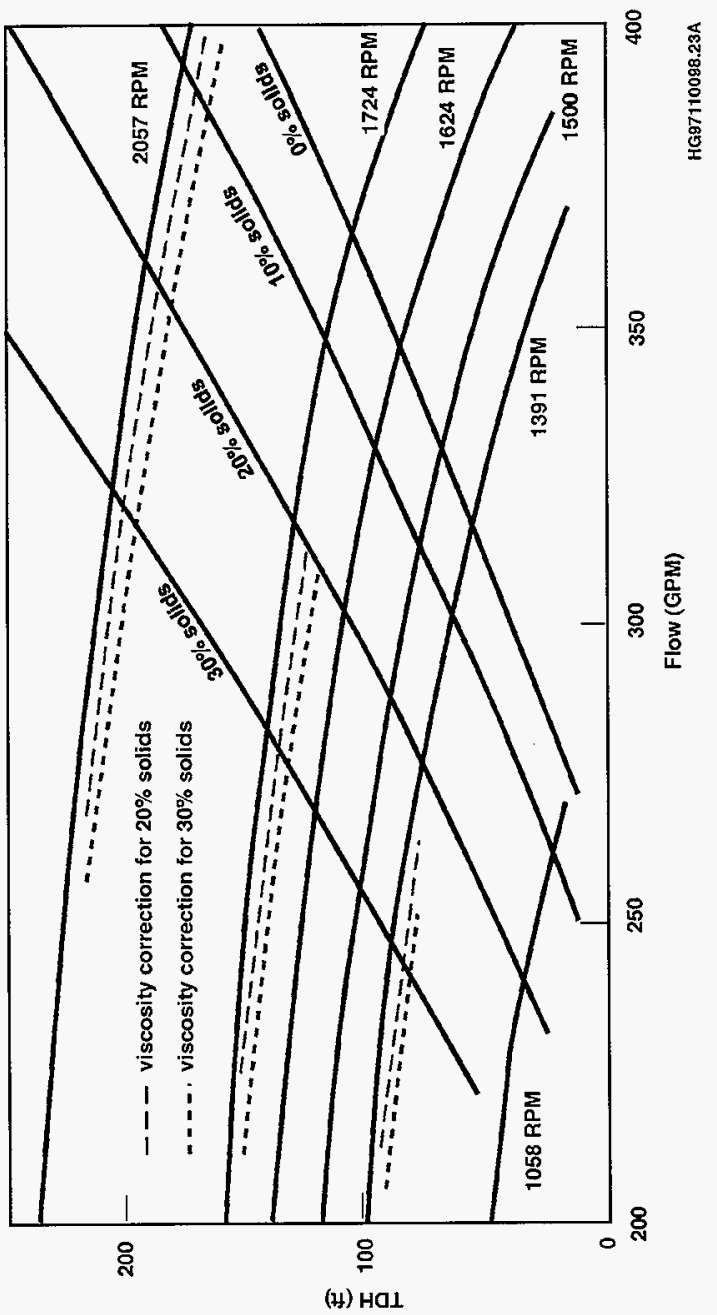


supernatant to a liquid level of $183 \mathrm{~cm}$ (72 in.). To start sluice batch 1.1.1 (see Figure 3-5), the P-1361 submersible slurry pump is positioned so that its low-level detector is located at $178 \mathrm{~cm}$ (70 in.). The P-0621/P-0622 sluice pump system is then started and the flow rate is adjusted to a nominal $1.325 \mathrm{~L} / \mathrm{min}$ (350 gal/min). Once the sluicer flow is verified in tank $241-C-106$, the sluice stream is aimed towards the region of the $P-1361$ submersibje slurry pump intake. This sluicer orientation floods the region with the dilute sluicing fluid and allows startup of the slurry pumping system with a low solids content slurry.

The P-1361/P-1362 slurry pump system is started next, and the P-1362 slurry booster pump speed is set at a nominal $1,624 \mathrm{rpm}$. This pump setting is expected to give a flow of approximately $1,325 \mathrm{~L} / \mathrm{min}$ (350 gal/min) at a low slurry solids loading. A lower mag-flow meter flow rate would be indicated for a higher slurry solids loading, which can be estimated by interpolation from the Figure 4-3 pump/system curve. Table 4-1 1ists the estimated solids loading for various slurry pump system flow rates at the 1.624 rpm slurry booster pump speed. The solids loading can be determined directly by monitoring the tank 241-AY-02A pit mass flowmeter output once the flow is established at the receiver end of the pipeline. This takes approximately three minutes on slurry pump system startup. The anticipated flow rate on startup ranges from $1,250 \mathrm{~L} / \mathrm{min}$ to $1,325 \mathrm{~L} / \mathrm{min}(330 \mathrm{gal} / \mathrm{min}$ to $350 \mathrm{gal} / \mathrm{min})$ corresponding to a slurry solids loading of 10 weight percent to 0 weight percent, respectively, for the pipeline completely filled with fluid. During the initial 3-minute period to fill the pipeline, the flow rate will fluctuate at higher values.

Table 4-1. Estimated STurry Solids Loading for Slurry Pump System Flow Rates at 1.624 rpm Booster Pump Speed.

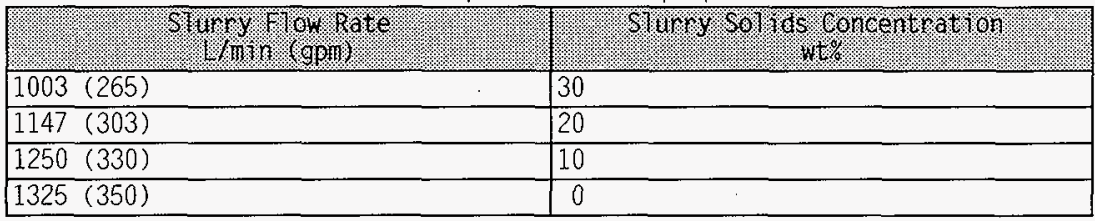

After the slurry pump system startup, the associated mass and slurry flowmeters are monitored continuously until a stable slurry loading is achieved. The operator adjusts the position of the sluicer nozzle. which is normally set in the semi-automatic operating mode, to gradually increase sluicing efficiency to produce a slurry stream containing 0 weight percent to 10 weight percent solids loading. Initial sluicing efficiency will be low because of the requirement to maintain the supernatant level above control limits during the first campaign. Beginning with Campaign 2, sluicing efficiency will be targeted for 10 to 20 weight percent solids loading.

Routine Sluicing. During routine sluicing, the operator continues adjusting the sluicer nozzle position to maintain a stable solids loading of 0 weight 
percent to 10 weight percent (10 to 20 weight percent starting with Campaign 2). The solids loading in the slurry pipeline is monitored using the mass flowmeter installed in the 241-AY Tank Farm end of the slurry transfer piping. The slurry pipeline mag-flow meter is also monitored to indicate solids loading. At the nominal 1.624 rpm slurry booster pump setting. the expected flow rate for a 0 weight percent to 10 weight percent solids slurry ranges from $1,325 \mathrm{~L} / \mathrm{min}$ to $1,250 \mathrm{~L} / \mathrm{min}$ ( $350 \mathrm{gal} / \mathrm{min}$ to $330 \mathrm{ga} / \mathrm{min}$ ), respectively. For higher solids loading, the flow rate range can be obtained from Table 4-1 and Figure 4-3.

To assist the operator in controlling the slurry loading at a level that will not potentially allow solids settling in the transfer pipeline, a 20 weight percent solids loading indicated by the mass flowmeter will cause an alarm to sound. Additionally, the flow rate from the mag-flow meter for a 20 weight percent solids loading will cause a redundant alarm to sound. At the nominal $1.624 \mathrm{rpm}$ slurry booster pump speed setting, this flow rate is approximately $1,147 \mathrm{~L} / \mathrm{min}(303 \mathrm{gal} / \mathrm{min})$. For a different pump speed setting, the mag-flow meter alarm function will be set for the corresponding flow rate determined by Figures 4-2 and 4-3. The response to either of these alarms will be to take action to avoid a further increase in solids loading and to reduce the solids loading to below 20 weight percent. The process control actions below will reduce the solids loading to below 20 weight percent:

\section{Raise the submersible slurry pump level}

2. Direct the sluice stream to the area of the submersible slurry pump intake to dilute the solids entering the pump.

3. Increase the pump speed to achieve a $1,700 \mathrm{~L} / \mathrm{min}(450 \mathrm{gal} / \mathrm{min})$ flow rate unt $i$ the higher solids content slurry clears the transfer system. After completing this action, the slurry loading process control pump speed setting (i.e.. nominaliy $1,624 \mathrm{rpm}$ ) will be reestablished to continue the sluice batch.

Sluicing Shutdown. Before the end of a sluicing batch, the submersible slurry pump height and/or sluicer aiming are adjusted to reduce the solids loading in the slurry pipeline. The WRSS shutdown is designed to minimize the amount of solids that settle out in the transfer pipeline when the slurry pump system is shut down and the piping system drains. Consequently, water flushing will not normally be required following system shutdown at the completion of a sluicing batch. The small amount of solids that settle out in the pipes are expected to be resuspended when the system starts back up during the subsequent batch.

A minimum of 15 minutes before the scheduled shutdown of a sluicing batch, the operator raises the submersible slurry pump level and directs the sluice stream to the area of the submersible slurry pump intake to dilute the solids entering the pump. At the nominal 1.624 rom slurry booster pump speed setting, approximately $1,325 \mathrm{~L} / \mathrm{min}(350 \mathrm{ga} 1 / \mathrm{min})$ of relatively solids-free solution is used to flush out the slurry transfer pipeline. After at least one-and-a-half pipeline volumes (i.e., 6,400 L [1,690 gal]) of relatively solids-free solution have been transferred, the sluice pump system and slurry pump system are shut down. At the process nominal flow rate, one-and-a-half pipeline volumes can be transferred in approximately five minutes. 
Subsequent Sluicing Batches. Controlling the slurry concentration during subsequent sluicing batches is the same as that for sluice batch 1.1.1 except for the higher slurry solids loading operating target. Also, the tank 241-C-106 liquid level and submersible slurry pump elevation settings at sluicing startup can be varied to optimize sluicing effectiveness. Only during campaign 1 are tank 241-C-106 liquid level and submersible slurry pump elevation limits applicable for each sluice batch.

\subsubsection{Tank 241-C-106 Liquid Level Control}

There are three reasons for control ling the liquid level in tank 241-C-106 during sluicing operations: tank 241-C-106 sludge temperature control. optimum sluicing, and leak prevention. Controlling tank 241-C-106 sludge temperatures takes precedence during the early stages of the WRSS process: optimizing sluicing and leak prevention once the first sluicing campaign is complete.

Tank 241-C-106 Sludge Temperature Control. During the first sluicing campaign, the tank 241-C-106 liquid Tevel will be controlled to maintain a hydrostatic head in the tank needed for sludge temperature control. For sluice batch 1.1.1, this liquid level limit is greater than $178 \mathrm{~cm}$ (70 in.) of waste in the tank. This minimum liquid level limit will prevent any regions of tank 241-C-106 sludge from reaching the loca? saturation temperature (boiling point) thereby eliminating the potential for a steam bump accident. The decision logic for establishing a minimum liquid level control limit for subsequent sluice batches is found in Section 4.3.1.3.

Siudge temperatures in tank 241-C-106 wi11 drop gradually as heat generating material is transferred to tank 241-AY-102 and as layers of insulating sludge are removed. However, reducing the hydrostatic head provided by the liquid in the tank before a sufficient amount of radiogenic high-heat solids are removed and sludge cooling occurs will affect the level of subcooling in the sludge and could lead to increasing sludge temperatures if voids are allowed to form at the tank bottom. Consequently, removing the sludge in a controlled manner while maintaining the required liquid level (and therefore hydrostatic head) in tank $241-C-106$ will be necessary unti 1 it can be demonstrated that saturation conditions are no longer a concern in the sludge.

The Tiquid level in tank 241-C-106 cannot be monitored using the ENRAF ${ }^{\text {TM }}$ liquid level gauge because the instrument displacer wi 11 be retracted out of the tank during sluicing operations to avoid damage by the sluice stream. Therefore. liquid level control will be provided by the combination of the lower liquid level sensor on the submersible slurry pump and level control in tank 241-AY-102.

Section 4.1.1 described the startup of sluicing operations where the P-1361 submersible slurry pump is positioned so its low-level detector is located at the $178 \mathrm{~cm}$ (70 in.) limit to begin sluice batch 1.1.1. To ensure the liquid head on the sludge in the tank is not lowered below the established limit during each sluice batch of the first campaign. the pump winch is locked out to fix the elevation of its lower liquid level sensor. At startup, the tank 241-AY-102 operator will try to maintain the tank 241-AY-102 i iquid level 
constant by monitoring the ENRAF TM level gauge and adjusting the P-0622 sluice booster pump speeds. The operator will have to take into account the approximate $8,500 \mathrm{~L}(2,250 \mathrm{ga})$ hold up in the transfer pipeline system. This volume of material equates to approximately a $2 \mathrm{~cm}(0.8 \mathrm{in}$.) drop in the starting tank 241-AY-102 liquid level. The level in tank 241-C-106 is verified during sluicing by the absence of the submersible slurry pump level low-level alarm. which is interlocked to shutdown P-1361/P-1362 slurry pump system when activated.

Once campaign 1 is complete, sufficient cooling of the sludge should have occurred so liquid level limits for sludge temperature control purposes can be eliminated (Bander et al. 1996). Before removing the control requirement, tank 241-C-106 temperature readings will be collected during the monitoring period following both increments of campaign 1 to verify by thermal modeling that subcooled temperatures exist throughout the sludge regardless of the hydrostatic head of the liquid. Hot spots caused by sludge mounding during the sluicing are not anticipated. The supernatant layer maintained in the tank during the campaign and semi-automatic sweeping operation of the sluicer favor a more uniform retrieval.

Optimum Sluicing. After the minimum liquid cover/hydraulic head control requirement is eliminated, an increase in sluicing effectiveness is anticipated with a lower supernatant depth above the solids during subsequent sluicing batches. The operator lowers the liquid level and adjusts the position of the submersible slurry pump and sluice nozzle direction to achieve the specified retrieval conditions. Based on past practice sluicing experience, the maximum liquid level cover through which sluicing could be effectively achieved was 23 to $31 \mathrm{~cm}$ ( 9 to $12 \mathrm{in.).} \mathrm{Therefore,} \mathrm{the} \mathrm{tank}$ $241-C-106$ Tiquid level is adjusted to achieve a cover of $23 \mathrm{~cm}$ ( 9 in.) or less starting with sluice batch 2.1.1. The supernatant average depth can be determined from ENRAF ${ }^{T M}$ liquid level data and the estimated cumulative mass transferred during completed sluicing batches. When sluicing is conducted with little or no liquid cover, a minimum supernatant layer is reestablished before sluicing is shut down to provide the evaporative cooling needed for effective sludge cooling. The in-tank imaging system is used to determine when supernatant just covers the solids within the sluice zone.

Leak Prevention/Minimization. The liquid level in tank 241-C-106 is controlled during al1 phases of the WRSS process to minimize the potential for a tank leak. At all times during the process, controls will be implemented to maintain the liquid level below the maximum $2 \mathrm{~m}$ (79 in.) limit (LMHC 1997a).

During sluice batches, this limit is met by controlling the tank 241-AY-102 liquid level to a height of $\geq 18 \mathrm{~cm}$ ( $7 \mathrm{in}$.) below the level equal to the level. at sluicing startup (i.e., the level after the completion of all pre-sluicing operations) plus the volume (in.) of all water and chemical additions made to the WRSS since startup. The ENRAF ${ }^{T M}$ level gauge is operated during the monitoring periods to show compliance with the limit.

Again, after removing the minimum liquid cover/hydraulic head control requirement, the volume of liquid in tank 241-C-106 during the sluicing operations is controlled to mitigate any potential tank leaks. By maintaining the liquid level required for optimum sluicing, the height of liquid above any potential leak sites is reduced, thereby slowing any potential leaks which 
HNF-SD-WM-PCP-013 REV. 1

might occur during sluicing operations. This action also reduces the volume of liquid that could leak from the tank if a tank liner breach should occur.

\subsubsection{Sluice Nozzle Directional Control}

The sluicer mobilizes tank 241-C-106 sludge and directs the resulting slurry to the suction of the submersible slurry pump for transport through the slurry pipeline to the receiver tank. The tank wall adjacent to the submersible slurry pump is expected to be exposed because of the action of the sluice stream and the slurry flow into the pump intake.

To minimize the potential for damaging the tank liner during sluicing operations, the sluice nozzle will not be directed to the remaining tank wall until the end of the sluicing operations. Because sluicing the wall could cause a leak by breaching a weak point in the tank wal1, the sluice stream will not be directed closer than $1.5 \mathrm{~m}(5 \mathrm{ft})$ to the tank wall during most of the sluicing operation. Figure 4-4 shows a cross-section of the tank and the "no-sluice zone", which will be administratively controlled. After the sludge located in the center of the tank has been removed to the maximum extent practical, the $1.5 \mathrm{~m}$ ( $5 \mathrm{ft}$ ) no-sluice zone will be removed and the wall will be sluiced to complete the retrieval.

During the first sluice campaign, the sluicer will be controlled to minimize homogenizing the tank $241-C-106$ sludge. The purpose of this control is to prevent excavating a depression in the sludge near the center of the tank where sludge temperatures at the bottom are expected to be the maximum. Such an occurrence could cause a momentary reduction in the local saturation temperatures, thereby reducing the required subcooling margin. To minimize homogenizing the sludge, the sluicer will be operated in semi-automatic mode, which will sweep across the waste in a pattern similar to that reflected by Figure 4-4. The speed at which the sluicer sweeps the waste surface is set at $6{ }^{\circ}$ per second and is not readily adjustable. The procedure for controlling slurry concentration wi11 apply with the operator adjusting the sluicer tilt angle and sweep cycles to achieve the desired solids loading (i.e, an expected 0 to 10 weight percent solids concentration) in the slurry transfer pipeline. Because the goal is uniform retrieval, one constraint on the sluicer operation is to sweep the entire tank cross-section (except the no-sluice zone) during the pump run time.

Routine sluicing after the first sluice campaign is also conducted in semi-automatic mode similar to Figure 4-4 and results in a non-homogenizing sluice action. Periodically, the sluicer is set to the manual mode where the operator directs the nozzle to sluice a channel directly between the sluicer and submersible slurry pump. This channel serves as the flow path for transporting the sluiced waste towards the submersible slurry pump intake.

After completing the first campaign, one sluice batch may be conducted to homogenize the sludge layers. This homogenizing operation may be beneficial to more evenly distribute the heat generating material transferred to tank 241-AY-102. Sludge homogenization is achieved by operating the sluicer in manual mode and directing the sluice stream at a fixed location for an 
HNF-SD-WM-PCP-013 REV. 1

Figure 4-4. Tank 241-C-106 Sluice Nozzle Directional Control.

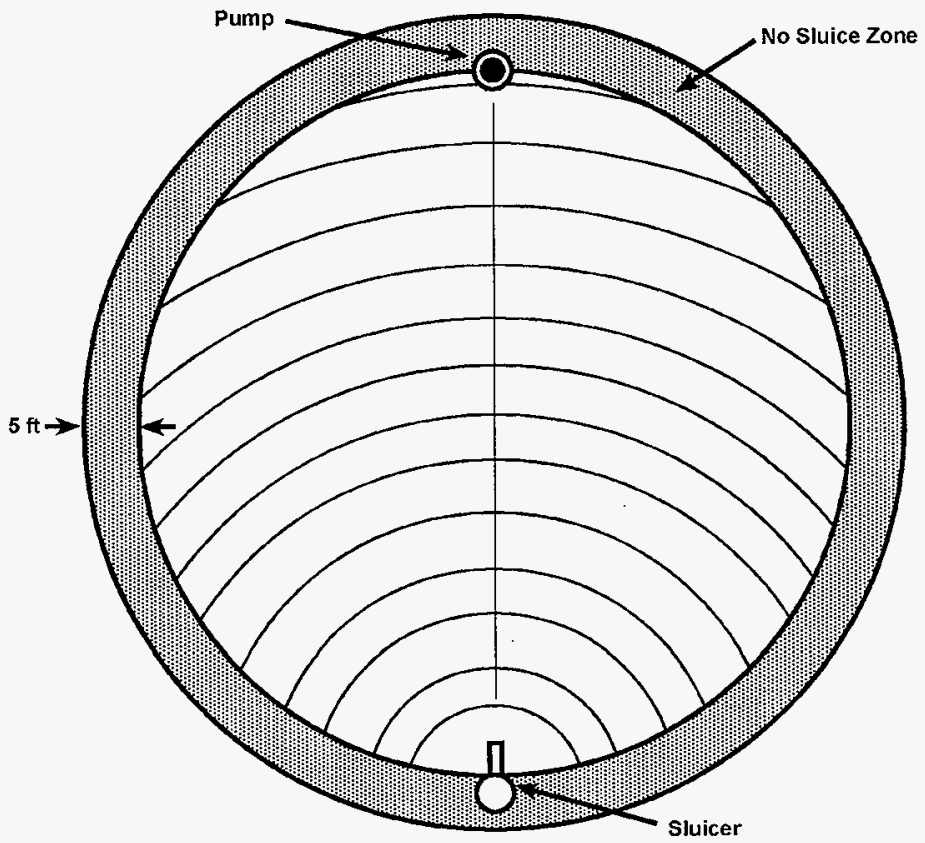

HG97110098.29 
extended period. This procedure allows for greater penetration of the sluice stream below the sludge surface, which causes localized mixing both axially and radially. The nozzle must be repositioned periadically to cover the waste surface in a grid-like fashion.

During all sluicing operations, the in-tank imaging system will be used to monitor the in-tank process to the extent possible, depending on fog removal capability of the ventilation system. The greatest benefit will occur after eliminating the minimum liquid level control limit and pumping the supernatant to expose the solids topography. Then the sluicing action can be observed directly. The subsequent sluicing recovery rate operating experience will be used to adjust the sluicer aiming plans to optimize the sludge recovery.

\subsubsection{Tank 241-C-106 Mass Transfer Control}

Section 4.1.1 described the process control of slurry solids concentration using the 241-AY-02A pit mass flowmeter. This same instrument is the principal means for controlling the amount of tank 241-C-106 sludge that is transferred to tank 241-AY-102 during sluice batches. The monitoring and controlling of sludge transferred during a sluice batch satisfies the conservative process control strategy for the WRSS process. By conducting the sluicing operation in batches, any one transfer batch or combination of batches is limited to no more than $124.900 \mathrm{~L}(33.000 \mathrm{ga}$ ) ) of sludge (a sluice increment). Following an increment, a tank thermal analysis is performed. Flammable gas evaluations are conducted after two sluice increments (a sluice campaign) have been retrieved.

However, at startup of sluicing operations, use of the mass flowmeter wil? not be relied upon for mass transfer control during the very first batch, even though it is expected to be fully operational to perform its intended function. This first batch basically provides the first opportunity to operate the equipment and control instrumentation in an integrated fashion and demonstrate that a17 components function as intended. Therefore, the first sluice batch (1.1.1) does not take credit for process control instrumentation to prevent the transfer of more than $0.61 \mathrm{~m}(2 \mathrm{ft})$ of sludge. Project thermal and flammable gas analyses have shown that $0.61 \mathrm{~m}$ ( $2 \mathrm{ft}$ ) of sludge can be received into tank 241-AY-102 safely even assuming the most pessimistic conditions (Ogden et a7. 1998 and Pasamehmetog 7u et a 1. 1997).

Mass transfer control during the first sluice batch will be achieved by establishing a maximum slurry pump system run time of $4-1 / 2$ hours. This onetime pump run time limit assures that the amount of tank $241-C-106$ sludge transferred during the first batch is limited to no more than $0.61 \mathrm{~m}$ ( $2 \mathrm{ft}$ ) of sludge even under worst-case conditions. These worst-case conditions assume pessimistic thermal parameters for the waste (Ogden et al. 1998). that both the mass flowneter and mag-flow meters on the transfer pipelines are not working, that the slurry and sluice pump systems unknowingly operate at maximum settings, and that a 30 wt\% solids slurry (7imiting transfer system solids concentration) is being pumped. At the maximum 3056 rpm 5 lurry booster pump setting, the flow rate for transfer of a $30 \mathrm{wt} \%$ solids slurry is approximately $1,740 \mathrm{~L} / \mathrm{min}$ (460 gpm) from the pump-systems curve (see Figure 4-3). The maximum speed of the sluice booster pump/submersible pump 
HNF-SD-WM-PCP-013 REV. 1

system will deliver approximately $1,530 \mathrm{~L} / \mathrm{min}$ (405 gpm) of solids free solution. Consequently, a sustainable transfer cannot be achieved under these conditions. The low-level limit switch on the submersible slurry pump, which is interlocked with the pumps. would actuate in roughly 100 minutes, after pumping the level in tank 241-C-106 down $5.0 \mathrm{~cm}$ (2 in.), and shut down the transfer after only roughly $0.25 \mathrm{~m}$ (10 in.) of sludge is retrieved.

Therefore, the assumption is made that the 241-AY Tank Farm operator in his attempt to control the liquid level in tank 241-AY-102 causes the slurry booster pump speed to be lowered thus balancing the flow rates between the tanks at $1,530 \mathrm{~L} / \mathrm{min}$ (405 gpm). This allows a sustainable transfer for the 4-1/2 hour maximum slurry pump system run time duration.

Once confidence in the process control instrumentation is gained (anticipated by the first batch but could extend into subsequent batches), the mass

flowmeter will provide control for the mass of solids transferred during sluice batches. The coriolis mass flowmeter is installed on the receiver tank end of the slurry transfer pipeline. The instrument measures the

instantaneous mass flow rate and slurry density during a sluicing batch. Data from the net flow computer coupled with the flowmeter allows the slurry solids loading to be determined based on a specified relationship between slurry density, carrier fluid density, and slurry solids particle density. By integrating the product of the slurry solids loading and slurry mass flow rate over time, the total mass of particulate solids transferred during sluicing can be calculated. This parameter is displayed for the current increment in the M0-211 control room and can be monitored to control sluicing to the mass transfer limit.

Section 4.1.1 described the relationship between slurry solids loading and input and measured variables: Once the carrier fluid density (ENRAF densitometer and grab samples) and slurry particulate density (see Table 3-4) are known, the mass flowmeter determines the solids loading in the slurry pipeline from real-time measurement of the slurry density. Figure 4-5 shows this relation for the WRSS process, given a solids density of $2.61 \mathrm{~g} / \mathrm{mL}$. At the start of sluicing, when the carrier fluid density is approximately $1.0 \mathrm{~g} / \mathrm{mL}$, the slurry density will range from $1.06 \mathrm{~g} / \mathrm{mL}$ to $1.126 \mathrm{~g} / \mathrm{mL}$ over the nominal sluicing operating range of 10 to 20 weight percent slurry solids loading. The supernatant density of tank 241-AY-102 is expected to range from $1.0 \mathrm{~g} / \mathrm{mL}$ to $1.043 \mathrm{~g} / \mathrm{mL}$ during the retrieval process. Therefore, over the course of the sluicing, the slurry density will vary from $1.06 \mathrm{~g} / \mathrm{mL}$ to $1.17 \mathrm{~g} / \mathrm{mL}$ for the nominal slurry solid loading range.

The slurry solids loading relationship also reflects its sensitivity to variations in the solids particulate density. Figure 4-6 plots the slurry solids loading as a function of slurry density. which is measured by the mass flowmeter, and solids particulate density for a carrier fluid density of $1.0 \mathrm{~g} / \mathrm{mL}$. For a constant slurry density within the nominal operating range. the slurry solids loading varies in direct proportion to changes in the solids particulate density. A 10 percent change in the solids particulate density results in an approximate 10 percent variation in slurry density. Therefore. obtaining an accurate measure of the carrier fluid density and slurry particulate density is important in obtaining an accurate measure of the slurry solids loading and total mass of solids transferred as determined from the mass flowmeter/net flow computer output. 
Figure 4-5. Slurry Solids Mass Fraction as Function of Slurry Density and Slurry Carrier Fluid Density for Solids Particulate Density of $2.61 \mathrm{~g} / \mathrm{mL}$.

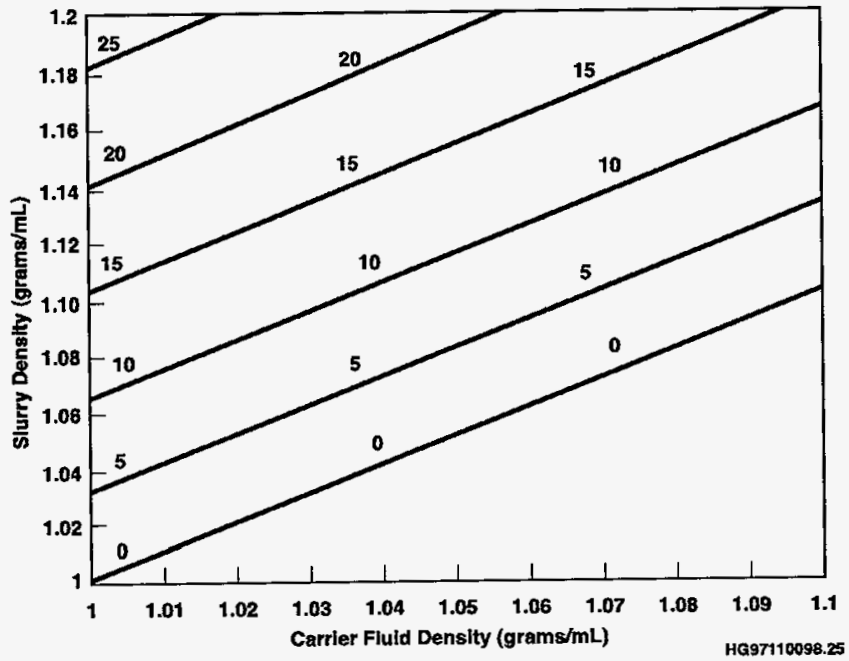


Figure 4-6. Slurry Solids Mass Fraction as Function of Slurry Density and Slurry Solids Particulate Density for Carrier Fluid

Density of $1.0 \mathrm{~g} / \mathrm{mL}$.

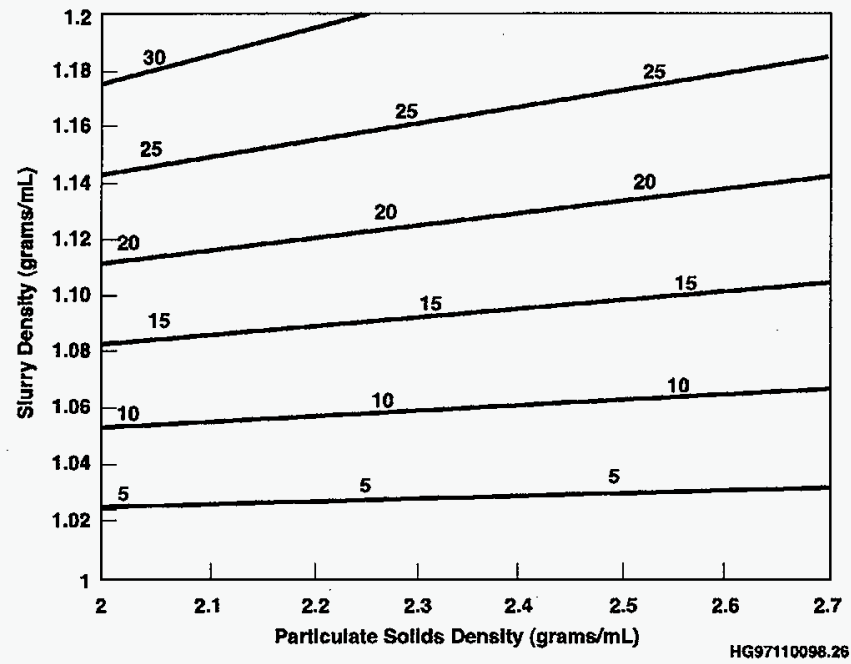


The uncertainty in the coriolis mass flowmeter to measure the slurry solids flowrate has been evaluated (see footnote 1). When the solids volume fraction in the slurry stream is $>10$ vol\%, the uncertainty in solids flow drops to less than 20 percent. Below 10 vol\% solids, the uncertainty increases substantially, indicating little confidence in the mass flowmeter to measure the solids transferred. Because of this large uncertainty at low solids loading, a limitation on the slurry pump system run time is required together with the mass transfer limit (determined from the mass flowmeter) to ensure that no more than $124,900 \mathrm{~L}(33,000$ gal) of tank $241-\mathrm{C}-106$ sludge is transferred into tank 241-AY-102 during the batches that make up a sluicing increment.

Except as noted above for the very first sluice batch (1.1.1), the duration of time to perform all subsequent sluicing batches is limited by two parameters:

(1) the total amount of sludge transferred as determined by the mass flowmeter, and (2) the slurry pump system run time based on mass flowmeter uncertainty. Based on the characterization of the tank 241-C-106 sludge (see Section 3. I and Reynolds [1997]), a $30.5 \mathrm{~cm}$ (1 ft) sluicing increment contains approximately $77,300 \mathrm{~kg}$ (170,000 1bs) of solids. A sluice batch time limit of 12 hours was determined from the uncertainties in waste characteristics and the measured accuracy of the coriolis mass flowmeter (see footnote 1). The following equation represents the primary process control relationship for the transfer of mass during all sluicing batches except for the very first batch.

$$
\theta=12\left[\frac{M_{p s}-\left(M_{\text {hold }}+M_{p l c}\right)}{M_{p s}}\right]
$$

where

$$
\begin{aligned}
& \theta=\text { Remaining pump run time during a batch transfer (hours) } \\
& M_{\text {plc }}=\text { Total mass of tank } 241-C-106 \text { particulate solids transferred } \\
& M_{p s}=\text { Mass of particulate solids contained in one sluicing increment } \\
& \text { (i.e., } 77,300 \mathrm{~kg}[170,000 \mathrm{lbs}] \text { ). } \\
& M_{\text {hold }}=\text { Sum of the total mass of tank 241-C-106 particulate solids } \\
& \text { transferred in all preceding batches of the current sluicing } \\
& \text { increment. Mold is set to zero for the first batch in any } \\
& \text { given sluicing increment. }
\end{aligned}
$$

The interpretation of the time limit is that solid particles could be transferred at a rate equal to $30.5 \mathrm{~cm}$ ( $1 \mathrm{ft}$ ) of tank $241-\mathrm{C}-106$ sludge in 12 hours at 95 percent confidence even if the mass flowmeter indicated no solids were being transferred. Any indication of particulate solids transfer then reduces the remaining allowed pump run time proportional to the ratio of the measured particulate solids transfer $\left(M_{\text {hold }}+M_{\text {plc }}\right)$ to the particulate solids transfer limit $\left(M_{p s}\right)$. The mass flowmeter programmable logic controller is 
located in the 241-AY-801A building. The M0-211 control room provides a direct readout of remaining pump run time during a sluice batch based on the above algorithm.

The mass of particulate solids transferred during the current batch $\left(M_{\text {plc }}\right)$ will be overestimated by $<6$ percent (see footnote 1 ). Some very fine solid particles will almost certainly be returned to tank $241-C-106$ as the sluicing fluid recirculates. Settling rate studies found that approximately three days are required before a solid-liquid interface forms. However, any fine particles that remain suspended during a sluice batch will be at low solids concentration because of the large dilution resulting from the initial supernatant volume. The 6 percent value was determined by assuming the entire first $2 \mathrm{ft}$ of sludge was suspended in the tank 241-AY-102 supernatant and that 12 in. of the recirculated sluice fluid remained in the tank 241-C-106 and the solids allowed to settle after completing a batch.

After the pump run time limit is reached (12 hours or less), the slurry pump system must be shut down. As indicated in Section 4.1.1, the shutdown procedure begins a minimum of 15 minutes before the scheduled pump shutdown to allow time for performing a solution flush of the slurry pipeline.

Thereafter, sluice batches are repeated following the specified monitoring periods until approximately $30.5 \mathrm{~cm}$ (1 ft) of tank $241-\mathrm{C}-106$ sludge is determined to have been retrieved. Provided a measurable solids transfer was made during the previous batch, the next batch in the current $30.5 \mathrm{~cm}$ ( $1 \mathrm{ft}$ ) sludge retrieval increment will have a shorter pump run time because of the reduction in the amount of solids transfer needed to effect the retrieval of the desired sludge volume increment ( $i . e$. , as the value of $M_{\text {hold }}$ increases, the fractional pump run time represented by the brackets in the above equation decreases).

\subsubsection{Transfer Pipeline Flushing Control}

Process supernatant flushing of the slurry pipeline is done routinely to prevent the buildup of solids in the slurry line. In addition, if a beginning solids buildup is identified during process monitoring, one of following two flushing operations would be undertaken to correct the problem.

Routine Process Solution Flushing. During routine sluicing operations, the procedure for flushing the transfer pipeline (see section 4.1.1) is followed at system shutdown. However, if the slurry pump system shuts down unexpectedly, flushing with process solution is not possible. In this event. the pump system is restarted, generally within eight hours, then the transfer system is flushed as stated in Section 4.1.1

Water Flushing. Water flushes have three uses: 1) to prevent the potential buildup of unacceptable flammable gas concentrations in the transfer pipeline during sluicing shutdown periods, 2) to reduce personnel exposure control when jumper change operations are planned, and 3) to remove solids buildups in the transfer pipeline if process data indicate the onset of a solids plug and the routine process solution flush is not possible (e.g. . the sluice pump system 
becomes inoperative and the liquid level cover is too shallow for a low solids flush solution using the routine procedure).

Both the sluice and slurry transfer lines can be water-flushed from the tank 241-AY-102 end using flush connections in the sluicing system jumpers, located in the 241-AY-02A (slurry distributor) pit and 241-AY-02E (sluice pump) pit. Cover block shielding plugs are first removed from the AY Farm pit cover blocks enabling access to the flushing port blank. The blank is removed and a flushing adapter jumper is attached in its place. Water from a tank truck is pumped through the transfer line to achieve the required flush. A minimum of one-and-a-half pipeline volumes is required to flush each transfer pipeline. This volume equates to $6,400 \mathrm{~L}(1,690 \mathrm{ga} 1)$ for each of the SN100 and SN200 transfer pipelines for a total of $12,800 \mathrm{~L}(3,380 \mathrm{gaT})$.

Because of the significant volume added to the WRSS system, water flushes are to be used judiciously. Normally, water flushing should not be required unless the shutdown duration is known to exceed two weeks (e.g. . at the conclusion of a sluicing campaign). A conservative hazards analysis indicates that a flammable concentration of gas will accumulate in the slurry transfer pipeline in 28 days assuming the pipeline is plugged with waste (Pasamehmetoglu et al. 1997).

\subsection{TANK 241-AY-102 MASS TRANSFER VERIFICATION CONTROL}

Upon the completion of each batch, monitoring takes place and verification requirements are met before the next sluice batch is performed. As shown by Figure 4-1, the performance of the slurry pipeline mass flowmeter is verified and an estimate of the heat load in the transferred waste is determined after every batch. whether or not the batch corresponds to the completion of an increment or campaign. The primary focus of this post-batch evaluation is to obtain an independent measure of the mass and volume of sludge received by tank 241-AY-102 during the batch. The primary mass transfer verification method uses the ENRAF ${ }^{T M}$ densitometer installed on riser $15-E$ of tank 241-AY-102. Grab samples taken from riser 15-N supplement the ENRAF ${ }^{\text {IM }}$ resuits. Additionally, the MIT will be monitored to provide supporting evidence of the liquid-solid interface.

The monitoring period between batches is a minimum of three days after each batch; the nominal duration varies from five to twelve days. The minimum duration is based on the solid-settling rate data from Reynolds (1997). A distinct supernatant-sludge interface is expected to form during the initial three-day settling period. Follow-on measurements with the ENRAF ${ }^{M}$ densitometer and the MIT, and data evaluation extend the monitoring an additional one or two days. Concurrent grab sampling and analysis and a Technical Review Group review and concurrence of subsequent sluicing plans will extend for nine days early on in the sluicing (i.e., sluice batches making up the first increment). As sluicing becomes more routine, the need for confirmatory grab sample results before restarting sluicing and the frequency of TRG reviews are anticipated to diminish. However, confirmatory grab sample results and a TRG review are required between campaigns. 
HNF -SD -WM-PCP-013 REV. 1

The ENRAF ${ }^{T M}$ densitometer in tank $241-A Y-102$ is used to obtain two key pieces of information: the density profile of the waste below the supernatant surface and the level of the supernatant-sludge interface. In addition to obtaining a measure of the clarified supernatant density immediately below the supernatant surface, the density in the settling solids region will be measured until the sludge mechanical strength prohibits further displacer descent (i.e., when neutral buoyancy is reached). For supernatant-solids interface level measurements, the wire tension setting will be maximized to enhance gauge performance and guard against excavating a depression in the solids bed, which would compromise the accuracy of the interface measurement.

The uncertainty in the ENRAF ${ }^{\text {TM }}$ densitometer's ability to measure the sludge transferred from tank 241-C-106 based on measurement taken in tank 241-AY-102 after the transfer has been evaluated (see footnote 1 ). When the solids settling fraction in tank 241-AY-102 is <20 percent, the uncertainty in the sludge transferred remains below 20 percent even with significant nonuniformity in the settled solids level. For intermediate settling fractions and nonuniformity fractions, the uncertainty generally falls below 30 percent. Therefore, the best results are obtained if the densitometer measurement is made immediately after completing each batch when the highest possible fraction of solids is still suspended.

Grab samples are obtained from the tank to refine the estimated amount of tank 241-C-106 sludge that has been transferred and to estimate the radiogenic heat associated with the sludge. Section 4.6 discusses the process control sampling requirements and schedule in more detail.

The MIT provides a second measurement of the supernatant-sludge interface in tank 241-AY-102. In addition to the stationary thermocouples that measure temperature at 22 elevations, the MIT is equipped with a validation temperature probe that can be positioned at any elevation. Establishing the initial stages of a parabolic temperature profile that identifies the nonconvective layer will require at least a few weeks once sluicing starts. The MIT provides a vertical temperature profile through the waste. The approximate elevation of the interface is determined by monitoring fixed thermocouples to detect the different temperature profiles between the solid and liquid phases. Monitoring the temperatures between fixed thermocouples using the validation probe enables a more accurate identification of the interface elevation using changes in the slope of the temperature profile data. Even so, the layer depth cannot be determined with sufficient precision from the temperature profile to quantify a small volume of solids transfer (Stewart et a1. 1998).

Table 4-2 lists the parameters to be monitored and the monitoring frequency used in the post-batch monitoring period. The listed monitoring requirements may be reduced after operating experience identifies the actua 7 accuracies achieved and demonstrates the best instrumentation combination for mass transfer control.

A density profile of tank 241-AY-102 is obtained with a lap-top computer that connects to the Communication Interface Unit (CIU) located in the 241-AY-801 bujlding. The CIU communicates with the ENRAF ${ }^{T M}$ densitometer installed on the 
Table 4-2. Monitoring Frequency for Tank 241-AY-102 Mass Transfer Verification.

\begin{tabular}{|c|c|c|}
\hline 19: Parameler: & NInswrumert: & Hortitor ng F requency \\
\hline Density profile & ENRAF ${ }^{\mathrm{TM}}$ densitometer & $\begin{array}{l}\text { Immediately following batch } \\
\text { shutdown (within } 2 \text { hours) } \\
\text { Once per shift ( } 6 \text { to } 10 \text { hours) } \\
\text { thereafter for three days }\end{array}$ \\
\hline \multirow[t]{2}{*}{$\begin{array}{l}\text { Supernatant-sludge } \\
\text { interface }\end{array}$} & $\begin{array}{l}\text { ENRAF }^{\mathrm{TM}} \text { densitometer, } \\
\text { MIT fixed elements }\end{array}$ & $\begin{array}{l}\text { Once a day (excluding weekends and } \\
\text { holidays) after the three-day } \\
\text { initial settling period until } \\
\text { sluicing restarts (frequency may } \\
\text { be relaxed as confidence is gained } \\
\text { in determining mass transferred) }\end{array}$ \\
\hline & MIT validation probe & $\begin{array}{l}\text { One full profile of the waste } \\
\text { ( } 4 \text { in. intervals) after the three } \\
\text { day initial settling period. One } \\
\text { ful p profile per week thereafter } \\
\text { until sluicing restarts with a } \\
\text { minimum of one profile before the } \\
\text { start of the next batch. }\end{array}$ \\
\hline $\begin{array}{l}\text { Slurry physical, } \\
\text { chemical, and } \\
\text { radionuclide } \\
\text { properties }\end{array}$ & Grab sampling device & $\begin{array}{l}\text { Per Table } 4-12 \text { after the three-day } \\
\text { initial settling period (this may } \\
\text { be relaxed as confidence is gained } \\
\text { in the ENRAF }{ }^{\text {TM }} \text { densitometer } \\
\text { method) }\end{array}$ \\
\hline
\end{tabular}

tank. Using the portable computer, the operator enters commands to lower the displacer into the waste to obtain a density profile. This computer algorithm controls the measurement process unt $i$ the displacer reaches a neutral buoyancy (as perceived by the gauge) and stops descending further into the tank. The ENRAF ${ }^{T M}$ densitometer functions by measuring the weight of the submerged displacer, with a known volume and mass, in tank 241-AY-102 waste. A programming option for measuring the solids-liquid interface is also provided.

In generating a density profile, density measurements are made in $30.5 \mathrm{~cm}$ (12 in.) increments referenced to an elevation of $193.87 \mathrm{~m}(636.07 \mathrm{ft})$ or $3.96 \mathrm{~m}$ (156 in.) above the tank bottom. Therefore, at the start of sluicing when the waste level is targeted for $4.3 \mathrm{~m}$ (168 in.), the first density measurement wi11 be made $30.5 \mathrm{~cm}$ (12 in.) below the supernatant surface. During sluice campaign 1, the waste level in tank 241-AY-102 wil1 be kept constant during batches. After the first sluicing batch of the campaign. density profile measurements will start at the $3.96 \mathrm{~m}$ (156 in.) waste level and descend in $30.5 \mathrm{~cm}$ (12 in.) increments until neutral buoyancy is achieved. When the tank 241-AY-102 waste level begins to increase during subsequent batches, the starting elevation for the density profile measurements indexes 
HNF-SO-WM-PCP-013 REV. 1

in $30.5 \mathrm{~cm}$ (12 in.) increments. The number of ascending increments depends on the new supernatant surface elevation. However, no density measurement is to be made at less than $15.2 \mathrm{~cm}$ ( 6 in.) below the waste surface to ensure total submergence of the ENRAF ${ }^{\mathrm{TM}}$ displacer. This procedure results in all density profile measurements being made at the same position in the tank during every post-batch monitoring period. Obtaining density measurements at fixed locations in the tank enables direct comparisons between batches to be made.

Because a clarified supernatant will form in the upper regions of the waste following shutdown of sluicing operations. ENRAF ${ }^{T M}$ density profiles are a means of monitoring changes in the supernatant density as the retrieval progresses. Using this change of supernatant density with time, the density versus depth profiles from one measurement to another can be compared. Knowing the density of the particulate solids (assumed or measured from grab samples), a graphical integration of the density versus depth (i.e.. volume) can be performed to determine the mass contained within the waste volume not attributed to the supernatant. This mass represents an estimate of the particulate solids that were transferred to tank 241-AY-102 during the preceding sluice batch.

To estimate the radiogenic heat load of the completed batch, the estimated mass transfer result is used together with the radionuclide concentrations in the solids obtained from grab sample analysis. The heat load estimates may provide a measure of the heat load distribution in the sluiced tank 241-C-106 waste. If waste stratification occurs. then waste homogenization operations can be performed in tank 241-C-106 to more uniformly distribute the heat load.

Coriolis mass flowmeter and the ENRAF' densitometer/grab sample data are independent measures of the mass of solids transferred to tank 241-AY-102 during the preceding sluicing batch. During the first campaign, when sluicing will be done through 5 to $12 \mathrm{in}$. of liquid, the solids loading is expected to be less than $10 \mathrm{wt} \%$ (equivalent to 4 vol\%). Consequently, the coriolis flowmeter, which has an uncertainty of 40 to 50 percent at this solids concentration, should not be used for the primary mass transfer measurement during the first campaign or when solids loading of a batch averages <10 vol\% (see footnote 1). During later stages of sluicing when the batch solids loading is expected to range from 10 to 20 wt $(4$ to 10 vol\%), the mass flowmeter uncertainty wi1l still remain relatively high between 10 to 40 percent. Therefore, the primary measurement method for determining mass transfer for each sluicing batch will be the ENRAF ${ }^{\mathrm{TM}}$ densitometer. The mass flowmeter will provide backup measurement in case substantial solids settling occurs before ENRAF ${ }^{\text {TM }}$ measurements can be made or in case of densitometer instrument problems.

Once the mass transfer has been determined, planning can begin for the next batch. Depending on the efficiency of the preceding batch in removing sludge from tank 241-C-106, four outcomes are possible:

1. Retrieval of a sluicing increment is achieved. Further evaluations are conducted according to Figure 4-1 depending on whether the increment also completes a sluicing campaign (see Sections 4.3 and 4.4). 
2. Sluicing efficiency was unacceptably low. To improve the efficiency of subsequent batches, the supernatant level in tank 241-C-106 is lowered, if this is possible given thermal-hydraulic constraints. If the minimum surface level limit is in effect, the requirements of Section 4.3 must be met to determine the minimum liquid level that is allowable in order to preclude exceeding local saturation temperatures in the sludge. Otherwise the liquid level can be adjusted to optimize the effectiveness of the sluice stream to achieve the desired slurry solids loading.

3. Sluicing efficiency was acceptable. Therefore, the subsequent sluicing batch would maintain the same supernatant level in the tank.

4. Al1 sluicable solids retrieved from tank $241-C-106$ satisfied the success criteria. Therefore, long-term monitoring of tank 241-AY-102 thermal and flammable gas conditions would be continued according to requirements in Sections 4.3 and 4.4 .

Before the next sluicing batch is started, the value of $M_{\text {hold }}$ is set equal to either the mass of particulate solids transferred during the current sluicing increment or zero (0) for the start of the new increment. The net particulate solids mass reading $\left(M_{\text {plc }}\right.$ ) on the mass flowmeter net flow computer is also reset to zero $(0)$ at the beginning of every batch.

\subsection{WASTE TEMPERATURE CONTROL}

The sluice batch-increment-campaign process control strategy is based primarily on thermal considerations in both tank 241-C-106 and tank 241-AY-102. The conclusions of the WRSS thermal evaluation (Odgden et a1. 1998) for the case of no loss of evaporation are as follows.

- Adequate subcooling can be maintained in tank 241-C-106 with both pre-sluice chiliing of the waste and incremental sluicing followed by monitoring periods for subsequent cooling before reducing the hydrostatic head in the tank.

- Incremental sluicing with real-time mass transfer monitoring and control wil 7 limit the thermal response of tank 24l-AY-102 during the course of tank 241-C-106 retrieval operations.

- The minimum WRSS objective of retrieving $0.6 \mathrm{~m}(2 \mathrm{ft})$ of waste from tank 241-C-106 does not require operation of the tank 241-AY-102 annulus ventilation system assuming best-estimate thermal parameters.

- Blocking tank 241-AY-102 wall annulus flow and operating the secondary ventilation system at high annulus vacuum to achieve between 1.000 to $1.300 \mathrm{cfm}$ floor channel flow provides a margin for waste transfers beyond the first $0.6 \mathrm{~m}(2 \mathrm{ft})$. Depending on the tank thermal behavior following the transfer of each sluicing increment. additional secondary ventilation system modifications 


$$
\text { HNF-SD-WM-PCP-013 REV. } 1
$$

(air inlet blower and/or chiller) may be implemented to achieve complete retrieva 1 of the tank 241-C-106 high-heat sludge.

- By monitoring and evaluating data with a transient thermal analyses, the steady-state temperatures of the waste accumulated in tank 241-AY-102 during the retrieval of tank 241-C-106 sludge can be predicted. Based on this prediction, sluicing can proceed without delays required to reach thermal equilibrium.

The loss of evaporation in tank 241-AY-102 caused by separation of an organic component during sluicing results in waste temperatures which exceed the local saturation temperture for 1) full waste transfer and al1 practicable annulus ventilation flows and 2) a two foot transfer of waste and not annulus flow (Ogden et al. 1998). Annulus ventilation completely mitigates loss of evaporation for the two foot transfer. However, forming a separable organic layer is not expected to occur in either tank 241-AY-102 or 241-C-106 (see Section 4.5.4)

This section presents the process control logic and the data evaluation associated with the waste temperature response of both tanks 241-C-106 and 241-AY-102 during the WRSS process. Included is the establishment of a pre-sluicing baseline for the tanks, the post-sluicing assessments, and decision logic for any mitigative action. This section implements the controls of Tank Waste Remediation System Basis for Interim Operations, Addendum 1. Section 3.4.2.11. Tank Bump and Section 3.4.2.12, Liner Breach Caused by Steam Between the Steel Liner and Concrete Shelf in Tank 241-C-106 (FDH 1998a).

\subsubsection{Tank 241-C-106 Sludge Temperature Control}

The temperatures of the sludge in tank 241-C-106 must be controlled during the early stages of the WRSS process to prevent the potential occurrence of a tank bump caused by the generation and global release of steam from the waste near the tank bottom. The steam void fraction at the tank bottom has been shown to increase significantly as the local waste temperature approaches the saturation temperature (Bander et a1. 1996). Figure 4-7 presents the relationship between the saturation pressure and temperature for the tank 241-C-106 waste based on 15 percent vapor pressure suppression of pure water (Bander et a 1. 1996). Table 4-3 gives the pressure and corresponding saturation temperature of the waste as a function of depth in the tank based on the Figure 4-7 relationship and the Section 3.1 waste characteristics. The controls specified below for the different phases of the waste retrieval process will keep the sludge temperature less than the saturation temperature corresponding to the local hydrostatic head (pressure) in the tank.

All operable thermocouples on the thermocouple trees installed in risers 8 and 14 of tank 241-C-106 are monitored on a continuous basis to determine the waste temperature response during a 11 phases of the retrieval process. The minimum number of operable tank 241-C-106 thermocouples required for the WRSS process is one bottom thermocouple on either the riser 8 or riser 14 thermocouple tree and one dome space thermocouple. Thermocouple number 
HNF-SD-WM-PCP-013 REV. 1

Figure 4-7. Saturation Pressure and Temperature.

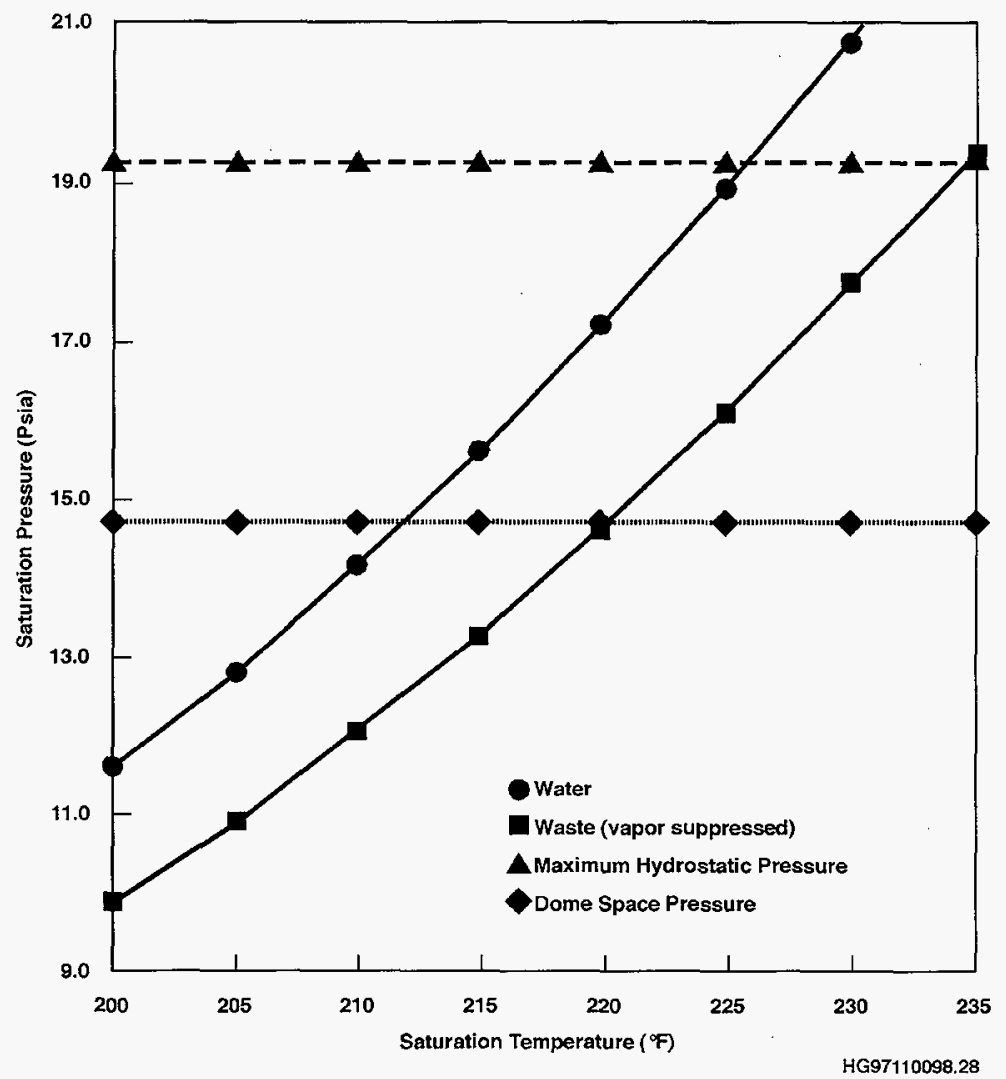


Table 4-3. Pressures and Waste Saturation Temperatures at various Waste Depths in Tank 241-C-106.

\begin{tabular}{|c|c|c|c|c|}
\hline $\begin{array}{l}\text { Siuter: } \\
\text { increment } \\
\text { Ninger: }\end{array}$ & $\begin{array}{l}\text { Whse herght by } \\
\text { STuge, nerents. }\end{array}$ & 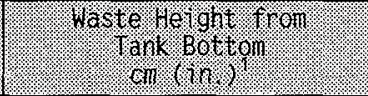 & 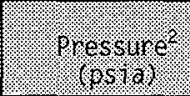 & 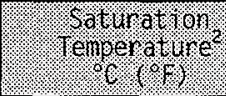 \\
\hline & & 213 (84) (liquid surface) & 14.7 & $104.4(220)$ \\
\hline \multirow[t]{2}{*}{1.1} & 201 (79) (s7udge surface) & & 14.9 & $105 \quad(221)$ \\
\hline & & $183(72)$ & 15.3 & $105.6(222)$ \\
\hline \multirow[t]{2}{*}{1.2} & $170(67)$ & & 15.6 & $106.1(223)$ \\
\hline & & $152(60)$ & 15.9 & $106.7(224)$ \\
\hline \multirow[t]{2}{*}{2.1} & $140(55)$ & & 16.2 & $107.2(225)$ \\
\hline & & $122(48)$ & 16.6 & $108.3(227)$ \\
\hline \multirow[t]{2}{*}{2.2} & $109(43)$ & & 16.9 & $108.9(228)$ \\
\hline & & $91(36)$ & 17.3 & $109.4(229)$ \\
\hline \multirow[t]{2}{*}{3.1} & $79(31)$ & & 17.6 & $110 \quad(230)$ \\
\hline & & $61 .(24)$ & 18.0 & $110.6(231)$ \\
\hline \multirow[t]{4}{*}{3.2} & $48(19)$ & & 18.2 & $111.1(232)$ \\
\hline & & 30 (12)( liquid level ref.) & 18.6 & $111.7(233)$ \\
\hline & $18(7)$ & & 18.9 & $112.2(234)$ \\
\hline & & 0 (tank middle bottom) & $19 . \overline{3}$ & $112.8(235)$ \\
\hline
\end{tabular}

Notes:

${ }^{1}$ Assumes a $13 \mathrm{~cm}(5 \mathrm{in.})$ supernatant depth, which corresponds to the $183 \mathrm{~cm}(72 \mathrm{in.}$ ) sluicing start up waste level of Section 3.2.4.

2values given for tank waste inventory before sluicing startup. 
HNF-SD-WM-PCP-013 REV. 1

TE-13620 up stream of the HX-1361 condenser in the 296-C-006 ventilation system ducting can serve to monitor the dome space temperature if none of the in-tank dome space thermocouples are operable.

\subsubsection{Sludge Pre-Sluicing Temperature Baseline: The pre-sluicing waste} temperature baseline for tank 241-C-106 is included in Section 3.2.2.2. This baseline is initiated following the start of tank 241-C-106 waste subcooling operations and continues concurrent with the cooling operation until the start of sluicing. The purpose of the waste cooling operation is to maximize the difference between the waste saturation (boiling) temperature at the tank bottom and the actual waste temperature (i.e.. achieve maximum waste subcooling) before beginning active sluicing. The 2.2 to $3.3^{\circ} \mathrm{C}\left(4\right.$ to $5^{\circ} \mathrm{F}$ ) tank 241-C-106 waste subcooling assumed in WRSS thermal analyses (Bander et a1. 1996; Sathyanarayana 1997 a and 1997b) must be maintained at all times during subsequent sluicing operations by adhering to the specified process control strategy.

Before starting sluicing operations, waste temperatures measured by thermocouple trees 8 and 14 must be reduced and maintained below the Limiting Control Setting 3.3 .1 of $\leq 96{ }^{\circ} \mathrm{C}$ (205 ${ }^{\circ} \mathrm{F}$ ) (FDH 1998b). The newer restrictive limit of Administrative Control 5.26 requires waste temperatures to be at wintertime temperature, thermocouple 1 on riser 8 thermocouple tree $\leq 64{ }^{\circ} \mathrm{C}$ (148 $\left.{ }^{\circ} \mathrm{F}\right)$.

4.3.1.2 Sludge Temperature Control During Sluicing Operations. During the Sluice Campaign 1 batches, local waste temperatures are maintained below corresponding saturation temperatures by controlling the liquid level in tank 241-C-106 as described in the procedure presented in Section 4.1.2. Bander et al. (1996) concluded that the liquid level control requirement in the tank is expected to be eliminated once the initial campaign is completed, thus allowing sluicing to continue at optimal efficiencies.

Table 4-4 presents the in-tank thermocouples that will be monitored during all sluice batches of the WRSS process and the waste temperature limits that apply for the batches making up each of the planned sluice increments.

These temperature limits assume liquid level will be the primary determining factor of the waste saturation temperature during the first campaign. The minimum liquid level limits that apply during this period will reduce the effectiveness of the sluice stream in excavating solids. Also, sluicing procedures will be designed to operate in a manner that will evenly retrieve the sludge during the campaign. Uneven sludge removal to the degree that could affect localized sludge temperatures is not anticipated.

The temperature limits of Table 4-4 were taken from Table 4-3. For every $0.3 \mathrm{~m}$ ( $1 \mathrm{ft}$ ) increment retrieved from tank 241-C-106, the pressure at the tank bottom is reduced by the hydraulic head equivalent of $0.3 \mathrm{~m}(1 \mathrm{ft})$ of sludge ( $\rho \mathrm{gh} / \mathrm{g}_{\mathrm{c}}$, where $\rho$ is the sludge bulk density, $h$ is the height of waste, $g$ is the gravitational constant. and $g_{c}$ is Newton's conversion constant). The pressure and saturation temperature at the tank bottom prior to initiating retrieval of each sluice increment is obtained by reading the corresponding values beginning with the last entry from the third column of Table 4-3 10 in. 
Table 4-4. Tank 241-C-106 Waste Temperature Limits During Sluice Increments.

\begin{tabular}{|c|c|c|c|c|c|c|c|}
\hline \multirow{2}{*}{$y^{4}$} & \multirow{2}{*}{ 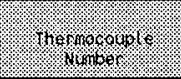 } & \multicolumn{6}{|c|}{ \%. } \\
\hline & & (3. & (2) & 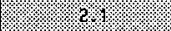 & (2. & $3.1 \%:$ & 82 \\
\hline \multirow[t]{5}{*}{ Riser 8} & 1 & $103^{\circ} \mathrm{C}\left(218^{\circ} \mathrm{F}\right)$ & $102 \cdot{ }^{\circ} \mathrm{C}\left(216^{\circ} \mathrm{F}\right)$ & $101^{\circ} \mathrm{C}\left(214^{\circ} \mathrm{F}\right)$ & $100^{\circ} \mathrm{C}\left(212^{\circ} \mathrm{F}\right)$ & $98^{\circ} \mathrm{C}\left(209^{\circ} \mathrm{F}\right)$ & $97^{\circ} \mathrm{C}\left(207^{\circ} \mathrm{F}\right)$ \\
\hline & 2 & $101^{\circ} \mathrm{C}\left(214^{\circ} \mathrm{F}\right)$ & $100^{\circ} \mathrm{C}\left(212{ }^{\circ} \mathrm{F}\right)$ & $78^{\circ} \mathrm{C}\left(207^{\circ} \mathrm{F}\right)$ & $97^{\circ} \mathrm{C}\left(207^{\circ} \mathrm{F}\right)$ & - & - \\
\hline & 3 & $78^{\circ} \mathrm{C}\left(209^{\circ} \mathrm{F}\right)$ & $97^{\circ} \mathrm{C}\left(207^{\circ} \mathrm{F}\right)$ & - & - & - & - \\
\hline & 4 & - & - & - & - & - & - \\
\hline & 5 & - & - & - & - & - & - \\
\hline \multirow[t]{5}{*}{ Riser 14} & 1 & $103^{\circ} \mathrm{C}\left(218^{\circ} \mathrm{F}\right)$ & $102{ }^{\circ} \mathrm{C}\left(216^{\circ} \mathrm{F}\right)$ & $101^{\circ} \mathrm{C}\left(214^{\circ} \mathrm{F}\right)$ & $100^{\circ} \mathrm{C}\left(212^{\circ} \mathrm{F}\right)$ & $98^{\circ} \mathrm{C}\left(209^{\circ} \mathrm{F}\right)$ & $97^{\circ} \mathrm{C}\left(207^{\circ} \mathrm{F}\right)$ \\
\hline & 2 & $101^{\circ} \mathrm{C}\left(214^{\circ} \mathrm{F}\right)$ & $100^{\circ} \mathrm{C}\left(212^{\circ} \mathrm{F}\right)$ & $98^{\circ} \mathrm{C}\left(209^{\circ} \mathrm{F}\right)$ & $97^{\circ} \mathrm{C}\left(207^{\circ} \mathrm{F}\right)$ & - & - \\
\hline & 3 & $98^{\circ} \mathrm{C}\left(209^{\circ} \mathrm{F}\right)$ & $97^{\circ} \mathrm{C}\left(207^{\circ} \mathrm{F}\right)$ & - & - & - & - \\
\hline & 4 & - & - & - & - & - & - \\
\hline & 5 & - & - & - & - & - & - \\
\hline
\end{tabular}

Note:

Temperature limits assume that a $13 \mathrm{~cm}(5 \mathrm{in}$.) supernatant depth is maintained throughout the sluicing operations and that sludge is removed evenly over the cross section of the tank during sluicing increments. 
waste height from tank bottom for sluice increment 1.1) and stepping up to the preceding entry for each succeeding sluice increment. The waste temperature limits of Table $4-4$ provide a $8.3^{\circ} \mathrm{C}\left(15^{\circ} \mathrm{F}\right)$ safety margin to the actual saturation temperature to account for instrument and calibration accuracies and to allow time to detect and respond to an off-normal temperature increase.

The safety margin is the same as that established in the basis for LCS/LCO 3.3.1 (FDH 1998b). Tables 4-3 and 4-4 implement the waste temperature controls of AC 5.26. "Tank 241-C-106 Waste Temperature Controls," of the Tank Waste Remediation System (TWRS) technical safety requirements (TSRS) (FDH 1998b) The LCS/LCO 3.3.1 temperature 7 imit of $596^{\circ} \mathrm{C}$ (205 ${ }^{\circ} \mathrm{F}$ ) is not applicable once sluicing starts.

If any of the temperature limits of Table 4-4 are exceeded, a 11 transfers and activities affecting tank 241-C-106 are to be stopped and the cover blocks are to be verified installed on the pits. The 296-C-006 ventilation system will be operating because its operation is required when conducting sluicing operations. A recovery plan is to be prepared. approved and implemented immediately to restore the waste temperatures to within limits. Recovery actions may include increasing the depth of the supernatant to increase the hydraulic head at the tank bottom, which will increase the saturation temperature, or start up the 296-P-16 ventilation system and inlet air chilling system to enhance waste cooling. Sluicing operations shall not restart until thermal analysis has been conducted to show that the pre-sluicing subcooling margin has been restored.

\subsubsection{STudge Temperature Control During Monitoring Periods. The tank} 241-C-106 in-tank thermocouples will continue to be monitored and recorded during monitoring periods following each sluice batch. The control limits are the same as those of Table 4-4. If any of the temperature limits are exceeded, the recovery is the same as that presented for sludge temperature control during sluicing operations (see Section 4.3.1.2).

Also, the tank 241-C-106 liquid level will be maintained to comply with applicable limits during the monitoring periods. Removing waste from tank 241-C-106 has three effects; reducing the heat load remaining in the tank, reducing the conduction length over which heat transfer must occur, and lowering the pressure exerted on any point in the remaining waste. Waste temperatures in the tank will decrease with time as heat-generating material is transferred to tank 241-AY-102 and as layers of insulating sludge are removed. However, waste removal immediately reduces the pressures throughout the waste depth, which causes the local saturation temperatures to drop abruptly. Initially, when the sludge is the hottest, this reduced saturation temperature can approach more closely the current temperature of the waste and could lead to formation of a significant steam void fraction near the tank bottom. During the early phases of the retrieval process, this potential loss of subcooling margin is prevented by controlling the liquid level.

From the standpoint of tank 241-C-106 sludge temperature control, the monitoring periods serve two purposes; 1) to allow time for sludge cooling. and 2) to determine the liquid level control limit for the subsequent sluice batch. The monitoring periods following each sluice batch allow time for the tank 241-C-106 sludge to cool as a result of the reduced heat load and 
conduction length achieved during the preceding batches. The length of any monitoring period depends on the liquid level control limit in effect at the time.

The logic for determining the liquid level control limit for the next sluice batch is shown in Figure 4-1. If there is no liquid level control limit in effect, then an analysis would have already been completed to demonstrate that saturation conditions are no longer a concern in the sludge and sluicing can proceed with a liquid level suitable for optimum efficiency. The duration of the monitoring period in this case is determined by the time required to complete the tank 241-AY-102 mass balance verification (see Section 4.2). The same duration happens if a liquid level control limit is in effect but no change in the supernatant level in tank $241-\mathrm{C}-106$ is required to effect efficient retrieval during the next batch.

For the case where a supernate level requirement is in effect at tank 241-C-106 and a level change is desired, a thermal analysis will determine whether the thermal conditions (degree of waste subcooling) in tank 241-C-106 support lowering the supernatant level. The computer model used in the analysis calculates the temperatures at the location of the maximum waste temperature; available tank instrumentation does not measure maximum temperatures direct $7 y$. The estimated waste temperatures must remain $2.8^{\circ} \mathrm{C}$ to $3.3^{\circ} \mathrm{C}\left(5^{\circ} \mathrm{F}\right.$ to $\left.6^{\circ} \mathrm{F}\right)$ less than the saturation temperatures of Table 4.5 for sluicing to continue. Before the liquid level control limit is lowered for the next sluice batch, the monitoring period must be long enough to increase the subcooling margin so the pre-sluicing subcooling margin will be maintained when the supernatant is lowered to the desired level. The subcooling margin wi]l become evident from the actual waste temperature readings from riser 8 and riser 14 thermocouples. The amount of time needed to achieve the required degree of subcooling will be determined by computer modeling (ogden et al. 1998)). Current estimates indicate that a 5 day monitoring period following the retrieval of the first $0.3 \mathrm{~m}$ (1 ft) increment will result in sufficient sludge cooling to allow lowering the liquid level $0.3 \mathrm{~m}$ (1 ft) without a reduction in the subcooling margin for the next batch (Ogden et a1. 1998)).

Current WRSS thermal studies indicate that the removal of the equivalent of $0.3 \mathrm{~m}$ to $0.6 \mathrm{~m}$ ( $1 \mathrm{ft}$ to $2 \mathrm{ft}$ ) of tank $241-\mathrm{c}-106$ sludge (i.e. . sluice campaign 1) will lower the peak sludge temperatures in the tank to the point that saturation conditions can no longer occur (ogden et a 1. 1998). Once this condition is verified. the liquid level control limit can be eliminated for all remaining sluice batches.

\subsubsection{Sludge Temperature Control after Completing Retrieval Operations.}

The maximum temperature in tank 241-C-106 after a 11 sluicable waste has been retrieved will depend on the amount of heat-generating material remaining in the tank. A thermal analysis will evaluate the long-term temperatures at dried-out waste conditions based on the remaining heat load in the tank. Appropriate control temperature limits will be established from the analysis. if required.

Until final control limits are established, the waste temperatures will continue to be monitored and recorded. The control limits that apply are those that implement Administrative Control 5.26. "Tank 241-C-106 WASTE 
Table 4-5. Saturation Temperature at Location of Maximum Waste Temperature in Tank 241-C-106.

\begin{tabular}{|c|c|c|c|c|c|c|}
\hline & & & 1hore & 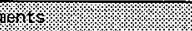 & & \\
\hline 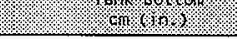 & $1 \%$ \% & 2. & Wx & 2 & $3 \%$ & 32 \\
\hline $201(79)$ & $105^{\circ} \mathrm{C}\left(221^{\circ} \mathrm{F}\right)$ & - & - & - & - & - \\
\hline $193(72)$ & $105.6^{\circ}(222 \mathrm{~F})$ & - & - & - & - & - \\
\hline $170(67)$ & $106.1^{\circ} \mathrm{C}\left(223^{\circ} \mathrm{F}\right)$ & $105^{\circ} \mathrm{C}\left(221^{\circ} \mathrm{F}\right)$ & - & - & - & - \\
\hline $152(60)$ & $106.7^{\circ} \mathrm{C}\left(244^{\circ} \mathrm{F}\right)$ & $105.6^{\circ} \mathrm{C}\left(222^{\circ} \mathrm{F}\right)$ & - & - & - & - \\
\hline $140(55)$ & $107.2^{\circ} \mathrm{C}\left(225^{\circ} \mathrm{F}\right)$ & $106.1^{\circ} \mathrm{C}\left(223^{\circ} \mathrm{F}\right)$ & $105^{\circ} \mathrm{C}\left(221^{\circ} \mathrm{F}\right)$ & - & - & - \\
\hline $122(48)$ & $108.3^{\circ} \mathrm{C}\left(227^{\circ} \mathrm{F}\right)$ & $106.7^{\circ} \mathrm{C}\left(224^{\circ} \mathrm{F}\right)$ & $105.6^{\circ} \mathrm{C}\left(222^{\circ} \mathrm{F}\right)$ & $\cdot$ & - & - \\
\hline $109(43)$ & $108.9^{\circ} \mathrm{C}\left(228^{\circ} \mathrm{F}\right)$ & $107.2^{\circ} \mathrm{C}\left(225^{\circ} \mathrm{F}\right)$ & $106.1^{\circ} \mathrm{C}\left(223^{\circ} \mathrm{F}\right)$ & $105^{\circ} \mathrm{C}\left(221{ }^{\circ} \mathrm{F}\right)$ & - & - \\
\hline $91(36)$ & $109.4^{\circ} \mathrm{C}\left(229^{\circ} \mathrm{F}\right)$ & $108.3^{\circ} \mathrm{C}\left(227^{\circ} \mathrm{F}\right)$ & $106.7^{\circ} \mathrm{C}\left(224^{\circ} \mathrm{F}\right)$ & $105.6^{\circ} \mathrm{C}\left(222^{\circ} \mathrm{F}\right)$ & - & - \\
\hline $79(31)$ & $110^{\circ} \mathrm{C}\left(230^{\circ} \mathrm{F}\right)$ & $108.9^{\circ} \mathrm{C}\left(228^{\circ} \mathrm{F}\right)$ & $107.2^{\circ} \mathrm{C}\left(225^{\circ} \mathrm{F}\right)$ & $106.1^{\circ} \mathrm{C}\left(223^{\circ} \mathrm{F}\right)$ & $\left.105^{\circ} \mathrm{C} 221{ }^{\circ} \mathrm{F}\right)$ & - \\
\hline $61(24)$ & $110.6^{\circ} \mathrm{C}\left(231^{\circ} \mathrm{F}\right)$ & $109.4^{\circ} \mathrm{C}\left(229{ }^{\circ} \mathrm{F}\right)$ & $108.3^{\circ} \mathrm{C}\left(227^{\circ} \mathrm{F}\right)$ & $106.7^{\circ} \mathrm{C}\left(224^{\circ} \mathrm{F}\right)$ & $105.6^{\circ}\left(222^{\circ} \mathrm{F}\right)$ & - \\
\hline $48(19)$ & $111.1^{\circ} \mathrm{C}\left(232^{\circ} \mathrm{F}\right)$ & $110^{\circ} \mathrm{C}\left(230^{\circ} \mathrm{F}\right)$ & $108.9^{\circ} \mathrm{C}\left(228^{\circ} \mathrm{F}\right)$ & $107.2^{\circ} \mathrm{C}\left(225^{\circ} \mathrm{F}\right)$ & $106.1^{\circ} \mathrm{C}\left(223^{\circ} \mathrm{F}\right)$ & $105^{\circ} \mathrm{C}\left(221^{\circ} \mathrm{F}\right)$ \\
\hline $30(12)$ & $111.7^{\circ} \mathrm{C}\left(233^{\circ} \mathrm{F}\right)$ & $110.6{ }^{\circ} \mathrm{C}\left(231{ }^{\circ} \mathrm{F}\right)$ & $109.4^{\circ} \mathrm{C}\left(229^{\circ} \mathrm{F}\right)$ & $108.3^{\circ} \mathrm{C}\left(227^{\circ} \mathrm{F}\right.$ & $106.7^{\circ} \mathrm{C}\left(224^{\circ} \mathrm{F}\right)$ & $105.6^{\circ} \mathrm{C}\left(222^{\circ} \mathrm{F}\right)$ \\
\hline $18(7)$ & $112.2^{\circ} \mathrm{C}\left(234^{\circ} \mathrm{F}\right)$ & $111.1^{\circ} \mathrm{C}\left(232^{\circ} \mathrm{F}\right)$ & $110^{\circ} \mathrm{C}\left(230^{\circ} \mathrm{F}\right)$ & $108.9^{\circ} \mathrm{C}\left(228^{\circ} \mathrm{F}\right)$ & $107.2^{\circ} \mathrm{C}\left(225^{\circ} \mathrm{F}\right)$ & $106.1^{\circ} \mathrm{C}\left(223^{\circ} \mathrm{F}\right)$ \\
\hline 0 (tank middle bottom) & $112.8^{\circ} \mathrm{C}\left(235^{\circ} \mathrm{F}\right)$ & $111.7^{\circ} \mathrm{C}\left(233^{\circ} \mathrm{F}\right)$ & $110.6^{\circ} \mathrm{C}\left(231^{\circ} \mathrm{F}\right)$ & $109.4^{\circ} \mathrm{C}\left(229^{\circ} \mathrm{F}\right)$ & $108.3^{\circ} \mathrm{C}\left(227^{\circ} \mathrm{F}\right)$ & $106.7^{\circ} \mathrm{C}\left(224^{\circ} \mathrm{F}\right)$ \\
\hline
\end{tabular}

\section{Note:}

Assumes a $13 \mathrm{~cm}$ (5 in.) supernatant depth is maintained throughout the sluicing operations and that sludge is removed evenly over the crosssection of the tank during sluicing increments. 


$$
\text { HNF-SD-WM-PCP-013 REV. } 1
$$

Temperature Controls." of the TSRs (FDH 1998b). The specific temperature control limits are those given in Table 4-4. Revising the temperature control limits will require an authorization basis change.

\subsubsection{Tank 241-AY-102 Waste Temperature Control}

The retrieval process will be controlled to ensure that waste temperatures in tank 241-AY-102 wi 11 remain below temperature 1 imits established by TSRs (FDH 1998b). Temperature control wi 71 be accomplished by operating the primary and annulus ventilation systems and by conducting the retrieval in increments. During sluicing operations, sludge temperatures (using the existing in-tank thermocouples and MIT) and insulating concrete temperatures wi 17 be monitored and the observed temperatures correlated with heat balance data provided by ventilation system airflow rates, temperatures, and humidities. From these measurements, steady-state temperatures can be predicted and compared with the temperature limits and the expected thermal behavior as the sluicing progresses.

Ventilation of the tank 241-AY-102 primary tank and annuTus during all sluicing operations will be provided by the 241-AZ-702 and 296-A-16 systems, respectively. The 241-AZ-702 primary tank ventilation system will be operated in recirculation mode, which ventilates the tank with a recirculation flow of approximately $400 \mathrm{cfm}$ and an intake flow of approximately $100 \mathrm{cfm}$ air. The 296-A-16 annulus system will operate at high vacuum and with the annulus wall inlet blocked to maintain a flow of 800 to $1,300 \mathrm{cfm}$ of air to the annulus bottom cooling channels. Figure 3-10 shows the flowsheet for the tank 241-AY-102 ventilation system used throughout the sluicing operations and monitoring periods (see Sections 3.4 .2 and 3.4.3).

The thermocouples and MIT in tank 241-AY-102 (see Table 3-9) will be continuously monitored throughout the sluicing operations to ensure that actual thermal behavior remains consistent with the estimated temperatures predicted by project thermal analysis (Ogden et a1. 1998). The minimum number of operable thermocouples required for the WRSS process is one tank dome space thermocouple. one supernatant thermocouple, one sludge thermocouple, the MIT validation probe, and six insulating concrete thermocouples (TE-102-1, -3, -6, $-10,-14$, and -24). If at any time the sludge temperature profiles indicate a significant adverse departure from the estimates, sluicing operations will be suspended to allow for further analysis of the tank conditions and to restore waste temperatures within allowable limits.

4.3.2.1 Pre-S7uicing Waste Temperature Baseline. The pre-sluicing waste temperature baseline for tank 241-AY-102 is included in Section 3.2.2.1.

4.3.2.2 Waste Temperature Control During STuicing Operations. The waste temperatures in tank 241-AY-102 are not expected to change appreciably during sluice batches. As sludge is transferred from tank 241-C-106, it accumulates in tank 241-AY-102. The tank 241-AY-102 sludge temperatures wi11 increase resulting from the increasing heat load and increasing thermal resistance of the sludge settling in the tank as the mass of particulate solids increases However, a tank transient thermal analysis concluded that following retrieval of a significant amount of sludge from tank 241-C-106, the sludge heating wi 11 
HNF-SD-WM-PCP-013 REV. 1

occur over long time periods, taking several months to reach thermal equilibrium (Ogden et a1. 1998). In fact. the observed waste temperatures following the first $0.6 \mathrm{~m}(2 \mathrm{ft}$ ) of tank $241-C-106$ sludge transfer may be quite low depending of the thermal properties exhibited by the actual settled sludge.

Although temperatures of concern are not anticipated during sluice batches. waste temperatures in tank 241-AY-102 wi1l be continuously monitored to ensure compliance with temperature limits. Table 4-6 lists the in-tank thermocouples that will be monitored during sluice batches, which make up each of the planned sluice increments, and compared with the waste temperature limit. The Limited Control Setting/Limiting Condition of Operation (LCS/LCO) 3.3.2, "DST and AWF Tank WASTE Temperature Controls," limit of $\leq 91{ }^{\circ} \mathrm{C}\left(\leq 195{ }^{\circ} \mathrm{F}\right)$ applies to the listed thermocouples as is applicable depending on the actual waste level in the tank (FDH 1998b). At startup of sluicing, the waste level is adjusted to $4.3 \mathrm{~m}$ (168 in.) and the thermocouples listed in the startup column of Table 4-6 are applicable. Once sluicing begins, the waste level in tank 241-AY-102 wi11 vary until a11 sluicable materjal has been transferred from tank 241-C-106. Table 4-6 assumes that each sluice increment adds $460 \mathrm{~cm}$ (18 in.) of waste to tank 241-AY-102 from all sources (i.e., sluice material. pipeline flushes, and other water additions) until the anticipated final level of $7 \mathrm{~m}$ (276 in.) is reached (see Figure $3-8$ ).

If the temperature limit of Table 4-6 is exceeded by any of the applicable thermocouples, then the recovery actions of LCS/LCO 3.3.2 are to be entered into immediately. Restoring the waste temperatures to within the limit will require an approved recovery plan.

4.3.2.3 Waste Temperature Control During Monitoring Periods. The tank 241-AY-102 in-tank thermocouples and MIT wi11 continue to be monitored and recorded during monitoring periods following each sluice batch. The waste temperature control limit for the applicable thermocouples is the same as that of Table 4-6. The recovery actions of LCS/LCO 3.3.2 are to be entered into immediately if any of the waste temperatures exceed the $91{ }^{\circ} \mathrm{C}\left(195^{\circ} \mathrm{F}\right)$ limit (FDH 1998b).

The tank waste temperature limits of LCS/LCO 3.3.2 were set to prevent the waste temperatures from reaching local saturation temperatures (FOH 1998D). Allowing the radiogenic high-heat sludge transferred from tank 241-C-106 into tank 241-AY-102 to heat up to saturation temperatures would cause a significant steam void fraction to form in the sludge, which potentially could lead to a steam bump accident (Bander et a 7.1996 and Sathyanarayana 1996a). Therefore, the conservative operating procedures to prevent such an occurrence are incorporated into the sludge retrieval process control strategy. Sluicing operations will occur in sluice batches-increments-campaigns followed by specified monitoring periods to verify sluicing performance and evaluate the temperature changes occurring in tank 241-AY-102 resulting from the added sludge (see Figure 4-1).

As shown in Figure 4-1, a thermal response evaluation of tank 241-AY-102 is performed after each sluice increment. During the subsequent monitoring period, sufficient data is collected to evaluate the thermal behavior of the tank 241-AY-102 sludge and ensure that the retrieval of the next increment 
(77.300 kg [170,000 1bs]) of tank 241-C-106 solids will remain within the tank temperature limits. Sathyanarayana (1997a) states:

"These analyses demonstrate that the thermal time constant can be many months. Process control using the maximum steady state temperature wi11 not be possible. However, the thermal transient response can be characterized through computer modeling and the expected steady state temperature can be evaluated from the short term transient wastetemperature response. This wi 11 allow for maximum waste transfer without delaying the project because of the large thermal time constant."

Table 4-6. Applicable Tank 241-AY-102 Waste Thermocouples to Comply with $91{ }^{\circ} \mathrm{C}\left(195^{\circ} \mathrm{F}\right)$ Limit During Sluice Batches. (2 sheets)

\begin{tabular}{|c|c|c|c|c|c|c|c|c|}
\hline \multirow{2}{*}{ Thernecouple? } & \multirow{2}{*}{ thernocouplo } & \multicolumn{7}{|c|}{ Inerenent } \\
\hline & & startigyo & 1.1. & 1.12 & $(2.1)$ & 2.2. & 3.1. & 3.2 ? \\
\hline \multirow[t]{5}{*}{ ALC } & TE-102-42 & $x$ & $X$ & $x$ & $x$ & $x$ & $x$ & $x$ \\
\hline & TE-102-44 & $x$ & $x$ & $x$ & $x$ & $x$ & $x$ & $x$ \\
\hline & TE-102-50 & $x$ & $x$ & $x$ & $x$ & $x$ & $x$ & $x$ \\
\hline & $T E-102-55$ & $x$ & $x$ & $x$ & $x$ & $x$ & $x$ & $x$ \\
\hline & TE-102-59 & $x$ & $x$ & $x$ & $x$ & $x$ & $x$ & $x$ \\
\hline \multirow[t]{10}{*}{ Profile } & TE-102-61 & $x$ & $x$ & $x$ & $x$ & $x$ & $x$ & $x$ \\
\hline & TE-102-62 & $x$ & $x$ & $x$ & $x$ & $x$ & $x$ & $x$ \\
\hline & TE-102-64 & $x$ & $x$ & $x$ & $x$ & $x$ & $x$ & $x$ \\
\hline & TE-102-65 & $x$ & $x$ & $x$ & $x$ & $x$ & $x$ & $x$ \\
\hline & TE-102-67 & $x$ & $x$ & $x$ & $x$ & $x$ & $x$ & $x$ \\
\hline & TE-102-68 & $x$ & $x$ & $x$ & $x$ & $x$ & $x$ & $x$ \\
\hline & TE-102-70 & $x$ & $x$ & $x$ & $x$ & $x$ & $x$ & $x$ \\
\hline & TE-102-71 & $x$ & $x$ & $x$ & $x$ & $x$ & $x$ & $x$ \\
\hline & TE-102-73 & $x$ & $x$ & $x$ & $x$ & $\bar{x}$ & $\bar{x}$ & $x$ \\
\hline & TE-102-74 & $x$ & $x$ & $x$ & $x$ & $x$ & $x$ & $x$ \\
\hline
\end{tabular}


HNF-SD-WM-PCP-013 REV. 1

Table 4-6. Applicable Tank 241-AY-102 Waste Thermocouples to Comply with $91{ }^{\circ} \mathrm{C}\left(195^{\circ} \mathrm{F}\right)$ Limit During Sluice Batches. (2 sheets)

\begin{tabular}{|c|c|c|c|c|c|c|c|c|}
\hline \multirow{2}{*}{ hermocouple } & \multirow{2}{*}{ 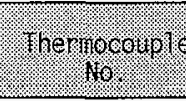 } & \multicolumn{7}{|c|}{ Ineremont } \\
\hline & & Startip & 1.1 & 1.2 & 2.1 & 2.2 & 3.3 & 3.2 \\
\hline \multirow[t]{7}{*}{ MIT } & $\begin{array}{l}\text { TE-06230 to } \\
\text { TE-06238 }\end{array}$ & $x$ & $x$ & $x$ & $x$ & $x$ & $x$ & $x$ \\
\hline & TE- 06239 & & $x$ & $x$ & $x$ & $x$ & $x$ & $x$ \\
\hline & TE-06240 & & & $x$ & $x$ & $x$ & $x$ & $x$ \\
\hline & TE-06241 & & & & $x$ & $x$ & $x$ & $x$ \\
\hline & TE-06242 & & & & & $x$ & $x$ & $x$ \\
\hline & TE-06243 & & & & & $x$ & $x$ & $x$ \\
\hline & TE-06244 & & & & & & $x$ & $x$ \\
\hline
\end{tabular}

After each sluicing increment, the thermal behavior of the solids settling in tank 241-AY-102 must be understood well enough to confidently predict that the tank temperatures will stay within control limits based upon the short-term transient temperature response in the waste. Measurement of the thermal response of the waste in tank 241-AY-102 will be made for a minimum of seven days following the completion of a sluice increment to collect the data required for computer analysis of steady-state temperatures. Tank temperature data and a heat balance around tank 241-AY-102 are required to perform the computer analysis. Analysis and documentation of the therma modeling results wi 1$]$ take another seven days for a total sluicing increment monitoring duration of 14 days. Data requirements include the following:

- Tank thermocouples and MIT (see Table 3-9).

- Supernatant-solids interface (see Table 4-2 for ENRAF ${ }^{T M}$ densitometer. MIT fixed elements, and MIT validation probe measurements).

- Tank 241-AY-102 primary ventilation system flow rate, temperature, and humidity.

- Tank 241-AY-102 AY102-K4-8-1 condenser glycol/water flowrate and inlet and outlet temperatures.

- Tank 241-AY-102 annulus ventilation system flow rate and temperature.

- Mass of tank 241-C-106 sludge transferred (see Sections 4.1.4 and 4.2) 
HNF-SD-WM-PCP-013 REV. 1

For the purposes of deciding whether sluicing can proceed following computer analysis to predict tank 241-AY-102 steady-state temperatures, the temperature control criteria is different than the $91{ }^{\circ} \mathrm{C}\left(195^{\circ} \mathrm{F}\right)$ temperature limit that applies during sluicing operations. The reason for different control criteria in the thermal evaluation is because steady-state temperatures are not expected until long after completing the tank 241-C-106 sludge retrieval. which is expected to take approximately 200 days. Table 4-7 gives the temperature control limits for the long-term storage of the tank 241-C-106 sludge transferred into tank 241-AY-102. The prediction that tank 241-AY-102 steady-state temperatures comply with the Table 4-7 temperature limits is a requirement for proceeding with the next sluicing increment.

Table 4-7. Tank 241-AY-102 Waste Temperature Limits During Post-Sluicing Monitoring. (2 sheets)

\begin{tabular}{|c|c|c|c|c|c|c|c|}
\hline \multirow{2}{*}{ Thernocouple } & \multirow{2}{*}{ hiernocoupler } & \multicolumn{6}{|c|}{ Therement } \\
\hline & & 1.1 & 1.2 & 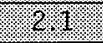 & 2.2 & 3.1 & 3.2 \\
\hline \multirow[t]{7}{*}{$\mathrm{ALC}$} & $T E-102-42$ & $91{ }^{\circ} \mathrm{C}^{1}$ & $102{ }^{\circ} \mathrm{C}^{2}$ & $102{ }^{\circ} \mathrm{C}$ & $102^{\circ} \mathrm{C}$ & $102^{\circ} \mathrm{C}$ & $102{ }^{\circ} \mathrm{C}$ \\
\hline & TE-102-44 & $91{ }^{\circ} \mathrm{C}$ & $102^{\circ} \mathrm{C}$ & $102{ }^{\circ} \mathrm{C}$ & $102^{\circ} \mathrm{C}$ & $102^{\circ} \mathrm{C}$ & $102^{\circ} \mathrm{C}$ \\
\hline & TE-102-50 & $91^{\circ} \mathrm{C}$ & $102^{\circ} \mathrm{C}$ & $102{ }^{\circ} \mathrm{C}$ & $102{ }^{\circ} \mathrm{C}$ & $102{ }^{\circ} \mathrm{C}$ & $102{ }^{\circ} \mathrm{C}$ \\
\hline & & & & & & & \\
\hline & & & & & & & \\
\hline & TE-102-55 & $91{ }^{\circ} \mathrm{C}$ & $102{ }^{\circ} \mathrm{C}$ & $102{ }^{\circ} \mathrm{C}$ & $102^{\circ} \mathrm{C}$ & $102^{\circ} \mathrm{C}$ & $102{ }^{\circ} \mathrm{C}$ \\
\hline & TE-102-59 & $91{ }^{\circ} \mathrm{C}$ & $102^{\circ} \mathrm{C}$ & $102{ }^{\circ} \mathrm{C}$ & $102^{\circ} \mathrm{C}$ & $102{ }^{\circ} \mathrm{C}$ & $102^{\circ} \mathrm{C}$ \\
\hline \multirow[t]{8}{*}{ Profile } & $T E-102-61$ & $91{ }^{\circ} \mathrm{C}$ & $102^{\circ} \mathrm{C}$ & $102^{\circ} \mathrm{C}$ & $102^{\circ} \mathrm{C}$ & $102^{\circ} \mathrm{C}$ & $102{ }^{\circ} \mathrm{C}$ \\
\hline & TE-102-62 & $91^{\circ} \mathrm{C}$ & $102^{\circ} \mathrm{C}$ & $102^{\circ} \mathrm{C}$ & $102{ }^{\circ} \mathrm{C}$ & $102^{\circ} \mathrm{C}$ & $102{ }^{\circ} \mathrm{C}$ \\
\hline & TE-102-64 & $91{ }^{\circ} \mathrm{C}$ & $102^{\circ} \mathrm{C}$ & $102{ }^{\circ} \mathrm{C}$ & $102^{\circ} \mathrm{C}$ & $102^{\circ} \mathrm{C}$ & $102^{\circ} \mathrm{C}$ \\
\hline & TE-102-65 & $91^{\circ} \mathrm{C}$ & $102^{\circ} \mathrm{C}$ & $102{ }^{\circ} \mathrm{C}$ & $102{ }^{\circ} \mathrm{C}$ & $102^{\circ} \mathrm{C}$ & $102{ }^{\circ} \mathrm{C}$ \\
\hline & TE-102-67 & $91{ }^{\circ} \mathrm{C}$ & $102^{\circ} \mathrm{C}$ & $102^{\circ} \mathrm{C}$ & $102^{\circ} \mathrm{C}$ & $102{ }^{\circ} \mathrm{C}$ & $102{ }^{\circ} \mathrm{C}$ \\
\hline & TE-102-68 & $91{ }^{\circ} \mathrm{C}$ & $102^{\circ} \mathrm{C}$ & $102^{\circ} \mathrm{C}$ & $102^{\circ} \mathrm{C}$ & $102^{\circ} \mathrm{C}$ & $102^{\circ} \mathrm{C}$ \\
\hline & TE-102-70 & $91{ }^{\circ} \mathrm{C}$ & $102^{\circ} \mathrm{C}$ & $102^{\circ} \mathrm{C}$ & $102{ }^{\circ} \mathrm{C}$ & $102^{\circ} \mathrm{C}$ & $102{ }^{\circ} \mathrm{C}$ \\
\hline & TE-102-71 & $91{ }^{\circ} \mathrm{C}$ & $102^{\circ} \mathrm{C}$ & $102{ }^{\circ} \mathrm{C}$ & $102{ }^{\circ} \mathrm{C}$ & $102{ }^{\circ} \mathrm{C}$ & $102^{\circ} \mathrm{C}$ \\
\hline \multicolumn{8}{|l|}{ Sludge } \\
\hline & $T E-102-73$ & $91^{\circ} \mathrm{C}$ & $102^{\circ} \mathrm{C}$ & $102^{\circ} \mathrm{C}$ & $102^{\circ} \mathrm{C}$ & $102^{\circ} \mathrm{C}$ & $102^{\circ} \mathrm{C}$ \\
\hline & TE-102-74 & $91{ }^{\circ} \mathrm{C}$ & $102^{\circ} \mathrm{C}$ & $102^{\circ} \mathrm{C}$ & $102{ }^{\circ} \mathrm{C}$ & $102^{\circ} \mathrm{C}$ & $102^{\circ} \mathrm{C}$ \\
\hline
\end{tabular}


Table 4-7. Tank 241-AY-102 Waste Temperature Limits During Post-Sluicing Monitoring. (2 sheets)

\begin{tabular}{|c|c|c|c|c|c|c|c|}
\hline \multirow{2}{*}{ Thermocouple } & \multirow{2}{*}{ Thernocoupre } & \multicolumn{6}{|c|}{ Ifrerent } \\
\hline & & 1.1 .1 & 1.2 & (2.) & 2.2 .2 & 3. & 12.2. \\
\hline \multirow[t]{7}{*}{ MIT } & $\begin{array}{l}\text { TE-06230 to } \\
\text { TE-06238 }\end{array}$ & $91{ }^{\circ} \mathrm{C}$ & $102{ }^{\circ} \mathrm{C}$ & $102^{\circ} \mathrm{C}$ & $102{ }^{\circ} \mathrm{C}$ & $102{ }^{\circ} \mathrm{C}$ & $102^{\circ} \mathrm{C}$ \\
\hline & TE-06239 & $91{ }^{\circ} \mathrm{C}$ & $102{ }^{\circ} \mathrm{C}$ & $102^{\circ} \mathrm{C}$ & $102{ }^{\circ} \mathrm{C}$ & $102{ }^{\circ} \mathrm{C}$ & $102^{\circ} \mathrm{C}$ \\
\hline & TE-06240 & & $91{ }^{\circ} \mathrm{C}$ & $91{ }^{\circ} \mathrm{C}$ & $91{ }^{\circ} \mathrm{C}$ & $91{ }^{\circ} \mathrm{C}$ & $91{ }^{\circ} \mathrm{C}$ \\
\hline & TE-06241 & & & $91{ }^{\circ} \mathrm{C}$ & $91{ }^{\circ} \mathrm{C}$ & $91^{\circ} \mathrm{C}$ & $91{ }^{\circ} \mathrm{C}$ \\
\hline & TE-06242 & & & & $91{ }^{\circ} \mathrm{C}$ & $91^{\circ} \mathrm{C}$ & $91{ }^{\circ} \mathrm{C}$ \\
\hline & TE-06243 & & & & $91{ }^{\circ} \mathrm{C}$ & $91{ }^{\circ} \mathrm{C}$ & $91{ }^{\circ} \mathrm{C}$ \\
\hline & TE-06244 & & & & & $91{ }^{\circ} \mathrm{C}$ & $91{ }^{\circ} \mathrm{C}$ \\
\hline
\end{tabular}

Notes:

$\begin{array}{ll}{ }_{1}^{1} 95 & { }^{\circ} \mathrm{F} \\ { }^{2} 215 & { }^{\circ} \mathrm{F}\end{array}$

Based on the WRSS thermal analysis, retrieval of the tank 241-C-106 sludge during the first campaign $(0.6 \mathrm{~m}[2 \mathrm{ft}])$ wi 11 not cause temperatures in tank 241-AY-102 to exceed control limits for the possible ranges of the thermal parameters (Ogden et al. 1998). Retrieval of the full $1.8 \mathrm{~m}$ ( $6 \mathrm{ft}$ ) of tank 241-C-106 sludge will likely be possible assuming optimistic values of the thermal parameters; fluffing factor of one, a thermal conductivity of 0.44 $\mathrm{Btu} / \mathrm{hr}-\mathrm{ft}-{ }^{\circ} \mathrm{F} .10$ percent lower heat $10 \mathrm{ad}$ and 10 percent of the $241-\mathrm{C}-106$ heat in the supernatant. Full retrieval based on the best estimate parameters of Tables 3-4 and 3-8 will require an annulus cooling channel flow of $>4,000 \mathrm{cfm}$, which may not be achievable on a practical basis (Ogden et al. 1998).

However. significant uncertainty exists in the thermal analysis and these uncertainties could alter the above conclusions. Therefore, modification of the annulus ventilation system may have to be made to increase its cooling capacity ( $i . e$. . increase the flow of air through the bottom cooling channels to $>1.200 \mathrm{cfm}$ through use of an inlet blower and chilling the airstream to provide $4{ }^{\circ} \mathrm{C}\left(40^{\circ} \mathrm{F}\right)$ air. to the floor slots) to accommodate full retrieval of the tank 241-C-106 sludge.

4.3.2.4 Waste Temperature Control after Completing Retrieval Operations. After all sluicable waste has been retrieved from tank $241-C-106$, the Table 3-9 tank 241-AY-102 temperatures will continue to be monitored and recorded. The control limits that apply to the waste temperatures are those that implement LCS/LCO 3.3.2. "DST and AWF Tank WASTE Temperature Controls." of the TSRs (FDH 1998b). The specific temperature control limits are those given in Table 4-7. The recovery actions of LCS/LCO 3.3.2 are to be entered into immediately if any of the waste temperatures exceed the temperature limits. 
HNF-SD-WM-PCP-013 REV. 1

The data required for performing a thermal analysis of tank 241-AY-102 to predict steady-state temperatures will continue to be collected for a period of one year following completion of sluicing operations (see Section 4.3.2.3 for data requirements). If the sludge temperature profile indicates a significant adverse departure from the current estimates during this time, a new thermal analysis of the tank will be completed to rebaseline the expected thermal response and ensure compliance with temperature limits. If at the end of the one year period, the tank thermal behavior indicates that steady-state temperatures will remain less than the temperature limits, then the monitoring can be reduced to the controls of the existing authorization basis (FDH 1998a).

\subsection{FLAMMABLE GAS RETENTION CONTROL}

This section presents the process control logic and the data evaluation associated with flammable gas generation, retention, and release during the retrieval of tank 241-C-106 sludge to tank 241-AY-102. Included is the establishment of a pre-sluicing baseline for both tanks, the post-sluicing assessment of tank 241-AY-102, and the decision logic for further transfer and mitigative action. This section implements the controls of Tank Waste Remediation System Basis for Interim Operations. Addendum 1, Section 2.5.2.2.3 Flammable Gas Process Control (FDH 1998a). Supporting information on the process control strategy is contained in Stewart et a1. (1997) and Pasamehmetoglu et al. (1997).

In the current configuration, tanks 241-C-106 and 241-AY-102 each generate relatively low rates of hydrogen and exhibit a relatively small retained gas inventory. It is estimated that tank 241-C-106 currently generates $0.2 \pm 0.01 \mathrm{~m}^{3} /$ day $\left(6.5 \pm 0.2 \mathrm{ft}^{3} /\right.$ day $)$ of hydrogen. This estimate is based on the results of a process test conducted in the tank in June 1997 (Jones 1997). Tank $241-A Y-102$ is estimated to generate $0.4 \pm 0.2 \mathrm{~m}^{3} /$ day $\left(14 \pm 6 \mathrm{ft}^{3} /\right.$ day $)$ of hydrogen. This is based on vapor grab sample analyses, and dome hydrogen concentrations from SHMS. The best estimate hydrogen concentration in the waste gas is 60 vol\% in tank 241-C-106, and approximately 100 vol\% in tank 241-AY-102. Because of considerable uncertainties in the prediction of the gas composition in the waste gas, Pasamehmetoglu et al. (1997) used 100 vol\% hydrogen for both tanks. Both tanks currently appear to be at steady-state where the gas generation is equal to the release rate. The transfer of tank 241-C-106 sludge to tank 241-AY-102 wi11 cause an increase in the hydrogen generation rate for tank 241-AY-102. The increase in tank 241-AY-102 is expected to be approximately equal to the sum of the current terms and gas retention is not expected to change significantly. The hydrogen generation rate and gas inventory in tank 241-C-106 are both expected to decrease to near zero by the completion of retrieval. However, uncertainties in both the parameters contributing to gas generation and the waste properties during and after the retrieval give rise to widely varying predictions of waste behavior. This section presents the parameters to be measured and the control strategy that will be implemented during the sluicing operations, during the hold periods between transfers, and after completion of sluicing operations. 


\subsubsection{Pre-Sluicing Flammable Gas Baseline}

The presluicing flammable gas baseline for both tanks 241-C-106 and 241-AY-102 is included in Section 3.2.2.2.

\subsubsection{Flammable Gas Controls During S7uicing Operations}

Sluicing operations in tank 241-C-106 are expected to release the inventory of retained gas in the region that is disturbed by the sluice jet. Increased gas generation and possible gas retention could occur in tank 241-AY-102 as the nonconvective sludge layer increases from continued solids additions. The controls to prevent a possible flammable gas deflagration during sluice batches includes existing TSRs, LCOS, and ACs. Defense-in-depth controls are also included. Table Al-1 in Appendix A provides these controls from the Tank Waste Remediation System Basis for Interim Operations, Addendum 1 (FDH 1998a).

4.4.2.1 Monitoring Requirements. The parameters to be monitored during sluicing operations are listed in Table 4-8. The purpose(s) for monitoring these data are also listed in the table.

Table 4-8. Monitoring Requirements During Sluicing Operations. (2 sheets)

\begin{tabular}{|c|c|c|c|}
\hline Porqueter lo be & $\begin{array}{l}\text { Expected } \\
\text { Value }\end{array}$ & Tistriment & Pyrpose \\
\hline $\begin{array}{l}\text { Flammable gas } \\
\text { concentration in } \\
\text { tank } 241-C-106\end{array}$ & $<500 \mathrm{ppm}$ & SHMS $^{1}$ & $\begin{array}{l}\text { - Used to determine gas } \\
\text { released in tank } 241-C-106 \\
\text { during transfer } \\
\text { - Used to compare with } \\
\text { shutdown criteria }\end{array}$ \\
\hline $\begin{array}{l}\text { Ventilation exhaust } \\
\text { flow rate in tank } \\
241-c-106\end{array}$ & $200 \mathrm{cfm}$ & $\begin{array}{l}\text { Vent } \\
\text { flowmeter }\end{array}$ & $\begin{array}{l}\text { - Used to determine gas } \\
\text { released in tank } 241-C-106 \\
\text { during transfer }\end{array}$ \\
\hline $\begin{array}{l}\text { Flammable gas } \\
\text { concentration in } \\
\text { tank 241-AY-102 }\end{array}$ & $<500 \mathrm{ppm}$ & SHMS $^{1}$ & $\begin{array}{l}\text { - Used to determine gas } \\
\text { released in tank 241-AY-102 } \\
\text { during transfer } \\
\text { - Used to compare with } \\
\text { shutdown criteria }\end{array}$ \\
\hline $\begin{array}{l}\text { Ventilation exhaust } \\
\text { flow rate in tank } \\
241-A Y-102\end{array}$ & $100 \mathrm{cfm}$ & $\begin{array}{l}\text { Vent } \\
\text { flowmeter }\end{array}$ & $\begin{array}{l}\text { - Used to determine gas } \\
\text { released in tank 241-AY-102 } \\
\text { during transfer }\end{array}$ \\
\hline $\begin{array}{l}\text { Dome pressure in } \\
\text { tank } 241-C-106\end{array}$ & $<0.1$ in. w.g & $\begin{array}{l}\text { Pressure } \\
\text { gauge }\end{array}$ & $\begin{array}{l}\text { - Detect large gas release } \\
\text { - event in tank } 241-C-106 \\
\text { - Shutdown criterion }\end{array}$ \\
\hline $\begin{array}{l}\text { Dome pressure in } \\
\text { tank } 241-A Y-102\end{array}$ & $<0.1$ in. w.g & \begin{tabular}{|l}
$\begin{array}{l}\text { Pressure } \\
\text { gauge }\end{array}$ \\
\end{tabular} & $\begin{array}{l}\text { - Detect large gas release } \\
\text { event in tank } 241-A Y-102 \\
\text { - Shutdown criterion }\end{array}$ \\
\hline
\end{tabular}


HNF-SD-WM-PCP-013 REV. 1

Table 4-8. Monitoring Requirements During Sluicing Operations. (2 sheets)

\begin{tabular}{|c|c|c|c|}
\hline Por manever lo ber & experted: & Irstrumenth & Pilpose : \\
\hline $\begin{array}{l}\text { Condition of waste } \\
\text { surface in tank } \\
241-A Y-102\end{array}$ & $\begin{array}{l}\text { Minor foam } \\
\text { that } \\
\text { dissipates } \\
\text { rapidly }\end{array}$ & $\begin{array}{l}\text { Video } \\
\text { camera }\end{array}$ & $\begin{array}{l}\text { - Detect foaming, and } \\
\text { possibility of large gas } \\
\text { release from foam collapse } \\
\text { - Shutdown criterion }\end{array}$ \\
\hline $\begin{array}{l}\text { Waste level in tank } \\
241-A Y-102\end{array}$ & $\begin{array}{l}\text { Consistent } \\
\text { with mass } \\
\text { transfer } \\
\text { measurements }\end{array}$ & $\begin{array}{l}\text { ENRAF TM }^{\text {TM }} \\
\text { level }\end{array}$ & $\begin{array}{l}\text { - Compare to ensure } \\
\text { consistency with mass } \\
\text { balance calculdtions } \\
\text { - Sudden level increase could } \\
\text { indicate foaming }\end{array}$ \\
\hline
\end{tabular}

Note:

Minimum one gas chromatograph and one whittaker cell operational.

4.4.2.2 Decision Logic for Shutdown and Restart of Sluicing. Controls to specify conditions for shutdown and restart during sluicing operations are as follows. Sluicing operations are to be shut down in less than 15 minutes upon detection of:

- Hydrogen concentrations $>5000$ ppm in either tank $241-\mathrm{C}-106$ or 241-AY-102.

- Ventilation failure in either tank 241-C-106 or 241-AY-102.

- Loss of negative dome space pressure in either tank 241-C-106 or 241-AY-102.

- Persistent and expanding foaming in tank 241-AY-102.

Upon detection of $f 7$ ammable gas above the limit and the resultant equipment. shutdown. the sluicing and transfer operations will be resumed only after the dome hydrogen concentrations decrease to $<500 \mathrm{ppm}$ in both tanks $241-\mathrm{C}-106$ and 241-AY-102.

No operations involving the air lift circulators in tank 241-AY-102 or other waste-intrusive piping in either tank 241-C-106 or tank 241-AY-102 are permitted without an Unreviewed Safety Question screening and, if required. a safety analysis pertinent to the proposed operation.

\subsubsection{Flammable Gas Controls During Monitoring Periods}

A minimum waiting time of 30 days between campaigns is necessary before initiating further sluicing. During this monitoring period, flammable gas monitoring wi 11 be focused on determining if gas retention is occurring in tank 241-AY-102. Tank 241-AY-102 currently shows no indication of significant amounts of retained gas. However, since the tank contains only about $20 \mathrm{~cm}$ 
( 8 in.) of nonconvective material that could retain gas. even a 15 percent void fraction would represent a gas volume well below the minimum detection limit using barometric pressure evaluation methods (Stewart et a1. 1997).

There is considerable uncertainty in current estimates of the amount of gas that can be retained in tank 241-AY-102 after the transfer of waste from tank 241-C-106 (Pasamehmetoglu et a7. 1997). Without being able to bound the maximum void, it is difficult to predict the potential for large gas releases. Therefore, field data should be relied upon to make judgments on gas retention and to guide decisions on further sluicing and potential mitigative measures. The Technical Review Group is the decision-making authority. This section presents the parameters to be measured for this purpose, and the decision logic to be used to ensure the timely detection of high gas retention. The bases for the process control logic discussed here are provided by Pasamehmetoglu et al.(1997): conservative estimates of the post-sluice campaign parameters are used.

The monitoring and process control logic discussed here are for the monitoring period following a campaign. It is recognized that the campaign actually will be performed in smaller batches. However, void growth observations for smaller amounts of waste are very difficuit and subject to large uncertainties. Therefore, the 30-day waiting time requirement is formulated for the monitoring periods following each campaign. However, it must be recognized that the 30 -day waiting time is the minimum necessary requirement. Using longer monitoring periods after the transfer of batches or increments of waste would be in complete compliance with the monitoring and process control logic presented here.

4.4.3.1 Monitoring Requirements. The monitoring and sampling requirements during the monitoring period are listed in Table 4-9.

Table 4-9. Monitoring Requirements During Monitoring Period. (2 sheets)

\begin{tabular}{|c|c|c|c|}
\hline Porameter to lo be: & Expedet Uavitue & 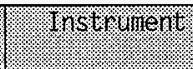 & PYirgores: \\
\hline $\begin{array}{l}\text { Time elapsed since } \\
\text { end of previous } \\
\text { transfer }\end{array}$ & - & - & $\begin{array}{l}\text { - Minimum waiting } \\
\text { time of } 30 \text { days } \\
\text { is required before } \\
\text { further transfer }\end{array}$ \\
\hline $\begin{array}{l}\text { Sludge thickness in } \\
\text { tank } 241-A Y-102\end{array}$ & $\begin{array}{l}1.3 \mathrm{~m}(50 \mathrm{in} .) \\
\text { after sluice } \\
\text { campaign } 1\end{array}$ & $\begin{array}{l}\text { ENRAF } \\
\text { dens tometer } \\
\text { and MIT } \\
\text { temperature } \\
\text { profiles }\end{array}$ & $\begin{array}{l}\text { - Used to quantify } \\
\text { fluffing after } \\
\text { transfer }\end{array}$ \\
\hline $\begin{array}{l}\text { Waste level in tank } \\
241-A Y-102\end{array}$ & $\begin{array}{l}5.2 \mathrm{~m} \text { (204 in.) } \\
\text { after sluice } \\
\text { campaign } 1\end{array}$ & ENRAF $^{\text {TM }}$ level & $\begin{array}{l}\text { Compare to ensure } \\
\text { consistency with } \\
\text { mass balance } \\
\text { calculations } \\
\text { Used in decision } \\
\text { logic for gas } \\
\text { retention }\end{array}$ \\
\hline
\end{tabular}


Table 4-9. Monitoring Requirements During Monitoring Period. (2 sheets)

\begin{tabular}{|c|c|c|c|}
\hline Paramerer lo lof & Vifocte & Ths r wunent? & Plupose: \\
\hline $\begin{array}{l}\text { Flammable gas } \\
\text { concentration in } \\
\text { tank } 241-A Y-102\end{array}$ & $<500$ ppm & SHMS & $\begin{array}{l}\text { - Used in decision } \\
\text { logic for gas } \\
\text { retention } \\
\text { Used to detect } \\
\text { large releases } \\
\text { in tank 241-AY-102 }\end{array}$ \\
\hline $\begin{array}{l}\text { Ventilation exhaust } \\
\text { flow rate in tank } \\
241-A Y-102\end{array}$ & $100 \mathrm{cfm}$ & Vent flowmeter & $\begin{array}{l}\text { Used to determine } \\
\text { gas released } \\
\text { during hold periods }\end{array}$ \\
\hline $\begin{array}{l}\text { Ventilation exhaust } \\
\text { humidity in tank } \\
\text { 241-AY-102 }\end{array}$ & - & $\begin{array}{l}\text { Relative } \\
\text { humidity probe }\end{array}$ & $\begin{array}{l}\text { Used to estimate } \\
\text { surface level } \\
\text { decrease as a } \\
\text { result of } \\
\text { evaporation }\end{array}$ \\
\hline $\begin{array}{l}\text { Dome space } \\
\text { temperature in tank } \\
241-A Y-102\end{array}$ & \begin{tabular}{|l}
- \\
\end{tabular} & Thermocouples & $\begin{array}{l}\text { - Used to estimate } \\
\text { surface level } \\
\text { decrease as a } \\
\text { result of } \\
\text { evaporation }\end{array}$ \\
\hline $\begin{array}{l}\text { Flammable gas } \\
\text { concentration in } \\
\text { tank } 241-C-106\end{array}$ & $<500 \mathrm{ppm}$ & SHMS & $\begin{array}{l}\text { - Used to determine } \\
\text { gas release rate in } \\
\text { tank } 241-C-106^{1} \\
\text { Used to detect } \\
\text { large releases } \\
\text { in tank 241-C-106 }\end{array}$ \\
\hline $\begin{array}{l}\text { Ventilation exhaust } \\
\text { flow rate in tank } \\
241-c-106\end{array}$ & $200 \mathrm{cfm}$ & Vent flowmeter & $\begin{array}{l}\text { - Used to determine } \\
\text { gas release rate in } \\
\text { tank 241-C-106 }\end{array}$ \\
\hline $\begin{array}{l}\text { Vapor grab samples } \\
\text { in tank } 241-A Y-102\end{array}$ & - & Sampling & $\begin{array}{l}\text { - To monitor changes } \\
\text { in gas composition } \\
\text { during the waiting } \\
\text { period. }^{2}\end{array}$ \\
\hline $\begin{array}{l}\text { Sludge and } \\
\text { supernatant 1iquid } \\
\text { grab samp les in tank } \\
241-A Y-102\end{array}$ & - & Sampling & $\begin{array}{l}\text { - Sample analysis to } \\
\text { determine densities } \\
\text { to estimate neutra } 1 \\
\text { buoyancy void } \\
\text { fractions after } \\
\text { transfer. }\end{array}$ \\
\hline
\end{tabular}

Notes:

${ }^{1}$ The accuracy of these estimates would depend on the ventilation system in tank $241-c-106$ during the hold period. Accuracy will decrease if the larger flow rates associated with the 296-P-16 system are used. However, the data will enable the detection of large releases.

${ }^{2}$ Three to four vapor grab samples must be taken toward the end of the 30-day monitoring period, with additional sampling if the monitoring period is extended beyond 30 days.

${ }^{3}$ One set of grab samples to be taken after sludge has settled; expected to be within approximately 10 to 15 days after completing campaign (see section 4.6 for sample requirements). 
HNF-SD-WM-PCP-013 REV. 1

4.4.3.2 Decision Logic for Further Transfer or Mitigative Actions. The proposed process control logic uses the monitoring data to make judgments on the extent of gas retention in tank 241-AY-102 following each campaign of the retrieval. The logic is based on the level rise of the waste, the rate of level rise, the hydrogen concentration in the dome space, and rate of change in the hydrogen concentration.

The level rise refers to the increase in the waste level starting from the waste level immediately after completion of a campaign. This measurement must be obtained using hourly ENRAFTM data, and the baseline must be established when the potential surface motion and intermediate foaming stop (within 1 day of completion of campaign). The rate of level rise is expressed in inches per day and must be averaged over 10 days. Thus, the rate-of-level-rise computations become meaningful after the first 10 days of the monitoring period. After that, the computations must continue using the values from the previous 10 days. The level and rate-of-level-rise computations must account for level changes resulting from evaporation. Data required for this evaluation are part of the monitoring requirements in Table 4-9.

The hydrogen concentration in the tank 241-AY-102 dome space must be base 7 ined before the start of the first sluicing batch (1.1.1). The rate of change in the hydrogen concentration is a daily value expressed in parts per million per day and can be obtained using the daily average values between two consecutive days.

The decision maps based on hydrogen concentration and level data are shown in Figures 4-8 and 4-9, respectively, for the first campaign. Baseline values to be used in Figure $4-8$ wi 77 be average measurements during the baselining period. If significant variations in the hydrogen concentration are observed during the baselining period. the data must be reviewed by the TRG and a suitable baseline value determined. It is recognized that instrument uncertainties and potential biases or drifts must be considered in implementing the decision maps shown in Figures 4-8 and 4-9. In addition, it should be recognized that Figures 4-8 and 4-9 are based on current estimates of post-sluice campaign 1 conditions. When additional data are obtained during the monitoring period following the campaign, the boundaries of the various zones in the decision maps may change. Thus, the use of Figures 4-8 and 4-9 wil1 be reviewed and approved by the TRG.

Based on Figures 4-8 and 4-9, a decision map is given in Table 4-10. The entry GO means that further sluicing can proceed. WAIT refers to additional monitoring time to allow the computed parameters to fall within the GO regions. The monitoring time must be extended one day at a time, and the criteria must be met for two consecutive days before further sluicing can occur (Pasamehmetoglu et al. 1997).

NO GO in Table 4-10 is an indication of high gas retention. This is an off-normal condition, and actions to be taken under this scenario are discussed in Section 5.0. 
HNF-SD-WM-PCP-013 REV. 1

Table 4-10. Decision Map.

\begin{tabular}{|c|c|c|c|c|}
\cline { 2 - 5 } \multicolumn{1}{c|}{} & II & I2 & H3 & W4 \\
\hline L1 & GO & GO & WAIT & WAIT \\
\hline L2 & WAIT & WAIT & WAIT & NO GO \\
\hline L3 & WAIT & WAIT & WAIT & NO GO \\
\hline L4 & NO GO & NO GO & NO GO & NO GO \\
\hline
\end{tabular}

If the above decision logic does not preclude further sluicing, the next campaign (i.e, sluice campaign 2) will be started after the monitoring period. The flammable gas controls for this phase of the retrieval are identical to those covered in Section 4.4.2. The monitoring requirements for the monitoring period following this second campaign are identical to those discussed in Section 4.4.3.1. The decision logic for further transfer is similar to that covered in Section 4.4.3.2. However, it should be recognized that the level rise data used in Figure 4-9 refer to the cumulative level swell since the beginning of the sluice campaigns. Therefore, at this stage, the 3.8 and $7.6 \mathrm{~cm}$ (1.5 and 3 in.) limits are replaced by 6.4 and $12.7 \mathrm{~cm}$ (2.5 and 5 in.) limits. As in Section 4.4.3.2, it should be recognized that these limits are based on current estimates of post-transfer conditions. When additional data are obtained during the monitoring period following the campaign, the boundaries of the various zones in the decision maps may change. Thus, the use of Figures 4-8 and 4-9 with the new level rise limits wi 71 be reviewed and approved by the TRG.

\subsubsection{Flammable Gas Controls After Completion of Tank 241-C-106 Retrieval}

After completion of the WRSS operations, when a11 sluicable solids are removed from tank 241-C-106, the principal concern is long-term gas retention in tank 241-AY-102. Tank 241-C-106 would be controlled per the existing authorization basis controls (FDH 1998a). Tank 241-AY-102 wi 71 continue to be monitored for flammable gas retention and release. If significant gas retention is observed or if there is excessive uncertainty in the estimates of retained gas inventory, a void fraction measurement is required. If high gas retention or gas release behavior is confirmed, this wi11 be considered an off-normal condition, and actions to be taken under this scenario are discussed in Section 5 .

The monitoring of tank 241-AY-102 for gas retention will be conducted for one year following the completion of WRSS operations. If at the end of that period, the tank does not exhibit a trend toward high gas retention or a buoyancy-driven gas release. then the monitoring can be reduced to the controls of the existing authorization basis (FDH 1998a). Table 4-11 provides the flammable gas monitoring requirements for the one-year period following completion of WRSS operations. 


\section{HNF-SD-WM-PCP-013 REV. 1}

Figure 4-8. Decision Map for Hydrogen Concentration Measurements.

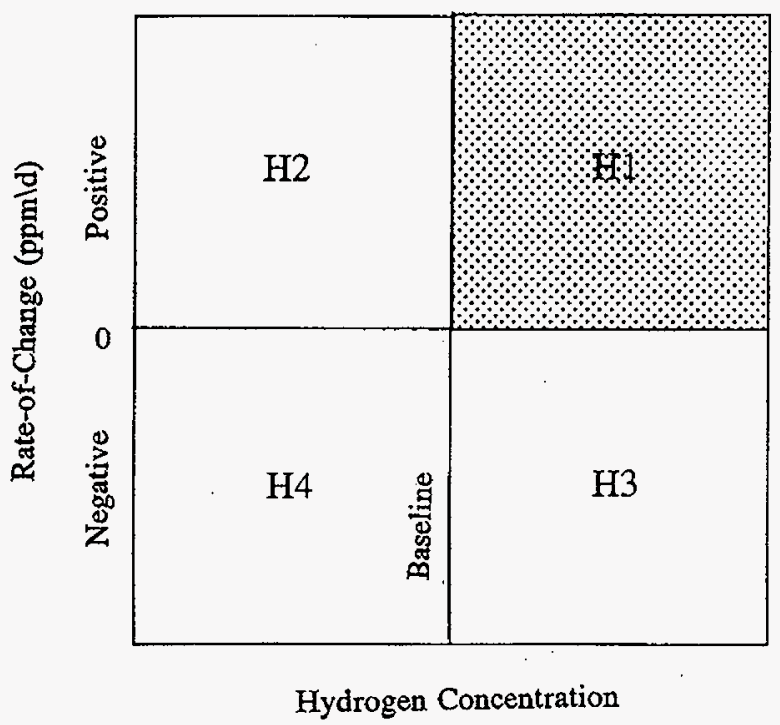


HNF-SO-WM-PCP-013 REV. 1

Figure 4-9. Decision Map for Level Measurements.

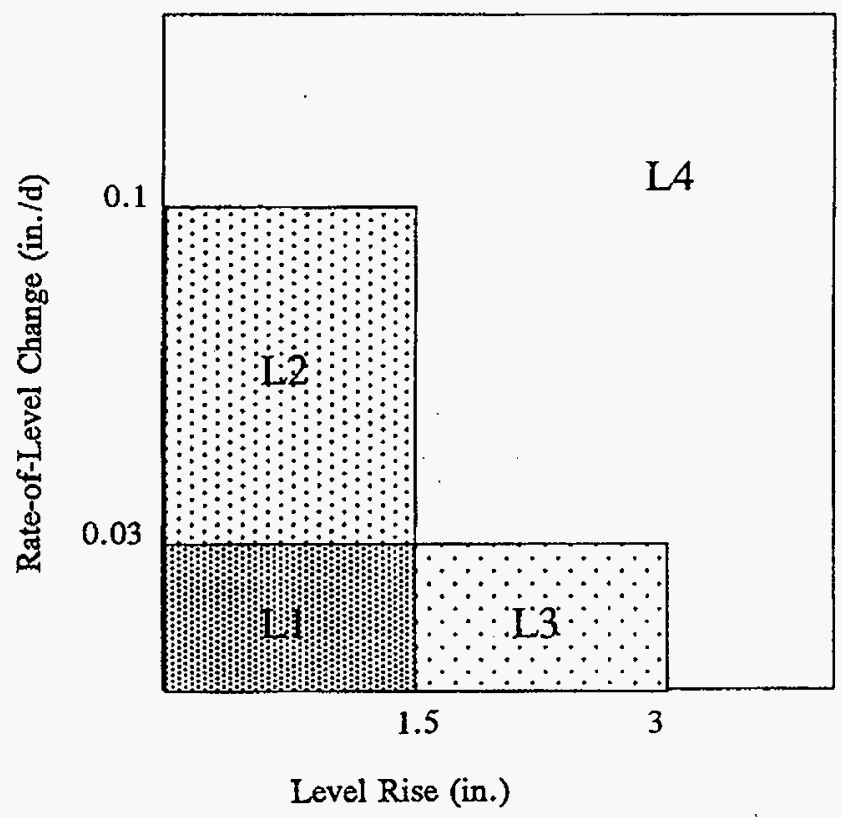


Table 4-11. Monitoring Requirements After Completion of Retrieval.

\begin{tabular}{|c|c|c|c|}
\hline 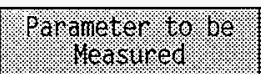 & Expected Va tue & instr uninent & Riruose \\
\hline $\begin{array}{l}\text { Sludge thickness } \\
\text { in tank } 241-A Y-102\end{array}$ & $\begin{array}{l}2.7 \mathrm{~m} \text { (108 in.) } \\
\text { ofter complete } \\
\text { transfer }\end{array}$ & $\begin{array}{l}\text { ENRAF } \\
\text { densitometer and } \\
\text { MIT temperature } \\
\text { profiles }\end{array}$ & $\begin{array}{l}\text { - Used to detect } \\
\text { gas retention }\end{array}$ \\
\hline \begin{tabular}{|l|} 
Waste level in \\
tank 241-AY-102
\end{tabular} & $\begin{array}{l}6.6 \mathrm{~m} \text { (258 in.) } \\
\text { after complete } \\
\text { transfer }\end{array}$ & ENRAF $^{\text {TM }}$ level & $\begin{array}{l}\text { - Indicator of gas } \\
\text { - Usetention } \\
\text { weather station data } \\
\text { for barometric } \\
\text { pressure } \\
\text { evaluation of } \\
\text { retained gas } \\
\text { inventory }\end{array}$ \\
\hline $\begin{array}{l}\text { Flammable gas } \\
\text { concentration in } \\
\text { tank 241-AY-102 }\end{array}$ & $<500 \mathrm{ppm}$ & SHMS & $\begin{array}{l}\text { - Used to determine } \\
\text { flammable gas } \\
\text { release rate } \\
\text { - Used to detect large } \\
\text { releases in } \\
\text { tank 241-AY-102 }\end{array}$ \\
\hline \begin{tabular}{|l|} 
Ventilation \\
exhaust flow rate \\
in tank 241-AY-102 \\
\end{tabular} & $100 \mathrm{cfm}$ & Vent flowmeter & $\begin{array}{l}\text { - Used to determine } \\
\text { flammable gas } \\
\text { release rate }\end{array}$ \\
\hline \begin{tabular}{|l|} 
Ventilation \\
exhaust humidity \\
in tank 241-AY-102
\end{tabular} & - & $\begin{array}{l}\text { Relative } \\
\text { humidity probe }\end{array}$ & $\begin{array}{l}\text { - Used to estimate } \\
\text { surface leve] } \\
\text { decrease as a } \\
\text { result of } \\
\text { evaporation }\end{array}$ \\
\hline $\begin{array}{l}\text { Dome space } \\
\text { temperature in } \\
\text { tank 241-AY-102 }\end{array}$ & - & Thermocouples & $\begin{array}{l}\text { - Used to estimate } \\
\text { surface level } \\
\text { decrease as a result } \\
\text { of evaporation }\end{array}$ \\
\hline
\end{tabular}

\subsection{OTHER CONTROLS}

During the sluicing operations, other controls are in force to ensure that operations proceed in a safe and efficient manner. Although the controls described below are important to the success of tank 241-C-106 waste retrieval, they are not anticipated to represent limiting conditions that could preclude retrieval of all sluicable material from the tank. 
HNF-SD-WM-PCP-013 REV. 1

\subsubsection{Leak Detection}

During all phases of the sluicing process, leak detection instrumentation is monitored to alert operators to the presence of a leak in the WRSS equipment. Alarm functions on the leak detection instrumentation allow timely identification of a potential leak so recovery actions can be taken to mitigate the consequences of a leak. Waste leakage that could occur during the sluicing operations can originate from tank 241-C-106, tank 241-AY-102, or the interfarm piping between the two tanks. Each of these systems has specific leak detection capabilities to provide early warning of a leak.

4.5.1.1 Tank 241-C-106. A leak from tank 241-C-106 wi11 be prevented or minimized during sluicing operations by implementing the following procedures:

- maintaining the $1.5 \mathrm{~m}$ (5 ft) "no-sluice zone" at the tank wall until the majority of the tank sludge has been retrieved

- controlling liquid level $\leq 0.23 \mathrm{~m}$ (9 in.) to achieve optimum sluicing, when possible

- sluicing the solids level down as eventy as possible

- sluicing flow channels into the solids surface to direct the flow of slurry to the submersible slurry pump suction

- maintaining minimum liquid heel during monitoring periods.

Leakage from tank 241-C-106 wi11 be determined using a combination of 1iquid level measurement, dry wel 1 measurement, and material balance estimates. The liquid level measurement can provide leakage indication that is specific to tank 241-C-106 as does dry well monitoring (although less sensitive). The material balance algorithm collects data from the entire WRSS process and determines an overa11 indication of potential leakage. Because the tank 241-AY-102 and transfer pipeline leak detection systems are highly reliable, any potential leakage identified from the material balance can be assigned to tank 241-c-106.

Liquid Level Monitoring. The primary leak detection method for tank 241-C-106 during the WRSS process is to monitor the liquid level using the ENRAF ${ }^{\mathrm{TM}}$ level gauge. Because the gauge could be damaged during sluice batches, the liquid level will be measured continuously only during the monitoring periods.

The occurrence of a leak from tank 241-C-106 during sluice batches is very unlikely because of the process control strategy that will be implemented in the sluicing procedures. Except for campaign 1 when the liquid level in tank 241-C-106 is maintained above a minimum limit during a sluice batch for temperature control reasons, the level during the short sluicing periods ( $\leq 12$ hours) will be kept at a minimum to optimize the efficiency of the retrieval and reduce the possibility of a leak (see Section 4.1.2). Other factors that reduce the chance of a tank leak are listed above including controlling the sluicer nozzle to leave a $1.5 \mathrm{~m}$ (5 ft) "no sluice zone" next to the tank wa11. Following these sluicing procedures during sluice batches will reduce exposure of 1 iquid to the tank steel 1 iner/waste interface level, 


$$
\text { HNF -SD-WM-PCP-013 REV. } 1
$$

which is believed to be the highest risk area for a leak to occur. However, a leak that occurs during a sluice batch may be detected during the subsequent monitoring period by either direct liquid level measurements or material balance. With time, detection by the dry wells is also possible.

The monitoring periods wi 11 present the best opportunity for detecting a potential leak. After shutdown of the slurry pumping system at the conclusion of a sluice batch, a minimum liquid level is reestablished in tank 241-C-106 that just covers the solids within the sluice zone. This will ensure continued evaporative cooling of the remaining solids in the tank (see Section 4.1.2). The monitoring periods are of sufficient duration (i.e., from 3 to 30 days) to detect a trend in the surface level exceeding estimated evaporative losses that may indicate the potential for a leak. If such a trend is observed, the sluicing leak management strategy of Section 5.2.6.1 would be implemented and a leak investigation initiated. Because of the dynamics of the sluicing operation, other possible explanations for the observed trend would need to be eliminated.

At the completion of a sluice batch, the ENRAF ${ }^{\mathrm{TM}}$ gauge will be lowered immediately into tank 241-C-106 and placed in the liquid level monitoring mode. Collection of level data will begin once the gauge is placed in service. A 24 hour baselining period will be required to al low the dynamics of the process to subside (e.g., slurry and sluicing transfer pipeline draining, solids wetting, and fog reduction). Once the baseline is established, the trend in the liquid level will be monitored and recorded.

The tank 241-C-106 liquid surface is expected to exhibit a s]ight negative trend during sluicing monitoring periods because of evaporative losses. This trend will drop substantially below the current trend of 194 gallons per day once startup of the 296-C-006 ventilation system occurs. This new ventilation system condenses and returns the majority of water vapor generated through evaporation. However, establishing a baseline evaporation rate as a leak detection criterion similar to the current tank leak detection specification will not be practicable because of the decreasing heat load in tank 241-C-106 as the retrieval progresses. For single-shel1 tanks equipped with an ENRAF ${ }^{\text {TM }}$ level gauge that measures a liquid surface, the leak detection criteria is that a $-1.3 \mathrm{~cm}(-0.5 \mathrm{in}$.) change in liquid level wi11 prompt a leak investigation (LMHC 1996). This same criteria will apply to tank 241-C-106 during the WRSS process monitoring periods.

When liquid level monitoring of tank $241-C-106$ is in process during the monitoring periods, video recording of the wall area of the tank using the in-tank imaging system will be required once per day. This video recording will detect any solids sloughing that may occur from the "no-sluice zone" near the tank wall and cause disruption of the ENRAF ${ }^{T M}$ level measurements. If this sloughing occurs or other liquid waste additions are made to the tank (e.g. . pit flushes, ventilation filter flushes, or pipeline water flushes). a new baseline will have to be established for purposes of leak detection. Any equipment flushing planned for a monitoring period should be performed immediately following completion of the sluice batch to minimize disturbances to the leak detection activity. 
HNF-SD-WM-PCP-013 REV. 1

Material Balance. Both a batch material balance and a cumulative material balance will be kept during the WRSS process to monitor the progress of the sluicing operations and to provide a secondary indication of a potential leak from tank 241-C-106. This cumulative material balance, which accounts for a 11 sources of potential volumetric charges, will be kept current by performing a material balance for each sluice batch and monitoring period.

The material balance leak detection methods will be useful only during the first sluicing campaign and at the conclusion of the retrieval. Tank 241-C-106 will have a minimum liquid layer maintained above the sludge during the first campaign for temperature control purposes. With this 1iquid layer cover, the volume of tank 241-C-106 waste remaining in the tank following the campaign 1 sluice batches can be accurately determined. In this case, the material balance method can be used to provide an indication of a potential tank leak. However, the uncertainty in the tank 241-C-106 waste volume becomes to great following campaign 1 for the material balance method to be useful for leak detection. The solids that accumulate in the "no-sluice zone" next to the tank wall during the retrieval process cannot be measured and may account for up to approximately $190,000 \mathrm{~L}$ (50 kgal) of waste. Not until the end of the last campaign when the wal1s are sluiced will the material balance provide an indication whether tank 241-C-106 leaked during the sluicing operations.

When the cumulative material balance method is applicable for leak detection, previous and current material balance estimates wi 11 be combined with WRSS process data to predict the expected tank liquid levels. Inconsistencies between the predicted level values and actual levels will be evaluated as potential indications of leakage. Actual waste volumes in tanks 241-C-106 and 241-AY-102 are obtained from the ENRAF ${ }^{\mathrm{TM}}$ level gauge measurements. The predicted volumes require the following information.

1. The water mass change in the WRSS due to the circulation of air to and from the tanks. Ventilation air drawn into the tanks and circulating in and out of the tanks will transfer water due to evaporation and condensation at different temperatures and relative humidities.

2. The volume additions to the tanks. Water will be used routinely for flushing the transfer pipelines, flushing the 296-C-006 ventilation system filters or the 296-P-16 de-entrainer, flushing pit equipment. and flushing in-tank instrumentation and other equipment. The volume of any chemical additions to the process also must be accounted along with any other materials added to the WRSS that could alter the total waste volume.

3. The temperature effect on the volume. The density of an aqueous solution decreases as the temperature rises and, therefore must be taken into account. Because over 70 weight percent of the settled sludge in tank 241-AY-102 is expected to be comprised of carrier fluid (tank 241-AY-102 supernatant) with less than 10 weight percent soluble salts, the water in the sludge will be the primary contributor to the slurry density variation with temperature. Similarly, the supernatant will contain greater than 90 weight 
percent water. As an approximation, the temperature coefficient of expansion of the WRSS sludge and Tiquid is assumed equivalent to that of pure water. Figure 4-10 shows the assumed thermal expansion of the WRSS slurry.

The data required to perform the cumulative material balance calculations are listed below. The batch material balance only requires tank liquid levels and water/material additions made to the WRSS during the batch. Except for the initial starting waste levels in the tanks, the following data are monitored throughout all phases of the WRSS process.

- liquid levels in tanks 241-C-106 and 241-AY-102 at the start of sluicing (ENRAF ${ }^{\text {IM }}$ level gauges)

- tank 241-C-106 (during monitoring periods only) and tank 241-AY-102 liquid levels

- average waste temperatures

- tank 241-AY-102 supernatant density (during monitoring periods only)

- volume of water additions and other materials

- tank 241-C-106 ventilation exhaust flow rate: tank 241-AY-102 primary ventilation exhaust flow rate, temperature, and relative humidity: and atmospheric psychrometric condition

- tank 241-C-105 dome space temperature (tank monitoring and control system)

- tank 241-C-106 and 241-AY-102 dome space pressures

- 296-C-006 ventilation system condenser upstream pressure, pressure drop, and downstream temperature.

Because several instruments are required to obtain these measured quantities, the possible errors in measurements will have a cumulative effect on the accuracy of the predicted volume. Therefore, the cumulative material balance method will be based on the assumption that if a measured tank level differs from (is lower than) the expected (predicted) level by an amount exceeding the possible cumulative error total, then a potential leak will be assumed to have occurred and a leak investigation will be initiated along with the leak management strategy (Section 5.2.6.1). The amount of leakage that can be determined by material balance is currently estimated at $30.000 \mathrm{~L}(8.000 \mathrm{gal})$ (DOE 1995). 
Figure 4-10. Assumed Thermal Expansion Factor of the WRSS Liquid and Sludge.

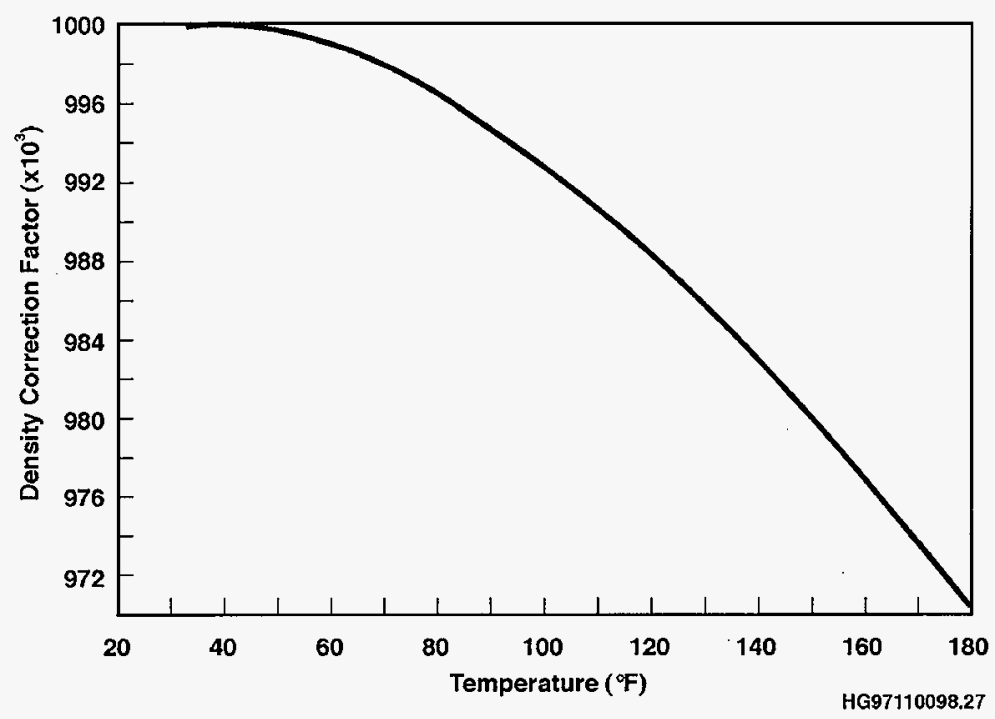


Procedure T0-320-003. Waste Retrieval STuicing System Material Balance, implements the batch material balance performed by operations. The cumulative material balance maintained by engineering is found in the Tank Waste Remediation System Process Engineering Instruction Manual (LMHC 1998).

Dry well Monitoring. In addition to the in-tank level measurement, eight dry wells located in the soil surrounding tank $241-\mathrm{C}-106$ will be monitored to provide a secondary means for detecting a possible leakage plume. These wells are open-bottom, mild steel cased, 15 - or 20-cm (6-or 8-in.) in diameter, and extend to depths of 25 to $33 \mathrm{~m}$ (75 to $100 \mathrm{ft}$ ). A leakage plume that migrate within detection range of the dry wells will be caught by this method. The monitoring uses radiation probes to detect a change in the radiation profile over the length of the dry well when compared with a baseline profile.

The wells will be monitored monthly to determine radiation profiles for the soil within several inches of the outer surface of the well. The frequency is based on an estimated maximum expected leak rate that results in a dry well response time ranging from 19 to 121 days (Isaacson 1981) The eight dry wells that will be monitored include $30-00-01,30-05-03,30-06-02,30-06-03$. $30-06-04,30-06-09,30-06-10$, and 30-06-12.

Because of the low percentage of soil interrogated and the long time frame required for leaks to migrate within range of the dry wells, detection of a small leakage volume is beyond the capabilities of the dry well system. However, the system would provide confirming information for the occurrence of a larger leak caused by either a continuing small leak or a large volume leak.

4.5.1.2 Tank 241-AY-102. A leak from the primary vessel of tank 241-AY-102 is detected by either a conductivity probe leak detection system installed in the annulus or a continuous air monitor (CAM) that detects airborne radionuclides entrained in the annulus ventilation exhaust stream. Detection of a leak into the annulus of the tank by either system activates an audible alarm and an annunciator panel light.

The tank annulus is designed to collect and direct waste that leaks from the primary tank to the annulus for detection and transfer. Slots cut in the insulating concrete that supports the tank at the bottom are designed to drain any leakage to the annulus floor. Three leak detection assemblies, each consisting of 17 conductivity probes, extend through an annulus riser into the annulus space. The bottom most conductivity probe on each assembly is located approximately $0.3 \mathrm{~cm}$ ( $1 / 8 \mathrm{in}$.) above the annulus floor. Upon contact with Tiquid, the leak detection element shorts, completing the electrical circuit to ground, and causes activation of an audible alarm and an annunciator panel light. The remaining conductivity probes are useful in determining the liquid level in the annulus in the event of a primary tank leak.

In addition to the conductivity probe assemblies, a radiation monitor leak detection system is installed on the annulus ventilation system to provide early warning of a potential leaking tank. An air sample is extracted from the annulus exhaust flow stream upstream of the HEPA filter and routed through a CAM, which scans the sample for radionuclide particles. An increase in radioactive particulate activity above the CAM setpoint would activate an alarm signifying a potential tank leak. 
4.5.1.3 Slurry and Sluice Pipelines. Liquid waste and slurries will be transferred between the sluice and receiver tanks using a double-wal?. interfarm pipeline system (see Section 3.5.1.1). Leakage from the primary transfer pipelines (inner pipes) wi11 be contained and detected by the secondary confinement system (outer pipe). The secondary confinement system has been designed to drain any fluid released from the primary piping to a common point for collection, detection, and removal. The hydraulics of the WRSS transfer system design cause any leakage to the secondary containment to drain towards either the 241-C-06A pump pit for the SL100 slurry transfer pipeline or the 241-C-06C sluice pit for the SN200 sluice transfer pipeline.

Leak detection elements are installed at the lower end of the secondary containment pipes to actuate an alarm and an annunciator light in the control room if a leak is detected (see Section 3.5.3.2).

\subsubsection{Tank 241-AY-102 Supernatant Chemical Composition}

Laboratory tests on tank 241-C-106 sludge samples identified a measurable buffering reaction when the samples were treated with a dilute sodium hydroxide solution (Herting 1996a). The buffering capacity was attributed to the presence of large amounts of sodium bicarbonate and amphoteric aluminum hydroxide. The study concluded that tank 241-C-106 sludge would consume significant amounts of hydroxide ion from the double-shel] tank sluice stream (tank 241-AY-102 supernatant) used for the waste retrieval. To counter this caustic demand, a chemical adjustment is made before beginning sluicing operations (see Section 3.2.6).

During WRSS retrieval, intermediate chemical adjustments may become necessary to maintain tank 241-AY-102 waste within the chemical operating specifications based on the grab sampling that is conducted during the monitoring periods. A chemical adjustment can be accomplished using the procedural approach outlined in Section 3.2.6 except for using air life circulators for mixing. Air lift circulators are disabled before the start of sluicing as a defensein-depth control for the tank bump accident of Addendum 1 of the Tank Waste Remediation System Basis for Interim Operations (FDH 1998a). The mixing of chemical additions will require adding a dilute sodium hydroxide solution $(\leq 5$ molar) and recirculating the supernatant between tanks 241-C-106 and 241-AY-102 until adequate mixing is achieved. Natural convection currents arising from the temperature difference across the solids-liquid interface will also mix the chemicals and tank supernatant.

\subsubsection{Criticality Safety}

A criticality assessment of the WRSS process has been completed (Vail 1997). The assessment used current fissile material inventories and waste characterization information in the analysis. The plutonium inventories of tanks 241-C-106 and 241-AY-102 were estimated at approximately $100 \mathrm{~kg}$ and $8 \mathrm{~kg}$, respectively. The study concluded that there were no credible mechanism that would constitute a nuclear criticality concern. 
HNF-SD-WM-PCP-013 REV. 1

Addendum 1 of the Tank Waste Remediation System Basis for Interim Operations (FDH 1998a) examined a bounding criticality accident for WRSS operations and concluded that an inadvertent criticality is considered extremely unlikely. Consequent7y, AC 5.7 - Nuclear Criticality Safety of the TSRs(FDH 1998b). specifies that"The concentration limit and subcritical mass ratios do not apply to the sluicing of tank 241-C-106 to tank 241-AY-102 under Project W-320." The applicability of AC 5.7 furthermore exempts any transfers made between tank farm facilities. No additional controls are required from the standpoint of criticality based on the criticality assessment for transfer of all tank 241-C-106 sludge to tank 241-AY-102.

\subsubsection{Separable Organic}

Organic material has been identified in tank 241-C-106 sludge that can be separated into a distinct phase under extreme laboratory conditions. This "sludge 0il" is mainly the sodium salt of bis (2-ethylhexyl) phosphoric acid, a low energy. largely nonreactive organic. Available data indicate that the physical forces, to which tank 241-C-106 waste will be subjected during the sluicing transfer, will be orders of magnitude less intense than those required to produce the separate organic phase. However, chemical dissolution of the solids, to which the organic liquid adheres, is postulated as a mechanism by which the sludge oil could subsequently separate from the remainder of the waste. Laboratory testing found the phase separation of the oil physically very unstable because the organic easily dispersed into the liquid layer by slight agitation. Once dispersed. there was no tendency of the oil to reseparate. During the tank 241-C-106 retrieval, the material pumped from the tank travels approximately $520 \mathrm{~m}(1,700 \mathrm{ft})$ under turbulent transport conditions before discharging below the liquid surface in tank 241-AY-102. Any tendency of the oil to separate in the slurry booster pump bowl or from solids dissolution will redisperse into the aqueous liquid phase as it flows through the transfer pipeline. No controls are required to protect against separable organic in the WRSS slurry receiver tank.

Like tank 241-AY-102, forming a separable organic phase in tank 241-C-106 is highly improbable for similar reasons. First. only a small portion of the waste is being disturbed by the sluicing actions during the retrieval before being pumped out and transferred to the receiver tank. Accumulation of the little amount of organic that could separate would be hindered by the processing operations. Also, the forces induced by the sluice stream are turbulent in nature which would act to disperse the organic as opposed to concentrate it through intense centrifugal action. Any organic extracted from the solid particles would easily disperse into the waste.

To confirm that the oil interacts as anticipated during the WRSS process, the supernatant surface in tank 241-AY-102 wi17 be sampled periodically. The surface samples wi 11 be shipped to the 222-S Analytical Laboratories for a visual of any separable organic. One sample will be taken following each of the increments. Additionally, the surface of the waste will be inspected for an oil slick during monitoring periods using the mobile color camera system. 
HNF-SD-WM-PCP-013 REV. 1

\subsection{PROCESS SAMPLING REQUIREMENTS AND SCHEDULE}

Grab samples, obtained from tank 241-AY-102 at specified intervals during the WRSS process, achieve the following objectives.

1. Supernatant samples are taken before sluicing operations begin to verify the end point of the pre-sluicing chemical addition operation and to establish a composition baseline for process control.

2. Tank 241-AY-102 supernatant and solids grab samples are taken after each sluice batch to refine the estimated amount of tank 241-C-106 sludge transferred, to estimate the heat load in the transferred solids, and to supplement the ENRAF ${ }^{\mathrm{TM}}$ densitometer measurement of supernatant density.

3. Surface samples are taken after each increment to verify the absence of an organic layer on the waste surface.

4. Periodically, samples are taken to update the chemical and radionuclide baseline of the waste.

Analyses will be performed to determine supernatant density, which is an input variable to the mass flowmeter computational algorithm, and to quantify the concentration of the major chemicals and radionuclides. During sluicing operations, some tank $241-\mathrm{C}-106$ solids dissolution is expected. This will cause a shift in the distribution of chemicals and radionuclides between the solids and liquid phases. These changes can affect tank 241-AY-102 sluicing fluid density, the distribution of the heat load in the tank, and solids fluffing. Monitoring these changes will enable adjustments to be made in the sluicing process operating parameters and in the evaluations performed to track the progress of the retrieval.

Table 4-12 lists the sampling and analysis requirements that will occur for each post-sluice batch monitoring period. Each sampling event will obtain the indicated number of grab samples using procedure T0-080-403. A11 sampling events will be made from the same location at riser 15-N. Each sample that is taken will be analyzed in duplicate. The turn around time for return of a11 sample analyses is about three to four analytical laboratory shifts from receipt of the sample shipment.

Additional sampling requirements may be specified by Process Engineering, Double-Shell Engineering, and Environmental Permits/Policy. 
Table 4-12. WRSS Sampling Requirements. (9 sheets)

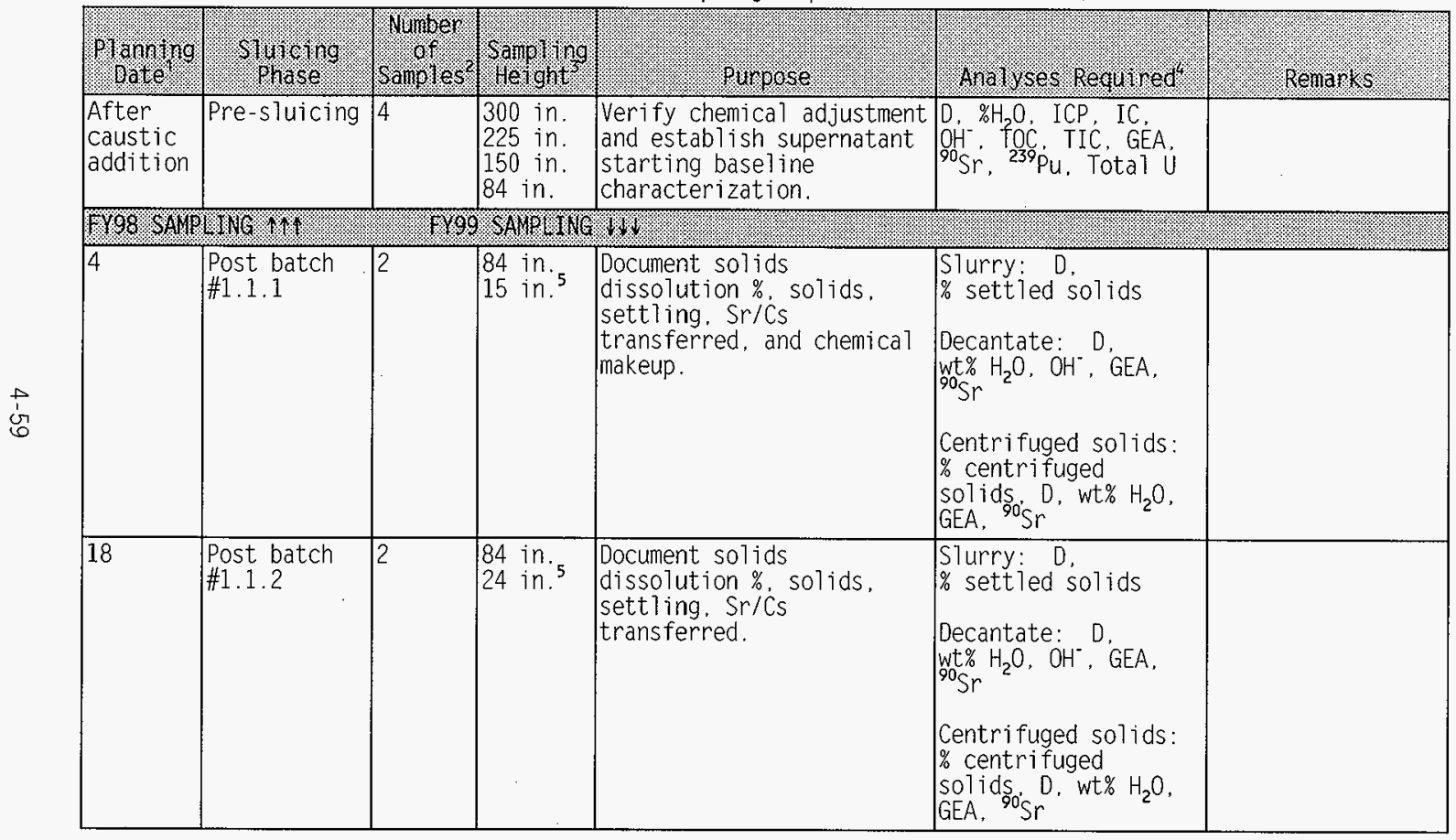


Table 4-12. WRSS Sampling Requirements. (9 sheets)

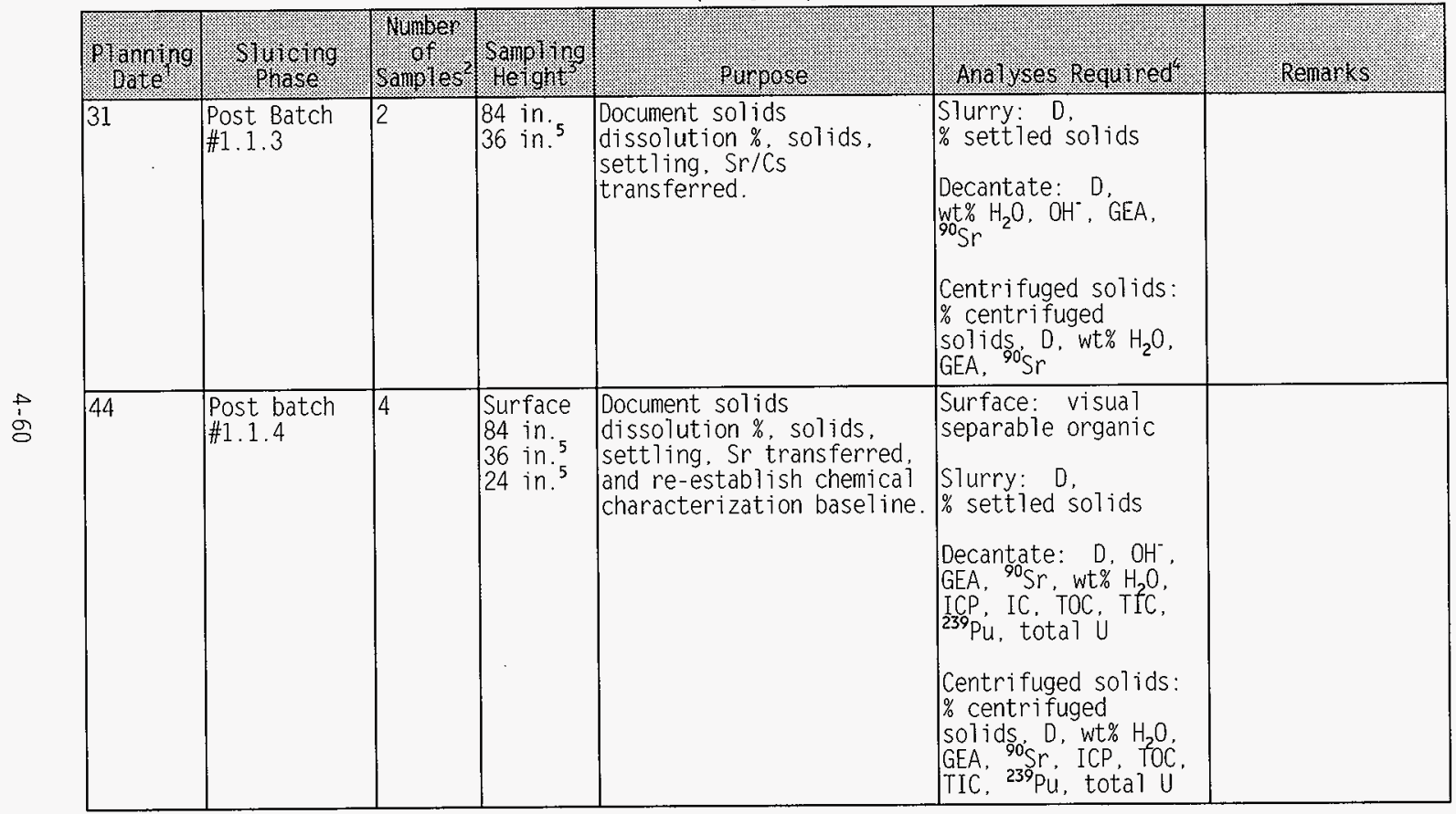


Table 4-12. WRSS Sampling Requirements. (9 sheets)

\begin{tabular}{|c|c|c|c|c|c|c|}
\hline Proming & $\begin{array}{l}\text { Shoring } \\
\text { - Phose }\end{array}$ & $\begin{array}{l}\text { Munger: } \\
\text { of } \\
\text { Sampres? }\end{array}$ & Sarniling & 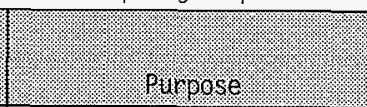 & 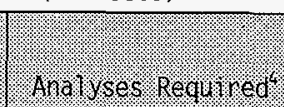 & Remart: \\
\hline 59 & $\begin{array}{l}\text { Post Batch } \\
\# 1.2 .1\end{array}$ & 2 & $\begin{array}{l}96 \text { in. } \\
36 \text { in. }^{-}\end{array}$ & $\begin{array}{l}\text { Document solids } \\
\text { dissolution \%, solids, } \\
\text { settling, Sr transferred. }\end{array}$ & 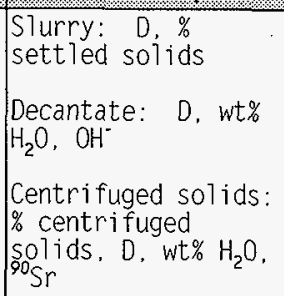 & $\begin{array}{l}\text { Assume ratio of } \\
\text { Cs/ }{ }^{\circ 0} \text { Sr in solids } \\
\text { same as prior } \\
\text { samples. Assume } \\
\text { distribution for } \\
\text { Cs and }{ }^{90} \text { Sr } \\
\text { between phases } \\
\text { same as prior } \\
\text { samples. }\end{array}$ \\
\hline 72 & $\begin{array}{l}\text { Post batch } \\
\# 1.2 .2\end{array}$ & 2 & $\begin{array}{l}96 \text { in. } \\
48 \\
48 \text { in. }\end{array}$ & $\begin{array}{l}\text { Document solids } \\
\text { dissolution \%, solids, } \\
\text { settling. Sr transferred. }\end{array}$ & $\begin{array}{l}\text { Slurry: } 0 \text {, } \\
\% \text { settled solids } \\
\text { Decantate: D, } \\
\text { wt\% } \mathrm{H}_{2} \mathrm{O}, \mathrm{OH}^{-} \\
\text {Centrifuged solids: } \\
\% \text { centrifuged } \\
\text { solids, } \quad \text {, wt\% } \mathrm{H}_{2} \mathrm{O} \text {, } \\
90 \mathrm{Sr}\end{array}$ & $\begin{array}{l}\text { Assume ratio of } \\
\mathrm{Cs} /{ }^{90} \mathrm{Sr} \text { in solids } \\
\text { same as prior } \\
\text { samples. Assume } \\
\text { distribution for } \\
\mathrm{Cs} \text { and }{ }^{90} \mathrm{Sr} \\
\text { between phases } \\
\text { same as prior } \\
\text { samples. }\end{array}$ \\
\hline
\end{tabular}


Table 4-12. WRSS Sampling Requirements. (9 sheets)

\begin{tabular}{|c|c|c|c|c|c|c|}
\hline Planving & 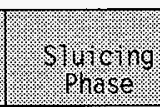 & $\begin{array}{l}\text { Numper } \\
\text { samples }\end{array}$ & Sampling & purpose: & Analyses : Required? & Remarks: \\
\hline 91 & $\begin{array}{l}\text { Post batch } \\
\# 1.2 .3\end{array}$ & 4 & $\begin{array}{l}\text { Surface } \\
96 \text { in. } \\
48 \text { in. } \\
36 \text { in. }{ }^{5}\end{array}$ & $\begin{array}{l}\text { Document solids } \\
\text { dissolution } \% \text {, solids, } \\
\text { settling, Sr/Cs } \\
\text { transferred, and } \\
\text { re-establish chemical } \\
\text { characterization baseline. }\end{array}$ & 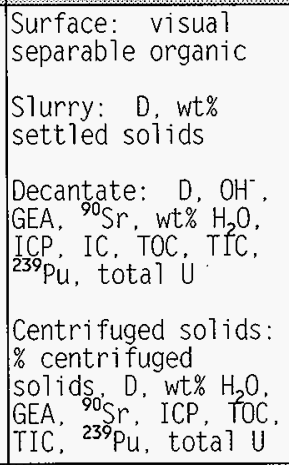 & \\
\hline 116 & $\begin{array}{l}\text { Post batch } \\
\# 2.1 .1\end{array}$ & 2 & $\begin{array}{l}96 \text { in. } \\
65 \text { in. }\end{array}$ & $\begin{array}{l}\text { Document solids } \\
\text { dissolution \%, solids, } \\
\text { settling. Sr transferred. }\end{array}$ & $\begin{array}{l}\text { Slurry: } \\
\text { D. \% settled solids } \\
\text { Decantate: D. } \\
\text { wt\% } \mathrm{H}_{2} \mathrm{O}, \mathrm{OH}^{-} \\
\text {Centrifuged solids: } \\
\% \text { centrifuged } \\
\text { solids. O, wt\% } \mathrm{H}_{2} \mathrm{O} \text {, } \\
90 \mathrm{Sr}\end{array}$ & $\begin{array}{l}\text { Assume ratio of } \\
\text { Cs/90 Sr in solids } \\
\text { same as prior } \\
\text { samples. Assume } \\
\text { distribution for } \\
\text { Cs and } 90 \mathrm{Sr} \\
\text { between phases } \\
\text { same as prior } \\
\text { samples. }\end{array}$ \\
\hline
\end{tabular}


Table 4-12. WRSS Sampling Requirements. (9 sheets)

\begin{tabular}{|c|c|c|c|c|c|c|}
\hline 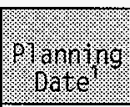 & Stulcing: & $\begin{array}{l}\text { Number? } \\
\text { or } \\
\text { Samples }\end{array}$ & Samelighe? & 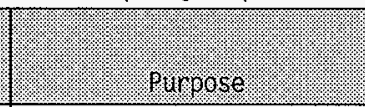 & 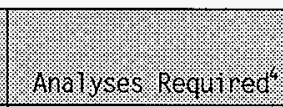 & 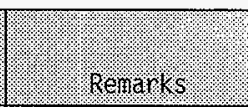 \\
\hline 122 & $\begin{array}{l}\text { Post batch } \\
\# 2.1 .2\end{array}$ & 4 & $\begin{array}{l}\text { Surface } \\
96 \text { in. } \\
65 \text { in. } \\
48 \text { in. }\end{array}$ & $\begin{array}{l}\text { Document solids } \\
\text { dissolution \%, solids, } \\
\text { settling. Sr transferred. }\end{array}$ & $\begin{array}{l}\text { Surface: visual } \\
\text { separable organic } \\
\text { Slurry: D, \% } \\
\text { settled solids } \\
\text { Decantate: } \mathrm{D}, \mathrm{OH}^{-}, \\
\text {GEA, Sr-90, wt\% } \mathrm{H}_{2} \mathrm{O} \text {. } \\
\text { ICP, IC, TOC TIC, } \\
\text { I39Pu, total U } \\
\text { Centrifuged solids: } \\
\% \text { centrifuged } \\
\text { solids, D, wt\% } \mathrm{H}_{2} \mathrm{O}, \\
\text { GEA, } 90 \mathrm{Sr} \text {, ICP, TOC, } \\
\text { TIC, }{ }^{339} \mathrm{Pu} \text {, total U }\end{array}$ & \\
\hline 137 & $\begin{array}{l}\text { Post batch } \\
\# 2.2 .1\end{array}$ & 2 & $\begin{array}{l}108 \text { in } \\
80 \text { in. }\end{array}$ & $\begin{array}{l}\text { Document solids } \\
\text { dissolution \%, solids, } \\
\text { settling. Sr transferred. }\end{array}$ & $\begin{array}{l}\text { Slurry: } \mathrm{D}, \% \\
\text { settled solids } \\
\text { Decantate: } \mathrm{D}, \\
\text { wt\% } \mathrm{H}_{2} \mathrm{O}, \mathrm{OH}^{-} \\
\text {Centrifuged solids: } \\
\% \text { centrifuged } \\
\mathrm{Sol}^{\circ} \mathrm{ids}, \mathrm{O} \text {, wt\% } \mathrm{H}_{2} \mathrm{O} \text {, } \\
{ }^{90} \mathrm{Sr}\end{array}$ & $\begin{array}{l}\text { Assume ratio of } \\
\text { Cs/90sr in solids } \\
\text { same as prior } \\
\text { samples. Assume } \\
\text { distribution for } \\
\text { Cs and }{ }^{90} \text { Sr } \\
\text { between phases } \\
\text { same as prior } \\
\text { samples. }\end{array}$ \\
\hline
\end{tabular}


Table 4-12. WRSS Sampling Requirements. (9 sheets)

\begin{tabular}{|c|c|c|c|c|c|c|}
\hline Pronolyg: & 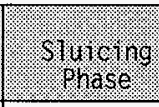 & $\begin{array}{l}\text { ilutber: } \\
\text { samples? }\end{array}$ & 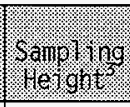 & 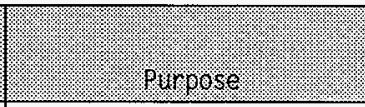 & Inalyses reglitired: & : 8 emarts. \\
\hline 149 & $\begin{array}{l}\text { Post batch } \\
\# 2.2 .2\end{array}$ & 4 & $\begin{array}{l}\text { Surface } \\
108 \text { in. } \\
80 \text { in. } \\
65 \text { in. }\end{array}$ & $\begin{array}{l}\text { Document solids } \\
\text { dissolution } \% \text {, solids, } \\
\text { settling. Sr/Cs } \\
\text { transferred and } \\
\text { re-establish chemical } \\
\text { characterization baseline. }\end{array}$ & 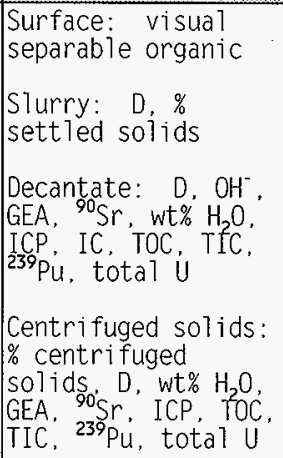 & \\
\hline 174 & $\begin{array}{l}\text { Post batch } \\
\# 3.1 .1\end{array}$ & 2 & $\begin{array}{l}108 \text { in } \\
96 \text { in. }^{5}\end{array}$ & $\begin{array}{l}\text { Document solids } \\
\text { dissolution \%, solids, } \\
\text { settling. Sr transferred. }\end{array}$ & 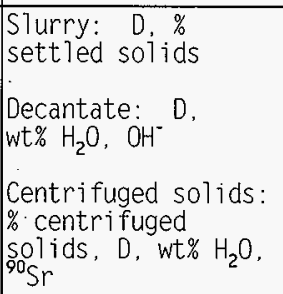 & $\begin{array}{l}\text { Assume ratio of } \\
\mathrm{Cs} /{ }^{\circ 0} \mathrm{Sr} \text { in solids } \\
\text { same as prior } \\
\text { samples. Assume } \\
\text { distribution for } \\
\text { Cs and }{ }^{90} \mathrm{Sr} \\
\text { between phases } \\
\text { same as prior } \\
\text { samples. }\end{array}$ \\
\hline
\end{tabular}


Table 4-12. WRSS Sampling Requirements. (9 sheets)

\begin{tabular}{|c|c|c|c|c|c|c|}
\hline Plonning & 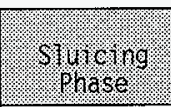 & $\begin{array}{l}\text { Mumiver: } \\
\text { of } \\
\text { of }\end{array}$ & S Sampling & Purpose: & 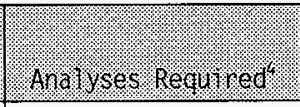 & Remarls: \\
\hline 180 & $\begin{array}{l}\text { Post batch } \\
\# 3.1 .2\end{array}$ & 4 & $\begin{array}{l}\text { Surface } \\
120 \text { in. } \\
96 \text { in. } \\
84 \text { in. }\end{array}$ & $\begin{array}{l}\text { Document solids } \\
\text { dissolution \%, solids, } \\
\text { settling, Sr/Cs } \\
\text { transferred. }\end{array}$ & 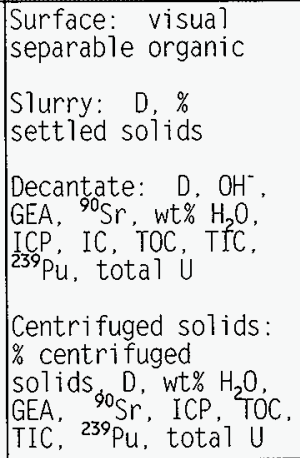 & \\
\hline \begin{tabular}{|l}
195 \\
\end{tabular} & $\begin{array}{l}\text { Post batch } \\
\# 3.2 .1\end{array}$ & 2 & $\begin{array}{l}132 \text { in. } \\
108 \text { in. }^{5}\end{array}$ & $\begin{array}{l}\text { Document solids } \\
\text { dissolution \%, solids, } \\
\text { settling. Sr transferred. }\end{array}$ & $\begin{array}{l}\text { Slurry: } \mathrm{D}, \% \\
\text { settled solids } \\
\text { Decantate: } \mathrm{O} \text {, } \\
\text { wt\% } \mathrm{H}_{2} \mathrm{O}, \mathrm{OH}^{-} \\
\text {Centrifuged solids: } \\
\% \text { centrifuged } \\
\text { solids, } \mathrm{O} \text {, wt\% } \mathrm{H}_{2} \mathrm{O} \text {, } \\
90 \mathrm{Sr}\end{array}$ & $\begin{array}{l}\text { Assume ratio of } \\
\text { Cs/90 Sr in solids } \\
\text { same as prior } \\
\text { samples. Assume } \\
\text { distribution for } \\
\text { Cs and }{ }^{90} \text { Sr } \\
\text { between phases } \\
\text { same as prior } \\
\text { samples. }\end{array}$ \\
\hline
\end{tabular}


Table 4-12. WRSS Sampling Requirements. (9 sheets)

\begin{tabular}{|c|c|c|c|c|c|c|}
\hline Planning & $\begin{array}{l}\text { Shlucling? } \\
\text { Phase? }\end{array}$ & Simpinger & Sampiting & purcoses: & Analisses required & 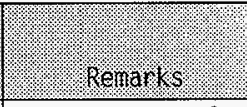 \\
\hline 201 & $\begin{array}{l}\text { Post batch } \\
\# 3.2 .2\end{array}$ & 2 & 144 in. & $\begin{array}{l}\text { Document solids } \\
\text { dissolution \%, solids, } \\
\text { settling. Sr transferred. }\end{array}$ & $\begin{array}{l}\text { Slurry: } \mathrm{D}, \% \\
\text { settled solids } \\
\text { Decantate: } \mathrm{D}, \\
\text { wt\% } \mathrm{H}_{2} \mathrm{O}, \mathrm{OH}^{-} \\
\text {Centrifuged solids: } \\
\% \text { centrifuged } \\
\text { solids, D, wt\% } \mathrm{H}_{2} \mathrm{O} \text {, } \\
{ }^{0} \mathrm{~S} \text { Sr }\end{array}$ & $\begin{array}{l}\text { Assume ratio of } \\
\text { Cs/90 Sr in solids } \\
\text { same as prior } \\
\text { samples. Assume } \\
\text { distribution for } \\
\text { Cs and }{ }^{90} \text { Sr } \\
\text { between phases } \\
\text { same as prior } \\
\text { samples. }\end{array}$ \\
\hline 213 & $\begin{array}{l}\text { Post batch } \\
\# 3.2 .3\end{array}$ & 4 & $\begin{array}{l}\text { Surface } \\
162 \text { in. } \\
108 \text { in. } \\
96 \text { in. }^{5}\end{array}$ & $\begin{array}{l}\text { Document solids } \\
\text { dissolution \%, solids, } \\
\text { settling, Srics } \\
\text { transferred and establish } \\
\text { final chemical } \\
\text { characterization baseline. }\end{array}$ & 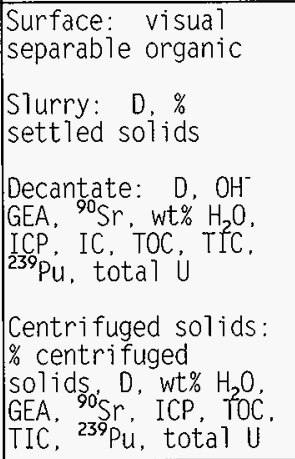 & \\
\hline
\end{tabular}


Table 4-12. WRSS Sampling Requirements. (9 sheets)

\begin{tabular}{|c|c|c|c|c|c|c|}
\hline 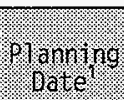 & Prover & Wramer & Hangerghts & 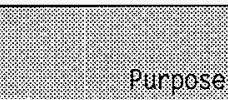 & Arav yses regurred' & Remar ofs \\
\hline Total (Ev & S/Samples & $17 / 48$ & & & & \\
\hline
\end{tabular}

Notes:

Density

ICP $\quad=\quad$ Inductively Coupled Plasma Spectrometer (Metals)

$\mathrm{IC}=$ I $=$ Con Chromatograph (Anions- $\mathrm{F}, \mathrm{C1}, \mathrm{NO}_{3}, \mathrm{NO}_{2}$, etc.) Total Alpha $=$ Pu

\section{sr-90 = $\quad$ Strontium 90 analys is}

TOC $\quad$ Total Organic Carbon

$\mathrm{OH}^{-} \quad=$ Hydroxide analysis

${ }^{2} P$ lanning dates are the number of dates after the start of sluicing operations.

${ }^{2} \mathrm{All}$ samples to be taken from riser $15-\mathrm{N}$.

${ }^{3}$ Sampling height is measured up from the tank bottom. These levels are preliminary and will be adjusted based on actual solids level measurements.

All samples are analyzed in duplicate.

${ }^{5}$ Take the sample at this level unless it will not penetrate to the indicated level; in which case, take sample at maximum penetration level and record level sample taken. 
HNF-SD-WM-PCP-013 REV. 1

This page intentionally left blank. 
HNF-SD-WM-PCP-013 REV. 1

\subsection{RESPONSE TO OFF-NORMAL CONDITIONS}

During conduct of the WRSS process, potential process upsets and facility upsets may occur. Process upsets may include pipeline plugging, reduced subcooling margin in tank 241-C-106, tank 241-AY-102 waste temperature prediction exceeding temperature control limits, and flammable gas retention higher than control limits. Possible facility upsets include equipment failures. transfer pipeline leaks, and tank leaks. These and other off-normal conditions together with recovery actions are described in the following sections.

\subsection{PROCESS UPSETS}

Process-related off-normal events may occur as a result of transferring the radiogenic high-heat sludge from tank 241-C-106 into tank 241-AY-102. The single characteristic that distinguishes these events as process upsets is that sluicing operations must be discontinued until parameters associated with the waste itself return to within control limits and/or expected ranges. Process upsets for the WRSS process include reduced subcooling margin in tank 241-C-106, tank 241-AY-102 waste temperatures potentially exceed temperature. control limits, flammable gas retention higher than control limits, pipeline plugging, aerosol formation in tank 241-C-106, and system operating temperature exceeding limit. The responses to these process-related off-normal events are presented in this section.

\subsubsection{Loss of Tank 24I-C-106 Sludge Subcooling Margin}

An extended delay in sluicing operations during the first campaign could cause a reduction in the required subcooling margin of the tank 241-C-106 sludge. Depending on the quantity of sludge retrieved from the tank. sludge temperatures could increase approximately $0.03{ }^{\circ} \mathrm{C}\left(0.05{ }^{\circ} \mathrm{F}\right)$ per day with the 296-C-006 ventilation system operating (Bander et al. 1996 and Sathyanarayana 1997b). If the calculated pre-sluicing subcooling margin is reduced at any time during the sluicing operations or if sluicing shutdown is anticipated to extend beyond 20 days, ventilation of the tank will be aligned to operate the 296-P-16 exhauster and the inlet air chiller system. Air cooled to $4.4{ }^{\circ} \mathrm{C}$ $\left(40^{\circ} \mathrm{F}\right)$ will ventilate the tank until sluicing start up is desired and the required subcooling is achieved. The response to this off-normal event is applicable only for the first campaign. Sufficient sludge cooling is expected to occur by the time $0.6 \mathrm{~m}$ ( $2 \mathrm{ft}$ ) of sludge has been retrieved such that waste temperatures will not exceed local saturation temperatures at any location in the tank waste.

\subsubsection{Tank 241-AY-102 Steady-State Temperature Predictions Above Limits}

There are two possible causes for higher tank 241-AY-102 steady-state temperatures that exceed the LCS/LCO 3.3.2. "DST and AWF Tank WASTE

Temperature controls," of the TWRS technical safety requirements (FDH 1998b). First, the total radiogenic heat load of the tank may be too high for the 
HNF-SO-WM-PCP-013 REV. 1

transport processes to dissipate the heat without causing a high temperature difference between the heating source and available heat sinks. Second, the sluiced sludge from tank 241-C-106 may deposit in layers of nonuniform heat distribution. A high-heat generating layer deposited near the middle of the settled solids bed may create a hot zone where temperatures could exceed Timits because of insufficient heat transfer.

For the off-normal event where the predicted tank 241-AY-102 steady-state temperatures exceed the LCS/LCO 3.3.2 7imits because of a high total heat load, the condition can occur by two separate processes. First, excessive mass transfer could occur as a result of nominal sluicing operations. This is unlikely, however, because of the conservative process control strategy adopted for the sluicing. The second process results from taking corrective action if high gas retention in the tank is indicated and the supernatant is removed to reduce the potential for a buoyancy-induced rollover (see Section 5.1.3.3). If the retrieval has progressed beyond the first campaign. then lowering the supernatant level to below $4.6 \mathrm{~m}$ (180 in.) causes the waste temperature control limit to resort to the more conservative $91{ }^{\circ} \mathrm{C}$ (195 ${ }^{\circ} \mathrm{F}$ ) limit (equivalent to the increment 1.1 limits of Table 4-7 for the applicable thermocouples that monitor the waste temperatures). If steady-state temperatures had been predicted to exceed $91^{\circ} \mathrm{C}\left(195{ }^{\circ} \mathrm{F}\right.$ ) but comply with the LCS/LCO 3.3.2 limits, then an off-normal condition would exist.

The response to the off-normal event where the predicted tank 241-AY-102 steady-state temperatures exceed the LCS/LCO 3.3.2 1imits because a high total heat load is as follows.

1. Shutdown sluicing operations, if under way.

2. Continue to monitor the instrumentation required to collect the data needed for performing thermal analysis (see Section 4.3.2.3). The purpose of this monitoring is to determine if the physical parameters (i.e., waste fluffing and thermal conductivity) important to the thermal behavior of the tank become more favorable. As the sludge continues to consolidate and compact in the tank bottom, the waste fluffing will decrease and the thermal conductivity will increase. Both of these trends will improve heat transfer and consequently lower steady-state temperatures.

3. Calculate steady-state temperatures once every 15 days using the WRSS thermal models and compare results with the temperature limits of Table $4-7$ or $91^{\circ} \mathrm{C}$ ( $\left.195^{\circ} \mathrm{F}\right)$, if supernatant has been removed to below $4.6 \mathrm{~m}$ (180 in.) after completing the first increment. The thermal modeling results will be reviewed by the Tank 241-C-106 Waste Retrieval Technical Review Group and a decision made to either proceed with sluicing, continue monitoring/evaluation activities or implement mitigating actions.

4. Upon a recommendation of the TRG to implement mitigating actions. either a backup air blower will be installed to increase the annulus bottom flow channel cooling capacity (i.e. increase air flow rate to $1,200 \mathrm{cfm}$ ) or the blower together with an inlet air chiller will be installed. A thermal analysis using the most current waste 


$$
\text { HNF-SD-WM-PCP-013 REV. } 1
$$

properties will determine the level of modification required and the time available for installing and starting up the equipment.

The response to the off-normal event caused by an axially varying heat load distribution in the transferred waste in tank 241-AY-102 is the same as that listed for the total high-heat load case. However. as the retrieval progresses, steps can be taken to avoid such an event. If a lower than expected heat load (as determined from sampling following each batch and thermal analysis after each increment) is transferred during the first campaign, then a nonuniform heat distribution would be anticipated in tank 241-C-106. Continuing to transfer layers of sludge may lead to an unacceptable axially varying heat load distribution in tank 241-AY-102. Therefore, an additional response to avoid an off-normal condition is warranted. In this case, actions will be taken to homogenize the tank 241-C-106 waste using the procedure outlined in Section 4.1.3. This same homogenization step can be repeated throughout the retrieval as evidence of concentrated heat generating material is encountered.

\subsubsection{Tank 241-AY-102 Flammable Gas Retention Above Limits}

This section presents the actions to be taken upon detection of off-normal conditions relating to flammable gas retention and release. Current estimates of post-transfer conditions in tank 241-AY-102 indicate that a high void retention that could lead to a large gas release event (GRE) is not expected to occur. Also flammable gas buildup is so slow that it is essentially unmeasurable until after one campaign, and it is virtually impossible for a GRE to occur before sluicing is complete, even under the worst possible conditions. Using the measured gas generation rates in tanks $241-C-106$ and 241-AY-102, and assuming that 211 the gas generated is retained (not physically possible), the maximum void fraction after 100 -days of sluicing would be only 13 percent. While this gas volume would probably be measurable. it would take another 130 days to reach the 23 percent void fraction required to cause a buoyant instability at the maximum fluffing factor of 1.8 (higher void is required for less fluffing). However, as discussed by Pasamehmetogiu et a 1. (1997), there is considerable uncertainty in the arguments. The process control logic outlined in Section 4.4 was aimed at collecting data on gas retention and identifying the potential for significant gas retention and release in tank 241-AY-102.

\subsubsection{Off-normal Conditions During Sluicing Operations. Off-norma 1} conditions during sluicing operations include: detection of hydrogen concentrations greater than $5,000 \mathrm{ppm}$ in either tank $241-\mathrm{C}-106$ or tank 241-AY-102, ventilation failure in either tank. loss of negative pressure in either tank, and detection of excessive foaming in tank 241-AY-102. As noted in Section 4.4.2.2, the sluicing operations are required to be shut down in less than 15 minutes if any of these conditions arise. Operations should be restarted only after verifying that dome hydrogen concentrations are less than $500 \mathrm{ppm}$ in both tanks.

\subsubsection{Off-normal Conditions During Monitoring Period Following Transfer} The first measurement point for flammable gas is after the first campaign. which has been shown from thermal analysis to resolve the high-heat issue. 
HNF-SD-WM-PCP-013 REV. I

Significant gas retention is not expected at this point in the retrieval process as discussed above. However, the worst-case GRE after a $0.61 \mathrm{~m}(2 \mathrm{ft}$ ) transfer has been evaluated and determined to result in a dome space concentration much less than the lower flammability limit (LFL) (Pasamethetoglu et al. 1997). Therefore, the potential for a flammable gas off-normal condition to occur before resolving the high-heat safety issue for tank 241-C-106 is highly unlikely if not virtually impossible. As discussed in Section 4.4.3.2. if TRG evaluation of data during the monitoring period indicates that high void retention is occurring in tank 241-AY-102. no further waste transfer will be made from tank 241-C-106. Exceptions to this are if a limited additional transfer is deemed necessary to resolve the high-heat issue in tank 241-C-106, or if a leak has been detected in tank 241-C-106 and additional transfer is required to minimize the consequences of the leak. The TRG must evaluate the most recent data for anticipated gas generation and level-rise rates before deciding whether to perform an emergency transfer.

5.1.3.3 Off-normal Conditions After Completion of Transfer. After completion of the WRSS operations, when all sluicable solids are removed from tank 241-C-106. the principal concern is long-term gas retention in tank 241-AY-102. If high void retention in tank 241-AY-102 is indicated, deployment of the void fraction instrument (VFI) must be considered as a means to verify the void fraction. A contingency plan for deplayment of the VFI wi 11 be in place before sluicing begins (FDH 1998a and Pasamethetoglu et al. 1997). If the VFI indicates low void, it could be assumed that the observed level changes are caused by phase changes other than gas retention.

If high gas retention is indicated, the supernatant will be removed to reduce the potential for a buoyancy induced rollover and to increase the tank headspace to reduce the consequences. The TRG will review available data and make recommendations on supernatant removal with appropriate consideration of waste temperature limits (see Section 5.1.2).

\subsubsection{Transfer Pipeline Plugging}

Historical experience indicates that transfer pipeline plugging due to the settling of solids occurs gradually and can be detected by monitoring the transfer flow rate and/or pressure. For the WRSS process, the flow rate is the more sensitive parameter and will be together with the mass flowmeter monitored during sluicing operations to control slurry solids concentration and the onset of plugging, if it occurs (see Section 4.1.1). Because the procedure to start batches involves starting with a dilute slurry flow and gradually increasing and controlling the solids loading in the slurry pumped from tank 241-C-106, timely corrective process control measures are expected to prevent the transfer pipeline from plugging.

In the unlikely event that design features and operating process controls are unsuccessful in preventing a pipeline plug. the following graded approach will be implemented as required to clear the plug from the pipeline.

1. At the tank 241-AY-102 end of the transfer pipeline, the cover block plug over the flush connection nozzle wi 11 be removed and the flush 
HNF-SD-WM-PCP-013 REV. 1

adapter installed. Pressurized hot water (maximum allowable pressure is 2.206 $\mathrm{kPa}[320 \mathrm{psig}]$ ) is used to remove the plug.

2. The tank 241-C-106 end pit is opened and the associated jumper is removed. A pressure test jumper is connected to the plugged transfer line and pressurized hot water (maximum allowable pressure is $2,206 \mathrm{kPa}$ [320 psig]) is used to remove the plug.

3. A commercially available hydrolase system will be installed to remove the plug. The hydrolase systems are special, moderate-pressure to high-pressure spray heads attached to a flexible hose. These systems are inserted into the pipeline until the spray head is in contact with the plug material. Water is then forced through the spray head to dislodge and flush the plug solids from the transfer pipeline. Because of the free-draining nature of the hydrolysing process, any pressure increase in the transfer pipeline will be limited to the design pressure of 2,206 $\mathrm{kPa}$ (320 psig).

4. If a 11 attempts to remove the plug fail, bypassing the plugged section of the pipeline will be considered. In replacing the pipe section. ALARA considerations are assessed, the obstruction is located by gamma assay (or other methods), and confinement barriers are placed around the area. Waste containment considerations are also assessed before excavating the berm, cutting and removing the pipeline, and replacing and welding the new pipe section.

\subsubsection{Aerosol Formation in Tank 241-C-106}

Past practice seems to indicate that fog formation during sluicing is more of an operational rather than an equipment design issue. Rodenhizer (1987) reports a history of fog clearing methods attempted during past sluicing campaigns. In 241-U Tank Farm, fog was a continual problem. Attempts to control the fog with water, steam, and $\mathrm{CO}_{2}$ additions were generally unsuccessful. The most effective method of eliminating fogging was to fill the effected tank with supernatant and then pump it back out. Spraying water into the tank to lower tank temperature $5^{\circ} \mathrm{C}\left(9^{\circ} \mathrm{F}\right)$ was also found to be effective. In tank 241-U-101, the addition of $50 \mathrm{lbs}$ of $\mathrm{CO}_{2}$ cleared fog in 20-30 minutes.

Control of fog during sluicing operations is accomplished by the design of the WRSS ventilation system (see Section 3.4.2.2). However, if excessive build-up of fog inside tank 241-C-106 occurs. sluicing may have to be interrupted to allow the ventilation system to improve in-tank visibility to acceptable levels. Fog/aerosol concentration is of concern to the WRSS process for two reasons. First, fog can directly affect the source term used in safety analysis of the 296-C-006 ventilation system. Second. fogging has the potential to interfere with the operation of the in-tank imaging system used to monitor sluicing progress and effect optimum directional control of the sluicing stream. 
HNF-SD-WM-PCP-013 REV. 1

\subsubsection{System Operating Temperature Limit Exceeded}

The WRSS system transfer pipeline and pumping equipment are designed to a $82{ }^{\circ} \mathrm{C}\left(180^{\circ} \mathrm{F}\right)$ structural 7 imit and specified to run below a $49{ }^{\circ} \mathrm{C}\left(120{ }^{\circ} \mathrm{F}\right)$ operating limit. Consequentiy, an important consideration for the WRSS is the waste and other operating temperatures that will result from the sluicing operation. The sources of energy input to the process are the radioactive decay heat production in the tank wastes and the heat input from the process pumps. Heat wi 17 be rejected from the system by mechanisms of convection. with the tank ventilation systems removing energy by means of the sensible heat of air (transferring heat to the influent air) and the latent heat of water (evaporation), and to a lesser extent by conduction through tank and piping surfaces. The difference between the heat produced and heat rejected during system operation wil1 result in a temperature change in the process wastes.

WRSS energy balance studies indicates that the key parameters in determining system temperatures will be the duration of sluicing operations, the length of time the transfer pumps operate, and the heat removal capacities of the tank ventilation systems (Fox 1994a and Fox 1994b). Based on the case most closely resembling the baseline flowsheet (except for near continuous pumping system operations and approximately 30 percent lower tank 241-AY-102 starting supernatant leve1), Table 5-1 lists the resulting supernatant temperatures that were estimated depending on the duration of sluicing operations.

Table 5-1. Estimated Sluicing Stream Temperatures for Varying Sluicing Operating Durations.

\begin{tabular}{|c|c|}
\hline 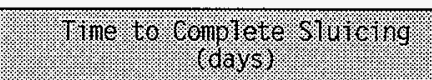 & 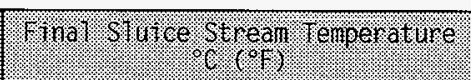 \\
\hline 30 & $36(97)$ \\
\hline 60 & $43(109)$ \\
\hline 120 & $52(126)$ \\
\hline 365 & $62(144)$ \\
\hline
\end{tabular}

These results indicate a wide margin between tank 241-AY-102 supernatant temperatures and the WRSS transfer system structural design temperature limit. Also, because of the conservative assumptions made in the energy balance studies, the actual supernatant temperatures are not expected to challenge the $49^{\circ} \mathrm{C}\left(120^{\circ} \mathrm{F}\right)$ operating $7 \mathrm{imit}$ : contrary to the conclusions explicit in the Table 5-1 values. The higher initial tank 241-AY-102 supernatant volume (i.e.. 30 percent) represents a significantly larger heat sink that would mitigate the apparently high operating temperatures shown in the table. Additionally, the pumping systems are operated for only a very short time period (hours) before sluicing operations revert to lengthy monitoring periods (days). With operating efficiencies of much less than 10 percent (see 
Section 3.3), the heat removal capacity of the 296-C-006 and 241-AZ-702 ventilation systems more than compensates for the heat introduced by the pumping system operations.

If a $49{ }^{\circ} \mathrm{C}\left(120^{\circ} \mathrm{F}\right)$ tank $241-\mathrm{AY}-102$ supernatant temperature could be reached. which is highly unlikely, sluicing operations would be shut down while the tank ventilation systems operate to dissipate the high temperature condition.

\subsection{FACILITY UPSETS}

Facility upsets are those off-normal events that occur as a result of the non-availability of equipment and support systems necessary to continue with sluicing operations. These type of events normally do not result from the transfer of tank 241-C-106 waste but wi11 limit the continuity of sluicing operations, if they occur. Some facility upsets for the WRSS process include loss of tank 241-C-106 and/or tank 241-AY-102 ventilation systems, loss of electrical power. loss of chilled water to the 296-C-006 ventilation system. and a leaking tank or transfer pipeline. These upsets are presented in this section.

The use of the completion time "immediate" in this section has the same meaning as found in the Tank Waste Remediation System technical safety requirements (FDN 1998b). A completion time of immediate requires action to be commenced without delay, and continuously pursued in a controlled manner until complete. A maximum completion time is established and documented based on an evaluation of the prevalent conditions.

\subsubsection{Loss of 296-C-006 Ventilation System}

If the tank 241-C-106 ventilation system (296-C-006) becomes inoperable for any reason, shut down of sluicing operations including the transfer pump systems will begin immediately. Follow the procedure outlined in Section 4.1.5 for transfer pipeline flushing. The recovery actions of Limiting Condition of Operation 3.2.2. "SST Ventilation System-Active, "will also be implemented immediately (FDH 1998b). If the ventilation system cannot be restarted immediately, either the 296-P-16 exhauster will be re-started or, if it is unavajlable, a portable exhauster will be connected to a tank riser to provide interim ventilation (see section 3.5 .2 .3 ). The interim ventilation capability must be operational within 126 days of the shutdown of the 296-C-006 ventilation system (FDH 1998b). Sluicing shall not be restarted until the 296-C-006 ventilation system operation is restarted.

\subsubsection{Loss of 241-AZ-702 Primary Ventilation System}

If the tank 241-AY-102 primary ventilation system (241-AZ-702) becomes inoperable for any reason, shut down of sluicing operations will begin immediately and be completed in less than 15 minutes following the procedure outlined in Section 4.1.1. The recovery actions of LCO 3.2.1, "DST and AWF Tank Ventilation Systems," will also be implemented (FDH 1998b). If the ventilation system cannot be restarted immediately, a portable exhauster will 
be connected to a tank riser to provide interim ventilation (see Section 3.5.2.3). The interim ventilation capability must be operational within 250 days of the shutdown of the 241-AZ-702 ventilation system (Ogden et a1. 1998). Sluicing shall not be restarted until the 241-AZ-702 ventilation system operation is restarted.

\subsubsection{Loss of 296-A-16 Annulus Ventilation System}

If the tank 241-AY-102 annulus ventilation system (296-A-16) becomes inoperable for any reason, shut down of sluicing operations will begin immediately and be completed in less than 15 minutes following the procedure outlined in Section 4.1.1. Verify that the annulus conductivity leak detection system is operable. If found inoperable, implement the recovery actions of LCO 3.2.6, "Primary Tank Leak Detection Systems," (FOH 1998b). The recovery actions of LCO 3.3.3. "Tank 241-AY-102 Annulus Venti lation System," will also be implemented for a loss of ventilation event. If the ventilation system cannot be restarted immediately, a portable exhauster will be connected to a tank riser to provide interim ventilation (see section 3.5.2.3). The interim ventilation capacity must be operational within 25 days of the shutdown of the 296-A-16 ventilation system (Ogden et al. 1998). However, if the superantant level has been reduced in response to a high gas retention (see Section 5.1.3.3), interim ventilation must be operational within 19 days of the annulus ventilation shutdown. Sluicing sha11 not be restarted until the 296-A-16 ventilation system operation is restarted.

\subsubsection{Loss of Electric Power}

Upon loss of electric power, the sluice and slurry pump systems will de-energize. Additionally, the tank ventilation systems will de-energize and the tanks will revert to passive breathing. The responses to losses in ventilation are the same as in Sections 5.2.1, 5.2.2, and 5.2.3. Until power is restored, passive ventilation of tank $241-C-106$ will occur through both the unpowered 296-C-006 ventilation system and the cascade pipeline connecting it to tank 241-C-105 but will be at a greatly reduced flow rate. Valving in the 296-P-16 ventilation equipment would provide a more effective passing breathing pathway.

If power cannot be immediately restored to the ventilation systems, actions required to connect the portable exhausters wi 11 be initiated to provide interim ventilation (see Sections 5.2.1.5.2.2, and 5.2.3). The priority for use of the portable exhauster is as follows.

1. Tank 241-C-106, if the remaining heat load is greater than 50,500 Btu/hr (Ogden et a 1. 1998).

2. Tank 241-AY-102 annulus.

3. Tank 241-AY-102 primary tank. 
HNF-SD-WM-PCP-013 REV. 1

\subsubsection{Loss of Chilled Water Supply to HX-1361 Condenser}

The supply of chilled propylene glycol-water solution to the HX-1361 condenser of the 296-C-006 ventilation system is crucial to tank 241-C-106 temperature and contamination control. To minimize the moisture and contaminant load on the ventilation system, the WRSS pumps are to be manually shutdown upon detecting a loss of the coolant supply.

\subsubsection{Tank or Transfer Pipeline Waste Leak}

During the WRSS process, leak detection instrumentation and procedures are implemented to identify a leak in tank 241-C-106, tank 241-AY-102, and the transfer pipeline system. The specific responses to any of these leak events are presented in this section.

5.2.6.1 Tank 241-C-106 Leak. In the event of a tank 241-C-106 leak, actions consistent with the Tank Waste Remediation System Basis for Interim Operation (FDH 1998a) and Tank Waste Remediation System Technical Safety Requirements (FDH 1998b) will be followed. Currently these actions include the following.

- Stop sluicing.

- Minimize liquid level while complying with any applicable minimum liquid level controls.

- Maintain evaporative cooling pending a thermal analysis to determine the need to continue water additions.

- Determine if leak has stopped (by liquid level and dry wel1 monitoring).

From an overall risk perspective, removing as much material as possible from tank 241-C-106 is desirable to maintain the post-sluicing temperatures below saturation with the minimum of controls (i.e., discontinued water additions and active ventilation). Therefore, after consultation and concurrence with DOE-RL and Washington State Department of Ecology, the following decision logic/leak management strategy, which depends on the amount of sludge remaining in the tank, will be implemented if tank 241-C-106 is confirmed as a leaking tank.

- For less than $2 \mathrm{ft}$ of tank 241-C-106 sludge retrieved, sluicing wi11 continue until a minimum of $2 \mathrm{ft}$ of sludge has been transferred to tank 241-AY-102. This action will resolve the high-heat safety issue for the tank and eliminate the need for ongoing routine water additions. Stopping sluicing and continuing with water additions necessary to control tank temperatures below tank structural limits would further contaminate the environment.

- For greater than $2 \mathrm{ft}$ but less than $4 \mathrm{ft}$ retrieved. sluicing would continue for a leak volume determined not to exceed $150,000 \mathrm{~L}$ $(40,000 \mathrm{ga} 7)$. This leak volume is the most conservative estimate of 
release evaluated in the Project $W-320$ environmental assessment (DOE 1995). The assessment concluded that "No immediate human health effect are anticipated from this accident ..." Removal of $4 \mathrm{ft}$ of waste will allow for the elimination of both water additions and al] active cooling ( $i$.e., forced ventilation).

- For greater than $4 \mathrm{ft}$ retrieved, stop sluicing and take actions to minimize the leak volume.

In al1 cases, steps will be taken to control the liquid inventory in the tank to minimize the leak volume. This and other possible corrective actions are detailed in Hand et a1. (1996). The above leak management strategy is consistent with the preplanned actions to respond to abnormal conditions for tank 241-C-106 that could lead to excessive waste temperatures (Hand et al. (1996). This action plan is applicable if sluicing were delayed indefinitely because of a tank leak before resolving the high-heat. safety issue.

5.2.6.2 Tank 241-AY-102 Leak. If a potential leak from tank 241-AY-102 is detected, shut down of sluicing operations will begin immediately and be completed in less than 15 minutes following the procedure outlined in Section 4.1.1. The recovery actions of LCO 3.2.6, "Primary Tank Leak Detection System." will also be implemented (FDH 1998b). Sluicing shall not restart unless the detected leak in determined to be a false-positive event. In the event of a tank 241-AY-102 leak is verified, actions wi 11 be taken to place the tank in the safest possible condition while follow-on actions are determined in consultation with the DOE-RL and Ecology.

5.2.6.3 Transfer Pipeline Leak. If a leak from the WRSS transfer pipeline system is detected, shut down of sluicing operations will occur immediately (i.e. . the routine pipeline flushing procedure will not be performed). Emergency response procedures which implement AC 5.14 of the TWRS technical safety requirements (FDH 1998D) are also activated. A decision on whether to perform a water flush of the pipelines will be evaluated and incorporated as appropriate into the approved recovery plan.

If considered practical, repairing or bypassing the failed section of the pipeline will be considered. In replacing the pipe section. ALARA

considerations are assessed, the leak location is determined by gamma assay (or other methods), and confinement barriers are placed around the area. waste containment considerations are also assessed before excavating the berm, cutting and removing the failed pipeline section, replacing and welding the new pipe section. 
HNF-SD-WM-PCP-013 REV. 1

\subsection{REFERENCES}

Bander. T. J., B. A. Crea, and D. M. Ogden, 1996. Tank 241-C-106 S7uicing Evaluation. WHC-SD-WM-ER-588, Rev. 1, Westinghouse Hanford Company,

Richland, washington.

Bevins, R. R., 1998. Project W-320 Safety Class and Safety-Significant Equipment Engineering Evaluation (SEL). HNF-2050, Rev. 0. Numatec Hanford Corporation for Fluor Daniel Hanford, Inc., Richland, Washington.

Blaak, T. M. . 1997; Waste Compatibility Assessment of Tank 241-AY-102 Waste with Tank 24l-AP-106 Waste, (internal memorandum \#97-005 to G. N. Hanson. February 3), Lockheed Martin Hanford Corp., Richland, Washington.

DOE. 1995. Environmental Assessment: Tank 241-C-106 Past-Practice S7uicing Waste Retrieva7, DoE/EA-0933, U.S. Department of Energy, Richland, Washington.

Ecology. EPA, and DOE, 1996. Hanford Federal Facility Agreement and Consent Order, Washington State Department of Ecology. U.S. Environmental Protection Agency, and the U. S. Department of Energy, Olympia, Washington.

Fowler, K. D. . 1995, Tank Farm Waste Compatibility Program, WHC-SD-WM-0CD-015. Rev. 1, Westinghouse Hanford Company, Richland, Washington.

Fox. J. V., 1994a. An Analysis of Energy and Temperature Effects for Tank 241-AY-102, TR-W-320-126, Kaiser Engineers Hanford Company, Richland, Washington.

Fंox. J. V., 1994b, ICF Memo/Supplemental Results for W-320, TR-W-320-140, Kaiser Engineers Hanford Company, Richland, Washington.

FDH, 1998, Waste Tank Summary Report for Month Ending March 31, 1998. HNF-EP-0182-120, Fluor Daniel Hanford, Inc., Richland, Washington.

FDH, 1998a, Tank Waste Remediation System Basis for Interim Operation. HNF-SD-WM-BIO-001. Rev. 0I, Fluor Daniel Hanford, Inc. Richland. Washington.

FDH, 1998b. Tank Waste Remediation System Technical Safety Requirements. HNF-SD-WM-TSR-006, Rev. 0-J, Fluor Daniel Hanford, Inc., Richland. Washington.

Hand, F. R., and G. E. Rensink, 1998. Action Plan for Response to Excessive Temperatures in Hanford Site High-Heat Waste Tank 241-C-106. Westinghouse Hanford Company, Richland, Washington.

Herting, D. L., 1996a, Caustic Demand - Tank C-106 S7udge, (interna1 memorandum 75764-PCS96-071 to R. A. Esch, July 15), Westinghouse Hanford Company, Richland, Washington. 
HNF-SD-WM-PCP-013 REV. 1

Herting, D. L., 1996b, Characterization of Sludge Sample from Tank 241-AY-102, (internal memorandum 75764-PCS96-021 to J. M. Jones, March 6), Westinghouse Hanford Company, Richland, Washington.

Isaacson, R. E. . 1981. Tank Farm Dry We77 Monitoring Frequency, (internal letter to J. L. Deichman and J. H. Roecker, May 20), Rockwell International. Richland, Washington.

Jones. J. M. . 1997, Process Test Plan: Tank 241-C-106 296-P-16 Exhauster Outage, HNF-SD-WM-PTP-030, Rev. 0, Lockheed Martin Hanford Corp. for Fluor Daniel Hanford. Inc.. Richland, Washington.

King, D. A., 1998, Project W-320 Instrument List, HNF-2520, Rev. O, SGN Eurisys Services Corp., Richland, Washington.

Lambert, S. L., 1997, Tank Characterization Report for Sing7e-She77 Tank 241-C-106. WHC-SD-WM-ER-615. Rev. 0A. SGN Eurisys Services Corporation for Fluor Daniel Hanford, Inc., Richland, Washington.

LMHC, 1996, Tank Farms Operating Specifications Document, "Operating Specification for Tank Farm Leak Detection and Single-Shell Tank Intrusion Detection, "OSD-T-151-00031, Rev. B-4, Lockheed Martin Hanford Corp. for Fluor Daniel Hanford. Inc., Richland, Washington.

LMHC, 1997a. Tank Farms Operating Specifications Document, "Operating Specification for Watch List Tanks," OSD-T-151-00030, Rev. B-26. Lockheed Martin Hanford Corp. for Fluor Daniel Hanford, Inc., Richland, Washington.

LMHC, 1997b, Tank Farms Operating Specifications Document, "Unclassified Operating Specifications for Single-Shell Waste Storage Tanks," OSD-T-151-0013, Rev. D-15, Lockheed Mart in Hanford Corp. for Fluor Daniel Hanford. Inc., Richland, Washington.

LMHC, 1997c, Tank Farms Operating Specifications Document, "Unclassified Operating Specifications for the 241-AN. AP. AW, AY, AZ, and SY Tank Farms," OSD-T-151-00007. Rev. H-19, Lockheed Martin Hanford Corp. for Fluor Daniel Hanford. Inc.. Richland. Washington.

LMHC, 1998, Tank Waste Remediation System Process Engineering Instruction Manua 7, HNF-SD-WM-PROC-021. Rev. 1-C, Lockheed Martin Hanford Corp. for Fluor Daniel Hanford, Inc., Richland, Washington.

Lytle, J. E., 1993, Request the Approval of a Justification of Mission Need and a Summary Project Plan for the Tank 241-C-106 S7uicing Project. U.S. Department of Energy, Washington, DC.

Mulkey, C. H., 1997, Data Quality Objectives for Tank Farms Waste Compatibility Program. HNF-SD-WM-DQ0-001. Rev. 2, Lockheed Martin Hanford Corp. for Fluor Daniel Hanford, Inc.. Richland, Washington.

National Defense Authorization Act for Fiscal Year 1991. Public Law 101-510. 
Ogden, D. M. . K. Sathyanarayana, B. A. Crea, B. C. Fryer, M. J. Thurgood. 1998. Project $W-320$ SAR and Process Control Thermal Analyses,

HNF-SD-W320-ER-004, Rev. 1, Numatec Hanford Corporation for Fluor Daniel Hanford. Inc., Richland, Washington.

Pasamehmetoglu, K. 0., W. L. Kubic, Jr. and P. Sadasivan, 1997, Discussion of Flammable Gas Issues for Project W-320, LA-UR-97-1330, Rev. 1A, Los Alamos National Laboratory, Los Alamos, New Mexico.

Peterson, T. K.. 1998, Design Basis Document, Project W-320, Tank 241-C-106 S7uicing, Project Rebaselining Change Request New Scope.

HNF-SD-W320-DB-001, Rev.1, Fluor Daniel Northwest for Fluor Daniel Hanford, Inc., Richland, Washington.

PNNL, 1997, Washing and Caustic Leaching of Hanford Tank C-106 Sludge. PNNL-11381. Pacific Northwest National Laboratory, Richland, Washington.

Reynolds. D. A., 1997, Chemical and Chemically-Related Considerations Associated with Sluicing Tank C-106 Waste Top Tank AY-102.

HNF-SD-WM-TI-756. Rev. 2, Lockheed Martin Hanford Corp. for Fluor Danie? Hanford, Inc., Richland, Washington.

Rodenhizer, D. G., 1987, Hanford Waste Tank S7uicing History, WHC-SD-WM-TI-302. Rev. 0, Westinghouse Hanford Company, Richland, Washington.

Sathyanarayana, K., 1997a. Project W-320 Thermal Evaluation. HNF-SD-W320-ER-002, Rev. 0. Numatec Hanford Corporation for Fluor Daniel Hanford, Inc, Richiand, Washington.

Sathyanarayana, K., 1997b, Project W-320 SAR and Process Contro7 Thermal Analysis, HNF-SO-W320-ER-004, Rev. 0, Numatec Hanford Corporation for Fluor Daniel Hanford, Inc, Richland, Washington.

Sathyanarayana, K., 1996a. Evaluation of Potentia7 and Consequences of Steam Bump in High-Heat Waste Tanks and Assessment and Validation of GOTH Computer Code, WHC-SD-WM-CN-022. Westinghouse Hanford Company, Richland. Washington.

Sathyanarayana, K., 1996b. Thermal Hydraulic Evaluation of Consolidating Tank C-106 Waste into Tank AY-102. WHC-SD-WM-ER-534, Rev. 0, Westinghouse Hanford Company, Richland, Washington.

Sathyanarayana, K., and D. M. Ogden, 1998, Project W-320 Portable Exhauster Evaluation for Tank 241-AY-102. HNF-2637. Rev. 0. Numatec Hanford Corporation for Fluor Daniel Hanford, Inc, Richland, Washington.

Sederburg, J. P., 1994. Chemica7 Compatibjlity of Tank Wastes In 241-C-106. 241-AY-101, and 241-AY-102. WHC-SD-WM-ES-290, Rev. 2, Westinghouse Hanford Company, Richland, Washington. 
Shelton. L. W., 1997, Tank Characterization Report for Double-Shell Tank 241-AY -102. WHC-SD-WM-ER-454, Rev. OB, Numatec Hanford Corporation for Fluor Daniel Hanford, Inc., Richland, Washington.

Stewart, C. W., F. F. Erian. P. A. Meyer, K. P. Recknagel, W. B. Gregory, Z. I. Antoniak, and D. M., Pfund, 1997, Monitoring Gas Retention and S7urry Transport During the Transfer of Waste from Tank 241-C-106 to Tank 24l-AY-102, PNNL-11627. Pacific Northwest National Laboratory, Richland, Washington.

Stewart, C. W and G. Chen, 1998, Baseline Estimate of the Retained Gas Volume in Tank 241-C-106. PNNL-11890. Pacific Northwest National Laboratory, Richland, Washington.

Vai1, T. S., 1997, Criticality Safety Assessment of Tank 241-C-106 Remediation. HNF-SD-W320-CSA-001, Rev. 1, DE\&S Hanford for Fluor Daniel Hainford, Inc., Richland, Washington.

\section{Drawings}

ARH, 1988, Heating and Ventilating Details - Mobile Exhaust Unit, drawing H-2-35769, Rev. 11. At lantic Richfield Hanford Company, Richland. Washington.

ARH, 1977, Plan \& Flow Diagram Vent. Duct. Insta7lation 241-C-105 to 241-C-106, drawing H-2-72286. Rev. 0. Atlantic Richfield Hanford Company, Richland, Washington.

FONW, 1997. Multi-Functional Instrument Tree Installation, drawing H-2-828969, Rev. 0. Fluor Daniel Northwest. Inc., Richland, Washington.

FDNw, 1998. Drawing 7ist, drawing H-2-818423, Rev. 0, Fluor Daniel Northwest, Inc., Richland, Washington.

FONW, 1998, Piping Project W-320 Hydraulic Diagram, drawing H-2-818536, Rev. 1. Fluor Daniel Northwest, Inc., Richland, Washington.

ICF KH, 1998. Electrica7 C-Farm One Line Diagram, drawing H-2-820748, Rev. 1 , ICF Kaiser Hanford Company, Richland, Washington.

ICF KH, 1998, Piping Transfer Lines P7an \#1, drawing H-2-818533, Rev. 1, ICF Kaiser Hanford Company, Richland, Washington.

ICF KH, 1998, Piping Transfer Line Plan \#2, drawing H-2-818534, Rev. 1, ICF Kaiser Hanford Company, Richland, Washington.

ICF KH. 1998. Piping Transfer Line Detai7s, drawing H-2-818535, Rev. 1, ICF Kaiser Hanford Company. Richland, Washington.

ICF KH, 1998, Piping Process Building Drain and Supply Plan. drawing H-2-818482. Rev. 1, ICF Kaiser Hanford Company, Richland, Washington. 
HNF -SD-WM-PCP-013 REV. I

ICF KH, 1998, Piping Pump and Winch Insta 77-C Tank and Drawing List, drawing H-2-818494, Rev. 1, ICF Kaiser Hanford Company. Richland, Washington.

ICF KH, 1998, Piping Pump and winch Assemb7y, drawing H-2-818495, Rev. 1, ICF Kaiser Hanford Company, Richland, Washington.

ICF KH. 1998, Piping Winch Assemb7y, drawing H-2-818496, Rev. 1, ICF Kaiser Hanford Company, Richland, Washington.

ICF KH, 1998, Piping Sheave Assemb7y, drawing H-2-818497, Rev. 1, ICF Kaiser Hanford Company, Richland. Washington.

ICF KH, 1998, Piping Winch Plate, drawing H-2-818498. Rev. 1, ICF Kaiser Hanford Company, Richland, Washington.

ICF KH. 1998, Piping Adapter Plate C-Tank, drawing H-2-818499, Rev. 1, ICF Kaiser Hanford Company, Richland, Washington.

ICF KH, 1998, Piping Seismic Restraint for S7urry Booster Pump. H-2-818500. Rev. 1, ICF Kaiser Hanford Company, Richland, Washington.

ICF KH, 1998, Jumper Assemb7y Pump Pit C-106 A-B-(A), drawing H-2-818508, Rev. 1, ICF Kaiser Hanford Company, Richland, Washington.

ICF KH, 1998, Piping Service Piping Plan \& Detaj7. drawing H-2-818519. Rev. 1. ICF Kaiser Hanford Company, Richland, Washington.

ICF KH, 1998, Piping Tank 241-C-106, drawing H-2-818521, Rev. 1, ICF Kaiser Hanford Company, Richland, Washington.

ICF KH, 1998. Piping Air and Water Service Building Plan and Sections, drawing H-2-818531, Rev. 1, ICF Kaiser Hanford Company, Richland, Washington.

ICF KH, 1998, Piping Support Detai7s, drawing H-2-818532. Rev. 1, ICF Kaiser Hanford Company, Richland. Washington.

ICF KH, 1998, Piping S7uicer Insta77ation, drawing H-2-818549, Rev. 1, ICF Kaiser Hanford Company. Richland, Washington.

ICF KH, 1998, Piping S7uicer Drive Assemb7y, drawing H-2-818550, Rev. 1. ICF Kaiser Hanford Company, Richland, Washington.

ICF KH, 1998, Piping Sluicer Assemb7y, drawing H-2-818551, Rev. 1, ICF Kaiser Hanford Company, Richland. Washington.

ICF KH, 1998, Piping Sluicer Drive Strong Back, drawing H-2-818553, Rev. 1, ICF Kaiser Hanford Company, Richland, Washington.

ICF KH, 1998, Piping Actuating Rack and Swive7s, drawing H-2-818555, Rev. 1 , ICF Kaiser Hanford Company. Richland. Washington.

ICF KH. 1998, Piping Hose Assemb7y, drawing H-2-818556, Rev. 1. ICF Kaiser Hanford Company, Richland. Washington. 
ICF KH, 1998, Piping S7uicer Drive Detai7s, drawing H-2-818557, Rev. 1, ICF Kaiser Hanford Company, Richland, Washington.

ICF KH, 1998. Electrical C-Farm In-Tank Imaging (CCTV), drawing H-2-818690, Rev. 1, ICF Kaiser Hanford Company, Richland, Washington.

ICF KH, 1998, P \& ID AY102K4 Recirc Vent Cooling, drawing H-2-131063, Rev. 3 , Kaiser Engineers Hanford Company. Richland. Washington.

ICF KH, 1998, P \& ID Kl Primary Tank Vent System, drawing H-2-131075, Rev. 3, Kaiser Engineers Hanford Company. Richland, Washington.

ICF KH, 1998, P \& ID KI Prim TK Ventilation System, drawing H-2-131076, Rev. 3, Kaiser Engineers Hanford Company, Richland, Washington.

ICF KH. 1998. Civil Project Site Plan, drawing H-2-818424, Rev. 2, ICF Kaiser Hanford Company, Richland, Washington.

ICF KH, 1998, Civil Interfarm Transfer System Plan and Profile, drawing $H-2-818426$, Rev. 2, ICF Kaiser Hanford Company, Richland, Washington.

ICF KH, 1998, Civil 241-C-106 Transfer System Plan and Profile, drawing H-2-818427, Rev. 2. ICF Kaiser Hanford Company. Richland, Washington.

ICF KH, 1998, Civi7 241-C-106 Raw Water System Plan \& Profile, drawing H-2-818430, Rev. 2, ICF Kaiser Hanford Company, Richland, Washington.

ICF KH, 1998, Civi 1 241-AY Tank Farm Site Plan, drawing H-2-818432, Rev. 2 , ICF Kaiser Hanford Company, Richland. Washington.

ICF KH, 1998, Civi7 241-AY-102 Transfer System Plan and Profile, drawing H-2-818434, Rev. 2. ICF Kaiser Hanford Company, Richland, Washington.

ICF KH, 1998, Civil 241-C-106 Raw Water System Sections \& Detai7s, drawing $\mathrm{H}-2-818435$, Rev. 2, ICF Kaiser Hanford Company, Richland, Washington.

ICF KH, 1998, Piping Process Building Skid Plan, drawing H-2-818481, Rev. 3, ICF Kaiser Hanford Company, Richland, Washington.

ICF KH, 1998, Jumper Assemb7y S7uice Pit AY-02E-U2-A-(B), drawing H-2-818503, Rev. 3. ICF Kaiser Hanford Company, Richland, Washington.

ICF KH, 1998. Piping Distributor Assembly Plans Elevation and Detai7s, drawing H-2-818537, Rev. 2, ICF Kaiser Hanford Company, Richland, Washington.

RHO, 1986, HEPA Filtered Inlet Modifications Tank Farms, drawing H-2-95451, Rev. 0. Rockwell Hanford Operations, Richland, Washington.

WHC, 1994, 296-P-16 Stack Monitor Instal7ation, drawing H-2-95267, Rev. 2. Westinghouse Hanford Company, Richland, Washington.

WHC, 1997, Ventilation Equipment Schedules and Control Diagram, drawing $\mathrm{H}-2-64462$, Rev. 7. Westinghouse Hanford Company, Richland, Washington. 
WHC. 1997. Multi-Functiona7 Instrument Tree Arrangement, drawing H-2-85122, Rev. 5, Westinghouse Hanford Company, Richland, Washington. 
HNF-SD-WM-PCP-013 REV. 1

This page intentionally left blank. 
HNF-SD-WM-PCP-013 REV . 1

APPENDIX A

INDEX OF TECHNICAL OPERATING REQUIREMENTS 
HNF -SD-WM-PCP-013 REV. 1

This page intentionally left blank. 


\section{A1.0 BASIS FOR INTERIM OPERATIONS CONTROLS}

Table Al-1. Project $W-320$ Safety SSCs and TSRs and Defense-in Depth for Representative Accidents. ${ }^{1}$ (11 sheets)

\begin{tabular}{|c|c|c|c|c|c|c|}
\hline 沙 & 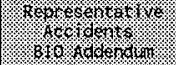 & & 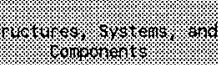 & & 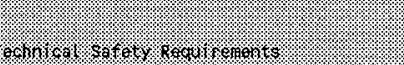 & 6r. \\
\hline 1 & $\begin{array}{l}\text { Nuclear } \\
\text { Critical ity } \\
(3.4 .2 .1)\end{array}$ & None & equired & $\begin{array}{l}\text { SL: } \\
\text { LCS: } \\
\text { LCO: } \\
\text { AC } 5.7\end{array}$ & $\begin{array}{l}\text { None required } \\
\text { None required } \\
\text { None required } \\
\text { Nuclear Criticality Safety } \\
\text { - Establish CPSs based on CSERs } \\
\text { - Recovery actions if limits exceeded } \\
\text { - Criticality training program }\end{array}$ & None \\
\hline 2 & $\begin{array}{l}\text { HEPA Filter } \\
\text { Fai lure-Exposure } \\
\text { to High } \\
\text { Temperature or } \\
\text { Pressure } \\
(3.4 .2 .2)\end{array}$ & $\begin{array}{l}\text { SS: } \\
\text { ss: } \\
\text { ss: } \\
\text { ss: }\end{array}$ & $\begin{array}{l}\text { CAM-interlock on } \\
\text { tank } 241-702-A \\
\text { ventilation system } \\
\text { CAM-interlock on } \\
\text { tank } 241-702-A Z \\
\text { ventilation system } \\
\text { CAM-inter lock on } \\
\text { tank } 296-p-16 \\
\text { ventilation system } \\
\text { CAM-interlock on } \\
\text { tank } 296-C-006 \\
\text { ventilation system }\end{array}$ & $\begin{array}{l}\text { SL: } \\
\text { LCS: } \\
\text { LCO } 3.1 .4 \\
\text { AC } 5.12 \\
\text { AC } 5.18\end{array}$ & $\begin{array}{l}\text { None required } \\
\text { None required } \\
\text { Ventilation Stack CAM Interlock Systems } \\
\text { Transfer Controls } \\
\text { - Material Balance (every } 24 \text { hours } \\
\text { during transfer operations) } \\
\text { HEPA Filter Controls } \\
\text { - Periodic (frequency established based } \\
\text { on rate of accumulation) radiation } \\
\text { surveillance } \\
\text { - Replacement at } \leq 2 \mathrm{mSv} / \mathrm{h}(200 \mathrm{mrem} / \mathrm{h} \text { ) }\end{array}$ & $\begin{array}{l}\text { HEPA Filter Delta } P \\
\text { - Low Delta } P \text { interlock across the } \\
\text { HEPA filters on the ventilation } \\
\text { system (where provided) } \\
\text { - High Delta } P \text { alarm across the } \\
\text { HEPA filters on the ventilation } \\
\text { system } \\
\text { - Periodic surveillance of HEPA } \\
\text { Delta } P \text { and cont inuous air monitor } \\
\text { HEPA Filter Testing } \\
\text { - Testing of filters after } \\
\text { installation and annually thereafter } \\
\text { Record Sampler } \\
\text { Heater Over Temperature } \\
- \text { Interlock/alarm (where provided) } \\
\text { HEPA Filter Replacement } \\
\text { - Typically performed at } 1 \mathrm{mSv} / \mathrm{h} \\
\text { (100 mrem/h) }\end{array}$ \\
\hline
\end{tabular}


Table A1-1. Project $W-320$ Safety SSCs and TSRs and

Defense-in Depth for Representative Accidents. ${ }^{1}$ (11 sheets)

\begin{tabular}{|c|c|c|c|c|c|c|}
\hline 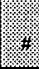 & 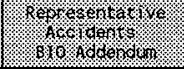 & & 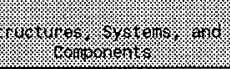 & & H. & 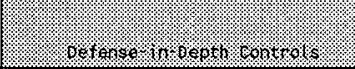 \\
\hline 3 & $\begin{array}{l}\text { Unf } j(t \text { tered } \\
\text { Release } \\
(3.4 \cdot 2.3)\end{array}$ & $\begin{array}{l}\text { ss: } \\
\text { ss: } \\
\text { ss: } \\
\text { ss: }\end{array}$ & $\begin{array}{l}\text { CAM-interlock on } \\
\text { tank } 241-702-A \\
\text { ventilation system } \\
\text { CAM-interlock on } \\
\text { tank } 241-702-A z \\
\text { ventilation system } \\
\text { CAM-interlock on } \\
\text { tank } 296-P-16 \\
\text { ventilation system } \\
\text { Continuous air } \\
\text { monitor-interlock on } \\
296-C-006 \text { vent } i \text { lation } \\
\text { system }\end{array}$ & $\begin{array}{l}\text { SL: } \\
\text { LCS: } \\
\text { LCO: } \\
\text { AC } 5.25 \\
\\
\text { TSR cont } \\
\text { filter } f\end{array}$ & $\begin{array}{l}\text { None required } \\
\text { None required } \\
\text { None required } \\
\text { Ventilation Controls } \\
\text { - Visual inspections of aboveground } \\
\text { recirculation ventilation ductwork for } \\
\text { tank } 241-\mathrm{C}-106 \text { every } 24 \text { hours during } \\
\text { sluicing (only appl ies after new } \\
296-\mathrm{C}-006 \text { ventilation system is } \\
\text { installed) } \\
\text { in HNF (1998) Section } 3.4 .2 .2 \text { (HEPA } \\
\text { e) and } 3.4 .2 .11 \text { (tank bump) also apply }\end{array}$ & $\begin{array}{l}\text { Transfer Controls } \\
\text { - Waste compatibility controls } \\
\text { Ignition Controls } \\
\text { - Speed Limit Controls } \\
\text { Plastic sleeves on aboveground } \\
\text { ventilation flanges }\end{array}$ \\
\hline 4 & $\begin{array}{l}\text { Fire in } \\
\text { Contaminated Area } \\
(3.4 .2 .4)\end{array}$ & None & required & $\begin{array}{l}\text { SL: } \\
\text { LCS: } \\
\text { LCO: } \\
\text { AC } 5.10 \\
\text { AC } 5.14\end{array}$ & $\begin{array}{l}\text { None required } \\
\text { None required } \\
\text { None required } \\
\text { Ignition Controls } \\
\text { - Vehicle fuel systen protection } \\
\text { - Physical barriers outside tank farms } \\
\text { - Speed limit controls } \\
\text { Energency Preparedness } \\
\text { - Response procedures }\end{array}$ & $\begin{array}{l}\text { Fire Protection Program } \\
\text { Radiation Protection Program } \\
\text { Contamination Control Program } \\
\text { Vehicle positioning spotters } \\
\text { Jank Farm fences } \\
\text { Vegetation Control Program }\end{array}$ \\
\hline 5 & $\begin{array}{l}\text { Caustic Spray } \\
\text { Leak } \\
(3.4 .2 .5)\end{array}$ & None & required & $\begin{array}{l}\text { SL: } \\
\text { LCS: } \\
\text { LCO: } \\
\text { AC } 5.23\end{array}$ & $\begin{array}{l}\text { None required } \\
\text { None required } \\
\text { None required } \\
\text { Caustic Transfer Controls } \\
\text { - Plastic sleeving } \geq 4 \text { mil thickness } \\
\text { around delivery piping } \\
\text { - Caustic delivery system transfer } \\
\text { pressure } \leq 125 \text { psig or below sodium } \\
\text { hydroxide cargo tanks specified maximum } \\
\text { allowable operating pressure whichever } \\
\text { is lower } \\
\text { - Piping thickness } \\
\text { - Sodium hydroxide cargo tanks meet } \\
\text { applicable Dot specifications }\end{array}$ & $\begin{array}{l}\text { Operator training } \\
\text { TWRS Hazardous Material Protection } \\
\text { Program } \\
\text { Emergency response plans and } \\
\text { procedures }\end{array}$ \\
\hline
\end{tabular}




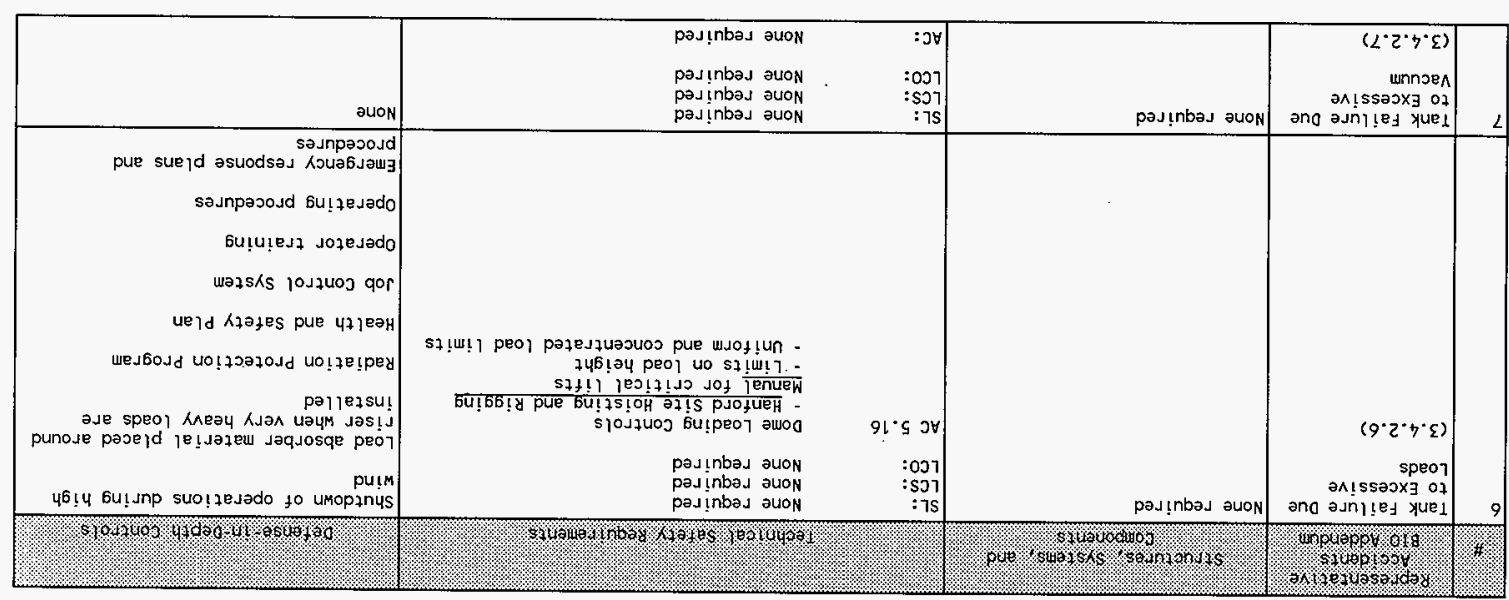

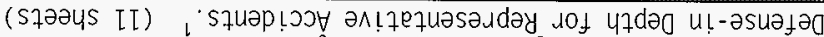

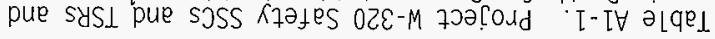


Table A1-1. Project $W-320$ Safety SSCs and TSRs and

Defense-in Depth for Representative Accidents. ${ }^{1}$ (11 sheets)

\begin{tabular}{|c|c|c|c|c|c|c|}
\hline \% & 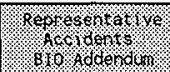 & & ronowos. & & 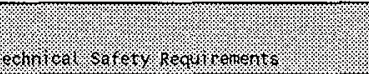 & 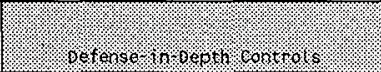 \\
\hline 8 & $\begin{array}{l}\text { F lammable Gas } \\
\text { Def lagrations } \\
(3.4,2.8)\end{array}$ & $\begin{array}{l}\text { SC: } \\
\text { SC: } \\
\text { SC: }\end{array}$ & $\begin{array}{l}\text { DST/AWF ventilation } \\
\text { Primary tank leak } \\
\text { detection systems } \\
\text { SST ventilation }\end{array}$ & $\begin{array}{l}\text { SL: } \\
\text { LCS: } \\
\text { LCO } 3.2 .1 \\
\text { LCO } 3.2 .2 \\
\text { LCO } 3.2 .6 \\
\text { AC } 5.9 \\
\text { AC } 5.10 \\
\text { AC } 5.11 \\
\text { AC } 5.14\end{array}$ & $\begin{array}{l}\text { None required } \\
\text { None required } \\
\text { DST and AWF Tank Ventilation Systems } \\
\text { SST Ventilation Systems - Active } \\
\text { Primary Tank Leak Detection Systems } \\
\text { Flarmability Controls } \\
\text { - JCO Controls } \\
\text { I gnition Controls } \\
\text { - JCO Controls } \\
\text { Flammable Gas Monitoring Controls } \\
\text { - JCO Controls } \\
\text { Emergency Preparedness }\end{array}$ & $\begin{array}{l}\text { Monitor dome pressure in tanks } \\
241-\mathrm{C}-106 \text { and } 241-\mathrm{AY}-102 \text { during } \\
\text { sluicing. } \\
\text { Periodic video monitoring of the } \\
\text { waste in tank } 241-\mathrm{AY}-102 \text {. } \\
\text { Measure background concentrations in } \\
\text { both tanks for } 3-4 \text { weeks before } \\
\text { sluicing. } \\
\text { Monitor the ventilation flow rates in } \\
\text { both tanks during and after sluicing. } \\
\text { Monitor level growth and use } \\
\text { barometric pressure evaluation after } \\
\text { sluicing. } \\
\text { Flammable gas monitoring during } \\
\text { sluicing }\end{array}$ \\
\hline
\end{tabular}


Table A1-1. Project $W-320$ Safety SSCS and TSRs and

Defense-in Depth for Representative Accidents. 1 (11 sheets)

\begin{tabular}{|c|c|c|c|c|c|}
\hline It & 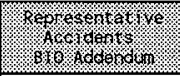 & 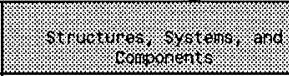 & & lem & 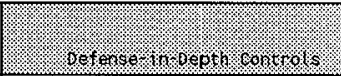 \\
\hline 9 & $\begin{array}{l}\text { Organic solvent } \\
\text { Fire }\end{array}$ & None required & $\begin{array}{l}\text { SL: } \\
\text { LCS: } \\
\text { LCO: }\end{array}$ & $\begin{array}{l}\text { None required } \\
\text { None required } \\
\text { None requi red }\end{array}$ & $\begin{array}{l}\text { Vehicle positioning spotters } \\
\text { Tank Farm fences }\end{array}$ \\
\hline & $(6.4,(2,9)$ & & $\begin{array}{l}\text { AC } 5.10 \\
\text { AC } 5.12 \\
\text { AC } 5.14 \\
\text { AC } 5.18\end{array}$ & $\begin{array}{l}\text { Ignition Controls } \\
\text { - Lightning (stop intrusive work, secure } \\
\text { elevated equipment) } \\
\text { - Barrier for hot metal during flame } \\
\text { cutting } \\
\text { - Vehicle fuel system protection } \\
\text { - Physical barriers outside tank farms } \\
\text { - Speed limit controls } \\
\text { Iransfer Controls } \\
\text { - Evaluate impact on organic solvent } \\
\text { transfer } \\
\text { - Material balance every } 24 \text { hours during } \\
\text { transfer operations } \\
\text { Emergency Preparedness } \\
\text { HEPA Filter Controls } \\
\text { - Periodic (frequency established based } \\
\text { on rate of accumulation) radiation } \\
\text { surveillance } \\
\text { - Replacement based on accumulation }\end{array}$ & $\begin{array}{l}\text { HEPA filter replacement typically } \\
\text { performed at } 1 \mathrm{mSv} / \mathrm{h}(100 \mathrm{mrem} / \mathrm{h})\end{array}$ \\
\hline 10 & $\begin{array}{l}\text { In-Tank Fuel } \\
\text { Fire/Deflagration } \\
(3.4 .2 .10)\end{array}$ & None required & $\begin{array}{l}\text { SL: } \\
\text { LCS: } \\
\text { LCO: } \\
\text { Note: T } \\
\text { Organic }\end{array}$ & $\begin{array}{l}\text { None required } \\
\text { None required } \\
\text { None required } \\
\text { accident credits the same controls as the } \\
\text { ent fire above }(3.4 .2 .9)\end{array}$ & \\
\hline
\end{tabular}


Table A1-1. Project $W-320$ Safety SSCs and TSRs and

Defense-in Depth for Representative Accidents. ${ }^{1}$ (11 sheets)

\begin{tabular}{|c|c|c|c|c|c|c|}
\hline If & 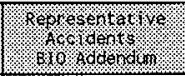 & & 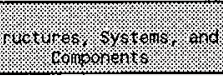 & & 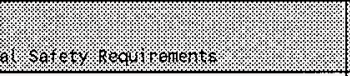 & (1) \\
\hline 11 & $\begin{array}{l}\text { Tank Bump } \\
(3.4 .2 .11)\end{array}$ & & $\begin{array}{l}\text { Primary ventilation } \\
\text { systems } \\
\text { Annulus ventilation } \\
\text { systems }\end{array}$ & $\begin{array}{l}\text { SL: } \\
\text { LCS } / L C O \quad 3.3 .1: \\
\text { LCS /LCO } 3.3 .2 \\
\text { AC } 5.12 \\
\text { AC } 5.19 \\
\text { AC } 5.25 \\
\text { AC } 5.26\end{array}$ & 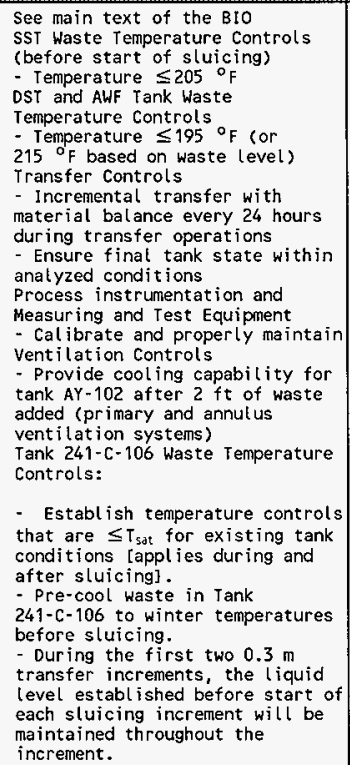 & $\begin{array}{l}\text { ALCs will be disabled before the } \\
\text { start of sluicing } \\
\text { Communications between tanks } \\
241-\mathrm{C}-106 \text { and } 241-\mathrm{AY}-102 \text { control } \\
\text { trailers will be maintained during } \\
\text { sluicing operations } \\
\text { Pump pit and sluice pit cover blocks } \\
\text { (including removable plugs) will be } \\
\text { in place before any sluicing } \\
\text { operations and before enabling of the } \\
\text { sluice or slurry pumps } \\
\text { The transfer pumps associated with } \\
\text { the sluice and slurry lines will be } \\
\text { administratively locked out except, } \\
\text { as necessary, during the actual } \\
\text { sluicing operations } \\
\text { Emergency Response Plan/Procedures: } \\
\text { - will be in place and implemented } \\
\text { in response to emergency conditions } \\
\text { resulting from a tank bump } \\
\text { - will be in place and implemented } \\
\text { in response to emergency conditions } \\
\text { resulting from sitewide emergencies } \\
\text { such as a seismic event }\end{array}$ \\
\hline
\end{tabular}


Table A1-1. Project $W-320$ Safety SSCS and TSRs and Defense-in Depth for Representative Accidents. 1 (11 sheets)

\begin{tabular}{|c|c|c|c|c|c|}
\hline \% & 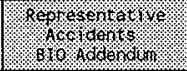 & 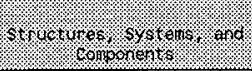 & & (2) & 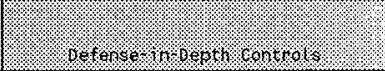 \\
\hline 12 & $\begin{array}{l}\text { Liner Breach due } \\
\text { to } \$ \text { team between } \\
\text { Steel Liner and } \\
\text { Concrete Shell in } \\
\text { tank 241-c-106 } \\
(3.4 .2 .12)\end{array}$ & & $\begin{array}{l}\text { SL: } \\
\text { LCS } / L C O 3.3 .1 \\
\text { AC } 5.12 \\
\text { AC } 5.19 \\
\text { AC } 5.26\end{array}$ & $\begin{array}{l}\text { None required } \\
\text { SST Waste Temperature Controls } \\
\text { (before start of sluicing) } \\
\text { - Temperature } \leq 205{ }^{\circ} \mathrm{F} \\
\text { Transfer controls } \\
\text { - Ensure final tank state within } \\
\text { analyzed conditions } \\
\text { Process Instrumentation and } \\
\text { Measuring and Test Equipment } \\
\text { - Cal ibrate and properly maintain } \\
\text { Tank } 241-\mathrm{C}-106 \text { Waste Temperature } \\
\text { Controls } \\
\text { - Establish temperature controls } \\
\text { that are } \leq T_{\text {sat for existing tank }} \\
\text { conditions (applies during and } \\
\text { after sluicing) }\end{array}$ & $\begin{array}{l}\text { Active ventilation or other heat } \\
\text { removal mechanisms will be } \\
\text { maintained. } \\
\text { Pump pit and sluice pit cover blocks } \\
\text { (including removal plugs) will be in } \\
\text { place whenever the conditions for } \\
\text { initiation of a liner breach are } \\
\text { present (i.e., leaking (iner, active } \\
\text { ventilation system down indefinitely) } \\
\text { Emergency Response Plan/Procedures } \\
\text { - Will be in place and implemented } \\
\text { in response to emergency conditions } \\
\text { resulting from a liner breach. } \\
\text { - Will be in place and implemented } \\
\text { in response to emergency conditions } \\
\text { resulting form sitewide emergencies } \\
\text { such as a seismic event. } \\
\text { A material balance every } 24 \text { hours } \\
\text { during transfer operations } \\
\text { Level monitoring to identify leakage } \\
\text { into the liner of tank } 241 \text {-c- } 106 \\
\text { Communication between tanks } 241-c-106 \\
\text { and } 241-A Y-102 \text { control trailers will } \\
\text { be maintained during sluicing } \\
\text { operations } \\
\text { Raw water is metered } \\
\text { Design feature - The hose is } \\
\text { engineered to maintain integrity } \\
\text { Design feature - Positive mechanical } \\
\text { stops are provided to limit nozzle } \\
\text { travel to < } 15 \text { degree above horizontal } \\
\text { sluicing controls }\end{array}$ \\
\hline
\end{tabular}




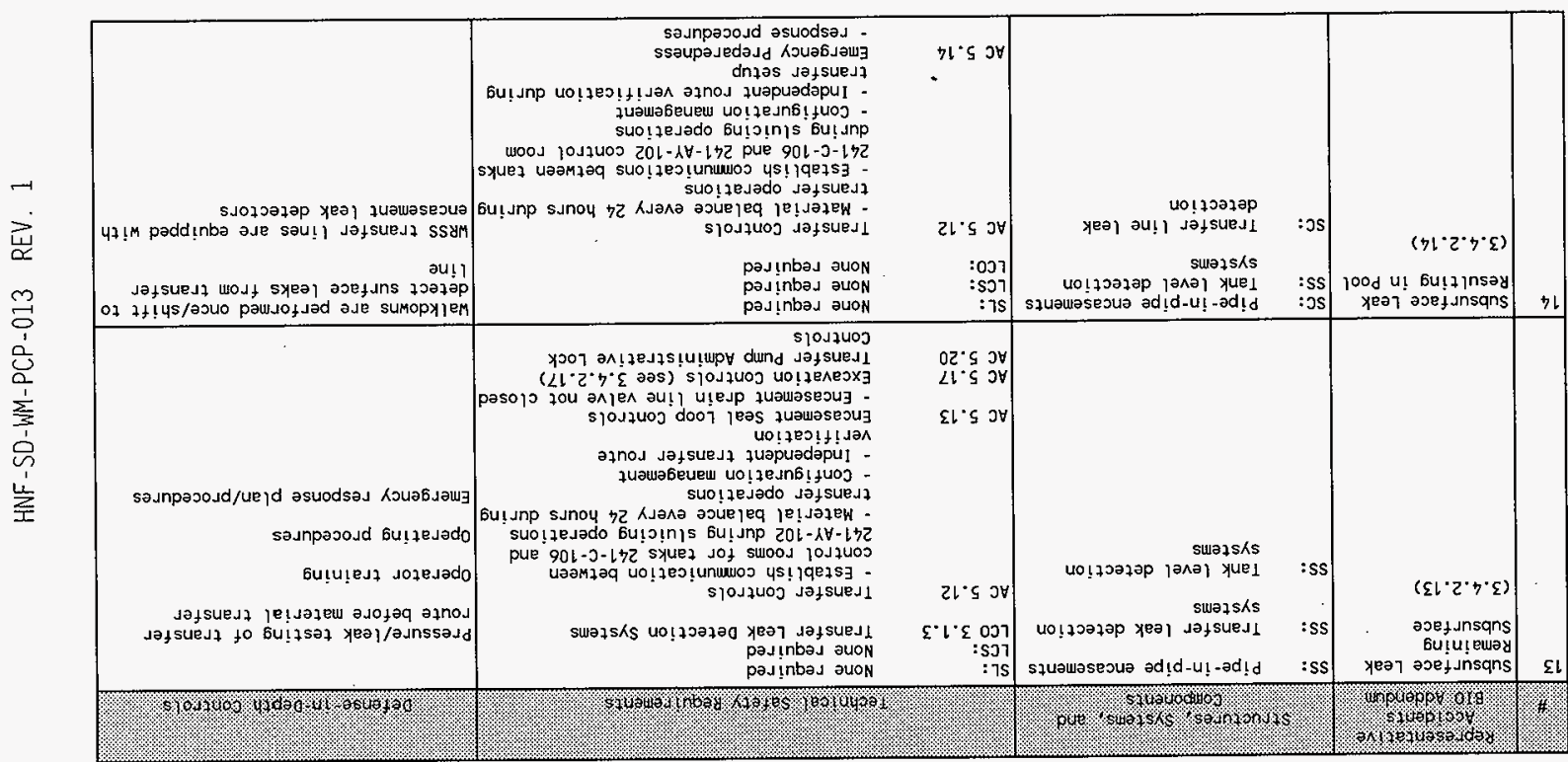

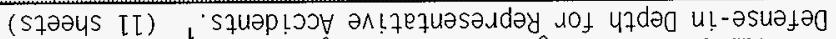

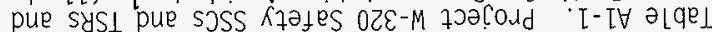


Table A1-1. Project $W-320$ Safety SSCS and TSRs and

Defense-in Depth for Representative Accidents. ' (11 sheets)

\begin{tabular}{|c|c|c|c|c|c|c|}
\hline \% & 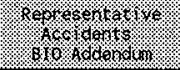 & & 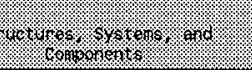 & & 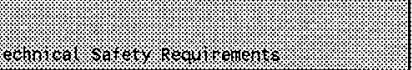 & her ors \\
\hline 15 & $\begin{array}{l}\text { Surface Leak } \\
\text { Resulting in Pool } \\
(3.4 .2 .15)\end{array}$ & $\begin{array}{l}\text { SC: } \\
\text { ss: } \\
\text { ss: } \\
\text { ss: } \\
\text { sc: } \\
\text { sc: } \\
\text { Ss: }\end{array}$ & $\begin{array}{l}\text { Transfer leak detector } \\
\text { alarms } \\
\text { Transfer system covers } \\
\text { Tank level detection } \\
\text { systems } \\
\text { Primary tank leak } \\
\text { detection system } \\
\text { Pipe-in-pipe encasements } \\
\text { Leak detectors in } \\
\text { interfacing pits and } \\
\text { their alarms } \\
\text { Backflow preventers }\end{array}$ & $\begin{array}{l}\text { SL: } \\
\text { LCS: } \\
\text { LCO } 3.1 .3 \\
\text { LCO } 3.2 .6 \\
\text { AC } 5.12 \\
\text { AC } 5.14 \\
\text { AC } 5.17 \\
\text { AC } 5.20 \\
\text { AC } 5.22\end{array}$ & $\begin{array}{l}\text { None required } \\
\text { None required } \\
\text { Transfer Leak Detection Systems } \\
\text { Primary Iank Leak Detection System } \\
\text { Transfer Controls } \\
\text { - Material Balance every } 24 \text { hours during } \\
\text { transfer operations } \\
\text { - Establ ish comfunication between } \\
\text { control rooms for tank } 241-c-106 \text { and } \\
241-\text { AY- } 102 \text { during sluicing operations } \\
\text { - Configuration management } \\
\text { - Cap/blank nozzles when not in use } \\
\text { - Vehicle restrictions around transfer } \\
\text { lines } \\
\text { Emergency Preparedness } \\
\text { - Response procedures } \\
\text { Excavation Controls (see } 3.4 .2 .17 \text { ) } \\
\text { Transfer Pump Administrative Lock } \\
\text { Controls } \\
\text { Transfer system Cover Removal controls }\end{array}$ & $\begin{array}{l}\text { Tank farms are visually surveyed by } \\
\text { operators at least once a day. } \\
\text { Pit drains, where open } \\
\text { Encasement leak detectors } \\
\text { Backflow preventers } \\
\text { Material balance every } 24 \text { hours } \\
\text { during transfer operations, including } \\
\text { total material transferred and solids } \\
\text { loading calculation }\end{array}$ \\
\hline 16 & $\begin{array}{l}\text { Spray Leak from } \\
\text { Structure or } \\
\text { Overground Waste } \\
\text { Transfer Line } \\
(3.4 .2 .16)\end{array}$ & $\begin{array}{l}\text { Sc: } \\
\text { ss: } \\
\text { Sc: } \\
\text { SC: }\end{array}$ & $\begin{array}{l}\text { Transfer system covers } \\
\text { Backflow preventers } \\
\text { Pipe-in-pipe encasements } \\
\text { Stack CAM and interlock }\end{array}$ & $\begin{array}{l}\text { SL: } \\
\text { LCS: } \\
\text { LCO } 3.1 .1 \\
\text { LCO } 3.1 .4 \\
\text { AC } 5.12 \\
\text { AC } 5.13 \\
\text { AC } 5.20 \\
\text { AC } 5.22\end{array}$ & $\begin{array}{l}\text { None required } \\
\text { None required } \\
\text { Transfer System Covers } \\
\text { - Removable plug installed } \\
\text { Ventilation Stack CAM Interlock Systems } \\
\\
\text { Transfer Controls } \\
\text { - Configuration management } \\
\text { - Independent transfer route } \\
\text { verification } \\
\text { - Vehicle restrictions } \\
\text { Encasement Seal Loop Controls } \\
\text { - Encasement drain line valve not closed } \\
\text { Transfer Pump Administrative Lock } \\
\text { Controls } \\
\text { Transfer System Cover Removal Controls }\end{array}$ & $\begin{array}{l}\text { Repositioned jumpers are in service } \\
\text { tested during initial sluicing. } \\
\text { Cameras lowered through penetrations } \\
\text { in the cover block are used to verify } \\
\text { initial jumper integrity during the } \\
\text { leak test. } \\
\text { Process pit and vault pit leak } \\
\text { detectors } \\
\text { Material balance every } 24 \text { hours } \\
\text { during transfer operations, including } \\
\text { total material transferred and solids } \\
\text { loading calculation } \\
\text { Encasement leak detectors } \\
\text { Isolation valves; manual valve is } \\
\text { closed to isolate the flush systen } \\
\text { when not in use } \\
\text { Backflow preventers }\end{array}$ \\
\hline
\end{tabular}


Table Al-1. Project $w-320$ Safety SSCs and TSRs and Defense-in Depth for Representative Accidents. ${ }^{\text {(11 sheets.) }}$

\begin{tabular}{|c|c|c|c|c|c|}
\hline \% & 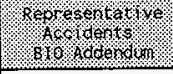 & 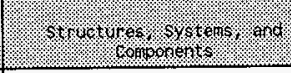 & & W.1\% & ber \\
\hline 17 & $\begin{array}{l}\text { Spray Leak from } \\
\text { an Underground } \\
\text { Waste Transfer } \\
\text { Line } \\
(3.4 .2 .17)\end{array}$ & None required & $\begin{array}{l}\text { SL: } \\
\text { LCS: } \\
\text { LCO: } \\
\text { AC } 5.12 \\
\text { AC } 5.17\end{array}$ & $\begin{array}{l}\text { None required } \\
\text { None required } \\
\text { None required } \\
\text { Transfer Controls } \\
\text { - Encased pipe outside of the tank farm } \\
\text { boundaries will be identified with } \\
\text { permanent aboveground labels } \\
\text { Excavation Controls } \\
\text { - Excavation permit including Composite } \\
\text { map, radiological evaluation, physical } \\
\text { marking of ground surface, activity } \\
\text { approval } \\
\text { - Excavations within } 15 \text { ft of waste } \\
\text { transfer are prohibited } \\
\text { - Restrictions on waste transfer through } \\
\text { uncovered/excavated lines (prohibited or } \\
\text { compensatory measures) } \\
\text { - Waste transfers will not be conducted } \\
\text { in transfer lines located within } \\
\text { approximately } 15 \text { ft of ongoing } \\
\text { excavation activities } \\
\text { - Establish emergency response actions } \\
\text { and communication between operations and } \\
\text { excavation personnel }\end{array}$ & $\begin{array}{l}\text { Access Control } \\
\text { - T-bars and chains } \\
\text { Material balance every } 24 \text { hours } \\
\text { during transfer operations, including } \\
\text { total material transferred and solids } \\
\text { loading calculation }\end{array}$ \\
\hline
\end{tabular}


Table A1-1. Project $W-320$ Safety SSCS and TSRs and

Defense-in Depth for Representative Accidents. ${ }^{1}$ (11 sheets)

\begin{tabular}{|c|c|c|c|c|c|}
\hline 4. & Whoselom & 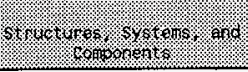 & & 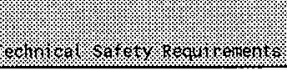 & H.t. \\
\hline 18 & $\begin{array}{l}\text { Natural Phenomena } \\
\text { - Seismic Events } \\
(3.4 .2 .18)\end{array}$ & $\checkmark$ & $\begin{array}{l}\text { SL: } \\
\text { LCS: } \\
\text { LCO: } \\
\text { AC: } \\
\text { None: }\end{array}$ & $\begin{array}{l}\text { None required } \\
\text { None required } \\
\text { None required } \\
\text { None required } \\
\text { Refer to BlO main text }\end{array}$ & Seismic Shutdown Switch \\
\hline
\end{tabular}

Notes:

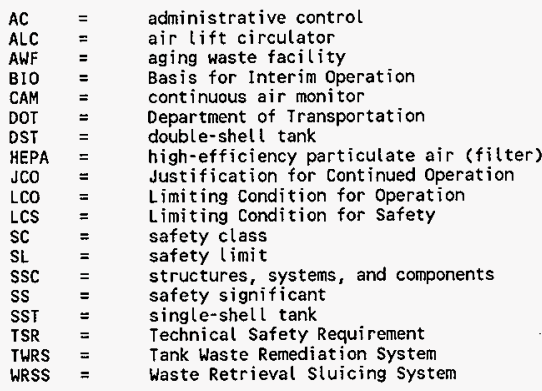

${ }^{1}$ FDH (1998) 


\section{A2.0 OPERATING SPECIFICATION DOCUMENT CONTROLS}

Table A2-1. Operating Specification Document Controls for Tank 241-AY-102. (6 sheets)

\begin{tabular}{|c|c|c|c|c|}
\hline renulrenter. & \}) & 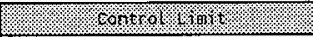 & 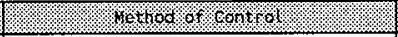 & So, 18 roocoment \\
\hline Tank Composition & 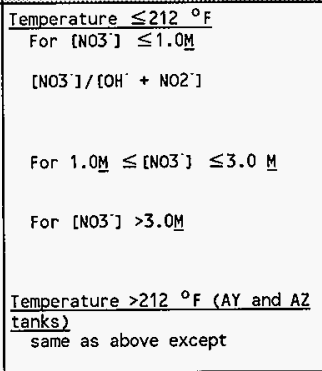 & 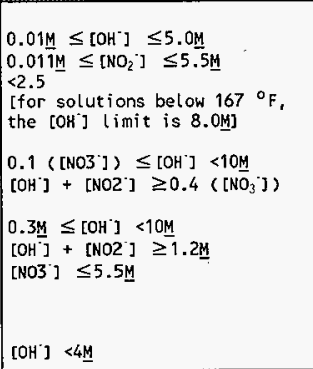 & $\begin{array}{l}\text { Waste sampling and verification of } \\
\text { compl iance of waste transfers. } \\
\text { Note: LCO } 3.3 .2 \text { restricts the waste } \\
\text { temperature to } 195 \text { of for the upper } \\
15 \mathrm{ft} \text { of waste and } 215 \mathrm{O}^{\mathrm{F}} \text { for the } \\
\text { waste below } 15 \mathrm{ft} \text {. }\end{array}$ & $\begin{array}{l}\text { OSD-T-151-00007 } \\
\text { 7.2.1.A }\end{array}$ \\
\hline Hydroxide & $\begin{array}{l}{\left[\mathrm{NO}_{3}\right]<1.0 \mathrm{M}} \\
1.0 \mathrm{M}<\left[\mathrm{NO}_{3}^{-3}<3.0 \mathrm{M}\right. \\
{\left[\mathrm{NO}_{3}^{-3}\right]+\left[\mathrm{NO}_{2}^{-}\right]>5.5 \mathrm{M}}\end{array}$ & $\begin{array}{l}{\left[\mathrm{OH}^{-}\right] \geq 0.01 \mathrm{M}} \\
{\left[\mathrm{OH}^{-}\right] \geq 0.8 \mathrm{M}} \\
{\left[\mathrm{OH}^{-}\right] \geq 1.0 \mathrm{M}}\end{array}$ & $\begin{array}{l}\text { Waste sample analysis and waste } \\
\text { transfers provide basis for tank } \\
\text { material balance. }\end{array}$ & $\begin{array}{l}\text { OSD } \mathrm{r}-151-00017 \\
17.4 .1 .1 .3\end{array}$ \\
\hline Liquid Levels & $\begin{array}{l}\frac{\text { Primary Tank Liquid Level }}{\text { Minimum }} \\
\text { Absolute minimum (AY and AZ) } \\
\text { Encasement leak detection } \\
\text { pit liquid level } \\
\text { Leak detection pit liquid } \\
\text { level }\end{array}$ & $\begin{array}{l}\text { Min. } 306 \text { in. (enough to } \\
\text { submerge the } 17,22-f t \text { long } \\
\text { ALCs by } 12 \text { in.) } \\
\text { Note: ALCs will be disabled. } \\
64 \text { in. (when annulus vent } \\
\text { system is operating } \\
\leq 408 \text { in. (AY and AZ) } \\
\leq 79 \text { in. (AY) }\end{array}$ & $\begin{array}{l}\text { Liquid level taken according to } \\
\text { procedure TO-040-180. } \\
\text { Auto l Iquid level measuring device } \\
\text { and/or manual tape } \\
\text { 0ip tubes used to monitor liquid level } \\
\text { in leak detection pit. } \\
\text { Alarm activated if liquid level } \\
\text { exceeds predetermined level. }\end{array}$ & $\begin{array}{l}\text { OSD }-T-151-00017 \\
17.2 .1 \text { and } \\
\text { OSD }-\mathrm{T}-151-00007 \\
7.2 .2\end{array}$ \\
\hline $\begin{array}{l}\text { Leak Detection Pit } \\
\text { Liquid Level }\end{array}$ & $\begin{array}{l}\text { Waste Storage Tank Leak } \\
\text { Detection Pit Liquid Level: AY } \\
\text { Encasement Leak Detection Pit } \\
\text { Liquid Level: AY and AZ }\end{array}$ & $\begin{array}{l}\leq 79 \text { in. } \\
\leq 408 \text { in. }\end{array}$ & $\begin{array}{l}\text { Weight factor dip tubes used to } \\
\text { monitor the liquid level in the leak } \\
\text { detection pits. T0-040-590 }\end{array}$ & $\begin{array}{l}\text { OSD-T-151-00017 } \\
17.2 .1 .2\end{array}$ \\
\hline
\end{tabular}


Table A2-1. Operating Specification Document Controls for Tank 241-AY-102. (6 sheets)

\begin{tabular}{|c|c|c|c|c|}
\hline regur renent & 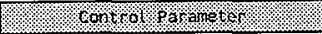 & (conor & 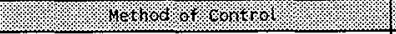 & 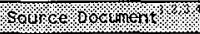 \\
\hline Hydrostatic Head & $\begin{array}{l}\text { Minimum hydrostatic head (AY } \\
\text { and AZ) on the primary tank } \\
\text { walls } \\
\text { Maximum hydrostatic head at the } \\
\text { primary tank wall }\end{array}$ & $\begin{array}{l}0 \text { in. water gauge } \\
744 \text { in. water gauge }\end{array}$ & $\begin{array}{l}\text { Liquid level measuring equipment, } \\
\text { Min. hydrostatic head obtained by } \\
\text { adding primary tank vapor space } \\
\text { pressure and liquid level. } \\
\text { Min. hydrostatic head recorded daily } \\
\text { according to procedure to-060-100. }\end{array}$ & $\begin{array}{l}\text { OSD }-\mathrm{T}-151-00007 \\
7.2 .3 \text { and } \\
\text { OSD }-\mathrm{T}-151-00017 \\
17.2 .3 \\
\text { OSD-T-151-00017 } \\
17.2 .3\end{array}$ \\
\hline $\begin{array}{l}\text { Vapor Space } \\
\text { Pressure } \\
\end{array}$ & No limits currently specified. & & & $\begin{array}{l}\text { OSD }-T-151-00007 \\
7.2 .5\end{array}$ \\
\hline Waste Temperatures & $\begin{array}{l}\text { waste temperature } \\
\text { Max. solution heat-up rate } \\
\text { for solution temp }<1250^{\circ} \mathrm{F} \text { : } \\
\text { for solution temp }>125{ }^{\circ} \text { : } \\
\text { Min. number of operational } \\
\text { solut ion thermocouples: } \\
\text { Min. number of operational } \\
\text { sludge thermocouples: } \\
\text { Min. number of operational ALC } \\
\text { thermocouples: } \\
\text { Temperature gradients of } \\
\text { solution in tanks } \\
\text { solution } \\
\text { solut ion/vapor interface }\end{array}$ & $\begin{array}{l}\leq 195{ }^{\circ} \mathrm{F} \text { in all levels of } \\
\text { waste } \\
\text { or } \\
\leq 195{ }^{\circ} \mathrm{F} \text { in the top } 15 \mathrm{ft} \text {. of } \\
\text { waste and } \leq 215{ }^{\circ} \mathrm{F} \text { in the } \\
\text { waste below } 15 \mathrm{ft} \text {. } \\
<10^{\circ} \mathrm{F} / \mathrm{h} \\
\leq 3{ }^{\circ} \mathrm{F} / \text { day or } 24{ }^{\circ} \mathrm{F} / \text { day } \\
\text { provided the tank temp. is kept } \\
\text { constant } \pm 3 \text { o } \mathrm{F} \text { for } 8 \text { days } \\
\text { thereafter. } \\
2 \\
3 \text { (outer) } \\
2 \text { (inner) } \\
\text { 11 } \\
11 \\
\leq 55{ }^{\circ} \mathrm{F} / \mathrm{ft} \\
\leq 55{ }^{\circ} \mathrm{F} / \mathrm{ft}\end{array}$ & $\begin{array}{l}\text { Thermocouple trees installed in tanks. } \\
\text { Temperatures taken according to } \\
\text { procedure ro-040-660. }\end{array}$ & $\begin{array}{l}\text { HNF-SD-WM-TSR-006 } \\
\text { LCO } 3.3 .2 \\
\\
\text { OSD-T-151-00017 } \\
17.4 .5 \\
\\
\text { OSD-T-151-00007 } \\
7.2 .6\end{array}$ \\
\hline
\end{tabular}


Table A2-1. Operating Specification Document Controls for Tank 241-AY-102. (6 sheets)

\begin{tabular}{|c|c|c|c|c|}
\hline 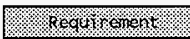 & (1) & 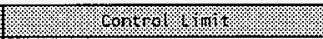 & 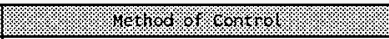 & 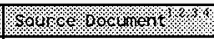 \\
\hline $\begin{array}{l}\text { Concrete } \\
\text { Temperature }\end{array}$ & $\begin{array}{l}\text { Max. temperature in dome } \\
\text { Temperature gradient } \\
\text { Min. number of operational } \\
\text { concrete thermocouples (in } \\
\text { active aging waste tank) } \\
\text { 1. Dome a } 36 \mathrm{ft} \text { radius } \\
\text { 2. Dome a } 41 \mathrm{ft} \text { radius } \\
\text { 3. Middle wall } \\
\text { 4. Bot tom wall } \\
\text { remperature change } \\
<125{ }^{\circ} \mathrm{F} \\
\geq 125{ }^{\circ} \mathrm{F}\end{array}$ & $\begin{array}{l}\text { See LCO } 3.3 .2 \\
\text { [HNF-SD-WM-TSR-006] } \\
\leq 18^{\circ} \mathrm{F} / \mathrm{ft} \text { (AY and AZ) } \\
\\
2 \text { inside/2 outside } \\
2 \text { inside/2 outside } \\
2 \text { inside/2 outside } \\
2 \text { inside/2 outside } \\
\leq 10^{\circ} \mathrm{F} / \mathrm{hr} \\
\leq 20^{\circ} \mathrm{F} / \text { day }\end{array}$ & $\begin{array}{l}\text { Concrete temperatures are checked once } \\
\text { every month according to procedure } \\
\text { To-040-660. }\end{array}$ & $\begin{array}{l}\text { HNF-SD-WM-TSR-006 } \\
\text { LCO } 3.3 .2 \\
\text { OSD-T-151-00017 } \\
17.2-6 \text { and } \\
\text { OSD-T-151-00007 } \\
7.2 .7\end{array}$ \\
\hline $\begin{array}{l}5 \text { Molar Sodium } \\
\text { Rule }\end{array}$ & $\begin{array}{l}\text { Max. sodium concentration } \\
\text { tank 101-Az: } \\
\text { Other tanks: }\end{array}$ & $\begin{array}{l}5.5 \mathrm{M} \text { (through concentration of } \\
\text { wastes already stored in the } \\
\text { tank) } \\
5.0 \mathrm{M}\end{array}$ & $\begin{array}{l}\text { Waste sample analys is and waste } \\
\text { transfers provide basis for tank } \\
\text { material balance. }\end{array}$ & $\begin{array}{l}\text { OSD }-\mathrm{T}-151-00017 \\
17,4,1,1.2\end{array}$ \\
\hline Corrosion Control & $\begin{array}{l}{\left[\mathrm{NO}_{3}^{-}\right] \text {and }\left[\mathrm{OH}^{-}\right] \text {each }<1.0 \mathrm{M}} \\
1.0 \mathrm{M}<\left[\mathrm{NO}_{3}^{-}\right]<3.0 \mathrm{M} \\
3.0 \mathrm{M}<\left[\mathrm{NO}_{3}^{-}\right]<5.5 \mathrm{M}\end{array}$ & $\begin{array}{l}{\left[\mathrm{NO}_{2}{ }_{2}\right] \geq 0.01 \mathrm{M}} \\
{\left[\mathrm{NO}_{3}\right] /\left(\left[\mathrm{OH}^{0}\right]+\left[\mathrm{NO}_{2}\right]\right)<2.5} \\
{\left[\mathrm{OH}^{-}\right]+\left[\mathrm{NO}_{2}\right] \geq 0.4 *\left[\mathrm{NO}_{3}\right]} \\
{\left[\mathrm{OH}^{-}\right]+\left[\mathrm{NO}_{2}\right] \geq 1.2 \mathrm{G}}\end{array}$ & $\begin{array}{l}\text { Waste sample analys is and waste } \\
\text { transfers provide basis for tank } \\
\text { material balance. }\end{array}$ & $\begin{array}{l}\text { OSD }-\mathrm{T}-151-00017 \\
17.4 .1 .1 .4\end{array}$ \\
\hline $\begin{array}{l}\text { Total Fuel } \\
\text { Concentration }\end{array}$ & $\begin{array}{l}\text { Maximum total fuel } \\
\text { concentration (Energetics) }\end{array}$ & 480 joules/gram (dry basis) & $\begin{array}{l}\text { Waste samples analyzed according to } \\
\text { appropriate sample analysis plan }\end{array}$ & $\begin{array}{l}\text { OSD }-\mathrm{Y}-151-00007 \\
7.2 .12 \text { and } \\
\text { OSD-T-151-00017 } \\
17.4 .9\end{array}$ \\
\hline $\begin{array}{l}\text { Vapor Space } \\
\text { Pressure }\end{array}$ & Primary tank max. pressure & $\begin{array}{l}\text { Primary aging-waste tanks shall } \\
\text { not exceed an instantaneous } \\
\text { concentration of radionucl ides } \\
\text { released to the environment in } \\
\text { excess of } 5,000 \text { times the } \\
\text { Derived Concentration Guides } \\
\text { (DCG) listed in whC-CM-7-5, } \\
\text { Appendix } C \text { averaged over any } \\
4 \text {-hour period at the point of } \\
\text { release. }\end{array}$ & $\begin{array}{l}\text { Primary tanks equipped with } \\
\text { differential pressure indicating } \\
\text { alarms for both excessive and } \\
\text { insufficient vacuum. See procedures } \\
\text { To-060-100 and To-060-331 }\end{array}$ & $\begin{array}{l}\text { OSD - T-151-00017 } \\
17.4 .7\end{array}$ \\
\hline
\end{tabular}


Table A2-1. Operating Specification Document Controls for Tank 241-AY-102. (6 sheets)

\begin{tabular}{|c|c|c|c|c|}
\hline 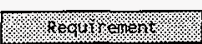 & 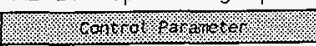 & I. & W & 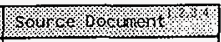 \\
\hline $\begin{array}{l}\text { Ventilation system } \\
\text { Chilled water } \\
\text { Condenser } \\
\text { (AZ-K1-8-1) }\end{array}$ & $\begin{array}{l}\text { Air stream outlet Temperature } \\
\text { (TALL for } T \mathrm{I}-\mathrm{AZK}(8-1 B)\end{array}$ & $\geq 35^{\circ} \mathrm{F}$ & $\begin{array}{l}\text { An audible and visual low temp. al arm, } \\
\text { TAL for TI-AZK18-1B, will annunciate } \\
\text { when the air stream outlet temp. } \\
\text { decreased to } 38{ }^{\circ} \mathrm{F} \text {. A second alarm, } \\
\text { TALL for TI-AZK18.1B will annunciate } \\
\text { when the air stream temperature } \\
\text { reached the OSD limit. }\end{array}$ & $\begin{array}{l}\text { OSD }-T-151-00019 \\
19.2\end{array}$ \\
\hline $\begin{array}{l}\text { High Efficiency } \\
\text { Mist El iminator } \\
\text { (HEME) } \\
\text { (AZ-K1-9-1) }\end{array}$ & $\begin{array}{l}\text { Differential Pressure (PDAHH } \\
\text { for PDI-AZK19-1) }\end{array}$ & $\leq 15.0$ in. water gauge & $\begin{array}{l}\text { An audible and visual high } \\
\text { differential pressure alarm, PDAH for } \\
\text { PDI-AZK19-1, will annunciate at } \\
10.0 \text { in. water gauge when the pressure } \\
\text { drop across HEME increases. A second } \\
\text { differential pressure alarms, PDAHH } \\
\text { for PDI-AZK19-1 will alarm at } 15.0 \text { in. } \\
\text { water gauge which is the OSD limit. } \\
\end{array}$ & 19.3 \\
\hline $\begin{array}{l}\text { Electric Heaters } \\
(A Z-K 1-2-1 A \text { and } \\
-1 B)\end{array}$ & $\begin{array}{l}\text { Differential Temperature (TDAL } \\
\text { for TDIC-AZK12-1A or }-1 B \text { ) } \\
\text { Out let Temperature (TAH for } \\
\text { T1-AZK12-3A or }-3 B \text { ) }\end{array}$ & $\begin{array}{l}\geq 17^{\circ} \mathrm{F} \\
\leq 195^{\circ} \mathrm{F}\end{array}$ & $\begin{array}{l}\text { An audible and visual low differential } \\
\text { temperature alarm, either TDAL for } \\
\text { IDIC-AZKI2-1A or TDAL for } \\
\text { TDIC-AZK12-1B, will annunciate at } \\
17 \text { of when the temperature rise } \\
\text { across the electric heater decreases } \\
\text { to the OSD limit. } \\
\text { An audible and visual high temperature } \\
\text { alarm, either IAH for II-AZK12-3A or } \\
\text { TAH for TI-AZK12-3B, will annunciate } \\
\text { when the out let temperature equals the } \\
\text { OSD timit. }\end{array}$ & $19.4 . B$ \\
\hline
\end{tabular}


Table A2-1. Operating Specification Document Controls for Tank 241-AY-102. (6 sheets)

\begin{tabular}{|c|c|c|c|c|}
\hline Kequrverstr. & 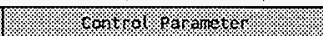 & 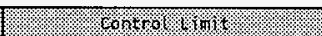 & Hethod of cont rol & 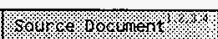 \\
\hline \multirow[t]{2}{*}{$\begin{array}{l}\text { High Efficiency } \\
\text { Particulate Air } \\
\text { (HEPA) Filters } \\
\text { (AZ-K1-4-1A } \\
-1 B,-2 A \text {, and } \\
-2 B \text { ) }\end{array}$} & $\begin{array}{l}\text { Differential Pressure CPDAHK } \\
\text { for POI-AZK14-1A, }-1 B,-2 A, \text { and } \\
-2 B\end{array}$ & $\begin{array}{l}\leq 6.0 \text { in. water gauge across } \\
\text { either the primary or secondary } \\
\text { filter }\end{array}$ & $\begin{array}{l}\text { Audible and visual high-high } \\
\text { different ial pressure alarms for the } \\
\text { operating filter train, either POAHH } \\
\text { for PDI-AZK14-1A and - } 2 A \text { or PDAHH for } \\
\text { PDI-AZK14-1B and -2B, will annunciate } \\
\text { at } 3.0 \text { in. water gauge when the } \\
\text { different ial pressure across the HEPA } \\
\text { filter increases. }\end{array}$ & $19.5 . \mathrm{A}$ \\
\hline & $\begin{array}{l}\text { Leak Test Efficiency } \\
\text { Leak Test Frequency }\end{array}$ & $\begin{array}{l}\geq 99.5 \% \text { for particles between } \\
0.1 \mu \mathrm{m} \text { and } 3.0 \mu \mathrm{m} \text { with an } \\
\text { average size of } 0.5 \mu \mathrm{m} \\
\text { Annual }\end{array}$ & $\begin{array}{l}\text { HEPA filters are aerosol tested in } \\
\text { place to ensure they meet the } \\
\text { efficiency requirement. A release of } \\
\text { radionucl ides can be detected by the } \\
\text { beta/gamma radiation monitor system } \\
\text { installed in exhaust stack } 296-A-42 \text {. } \\
\text { This monitor will annunciate an } \\
\text { audible and visual high radiation } \\
\text { alarm. }\end{array}$ & $\begin{array}{l}19.5 . \mathrm{B} \\
19.5 . \mathrm{C}\end{array}$ \\
\hline $\begin{array}{l}\text { High Efficiency } \\
\text { Gas Absorber } \\
\text { (HEGA) } \\
\text { (AZ-K1-10-1A and } \\
-1 B \text { ) }\end{array}$ & $\begin{array}{l}\text { Differential Pressure (PDAHH } \\
\text { for PD1-AZK110-1A and }-1 \mathrm{~B} \text { ) } \\
\text { Leak Test Efficiency } \\
\text { Leak Test Frequency }\end{array}$ & $\begin{array}{l}\geq 99.95 \% \\
\text { Annually }\end{array}$ & $\begin{array}{l}\text { Audible and visual high differential } \\
\text { pressure alarms for the operating } \\
\text { filter train, either PDAH for } \\
\text { PDI-AZK } 110-1 A \text { or PDAH for } \\
\text { POI-AZK110-1B, will annunciate when } \\
\text { the differential pressure across the } \\
\text { HEGA filter increases to } 2.5 \text { in. water } \\
\text { gauge. A second alarm, PDAHH for } \\
\text { POI-AZK110-1A or PDAHH for } \\
\text { PDI-AZK110-1B will annunciate when the } \\
\text { differential pressure reaches the OSD } \\
\text { limit. } \\
\text { The HEGA is tested in place using a } \\
\text { refrigerant gas, or equivalent, to } \\
\text { ensure it meets the specifies OSD } \\
\text { limit. }\end{array}$ & $\begin{array}{l}19.6 .8 \\
19.6 . \mathrm{C}\end{array}$ \\
\hline $\begin{array}{l}\text { Exhaust stack } \\
(296-A-42)\end{array}$ & $\begin{array}{l}\text { Flow Rate, Maximum (FAH for } \\
\text { FI-AZK1-3) } \\
\text { Flow Rate, Minimum (FAL for } \\
\text { FI-AZK1-3) }\end{array}$ & $\begin{array}{l}\leq 1,050 \mathrm{scfm} \\
\geq 200 \mathrm{scfm}\end{array}$ & $\begin{array}{l}\text { An audible and visual high flow rate } \\
\text { alarm, FAH for FI-AZK1-3, will } \\
\text { annunciate when the flow rate } \\
\text { innreases to the OSD limit for maximum } \\
\text { flow rate. An audible and visual low } \\
\text { flow rate alarm, FAL for FI-AZK1-3, } \\
\text { will annunciate when the flow rate } \\
\text { decreases to the OSD limit for minimum } \\
\text { flow rate. }\end{array}$ & $\begin{array}{l}19.7 . A \\
19.7 . B\end{array}$ \\
\hline
\end{tabular}


Table A2-1. Operating Specification Document Controls for Tank 241-AY-102. ( 6 sheets)

\begin{tabular}{|c|c|c|c|c|}
\hline 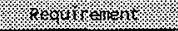 & roptrov & $601 \% 01 / 1 \% 1 \%$ & metholor o control & S. \\
\hline $\begin{array}{l}\text { Primary } \\
\text { Ventitation cell } \\
\text { Sump }\end{array}$ & Liquid Level (LDA-702-1) & $\begin{array}{l}\text { If the liquid level in the sump } \\
\text { exceeds the level of the sump } \\
\text { leak detection probe } \\
\text { LDE-AZ702-1, enter the recovery } \\
\text { actions. }\end{array}$ & $\begin{array}{l}\text { Leak detection alarm LDA-702-1 will } \\
\text { annunciate when the liquid in the sump } \\
\text { contacts the leak detection probe or } \\
\text { element LDE-AZ702-1. After the leak } \\
\text { detection alarm is tripped, the liquid } \\
\text { in the sump is manually transferred to } \\
\text { the condensate seal pot AZ-PC-SP-1 } \\
\text { using jet AZ-PC-J-1. }\end{array}$ & 19.8 \\
\hline
\end{tabular}

Notes:

$\begin{array}{lll}\min & = & \text { minimum } \\ \max & = & \text { maximum } \\ \text { DCG } & = & \text { derived concentration guides }\end{array}$

ILMHC (1997d)

'LMHC (1997b)

${ }^{3}$ LMHC (1997c)

${ }^{4} \mathrm{FDH}$ (1998) 
Table A2-2. Operating Specification Document Controls for Tank 241-C-106. (4 sheets)

\begin{tabular}{|c|c|c|c|c|}
\hline Renur ronent: & 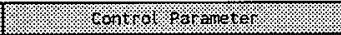 & 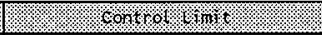 & 1/. & 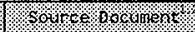 \\
\hline Waste Level & $8, B X, C, T, U(100$ series tanks) & Max. 185 in. & $\begin{array}{l}\text { Tank equipped with waste surface } \\
\text { level measuring device. Taken } \\
\text { according to procedure To-040-020. }\end{array}$ & $\begin{array}{l}\text { OSD - T-151-00013 } \\
13.2 .1 . \mathrm{B}\end{array}$ \\
\hline Dome Deflection & $\begin{array}{l}\text { Deflection limit } \\
\text { Surveying } \\
\text { Bench marks } \\
\text { Actively jet pumping and net jet } \\
\text { pump production }<60.000 \text { gal. } \\
\text { Last survey }<0.01 \mathrm{ft} \\
\text { Last survey }>0.01 \mathrm{ft} \\
\text { Actively jet pumping and net jet } \\
\text { pump production }>60,000 \text { gal. } \\
\text { All previous surveys }<0.01 \mathrm{ft} \\
\text { Any previous survey other } \\
\text { than last survey }>0.01 \mathrm{ft} \\
\text { Last survey }>0.01 \mathrm{ft} \text {. }\end{array}$ & 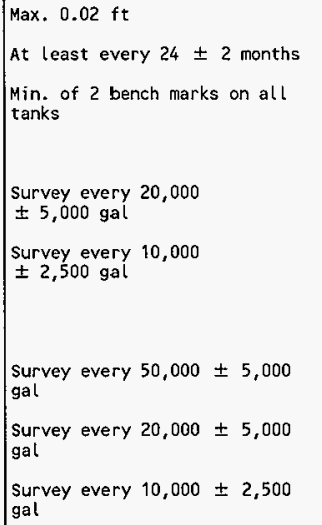 & $\begin{array}{l}\text { Survey schedules as shown. Tank Farm } \\
\text { Surveilllance Analysis and Support and } \\
\text { Tank farm Engineering revi ew survey } \\
\text { results. }\end{array}$ & $\begin{array}{l}\text { OSD-T-151-00013 } \\
13.1 . D\end{array}$ \\
\hline $\begin{array}{l}\text { Waste } \\
\text { Temperatures }\end{array}$ & $\begin{array}{l}\text { Max. temperature limit for tank } \\
\text { c-106 waste } \\
\text { Maximum change per day } \\
\text { Thermocouple trees }\end{array}$ & $\begin{array}{l}205^{\circ} \mathrm{F} \text { (before start of Waste } \\
\text { Retrieval sluicing System } \\
\text { operations) } \\
200^{\circ} \mathrm{F} / \text { day } \\
\text { Installed in any SST that has a } \\
\text { heat load greater than } \\
40,000 \text { Bturhr. } \\
\text { If } 2 \text { or more probes on a tree } \\
\text { fail, operability shall be } \\
\text { restored as soon as practical. }\end{array}$ & $\begin{array}{l}\text { Readings are taken by Iank Farm } \\
\text { Operations on frequencies specified } \\
\text { by operating procedures. } \\
\text { Temperatures taken according to } \\
\text { procedure O-040-650 and evaluated by } \\
\text { Tank Farm Surveillance and Analysis. }\end{array}$ & $\begin{array}{l}\text { HMF-SD-WM-TSR-006 } \\
\text { LCO } 3.3 .1 \\
\text { OSD-T-151-00013 } \\
13.2 .1 . E\end{array}$ \\
\hline
\end{tabular}


Table A2-2. Operating Specification Document Controls for Tank 241-C-106. (4 sheets)

\begin{tabular}{|c|c|c|c|c|}
\hline hegulfojn) & 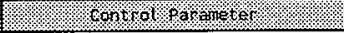 & 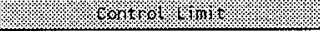 & 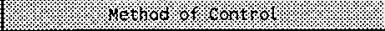 & $501 \%$ C 0 ocunent \\
\hline $\begin{array}{l}\text { Vapor Space } \\
\text { Pressure }\end{array}$ & $\begin{array}{l}\text { Minimum pressure relative to } \\
\text { atmosphere } \\
\text { Pressure gauge }\end{array}$ & $\begin{array}{l}1 \text { in. water gauge minus waste } \\
\text { height (in.) not to exceed } \\
-9 \text { in. water gauge. } \\
\text { Installed at tank side inlet of } \\
\text { each exhauster. Pressure } \\
\text { recorded at least every } \\
24 \text { hours. on act ively } \\
\text { ventilated tanks. }\end{array}$ & $\begin{array}{l}\text { Tank pressure within each ventilation } \\
\text { system monitored every } 2 \text { weeks } \\
\text { according to procedure To-060-015. }\end{array}$ & $\begin{array}{l}\text { OSD - I-151-00013 } \\
13.2 .1 . \mathrm{F}\end{array}$ \\
\hline $\begin{array}{l}\text { Active } \\
\text { Ventilation }\end{array}$ & Temperature data & $\begin{array}{l}\text { Tank Farm Engineering and Tank } \\
\text { Farm Surveil lance and Analys is } \\
\text { review periodic SST temp. data } \\
\text { at least every } 3 \text { months. Peak } \\
\text { temps. predicted for any tank } \\
\text { showing rising temp. trend. } \\
\text { shall not exceed waste temp. } \\
\text { limits specified in LCo } 3.3 .1 \text {. }\end{array}$ & $\begin{array}{l}\text { Replaceable T/C trees installed in } \\
\text { tanks w/high heat load history. } \\
\text { Simulation used to predict final } \\
\text { temperature peaks for sSTs which have } \\
\text { not cooled, and tanks predicted to } \\
\text { peak at above spec. maximums are } \\
\text { equipped w/exhauster systems. See } \\
\text { procedure TO-060-050 }\end{array}$ & $\begin{array}{l}\text { OSD }-\Upsilon-151-00013 \\
13.2 .1 . \mathrm{G}\end{array}$ \\
\hline $\begin{array}{l}\text { Radiation } \\
\text { Containment } \\
\text { Requirements } \\
\text { Gaseous } \\
\text { Effluents } \\
\text { Concentration }\end{array}$ & $\begin{array}{l}\text { Radionuclides released to the } \\
\text { environment in airborne effluents } \\
\text { Annual average concentration } \\
\text { Weekly average concentration } \\
\text { Max. instantaneous concentration } \\
\text { Functional testing }\end{array}$ & $\begin{array}{l}\text { Not to exceed derived } \\
\text { concentration specified in } \\
\text { Appendix C, WHC-CM-7-5 } \\
\text { Not to exceed } 4 \text { times the } \\
\text { derived concentration guides } \\
\text { specified in Appendix C, } \\
\text { WHC-CM-7-5 } \\
\text { Not to exceed } 5,000 \text { times the } \\
\text { derived concentration guides } \\
\text { specified in Appendix C. } \\
\text { WHC-CM-7-5. } \\
\text { Monitors and alarms for active } \\
\text { exhaust shall be functionally } \\
\text { tested on a monthly frequency } \\
\text { not to exceed } 45 \text { days. }\end{array}$ & $\begin{array}{l}\text { Active ventilation systems equipped } \\
\text { W/CAMS and record samplers. } \\
\text { Record samples are collected } \\
\text { cont inuously and analyzed weekly for } \\
\text { gross beta/gamma and alpha }\end{array}$ & $\begin{array}{l}\text { OSD }-\mathrm{T}-151-00013 \\
13.2 .2 . \mathrm{B}\end{array}$ \\
\hline
\end{tabular}


Table A2-2. Operating Specification Document Controls for Tank 241-C-106. (4 sheets)

\begin{tabular}{|c|c|c|c|c|}
\hline 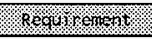 & 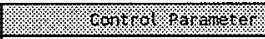 & 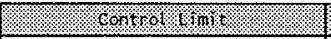 & 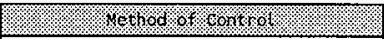 & Sorrce oourent \\
\hline $\begin{array}{l}\text { Gaseous } \\
\text { Effluent } \\
\text { Filtration }\end{array}$ & Passive ventilation & $\begin{array}{l}\text { All tanks on active ventilators } \\
\text { shall have } 2 \text { stages of HEPA } \\
\text { filtration in the outlet } \\
\text { stream. Air inlets for active } \\
\text { vent ilation systems shall be } \\
\text { HEPA filtered. } \\
\text { All sSTs shall be passively } \\
\text { ventilated using HEPA breather } \\
\text { filters even if active } \\
\text { ventilation is temporarily } \\
\text { installed. }\end{array}$ & $\begin{array}{l}\text { Loss of filtration (active and } \\
\text { passive) indicated by failure of } \\
\text { aerosol testing, and for active } \\
\text { systems may be is indicated by CAM } \\
\text { which causes exhauster to shut down } \\
\text { or alarm locally on CASS. TO-060-050 }\end{array}$ & $\begin{array}{l}\text { OSD - T-151-00013 } \\
13.2 .2 . D\end{array}$ \\
\hline $\begin{array}{l}\text { Filter } \\
\text { Differential } \\
\text { Pressure } \\
\text { (drop in } \\
\text { pressure from } \\
\text { inlet to } \\
\text { outlet } \\
\text { of filter) }\end{array}$ & $\begin{array}{l}\text { First filter in a series } \\
\text { Other filters in a series } \\
\text { Total series of filters }\end{array}$ & $\begin{array}{l}\text { Max. } 5.9 \text { in. water gauge } \\
\text { Min. } 0.05 \text { in. water gauge } \\
\text { Max. } 4.0 \text { in. water gauge } \\
\text { Min. } 0.05 \text { in. water gauge } \\
\text { Max. } 5.9 \text { in water gauge } \\
\text { Min. } 0.05 \text { in. water gauge }\end{array}$ & $\begin{array}{l}\text { All active vent. systems used w/SSIs } \\
\text { are equipped w/diff. pressure sensors } \\
\text { between each filter and across the } \\
\text { filter set. Alarms signal if diff. } \\
\text { pressure is outside the operating. } \\
\text { range and each exhauster is } \\
\text { interlocked to shutdown if overall } \\
\text { diff. pressure is tool high, or if } \\
\text { final stage diff. pressure is too } \\
\text { low. To-060-015, To-060-050 }\end{array}$ & 13.2.2.E \\
\hline $\begin{array}{l}\text { HEPA Filter } \\
\text { Temperature }\end{array}$ & Filter temperature & Max. $200^{\circ} \mathrm{F}$ & $\begin{array}{l}\text { Temp. sensors and controllers } \\
\text { installed on each exhauster serving } \\
\text { SSTs. Control shut off heaters at a } \\
\text { set temp. }\end{array}$ & $13.2 .2 . \mathrm{F}$ \\
\hline $\begin{array}{l}\text { HEPA Filter } \\
\text { Testing and } \\
\text { Efficiency }\end{array}$ & $\begin{array}{l}\text { Efficiency } \\
\text { Testing frequency }\end{array}$ & $\begin{array}{l}\text { Min. } 99.5 \% \text { for } 0.3 \mu \mathrm{m} \text { particles } \\
\text { Conditions requiring system to } \\
\text { be aerosoled tested } \\
\text { 1. system is new } \\
\text { 2. system is moved } \\
3 \text {. filters replaced } \\
\text { 4. system has been off over } \\
60 \text { days } \\
\text { 5. every } 12 \pm 1 \text { month during } \\
\text { use (may be tested more } \\
\text { often) }\end{array}$ & $\begin{array}{l}\text { Records maintained by Tank Farm } \\
\text { Engineering. Filters tested as } \\
\text { specified. Replacement of filter } \\
\text { systems is directed by Tank Farm } \\
\text { operations, as necessary. }\end{array}$ & 13.2 .2 .6 \\
\hline
\end{tabular}


Table A2-2. Operating Specification Document Controls for Tank 241-C-106. (4 sheets)

\begin{tabular}{|c|c|c|c|c|}
\hline 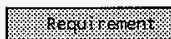 & 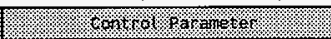 & 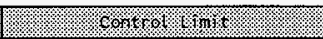 & (1) & 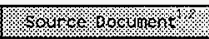 \\
\hline Water Additions & $\begin{array}{l}\text { Water amount allowed each } \\
\frac{\text { addition }}{\text { Tank 241-c-106 }}\end{array}$ & $\begin{array}{l}\text { As necessary w/approval of } \\
\text { IFS\&O shift manager. }\end{array}$ & $\begin{array}{l}\text { Water addition done via water meter } \\
\text { if practical or estimation. } \\
\text { Receiving tank surface level used. } \\
\text { See procedure To-350-200 }\end{array}$ & $\begin{array}{l}\text { OSD }-\mathrm{T}-151-00013 \\
13 \cdot 2: 3 \cdot \mathrm{B}\end{array}$ \\
\hline $\begin{array}{l}\text { Psychrometric } \\
\text { Data Collection }\end{array}$ & $\begin{array}{l}241-C \text { Psychrometric Data } \\
\text { Collection }\end{array}$ & $\begin{array}{l}\text { From exhaust of tanks } 241-\mathrm{C}-106 \\
\text { and } 241-\mathrm{C}-105 \text { on a monthly } \\
\text { basis white ventilation system } \\
\text { is operating. }\end{array}$ & $\begin{array}{l}\text { 7-GN-062 and Engineering Guidance for } \\
\text { Collecting } 241-\mathrm{C}-105 / 106 \\
\text { Psychrometric Data. }\end{array}$ & $\begin{array}{l}\text { OSD -T-151-00013 } \\
13.2 .5\end{array}$ \\
\hline $\begin{array}{l}\text { Total fuel } \\
\text { Concentration }\end{array}$ & $\begin{array}{l}\text { Maximum total fuel concentration } \\
\text { (Energetics) }\end{array}$ & 480 joules/gram (dry basis) & $\begin{array}{l}\text { Waste samples analyzed according to } \\
\text { the appropriate sample analysis plan } \\
\text { (SAP) }\end{array}$ & $\begin{array}{l}\text { OSD }-T-151-00013 \\
13.2 .6 . C\end{array}$ \\
\hline
\end{tabular}

Notes:

IFS\&O = Tank Farm Surveillance and Operations

LLMHC (1997c)

${ }^{2} \mathrm{FDH}(1998)$ 


\section{A3.0 PROJECT $W$-320 ENVIRONMENTAL CONTROLS}

The nonradioactive controls for $W-320$ are found in DOE-RL (1996a). The Washington State Department of Ecology approval is documented in Wilson (1997).

The radioactive controls for $W-320$ are in DOE-RL (1996b). Revision 0 of the document was approved, but the letter has expired. Revision 1 has been submitted for approval. 


\section{A4.0 INDUSTRIAL SAFETY (TANK FARM HASP) CONTROLS}

Table A4-1. Industrial Safety (Tank Farm HASP) Controls for Tank 241-C-106. .(2 sheets)

\begin{tabular}{|c|c|c|c|}
\hline (1.6. & 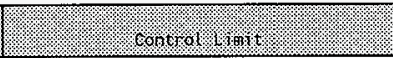 & 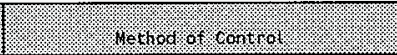 & 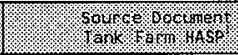 \\
\hline Ferrocyanide & No control on tank $241-\mathrm{c}-106$ & None & Appendix K, III.A.1 \\
\hline Vapor/Gas & No control on tank $241-\mathrm{c}-106$ & None & Appendix K, III.A.2 \\
\hline High Heat & Temperature of waste $<300^{\circ} \mathrm{F}$ & Water added periodically & Appendix K, III.A.3 \\
\hline $\begin{array}{l}\text { High-Level Radioactive Waste } \\
\text { Activities }\end{array}$ & $\begin{array}{l}\text { Activities involving containment } \\
\text { breaches and intrusive work must be } \\
\text { handled according to specific } \\
\text { operating and safe work practice } \\
\text { procedures and work permit processes. }\end{array}$ & $\begin{array}{l}\text { Operating and safety work practice } \\
\text { procedures and work permi ts }\end{array}$ & Appendix K, III.A.4 \\
\hline Surface Contamination & $\begin{array}{l}\text { Controls specified in rank farm HASP, } \\
\text { Rad Worker Permits, ALARA Worksheets. }\end{array}$ & Carls (1995), RWP, ALARA Worksheets & Appendix K, III.A.5 \\
\hline Noise & $\begin{array}{l}\text { No stationary high-sources present in } \\
\text { c Farm. Only required if specified in } \\
\text { work packages or permits to control } \\
\text { intermittent noise sources from any } \\
\text { equipment brought into the farm. }\end{array}$ & Hork packages or permits & Appendix K, III.B.1 \\
\hline $\begin{array}{l}\text { Chemicals } \\
\text { Caustic Additions }\end{array}$ & $\begin{array}{l}\text { Prevent and mitigate the consequences } \\
\text { of caustic spray leaks. }\end{array}$ & $\begin{array}{l}\text { Delivery piping encased in transparent } \\
\text { plastic sleeving. } \\
\text { Maximum operating pressure } \leq 125 \text { psig. } \\
\text { Steel pipe with a wall thickness of no } \\
\text { less that schedule } 10 \text {. } \\
\text { Proper eye, face, skin protection and } \\
\text { emergency wash facilities provided. }\end{array}$ & Section 2.8 .24 \\
\hline Confined Spaces & $\begin{array}{l}\text { Listed in Table K-1 of Appendix K. } \\
\text { See Carls (1995) }\end{array}$ & & Appendix K, III.B.3 \\
\hline Asbestos & $\begin{array}{l}\text { Anything painted pink is assumed to } \\
\text { contain asbestos. This material is } \\
\text { not to be disturbed. }\end{array}$ & $\begin{array}{l}\text { Warning signs at } C \text { farms alert workers } \\
\text { that asbestos material are present. }\end{array}$ & Appendix K, 111.B.4 \\
\hline Lighting & & $\begin{array}{l}\text { Adequate lighting shall be provided } \\
\text { when operations are to be performed in } \\
\text { low light situations. }\end{array}$ & Appendix K, III.B.5 \\
\hline
\end{tabular}


Table A4-1. Industrial Safety (Tank Farm HASP) Controls for Tank 241-C-106. (2 sheets)

\begin{tabular}{|c|c|c|c|}
\hline 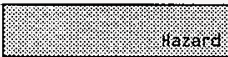 & 3. & 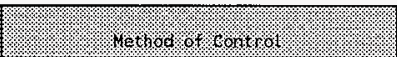 & 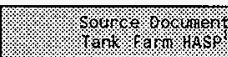 \\
\hline Tank-Based Hazards & & $\begin{array}{l}\text { Found in work packages and work } \\
\text { permits developed for specific tank as } \\
\text { part of work control process. }\end{array}$ & $\begin{array}{l}\text { Appendix K, III.C } \\
\text { Section } 2.0\end{array}$ \\
\hline
\end{tabular}

Notes: ALARA $=$ as low as reasonably achievable RWP $=$ radiation work permit

'Carls (1995) 
Table A4-2. Industrial Safety (Tank Farm HASP) Controls for Tank 241-AY-102.

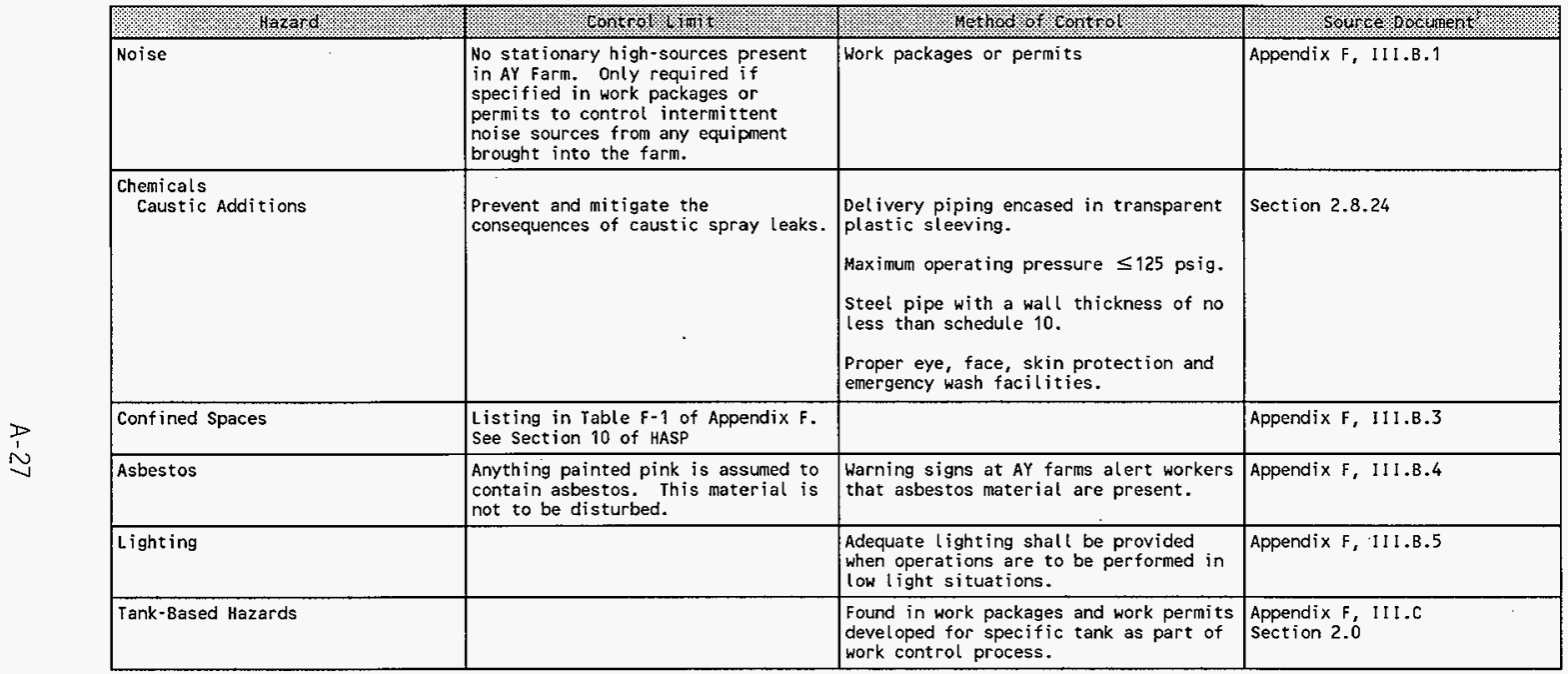




\section{A5.0 REFERENCES}

Carls, D. R., 1995 Tank Farms Health and Safety P7an, WHC-SD-WM-HSP-002. Rev. 2J. Westinghouse Hanford Company, Richland, Washington.

DOE-RL, 1996a, Nonradioactive Air Emissions Notice of Construction Project W-320. Tank 241-C-106 Sluicing, DOE/RL-95-45, Rev. 1, U.S. Department of Energy Richland Operations Office, Richland, Washington.

DOE-RL, 1996b. Radioactive Air Emissions Notice of Construction Project W-320. Tank 241-C-106 S7uicing, DOE/RL-95-45, Rev. 1, U.S. Department of Energy Richland Operations office, Richland, Washington.

FDH. 1998, Tank Waste Remediation System Technica7 Safety Requirements, HNF-SD-WM-TSR-006, Rev. 0-J, Fluor Daniel Hanford, Richland, Washington.

LMHC, 1997a, Operating Specifications for the 241-AZ-702 Vessel Ventilation System, OSD-T-151-00019, Rev. A-0, Lockheed Martin Hanford Company, Richland, Washington.

LHMC, 1997b, Operating Specification for Aging-Waste Operations in 241-AY and 241-AZ, OSD-T-251-00017, Rev. D-10, Lockheed Mart in Hanford Corp. for Fluor Daniel Hanford, Inc., Richland, Washington.

LHMC, 1997c, Operating Specifications for Single-Shel1 Waste Storage Tanks. OSD-T-151-00013, Rev. D-15, Lockheed Mart in Hanford Corp. for Fluor Daniel Hanford, Inc., Richland, Washington.

LMHC, 1997d, Operating Specification of the 241-AN, AP, AW,AY. AZ, and SY Tank Farms, OSD-T-151-00007, Rev. H-19, Lockheed Mart in Hanford Corp. for Fluor Daniel Hanford. Inc. Richland, Washington.

Wilson. M. A., 1997. Notice of Construction (NOC) Rev. I Approval Order for Project W-320. 241-C-106 Tank S7uicing Phase II, (1etter to Ecology), $07 y m p i a$, Washington. 
DISTRIBUTION SHEET

\begin{tabular}{|c|c|c|c|c|c|}
\hline \multirow[b]{2}{*}{ Distribution } & \multirow{2}{*}{\multicolumn{3}{|c|}{ Process Control }} & \multicolumn{2}{|l|}{ Page 1 of 2} \\
\hline & & & & \multicolumn{2}{|c|}{$07 / 20 / 98$} \\
\hline \multicolumn{4}{|c|}{ Project Title/Work Order } & \multicolumn{2}{|c|}{ EDT No. N/A } \\
\hline \multicolumn{4}{|c|}{$\begin{array}{l}\text { HNF-SD-WM-PCP-013, Rev. 1, "Tank 241-C-106 Waste Retrieval } \\
\text { Slucing System Process Control Plan" }\end{array}$} & \multicolumn{2}{|c|}{ ECN No. ECN-643804 } \\
\hline \multicolumn{2}{|l|}{ Name } & $\begin{array}{c}\text { Text } \\
\text { With } \\
\text { A11 } \\
\text { Attach. }\end{array}$ & Text Only & $\begin{array}{l}\text { Attach./ } \\
\text { Appendix } \\
\text { OnTy }\end{array}$ & $\begin{array}{l}\text { EDT/ECN } \\
\text { Only }\end{array}$ \\
\hline
\end{tabular}

COGEMA

J. R. Bellomy

S. W. Shaw

$\begin{array}{ll}\$ 2-48 & x \\ \$ 2-48 & x\end{array}$

DE\&S Hanford. Inc.

R. G. Stickney

R1-49 X

Fluor Daniel Northwest

K. C. Conrad

$52-48$

$\mathrm{S} 2-47$

T. J. Kasnick

M. A. Lane

$\mathrm{S} 2-47$

D. A. Smith

R1-49

Lockheed Martin Hanford Corp.

J. E. Andrews

K. J. Anderson

D. G. Baide

D. A. Bragg

K. G. Carothers

W. T. Dixon

R. A. Dodd

S. D. Estey

G. N. Hanson

J. M. Jones

T. J. Kelley

N. W. Kirch

J. A. Lechelt

W. J. Powe 11

R. L. Powers

L. A. Stauffer

G. R. Tardiff

W. T. Thompson

N. E. Wilkins

S. U. Zaman

T.C.S.R.C.

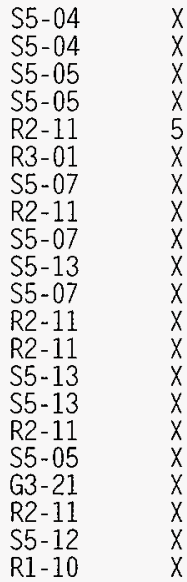

Lockheed Mart in Services. Inc.

\section{Prontral Files}

Numatec Hanford Corporation

J. W. Bailey

R. R. Bevins

$\begin{array}{ll}81-07 & x \\ 01-29 & x\end{array}$

A. F. Choho

S2-48

$\mathrm{S} 2-48$

H6-35

$X$
$X$
$X$
$X$

$x$

$x$ 


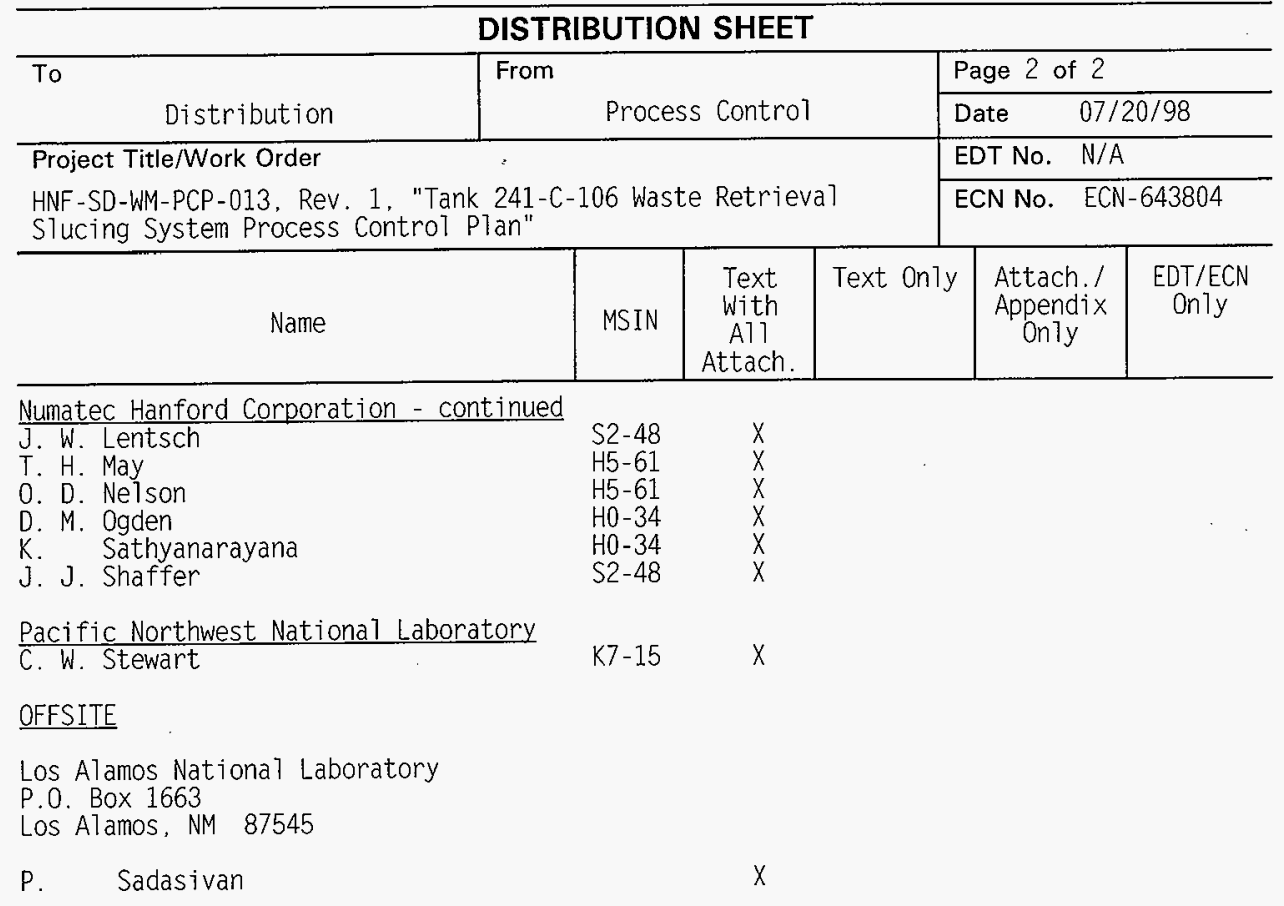

